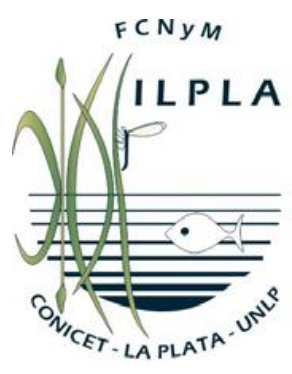

Doctorado en Ciencias Naturales

Facultad de Ciencias Naturales y Museo - UNLP.

Año 2018

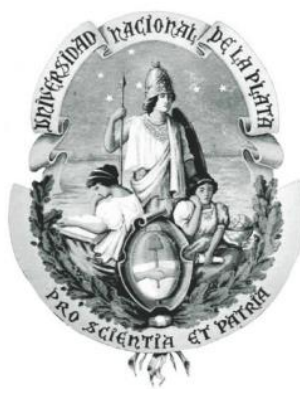

\title{
Impacto de agroquímicos sobre los ensambles de macroinvertebrados en arroyos rurales
}

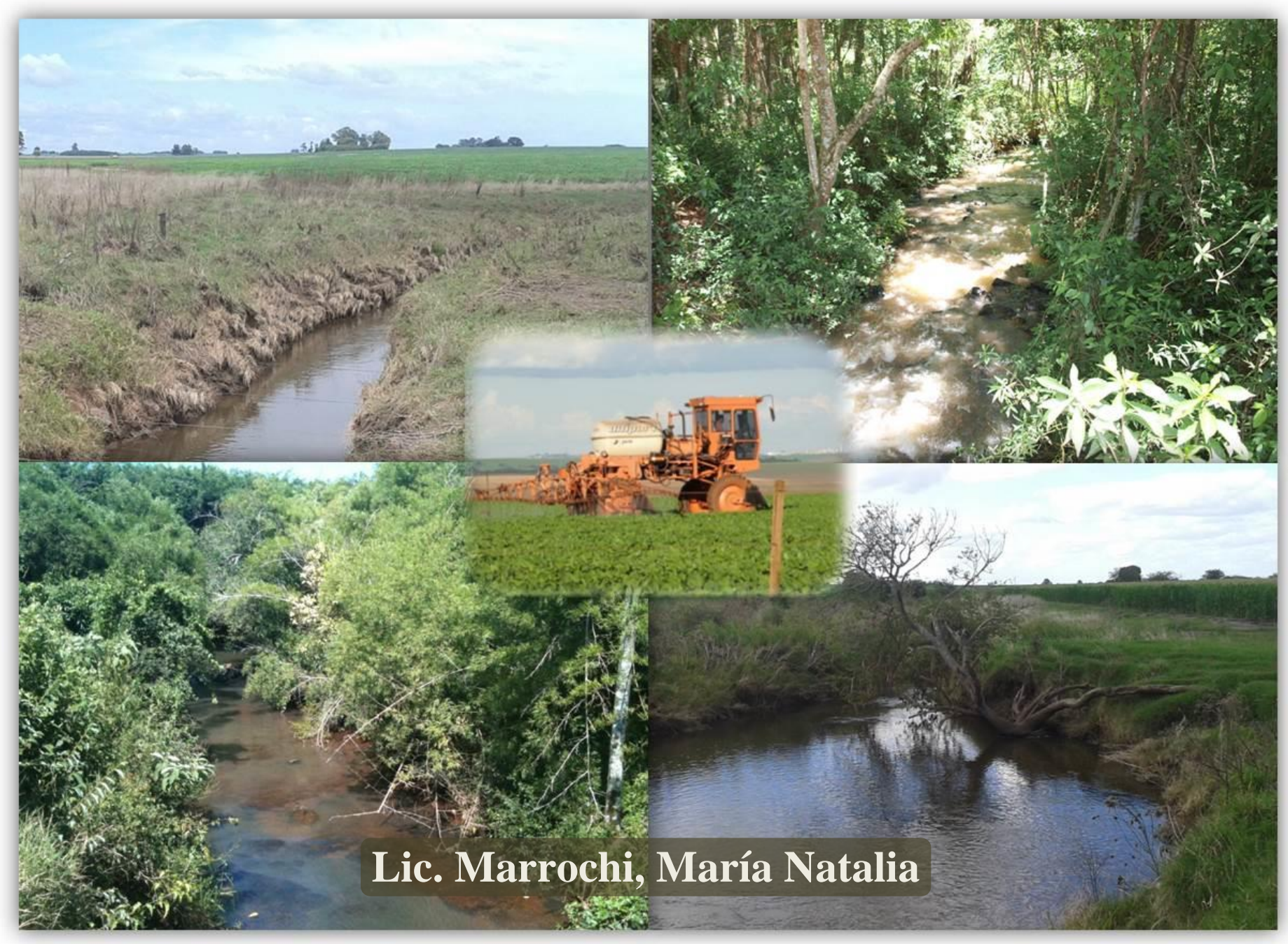

Director: Dr. Bonetto, Carlos

Director: Dr. Mugni, Hernán 
A Maia y Victor, mis complementos 


\section{Agradecimientos}

A mis directores Carlos Bonetto y Hernán Mugni por haberme dirigido, guiado e incentivado durante la realización de este trabajo. Por la confianza brindada en el transcurso de mis años como pasante y becaria. Por regañarme y apurarme con la escritura de la tesis; pero sobre todo porque nunca dejaron de aconsejarme, escucharme, acompañarme y pensar siempre en mi bienestar.

A mis compañeros de laboratorio por su gran colaboración y aguante: a Any Scalise, compañera de viaje y de vida, por todos los momentos vividos; Marina Solis por su apoyo, consejos e incentivo permanente; Marina Arias por sus conocimientos en plantas acúaticas; Ignacio García por sus consejos; Ariel Paracampo por su invaluable colaboración con la estadística de los datos aquí presentados y recomendaciones de manera desinteresada $\mathrm{y}$, especialmente, a Silvia Fanelli por sus determinaciones químicas y el apoyo logístico y moral en la escritura de la tesis. Gracias a todos por sus aportes y gran compañerismo.

Agradezco a Lisa Hunt por su camaradería y empeño para realizar las gestiones necesarias a fin de concretar los muestreos en Brasil y Paraguay.

A todas las personas que compartimos diariamente el ILPLA. A Melina Mauad y Raúl Campos por su ayuda con las primeras determinaciones y problemáticas taxonómicas. A Hernán Benitez por las campañas compartidas en La Plata.

Agradezco a mis padres, Marisa y Walter, por su tenacidad y enseñanzas de vida. A mis hermanos Eli, Otto y Cony por estar siempre a mi lado. A Noe, Victor y Diego, mi otra gran familia, que me acompañan a concretar mis metas. A mis amores Victor y Maia. Sin todos ustedes no podría haberlo logrado.

A mis amigos de la vida, los que están siempre a mi lado.

Gracias a los jurados Carolina Ocon, Pablo Collins y Karina Miglioranza por sus sugerencias y correciones.

A la Facultad de Ciencias Naturales y Museo, CONICET e ILPLA por brindarme los medios para la realización de esta tesis. 


\section{Índice}

Resumen 6

$\begin{array}{ll}\text { Abstract } & 9\end{array}$

Introducción 12

$\begin{array}{ll}\text { Objetivos } & 19\end{array}$

Hipótesis 20

Ensayos de toxicidad 21

$\begin{array}{ll}\text { Objetivos específicos } & 22\end{array}$

Materiales y métodos $\quad 22$

Distribuciones de Sensibilidad de Especies $\quad 24$

Resultados $\quad 25$

$\begin{array}{ll}\text { Discusión } & 30\end{array}$

Estudio de campo

Materiales y métodos $\quad 34$

$\begin{array}{ll}\text { Área de estudio } & 34\end{array}$

$\begin{array}{ll}\text { Datos ambientales } & 40\end{array}$

Análisis de Nutrientes $\quad 43$

Análisis de Agrotóxicos $\quad 44$

Cálculo de Unidades Tóxicas (UT) 45

$\begin{array}{ll}\text { Muestras de Macroinvertebrados } & 45\end{array}$

$\begin{array}{ll}\text { Análisis Estadístico } & 48\end{array}$

Región Pampeana (Argentina) 52

Resultados

$1^{a}$ Etapa: Arroyos con distinto uso del suelo en sus cuencas

$\begin{array}{lr}\text { Variables ambientales } & 52\end{array}$

$\begin{array}{ll}\text { Agrotóxicos } & 53\end{array}$ 
$\begin{array}{ll}\text { Unidades Tóxicas (UT) } & 55\end{array}$

Ensamble de macroinvertebrados $\quad 56$

Relaciones del ensamble de macroinvertebrados con $\quad 61$ los agrotóxicos y parámetros físico-químicos 61

$\begin{array}{ll}\text { Relaciones con las características del hábitat } & 62\end{array}$

$2^{a}$ Etapa: Arroyos de cuencas agrícolas (Arrecifes 2011-2014) 66

$\begin{array}{ll}\text { Variables ambientales } & 66\end{array}$

$\begin{array}{ll}\text { Agrotóxicos } & 67\end{array}$

$\begin{array}{ll}\text { Unidades Tóxicas (UT) } & 69\end{array}$

$\begin{array}{ll}\text { Ensamble de macroinvertebrados } & 70\end{array}$

Relaciones del ensamble de macroinvertebrados con
los agrotóxicos y variables ambientales

$\begin{array}{ll}\text { Relaciones con las características del hábitat } & 84\end{array}$

$\begin{array}{lr}\text { Discusión } & 89\end{array}$

$\begin{array}{lr}\text { Selva Paranaense (Paraguay y Brasil) } & 100\end{array}$

$\begin{array}{ll}\text { Resultados } & 100\end{array}$

$\begin{array}{ll}\text { Variables ambientales } & 100\end{array}$

$\begin{array}{lr}\text { Agrotóxicos } & 102\end{array}$

$\begin{array}{ll}\text { Unidades Tóxicas (UT) } & 104\end{array}$

$\begin{array}{lr}\text { Ensamble de macroinvertebrados } & 106\end{array}$

$\begin{array}{ll}\text { Influencia de la franja de atenuación } & 111\end{array}$

Relaciones del ensamble de macroinvertebrados con el RBP 112

Relaciones del ensamble de macroinvertebrados con
los agrotóxicos

Relaciones con las características del hábitat $\quad 114$

$\begin{array}{ll}\text { Discusión } & 116\end{array}$

$\begin{array}{lr}\text { Conclusiones } & 124\end{array}$

$\begin{array}{lr}\text { Bibliografía } & 128\end{array}$

$\begin{array}{lr}\text { Anexos } & 140\end{array}$ 


\section{Resumen}

La creciente adopción de sistemas productivos basados en la siembra directa, junto con el uso de agroquímicos y la introducción de semillas modificadas genéticamente permitió extender la superficie sembrada de los cultivos, principalmente de soja. Es en el sur de América Latina donde este cambio tecnológico se ha implementado con mayor velocidad e intensidad. En Argentina, el área sembrada del cultivo de soja aumentó de 4,9 a 20,5 millones de hectáreas desde la campaña 90/91 hasta el presente; en Brasil, el área cultivada con soja se incrementó en 126\% durante el período 1995/2011 y en Paraguay, aumentó de 1,3 a 3,5 millones de hectáreas entre el 2000 y el 2015. La misma tendencia se observa con el consumo de agrotóxicos y fertilizantes para las tres regiones. Los biocidas más utilizados en nuestra región son el herbicida glifosato y los insecticidas cipermetrina, clorpirifos y endosulfán. El organoclorado endosulfán fue prohibido en Argentina, a partir de 2013.

El objetivo del presente trabajo de tesis es estudiar el impacto de la práctica agrícola sobre los ensambles de macroinvertebrados acuáticos de cuencas rurales, poniendo especial énfasis en el efecto producido por los agroquímicos. Se compararon los ensambles de macroinvertebrados, las características físicas y químicas del agua, las concentraciones de agrotóxicos en sedimentos y la calidad del hábitat en arroyos que atraviesan zonas con uso intensivo del suelo y arroyos de características similares, en cuyas cuencas no se realiza agricultura intensiva y/o poseen franjas de atenuación cubiertas por vegetación.

En el laboratorio se realizaron ensayos de toxicidad para determinar la concentración letal $\left(\mathrm{LC}_{50}\right)$ de los agrotóxicos más utilizados (cipermetrina, lambdacialotrina, endosulfán, clorpirifos) en el anfípodo Hyalella curvispina en agua y sedimento. La sensibilidad de $H$. curvispina fue comparada con la de otras especies por medio de la curva de distribución de sensibilidad de especies (SSDs). El piretroide lambda-cialotrina registró los valores de $\mathrm{LC}_{50}$ más bajos, seguido de cipermetrina, clorpirifos y endosulfán. Se observó que la sensibilidad de H. curvispina es similar a la de $H$. azteca, comúnmente utilizado como organismo indicador de contaminación en 
America del Norte, y que ambos organismos son más sensibles que la mayoría de los taxones de invertebrados de agua dulce.

Los arroyos estudiados se encuentran en áreas agrícolas de Argentina, Paraguay y Brasil. Los muestreos se realizaron durante el período de crecimiento de la soja, correspondiente a los meses de noviembre a abril. En Argentina se llevó a cabo el estudio durante un período de tres años y se monitorearon 23 arroyos ubicados en dos regiones de La Pampa argentina, incluyendo una región de producción intensiva de soja, en Arrecifes, y una región mixta: agrícola y ganadera, en La Plata. En el año 2013 se estudiaron dos regiones de la Selva Paranaense: 17 arroyos en Paraguay ubicados sobre la cuenca del río Pirapó, departamento de Itapúa y 18 arroyos en Brasil en Toledo, estado de Paraná. Ambas regiones poseen producción intensiva de soja y una legislación que exige a los productores dejar una franja sin cultivar entre el cultivo y los arroyos.

En la región Pampeana se determinó que los ensambles de macroinvertebrados registraron diferencias significativas entre arroyos con distinto uso del suelo en sus cuencas (agrícolas, ganaderos y reserva). Las mayores concentraciones de nutrientes y la presencia de agrotóxicos se registraron en los arroyos de cuencas donde la agricultura fue la actividad dominante. Asimismo, en los arroyos agrícolas se registraron los mayores valores de Unidad Tóxica total (UT) alcanzando, en algunos sitios, valores extremos mayores a la unidad. Se observó que en los sitios menos disturbados la dominancia correspondió a Hyalellidae (Amphipoda), Palaemonidae (Decapoda) y Caenidae (Ephemeroptera), considerados sensibles a los agrotóxicos, mientras que en los sitios más disturbados Gastropoda, Oligochaeta e Hirudinea, considerados tolerantes, fueron los taxones mejor representados. En la Selva Paranaense se observó que la mayor riqueza taxonómica y abundancia correspondió a los arroyos estudiados de Paraguay, como así también los índices de diversidad y equitatividad. Los taxones Coleoptera, Ephemeroptera y Trichoptera resultaron ser más abundantes en Paraguay y registraron una correlación inversa con la concentración de los biocidas. Por el contrario, los taxones Diptera y Bivalvia fueron más abundantes en Brasil y registraron correlación positiva con la concentración de algunos agrotóxicos. Cabe destacar, que el ancho de la franja de atenuación en Paraguay fue mayor y menos variable que en los arroyos estudiados de Brasil. 
En los sedimentos analizados de los arroyos de Argentina, en cuencas con producción intensiva de soja, Brasil y Paraguay se detectó la presencia de todos los biocidas utilizados con mayor frecuencia en los cultivos regionales. Sin embargo, el impacto de los mismos sobre los taxones sensibles estaba más claramente correlacionado en los arroyos pampeanos. Una posible razón de esta discrepancia puede ser que las franjas de atenuación de los arroyos de Argentina son mucho más pequeñas y no están forestadas, por lo que las comunidades de invertebrados no serían tan resilientes. Estos resultados confirmarían el efecto protector de las franjas de atenuación y ponderan su utilidad como norma de manejo para mitigar el impacto agrícola.

En la presente tesis se observaron reiteradamente correlaciones positivas entre la concentración de PRS y la concentración de agrotóxicos y negativas entre el PRS y la abundancia de algunos grupos taxonómicos. Su correlacion no significa una relación causa efecto sino la simultaneidad de su aplicación con los agrotóxicos y su similar comportamiento ambiental, por lo cual, resulta un buen indicador del impacto agrícola. Asimismo, se determinaron las variables ambientales que tienen mayor influencia en la composición de los ensambles de macroinvertebrados, entre ellos se encuentran la materia orgánica y textura de los sedimentos.

En este estudio se concluye que la exposición a los agrotóxicos contribuye a las diferencias observadas en la composición del ensamble de macroinvertebrados en arroyos con distinto uso del suelo en sus cuencas. Aquellos arroyos que atraviesan zonas con uso intensivo del suelo sin franja de atenuación poseen una fauna con mayor abundancia de taxones tolerantes a los agrotóxicos y una disminución o ausencia de taxones sensibles. Se concluye también que los ensambles de macroinvertebrados son una herramienta eficaz para evaluar ecosistemas acuáticos y sus respuestas a los cambios en el uso del suelo de la cuenca. 


\section{Abstract}

The increasing adoption of productive systems based on direct sowing, together with the use of agrochemicals and the introduction of genetically modified seeds increased the sown area of the crops, mainly soybean. It is in southern Latin America where this technological change has been implemented with greater speed and intensity. In Argentina, the area planted with soybean increased from 4.9 to 20.5 million hectares form 90/91 up to the present; in Brazil, the area cultivated with soybeans increased by $126 \%$ during the period 1995/2011 and in Paraguay, increased from 1.3 to 3.5 million hectares between 2000 and 2015. The same trend is observed with the consumption of pesticides and fertilizers for the three regions. The most used biocides in our region are the glyphosate herbicide and the cypermethrin, chlorpyrifos and endosulfan insecticides. The organochlorine endosulfan has been prohibited in Argentina, since 2013.

The objective of this thesis is to study the impact of the agricultural practice on the assemblage of aquatic macroinvertebrates of rural basins, with special emphasis on the effect produced by agrochemicals. The assemblage of macroinvertebrates, the physical and chemical characteristics of the water, the concentrations of agrochemicals in sediments and the quality of the habitat in streams adjacent to plots with different land use were compared.

Laboratory toxicity tests were performed to determine the lethal concentration (LC50) of the most commonly used agrotoxics (cypermethrin, lambda-cyhalothrin, endosulfan, chlorpyrifos) for the amphipod Hyalella curvispina in water and sediment. The sensitivity of $H$. curvispina was compared with the sensitivity of other species by means of the species sensitivity distribution curve (SSDs). The pyrethroid lambdacyhalothrin registered the lowest LC50 values, followed by cypermethrin, chlorpyrifos and endosulfan. It was observed that the sensitivity of $H$. curvispina is similar to $H$. azteca, a commonly used test organism in North America, and that both organisms are more sensitive than most freshwater invertebrate taxa.

The streams studied are found in agricultural areas of Argentina, Paraguay and Brazil. The samplings were made during the period of soybean growth, corresponding 
to the months of November to April. In Argentina, the study was conducted over a three years period and 23 streams were monitored in two regions of the Argentine Pampa, including a region of intensive soy production, in Arrecifes, and a mixed region: agricultural and livestock, in La Plata. Two regions of the Paranaense Forest were studied in 2013: 17 streams in Paraguay located on the Pirapó river basin, Itapúa department and 18 streams in Brazil in Toledo, Paraná state. Both regions have intensive soy production and legislation that requires farmers to leave a strip of uncultivated land between the crop and the streams.

In the Pampean region it was shown that the assemblage of macroinvertebrates registered significant differences between streams with different land use in their basins (agricultural, livestock and reserve). The highest concentrations of nutrients and the presence of agrotoxics were recorded in the streams of basins where agriculture was the dominant activity. Likewise, in the agricultural streams the highest values of Total Toxic Unit (TU) were recorded, reaching, in some places, extreme values greater than unity. It was observed that in the least disturbed sites the dominance corresponded to Hyalellidae (Amphipoda), Palaemonidae (Decapoda) and Caenidae (Ephemeroptera), considered sensitive to the agrotoxics, while in the most disturbed site Gastropoda, Oligochaeta and Hirudinea, considered tolerant, were the taxa best represented. In the Paranaense Forest it was observed that the highest taxonomic richness and abundance corresponded to the studied streams of Paraguay, as well as diversity and equitability indexes. Coleoptera, Ephemeroptera and Trichoptera were found to be more abundant in Paraguay and showed an inverse correlation with the concentration of the biocides. On the contrary, Diptera and Bivalvia were more abundant in Brazil and showed a positive correlation with the concentration of some agrotoxics. It is noteworthy that the width of the attenuation strip in Paraguay was greater and less variable than in the streams studied in Brazil.

In the analyzed sediments of the streams of Argentina, in basins with intensive soybean production, Brazil and Paraguay, the presence of all the biocides most frequently used in regional crops was detected. However, the impact of them on sensitive taxa was more clearly correlated in the Pampean streams. One possible reason for this discrepancy may be that the attenuation strips of stream in Argentina are much smaller and are not forested, so that invertebrate communities would not be so resilient. 
These results confirm the protective effect of the attenuation strips and their usefulness as a management practice to mitigate the agricultural impact.

In the present thesis, positive correlations were observed between the PRS concentration and the concentration of agrotoxics and negatives between the PRS and the abundance of some taxonomic groups. Its correlation does not mean a cause-effect relationship but the simultaneity of its application with agrotoxics and its similar environmental behavior, which is a good indicator of agricultural impact. The environmental variables that have the greatest influence on the composition of the macroinvertebrate assemblage were determined; among them are the organic matter content and texture of the sediments.

In this study it is concluded that the exposure to agrotoxics contribute to the observed differences in the composition of the macroinvertebrate assemblage in streams with different land use in their basins. Draining basins with intensive land use without attenuation strips possess a fauna with greater abundance of taxa tolerant to the agrotóxicos and a decreased or absence of sensible taxa. It is also concluded that the assemblage of macroinvertebrates is an effective tool to evaluate aquatic ecosystems and their responses to changes in the land use from the adjacent fields. 


\section{Introducción Objetivos e Hipótesis}




\section{INTRODUCCIÓN}

La siembra directa de cultivos asociada con la implementación de soja transgénica, glifosato y aplicación intensiva de agroquímicos ha revolucionado la forma de hacer agricultura en el mundo. Sin embargo, es en el cono sur de América Latina donde este cambio tecnológico se ha implementado con mayor velocidad e intensidad (Ekboir, 2001). En Estados Unidos, esta modalidad es aplicada en sólo $25 \%$ del área agrícola total. La tasa de adopción en Argentina, Paraguay y Brasil representa aproximadamente 70-75\% (Derpsch, 2010).

El área sembrada con los cuatro cultivos principales: soja, girasol, maíz y trigo aumentó de 15,7 millones de hectáreas en 1990/91 a 33,2 millones en 2015/16 en Argentina; siendo la soja el cultivo que mostró el mayor aumento (de 4,9 a 20,5 millones de hectáreas). Paralelamente, la producción ganadera se intensificó, concentrándose en unidades denominadas "feed lots", y se trasladó a zonas tradicionalmente marginales (MAGyP, 2017). El consumo de fertilizantes aumentó de 0,4 a 2,4 millones de toneladas desde principios de la década del 90 al 2015 (CIAFA, 2015). El consumo de biocidas se acrecentó de 39 millones de kilogramos o litros en 1991 (Moltoni, 2012) hasta 336 millones de kilogramos o litros en 2011 (CASAFE, 2012). Los agrotóxicos más utilizados en el cultivo de soja correspondieron al herbicida glifosato y los insecticidas cipermetrina, clorpirifos y endosulfán (Mugni et al., 2012). Este último fue utilizado en cultivos extensivos y representó uno de los pesticidas del mercado con mayor persistencia en el ambiente, alta capacidad de bioacumulación y su eventual traslado a grandes distancias de los sitios de aplicación (Astoviza et al., 2015). Como consecuencia de ello, en la V Reunión de las Partes del Convenio de Estocolmo

sobre los Contaminantes Orgánicos Persistentes (COPs), se prohibió el uso del endosulfán en todo el mundo (UNEP, 2011). En Argentina se prohibió a partir del 1 de julio de 2013 mediante la resolución 511/11 del SENASA, la elaboración, formulación, comercialización y el uso de todos los productos que contengan el principio activo endosulfán. En Brasil, el gobierno fijo un plazo 3 años a partir del 31 de julio de 2010, para retirar todos los productos formulados a base de endosulfán del mercado brasileño (ANVISA-RDC $\mathrm{N}^{\mathrm{o}} 28$ ); mientras que, en Paraguay, la prohibición fue a partir del año 2010 (SENAVE-Resolución 635/10). Esto implica un aumento de la utilización de insecticidas sustitutos como el piretroide lambda-cialotrina. El proceso de incremento en la superficie sembrada con soja ligado a la adopción de un paquete tecnológico 
basado en la utilización de semillas modificadas genéticamente y del herbicida glifosato presenta características similares en todos los países que conforman el MERCOSUR: en Uruguay desde comienzos del 2000 se vienen desarrollando cambios muy importantes en el sector agropecuario vinculados a la explosiva inclusión del cultivo de soja; en Brasil la producción total de granos se incrementó de 81 millones de toneladas en 1995 a cerca de 130 millones de toneladas en 2006 entre las cuales cerca de 59 millones corresponden al cultivo de soja (Bejarano et al., 2008) y el área del mismo se expandió en 126\% durante el período 1995/2011 (Castanheira \& Freire, 2013). En Paraguay, el área de cultivo de soja aumentó de 1,3 millones de hectáreas en 2000/01 a 3,5 millones de hectáreas en 2014/15 (García-Lopez \& Arizpe, 2010; DGEEC, 2015). En Brasil, los insecticidas del grupo diamida y los inhibidores del crecimiento son cada vez más utilizados para controlar las plagas de lepidópteros, mientras que las mezclas de neonicotinoides y piretroides se utilizan a menudo para controlar las plagas de hemípteros (Bueno et al., 2011). Además, el insecticida sistémico imidacloprid (neonicotinoide) se aplica comúnmente en Paraguay y Brasil para el tratamiento de semillas y más tarde sobre el cultivo en forma de aerosol junto con piretroides.

Los cambios en el uso del suelo causados por esta expansión del cultivo de soja provocan la degradación de los ecosistemas acuáticos adyacentes a través de múltiples mecanismos. Entre los factores de estrés relacionados con la agricultura se pueden incluir enriquecimiento de nutrientes, sedimentación, deforestación y canalización (Jones et al., 2001; Gücker et al., 2009; Matthaei et al., 2010).

Si bien existe abundante información disponible en la literatura sobre la toxicidad de numerosos agrotóxicos en experimentos de laboratorio para varias especies en condiciones estándar, los estudios sobre el efecto de los mismos en condiciones ambientales más complejas y realistas, donde las poblaciones interactúen entre sí, se reducen a un número sensiblemente menor. En la bibliografía aparecen trabajos que determinan concentraciones de algún tóxico utilizado en la cuenca y el efecto inmediato producido, típicamente la disminución en la densidad y eventualmente desaparición de algún organismo considerado indicador de contaminación. Schulz \& Liess (1999a) observaron la desaparición de 8 de 11 especies de invertebrados con posterioridad a un pulso de paratión, un insecticida organofosforado, producido por la escorrentía superficial de los cultivos en un pequeño arroyo de Alemania. Schulz \& Liess (1999b) registraron mortalidad del anfípodo Gammarus pulex y del tricóptero Limnephilus 
lunatus en pulsos de contaminación del piretroide fenvalerato, producidos por la escorrentía superficial. En nuestra región, Jergentz et al. (2004 a, b) determinaron pulsos de toxicidad en arroyos con cuencas cultivadas de Arrecifes-Pergamino, provincia de Buenos Aires, asociados a eventos de escorrentía superficial. Paralelamente, estudiaron la dinámica de la población residente y realizaron bioensayos in situ con dos especies locales de crustáceos: Hyalella curvispina y Macrobrachium borellii concluyendo que existía una correspondencia entre la presencia de clorpirifos en sedimento, la densidad de la fauna local y la mortalidad observada en los bioensayos. Asimismo, determinaron que la metodología utilizada de exposición de organismos es un indicador sensible y confiable de la toxicidad para la población residente. Marino \& Ronco (2005) y Jergentz et al. (2005) determinaron la concentración de agrotóxicos en un arroyo que nace en una parcela cultivada con soja cercano a Arrecifes donde el responsable de la producción informaba con anterioridad los momentos de aplicación. La concentración de cipermetrina, clorpirifos y endosulfán fueron analizadas en aguas y sedimentos. Las mayores concentraciones se registraron en los sedimentos de fondo después de la primer lluvia con posterioridad a la aplicación y decayeron en un período cercano a un mes. Las concentraciones fueron mayores en la parcela fumigada, disminuyendo aguas abajo. Los valores en agua fueron órdenes de magnitud menores a las determinadas en sedimentos. Mugni et al. (2011a) estudiaron la persistencia de la toxicidad en las nacientes de un arroyo que atraviesa un campo cultivado y detectaron pulsos de toxicidad efímeros producidos por las aplicaciones de cipermetrina y clorpirifos. La toxicidad introducida en el arroyo por la escorrentía superficial de la primer lluvia con posterioridad a la aplicación es el proceso más importante. Asimismo, la toxicidad es mayor que la introducida por la deriva de la fumigación e incluso mayor que la producida por aplicaciones aéreas, donde el arroyo recibe la misma carga que el cultivo. El tiempo transcurrido entre la aplicación y la primera lluvia es crítico. Cuando la primera lluvia se produjo con posterioridad al mes de la aplicación, no registraron toxicidad en la escorrentía. Cuando el período transcurrido fue menor al mes, la mortalidad de $H$. curvispina fue total.

Cabe interrogarse respecto de la persistencia del efecto de los reiterados pulsos de toxicidad en el tiempo en los ambientes naturales adyacentes a cultivos. La comunidad tiene mecanismos homeostáticos. La ocurrencia de un único pulso de toxicidad producido en un sector de la cuenca se revierta con el tiempo porque habrá un 
repoblamiento de los grupos afectados por migración desde otros sectores o refugios (Orlinskiy et al., 2015). No obstante, si el ambiente se encuentra en una cuenca que recibe sucesivos pulsos de toxicidad en distintas oportunidades, con distintos tóxicos, y en áreas cada vez mayores de la misma, es probable que haya un deterioro paulatino de la calidad del agua y una pérdida definitiva de diversidad.

El estudio de los ensambles de macroinvertebrados es una alternativa metodológica utilizada para detectar modificaciones en los ecosistemas acuáticos (Plafkin et al., 1989). Este enfoque asume que la composición del ensamble funciona como bioindicador reflejando el estado de un cuerpo de agua (Rosenberg \& Resch, 1993; Hering et al., 2004). En nuestro medio, varios autores enfocaron el estudio de los ensambles de invertebrados como bioindicadores de calidad de aguas y la aplicación de índices bióticos para detectar variados impactos, desde contaminación industrial (Gomez et al., 2008), el efecto del uso del suelo (Miserendino \& Pizzolón, 1999; Rodrigues-Capítulo et al., 2001; Corigliano et al., 2005; Miserendino et al., 2008; Miserendino et al., 2011; Solis et al., 2016; Solis et al., 2017) como así también por distintos tipos de hábitats (Velasquez \& Miserendino, 2003). Domínguez \& Fernández (1998) determinaron el estado de los ríos de Tucumán en base a su fauna bentónica. Miserendino et al. (2011) estudiaron las diferencias en la composición de los ensambles de invertebrados en arroyos de cuencas de estepa, pasturas, bosque natural e implantado, y urbanos, en Patagonia, y concluyeron que los distintos usos del suelo modifican la composición de los ensambles y que puede ser utilizada para el monitoreo de la calidad ambiental de los cuerpos de agua regionales. Ocón \& Rodrigues-Capítulo (2004) investigaron las comunidades bentónicas de arroyos y ríos de distintas áreas de la región Pampeana afectados principalmente por efluentes urbanos e industriales.

Estudios realizados en microcosmos con diferentes agroquímicos registraron cambios en la estructura de la comunidad de invertebrados. Friberg-Jensen et al. (2003) estudiaron el efecto del agregado de cipermetrina en concentraciones crecientes en mesocosmos suspendidos en un lago somero. En todos los tratamientos la concentración de cipermetrina disminuyó rápidamente. El efecto fue la rápida disminución en la densidad de cladóceros y copépodos y el aumento de rotíferos, bacterias y fitoplancton. Giddings et al. (2001) recopilaron estudios sobre el efecto de cipermetrina en comunidades de mesocosmos y en ambientes naturales, registrando una diferencia en la sensibilidad de anfípodos, isópodos, culícidos, copépodos y cladóceros (más sensibles) 
respecto a peces, moluscos, oligoquetos y rotíferos (menos sensibles). Con pocas excepciones, poblaciones afectadas por piretroides en los mesocosmos se recuperaron a niveles normales antes del final del año desde la exposición; la mayor parte de poblaciones se recuperaron dentro de unas pocas semanas. En nuestra región, Solis et al. (2016) compararon el ensamble de invertebrados en arroyos de cuencas con distinto grado de disturbio ocasionado por la actividad agrícola y ganadera en la región Pampeana, Argentina. Las mayores concentraciones de nutrientes e insecticidas se determinaron en los sitios agrícolas y de ganadería intensiva. Además, observaron que en esos sitios la composición del ensamble de macroinvertebrados era distinta que en las cuencas no disturbadas o de ganadería extensiva. En los sitios menos disturbados la dominancia correspondió al anfípodo $H$. curvispina mientras que en los disturbados Gastropoda, Zygoptera e Hirudinea fueron los taxones mejor representados. Estos estudios muestran que el efecto de un tóxico sobre los grupos más sensibles causa el incremento de los organismos menos sensibles.

Las referencias bibliografícas sobre la concentración de nutrientes indican que la agricultura con intensiva aplicación de fertilizantes, como se realiza en Europa y Estados Unidos, produce un aumento de la concentración de nitratos en los ecosistemas acuáticos. Meybeck (1998) observó que, en cuerpos de agua en áreas de agricultura intensiva, las concentraciones de nitratos aumentan en un orden de magnitud (6 mg N/l) respecto a aquellos cuerpos de agua que drenan cuencas cubiertas con bosque. Sin embargo, no registraron diferencias significativas en las concentraciones de fósforo reactivo soluble (PRS) para cuencas con distintos usos del suelo. Un estudio realizado en arroyos del Cerrado brasileño informó que los sitios con agricultura en sus cuencas presentaron mayor concentración de nutrientes, morfología de canal reducido, velocidades más altas y menor biomasa microbiana en comparación con los arroyos menos disturbados (Gücker et al., 2009).

En nuestra región, Mugni (2009) y Mugni et al. (2013a) observaron que arroyos con distinto uso del suelo en su cuenca mostraron diferencias significativas en las concentraciones de nutrientes, siendo mayores en arroyos con uso agrícola que en cuencas con ganadería extensiva y en una reserva. Mugni et al. (2013a) estudió la concentración de nutrientes en el agua de escorrentía superficial de una parcela con agricultura durante 3 años consecutivos con distintos cultivos. Las mayores concentraciones se determinaron cuando el cultivo (maíz) fue fertilizado con un 
fertilizante foliar líquido. Asimismo, las concentraciones en el agua de escorrentía superficial, en la primer lluvia con posterioridad a la aplicación, resultó mayor que la de otros eventos de escorrentía. Los resultados disponibles sugieren que el uso del suelo en la cuenca influye en las concentraciones de nutrientes y aumenta en los arroyos adyacentes a cultivos fertilizados (Mugni et al., 2013a).

Mantener una franja de atenuación entre el cultivo y los arroyos puede representar una estrategia de manejo tendiente a mitigar el impacto de los agroquímicos reteniendo el aporte de agrotóxicos, fertilizantes, sedimentos y otros contaminantes de los cultivos a los cuerpos de agua en áreas agrícolas (Jones et al., 2001; Stone et al., 2005; Rasmussen et al., 2011b; Bunzel et al., 2014). En Brasil y Paraguay existen regulaciones que exigen a los productores mantener franjas de atenuación. En Paraguay, la Ley $\mathrm{N}^{\circ} 3742 / 09$ del Ministerio de Agricultura requiere una zona protegida de $100 \mathrm{~m}$ alrededor de todos los cuerpos de agua. En Brasil, se aprobó un nuevo código forestal en 2012 (Ley $\mathrm{N}^{\mathrm{o}}$ 12.651/12) que establece que el ancho de la franja de atenuación de la ribera debe variar según el uso del suelo adyacente al cuerpo de agua, el ancho del arroyo y el tamaño de la propiedad rural. En contraposición, Argentina no posee una legislación nacional que exija una franja de atenuación adyacente a los cuerpos de agua. Al mismo tiempo, en regiones con producción intensiva de soja se siembra hasta las orillas sin dejar zonas de amortiguación. Sin embargo, algunas provincias argentinas prohíben la aplicación de agrotóxicos a una distancia específica de los cuerpos de agua superficiales: Chaco Ley 7032 - DR 1567/13; Formosa Ley 1163 - DR 109/02; Río Negro Ley 2175 - DR 769/94 (FARN, 2015). 


\section{OBJETIVOS}

El objetivo general del presente trabajo de tesis es estudiar el impacto de la práctica agrícola sobre los ensambles de macroinvertebrados acuáticos de cuencas rurales, poniendo especial énfasis en el efecto producido por los agroquímicos. Para llevar a cabo dicho objetivo se evaluará la sensibilidad de una especie local (Hyalella curvispina) a distintos agrotóxicos mediantre bioensayos en laboratorio y se compararán los ensambles de invertebrados, las características físicas y químicas del agua, las concentraciones de agrotóxicos en sedimentos y la calidad del hábitat en arroyos que atraviesan zonas con uso intensivo del suelo y arroyos de características similares, en cuyas cuencas no se realiza agricultura intensiva y/o posean franjas de atenuación cubiertas por vegetación.

\section{Objetivos específicos:}

$>$ Determinar la concentración letal $\left(\mathrm{LC}_{50}\right)$ de los agrotóxicos más utilizados (cipermetrina, lambda-cialotrina, endosulfán, clorpirifos) para el anfípodo Hyalella curvispina en ensayos de laboratorio con agua y sedimento.

$>$ Comparar la riqueza taxonómica y densidad de macroinvertebrados acuáticos asociados a la interfaz agua - sedimento en arroyos con uso contrastante del suelo en sus cuencas.

$>$ Comparar la concentración de nutrientes en arroyos con distinto uso del suelo en su cuenca.

$>$ Proveer información respecto a la efectividad de las medidas paliativas (franjas de atenuación) para minimizar el impacto de los agroquímicos sobre los ensambles de macroinvertebrados.

> Comparar las Unidades Tóxicas (UT) de los arroyos con distinto uso del suelo, calculada a partir de las concentraciones letales $\left(\mathrm{LC}_{50}\right)$ y los niveles de agrotóxicos determinados en los sedimentos de los arroyos estudiados. 


\section{HIPÓTESIS}

El presente estudio propone como hipótesis general que la utilización intensiva de agroquímicos (agrotóxicos y fertilizantes) en la agricultura produce un impacto en los ensambles de macroinvertebrados que habitan en los cuerpos de agua adyacentes a los cultivos.

\section{Hipótesis derivada:}

Se propone como hipótesis derivadas que la resultante final de la aplicación de distintos agroquímicos causará el aumento de la concentración de nutrientes y agrotóxicos y una disminución de la biodiversidad general por la pérdida de los grupos taxonómicos más sensibles a los biocidas y proliferación de las especies más resistentes.

Asimismo, se presume que los arroyos que posean franjas de atenuación cubiertas por vegetación presentarán un impacto menor respecto a los que no posean dicha franja. 


\section{Ensayos de toxicidad}




\section{Ensayo de Toxicidad Aguda para Hyalella curvispina en Agua y Sedimento}

\section{OBJETIVOS ESPECÍFICOS}

* Determinar las concentraciones letales $50 \% \quad\left(\mathrm{LC}_{50}\right)$ de los agrotóxicos clorpirifos, endosulfán I, cipermetrina y lambda-cialotrina para Hyalella curvispina, tanto en agua como en sedimento.

* Comparar la sensibilidad de los diferentes grupos de edad de Hyalella curvispina y evaluar su viabilidad para el uso en ensayos de toxicidad.

* Comparar la sensibilidad de Hyalella curvispina con Hyalella azteca y otros invertebrados acuáticos de agua dulce.

\section{MATERIALES Y MÉTODOS}

La determinación de la dosis letal se llevó a cabo con organismos de $H$. curvispina colectados en el arroyo El Destino, ubicado en la reserva de la biosfera Parque Costero Sur, $65 \mathrm{~km}$ al sur de la ciudad de La Plata, Argentina (Athor, 2009). Los anfípodos fueron transportados al laboratorio y aclimatados antes de su uso para los bioensayos. Los individuos se criaron en recipientes de plástico con agua reconstituida preparada de acuerdo con las recomendaciones para H. azteca (USEPA, 2000). En los recipientes de cultivo se colocaron hojas de lechuga como sustrato y alimento, suplementando con alimento formulado para peces (Shulet $\left.{ }^{\circledR}\right)$ cada dos días.

El sedimento se recogió del mismo sitio que los anfípodos y se homogeneizó completamente antes de tomar una alícuota para el análisis de insecticidas. En los mismos no se detectaron ninguno de los biocidas ensayados (clorpirifos, endosulfán, cipermetrina y lambda-cialotrina). El contenido de carbono orgánico fue 1,7\%, y la humedad $3,6 \%$.

Los bioensayos de toxicidad aguda en agua (96h.) y en sedimento (10 días) siguieron los métodos de Weston et al. (2009) y Weston \& Jackson (2009), excepto el régimen de alimentación especificado levadura/cerophyll@/trucha que se cambió por alimento formulado para peces Shulet ${ }^{\circledR}$. Los organismos de los ensayos en agua fueron alimentados en una única oportunidad a las 48 horas de comenzado el experimento y en 
sedimento diariamente. Los bioensayos se mantuvieron a una temperatura de $23 \pm 2{ }^{\circ} \mathrm{C}$ con fotoperíodo natural.

Las pruebas de toxicidad se realizaron usando estándares certificados de Accustandard: lambda-cialotrina (99\% pureza) cipermetrina (95\% pureza), clorpirifos (100\% pureza) y endosulfán I (97,5\% pureza). Las concentraciones utilizadas en los bioensayos de agua fueron: lambda-cialotrina 0,$75 ; 1,5 ; 3 ; 6 ; 12 \mathrm{ng} / \mathrm{l}$, cipermetrina 20 , 40, 80 y 160 ng/l, clorpirifos 80, 160, 320 y 640 ng/l y endosulfán I 1000, 2000, 4000 y $8000 \mathrm{ng} / \mathrm{l}$. Las concentraciones ensayadas en sedimento, normalizado según carbono orgánico, fueron: lambda-cialotrina 100, 200, 800 y $1600 \mathrm{ng} / \mathrm{g}_{\mathrm{co}}$, cipermetrina 1000 , 2000 y 8000 ng/g $\mathrm{g}_{\mathrm{co}}$, clorpirifos 1970, 3900 y 7900 ng/g $\mathrm{g}_{\mathrm{co}}$ y endosulfán I 11800, 23600, 47200 y $94500 \mathrm{ng} / \mathrm{g}_{\mathrm{co}}$. Las muestras de sedimento fueron homogeneizadas a mano y se almacenaron en refrigerador. La preparación del agua se realizó inmediatamente antes de comenzar los bioensayos. Cada concentración se preparó añadiendo la cantidad apropiada de tóxico disuelto en acetona. Los controles fueron realizados adicionándole la máxima concentración de acetona que se utilizó en el tratamiento de exposición, 32 $\mu \mathrm{l} / \mathrm{L}$ en los ensayos en agua y $1,1 \mu \mathrm{l} / \mathrm{g}$ en sedimento. Para cada concentración de agrotóxico y control se utilizaron vasos de vidrio por triplicado, cada uno conteniendo 10 individuos de $H$. curvispina.

Para los bioensayos de agua, se colocaron en cada vaso de precipitados $80 \mathrm{ml}$ de agua reconstituida con el agrotóxico y una red de nylon de $1 \mathrm{~cm}^{2}$ como sustrato para que los anfípodos puedan aferrarse. Durante las primeras 48 horas se mantuvieron sin alimentación, ni cambio de agua (protocolo estándar en las pruebas agudas de 96 horas - USEPA 2002). Posteriormente, se añadió $1 \mathrm{ml}$ de alimento formulado para peces (Shuletß) a cada vaso de precipitado y se esperó un período de seis horas para realizar el recambio del agua. Pasado ese tiempo, se retiró el $80 \%$ del agua y se reemplazó con una nueva muestra de agua reconstituida que contenía la concentración del pesticida correspondiente. Al finalizar el ensayo, 96 horas en total, se contaron los sobrevivientes y se calculó la concentración letal media $\left(\mathrm{LC}_{50}\right)$ mediante el análisis Probit con un intervalo de confianza del $95 \%$. 
Para comparar la sensibilidad de diferentes edades, se realizaron bioensayos en agua para dos grupos:

(1) Organismos de 1-2 semanas de edad (individuos correspondientes a un tamaño de tamiz entre 500 y $355 \mu \mathrm{m}) ; \mathrm{y}$

(2) Organismos de 2-3 semanas de edad (individuos correspondientes a un tamaño de tamiz entre 710 y $500 \mu \mathrm{m})$.

Los organismos fueron tamizados tres días antes de iniciar los bioensayos.

El análisis utilizado para comparar la sensibilidad de las diferentes edades fue un test de "t". Para comparar las $\mathrm{LC}_{50}$ de cada agrotóxico, según los diferentes grupos de edades, se realizó un análisis de la varianza (ANOVA) de una vía y un test a posteriori de múltiples comparaciones de pares (Test Tukey). Previo al análisis se probaron los supuestos estadísticos de homogeneidad de la varianza y normalidad. En los casos en que los supuestos no se cumplieron se aplicó el método de Kruskal Wallis. Cuando se detectaron diferencias significativas $(\mathrm{p}<0,05)$ se procedió con la comparación de medianas para determinar diferencias por el método de comparación múltiple entre medianas (método Dunn's).

Para los ensayos de sedimento, se añadieron $70 \mathrm{~g}$ de sedimento con el agrotóxico y $200 \mathrm{ml}$ de agua reconstituida a cada vaso de precipitados. Para el ensayo se seleccionaron individuos de entre 355-710 $\mu \mathrm{m}$ (aproximadamente de 1 a 3 semanas de edad). Los organismos fueron tamizados cinco días antes de iniciar los bioensayos. Dos veces al día se reemplazó el $80 \%$ del agua con agua reconstituida. Se añadió diariamente $1 \mathrm{ml}$ de alimento formulado para peces inmediatamente después del primer cambio de agua. Se usaron los datos de mortalidad para estimar los valores de $\mathrm{CL}_{50}$ mediante el análisis Probit con un intervalo de confianza del 95\%. La toxicidad de los biocidas en sedimentos depende en gran medida del contenido de carbono orgánico total; con la finalidad de poder comparar resultados, se normalizaron las concentraciones por el porcentaje de carbono orgánico.

\section{Distribuciones de Sensibilidad de Especies}

Para comparar la sensibilidad de $H$. curvispina con otros taxones de invertebrados acuáticos, se calculó la distribución de sensibilidad de las especies (SSDs) para cada agrotóxico, utilizando el software "SSD Generator V1" creado por Agencia 
de Protección Ambiental de los Estados Unidos (USEPA, 2015a). La SSDs utiliza los valores de toxicidad disponibles para diferentes especies con respecto a un químico particular para derivar una distribución de sensibilidad conjunta, a partir de la cual se puede estimar la fracción de especies afectadas por una determinada concentración tóxica (Smetanová et al., 2014). El software SSD Generator de USEPA produce la curva de la distribución de sensibilidad de las especies (SSDs) ajustando la distribución log-probit a datos de toxicidad (USEPA, 2015a). En el eje de las X se grafica la intensidad del estrés, representada en escala logarítmica y en el eje de las Y se representa la proporción de las especies afectadas.

Para calcular la curva de la distribución de sensibilidad de las especies (SSDs) para cada agrotóxico analizado se utilizaron los valores de $\mathrm{LC}_{50}$ obtenidos para $H$. curvispina del presente estudio, así como todos los datos de toxicidad aguda en agua (uno a cuatro días) para los invertebrados de agua dulce disponibles en la base de datos ECOTOX de USEPA (USEPA, 2015b).

Existen trabajos que informan los valores de $\mathrm{LC}_{50}$ para $H$. curvispina a $48 \mathrm{~h}$ en agua (Mugni et al. 2011b, 2012, 2013b, 2015 y Solis, 2017). Estos datos no fueron combinados con los resultados del presente estudio con el objetivo de poder comparar las sensibilidades relativas de $H$. curvispina con la obtenida. Para el resto de los taxones, cuando se reportaban varias determinaciones para un mismo organismo, se combinaron en un único punto de datos utilizando la media de todos los valores de $\mathrm{LC}_{50}$ informados para el ingreso en la curva SSDs (USEPA, 2015a).

En la base de ECOTOX se dispone de datos sobre la toxicidad en agua para los cuatro insecticidas: 132 taxones tenían datos disponibles para clorpirifos, 69 para endosulfán, 57 para cipermetrina y 31 para lambda-cialotrina. Las curvas de distribución de sensibilidad de especies se generaron sólo para la toxicidad en agua, debido a la ausencia de datos de toxicidad en sedimentos.

\section{RESULTADOS}

Los resultados de los ensayos de toxicidad en agua y sedimentos registraron valores de $\mathrm{LC}_{50}$ más bajos para lambda-cialotrina, seguido de cipermetrina, clorpirifos y endosulfán I (Tabla 1.1). En los organismos de menor tamaño la $\mathrm{LC}_{50}$ de lambdacialotrina en agua fue significativamente menor que de clorpirifos (Kruskal Wallis, 
Dunn's p: 0,011). Los valores de $\mathrm{LC}_{50}$ de endosulfán en agua no se pudieron calcular en la clase de edad más joven, debido a la alta variabilidad en la mortalidad de las replicas y los controles. Sin embargo, en los organismos más grandes los valores de $\mathrm{LC}_{50}$ del endosulfán en agua resultó ser significativamente mayor que la determinada para el resto de los agrotóxicos (ANOVA, Tukey p<0,001). Las diferencias aparentes entre los organismos de distintas edades en los ensayos con piretroides en agua no fueron significativas, debido probablemente a la variabilidad entre las réplicas. La supervivencia media de los controles en agua con organismos entre 500-710 $\mu \mathrm{m}$ fue de 98\% y $90 \%$ en los individuos más pequeños (entre $355-500 \mu \mathrm{m}$ ). Los controles de los ensayos en sedimento tuvieron una supervivencia media de $93 \%$.

Tabla 1.1 Valores de $\mathrm{LC}_{50}$ para $H$. curvispina e intervalos de confianza 95\%, para los agrotóxicos lambda-cialotrina, cipermetrina, clorpirifos y endosulfán I, en agua y sedimento (co: normalizado según carbono orgánico).

\begin{tabular}{|l|c|c|c|}
\cline { 2 - 4 } \multicolumn{1}{c|}{} & \multicolumn{2}{c|}{$\mathbf{L C}_{\mathbf{5 0}}$ Agua $(\mathbf{n g} / \mathbf{L})$} & LC $_{\mathbf{5 0}}$ Sedimento $\left(\mathbf{n g} / \mathbf{g}_{\mathbf{C o}}\right)$ \\
\hline Tamaño & $355-500 \mu \mathrm{m}$ & $500-710 \mu \mathrm{m}$ & $355-710 \mu \mathrm{m}$ \\
(edad) & $(1-2$ semanas $)$ & $(2-3$ semanas $)$ & $(1-3$ semanas $)$ \\
\hline$\lambda$-cialotrina & $4,1(3,2-5,1)$ & $13,5(9,8-26,5)$ & $256(197-334)$ \\
Cipermetrina & $34,5(25,7-42,1)$ & $71,8(61,6-83,8)$ & $2073(1644-2758)$ \\
Clorpirifos & $138(119-160)$ & $142(112-170)$ & $3101(2327-3674)$ \\
Endosulfan I & - & $3264(2784-3831)$ & $33342(25185-40424)$ \\
\hline
\end{tabular}

La figura 1.1 muestra la curva de distribución de sensibilidad de especies (SSDs) para clorpirifos, en la cual se observa que $H$. curvispina es más sensible que el $94 \%$ de las especies. Los organismos más sensibles incluyen a H. azteca (97\%), los efemerópteros Deleatidium sp. (99\%) y Procloeon sp. (97\%), los cladóceros Daphnia ambigua (100\%) y Ceriodaphnia dubia (97\%) y el odonato Pseudagrion sp. (96\%). Algunos de los taxones que poseen una baja sensibilidad al clorpirifos son el platelminto Dugesia japonica (9\%) y los gasterópodos Pomacea canaliculata (4\%) y Lanistes carinatus (3\%). 


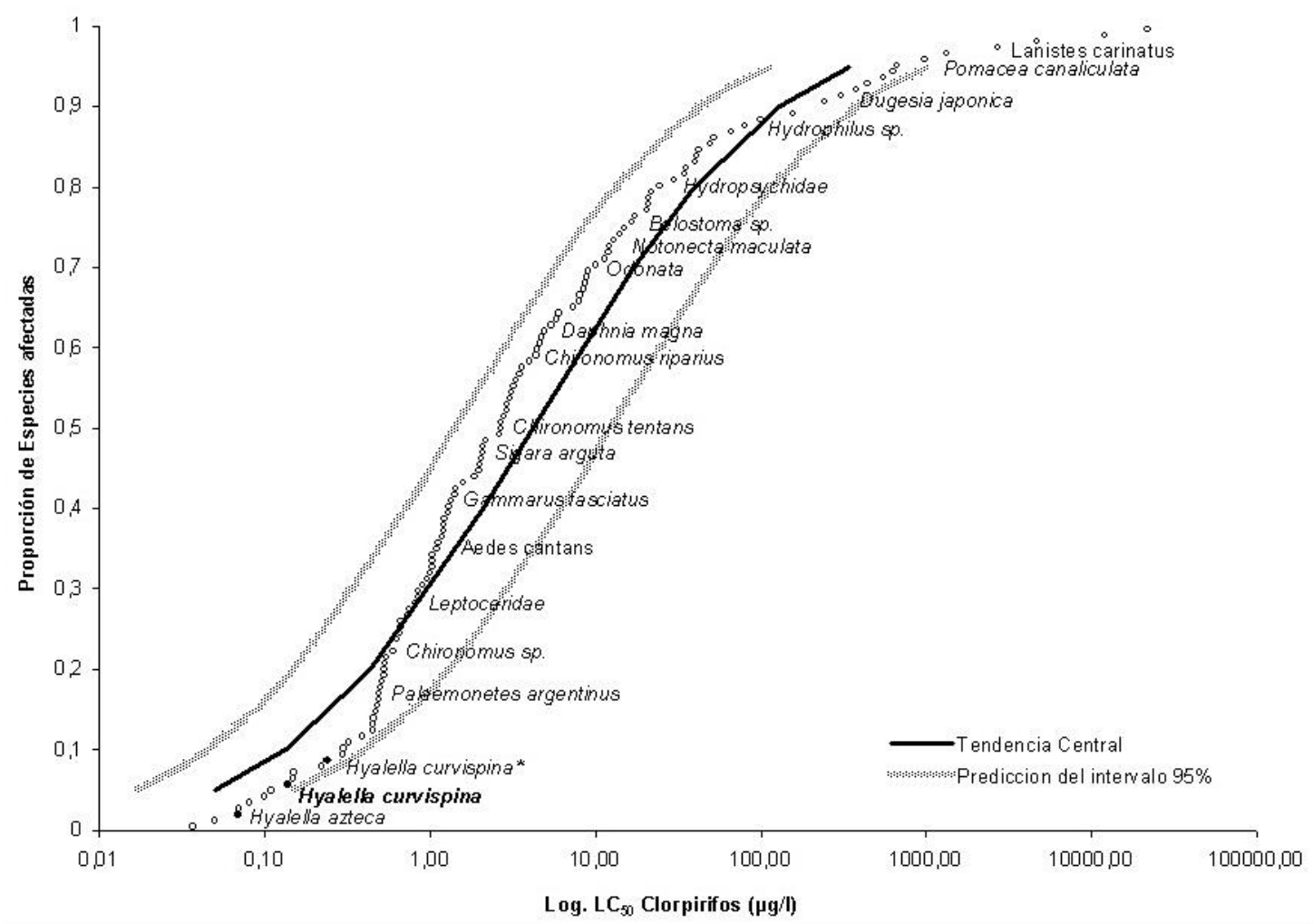

Figura 1.1 Sensibilidad de Hyalella curvispina comparada con la de otros macroinvertebrados de agua dulce para clorpirifos. Hyalella curvispina* Mugni et al., 2012 y Solis, 2017. (Ver Anexo Tabla A1 para los valores de $\mathrm{LC}_{50} \mathrm{y}$ valores de sensibilidad relativa para cada taxón).

La curva de SSDs para endosulfán indica que $H$. curvispina es más sensible que el 79\% de las especies (Figura 1.2). En el presente estudio sólo se utilizó el isómero endosulfán I, que es más tóxico que la mezcla típica de isómeros de endosulfán (Wan et al., 2005), que es usada en 56\% de los otros resultados reportados. Dentro de las 15 especies más sensibles que $H$. curvispina, todos son crustáceos, excepto por dos efemerópteros (Atalophlebia australis y Jappa kutera) y un tricóptero (Cheumatopsyche $s p$.). Entre los organismos menos sensibles se encontraron el oligoqueto Tubifex tubifex y los gasterópodos Physella acuta, Indoplanorbis exustus y Melanopsis dufouri. 


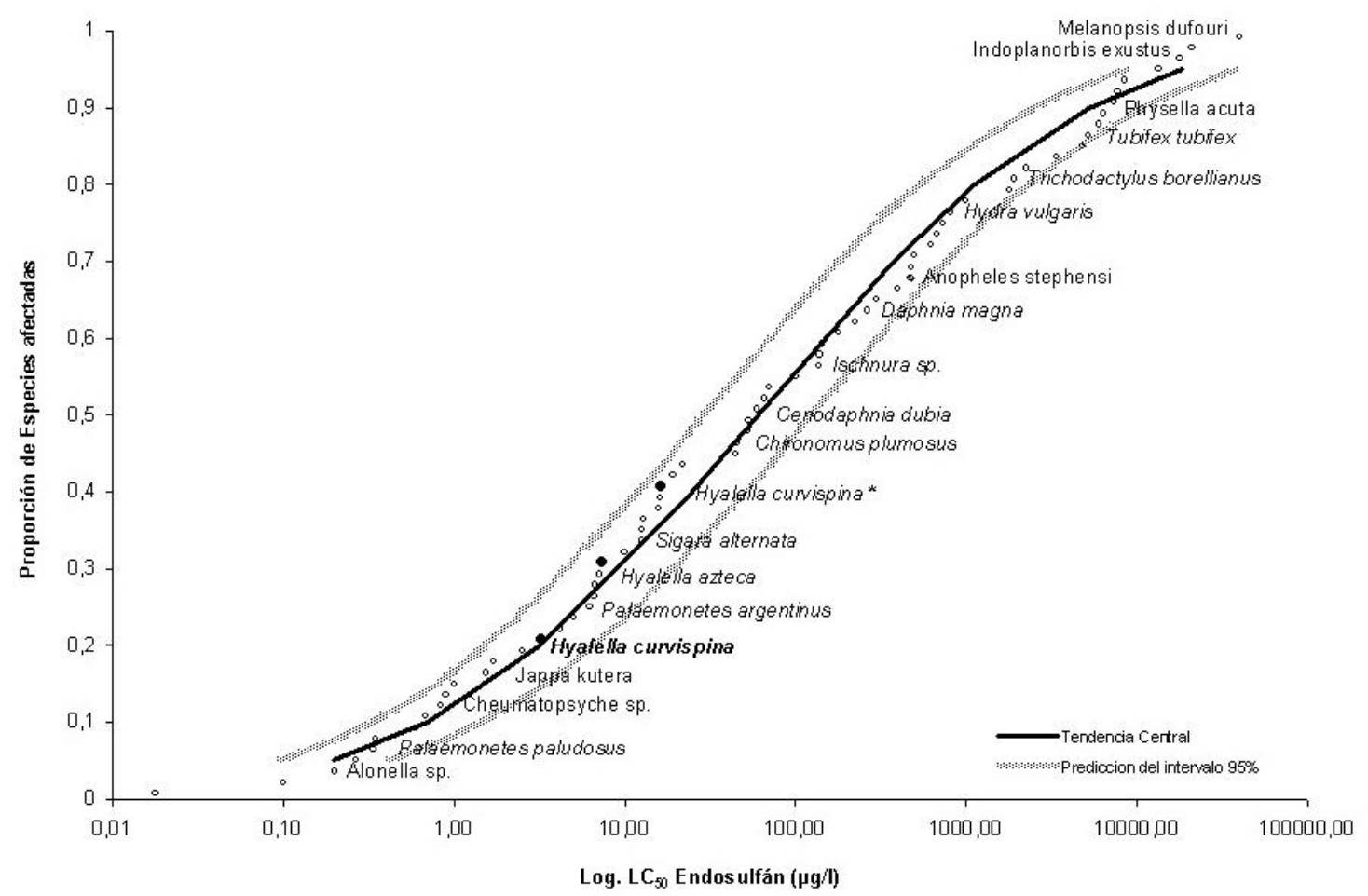

Figura 1.2 Sensibilidad de Hyalella curvispina comparada con la de otros macroinvertebrados de agua dulce para endosulfán. Hyalella curvispina* Mugni et al., 2012 y 2015. (Ver Anexo Tabla A2 para los valores de $\mathrm{CL}_{50}$ y valores de sensibilidad relativa para cada taxón).

La curva de SSDs para cipermetrina indica que $H$. curvispina es más sensible que el $91 \%$ de las especies (Figura 1.3). Los valores de $\mathrm{LC}_{50}$ de cipermetrina de $H$. azteca no se encontraron en la base de datos ECOTOX, por lo cual no se realizó una comparación. Los taxones que fueron más sensibles que $H$. curvispina incluyen a los crustáceos Palaemonetes argentinos, Trichodactylus borellianus, Macrobrachium rosenbergii y Diaptomus forbesi y, el chironómido Tanytarsus sp. Dentro de los menos sensibles se ubican los gasterópodos Lymnaea acuminata y Melanoides tuberculata y el bivalvo Lamellidens marginalis.

Para lambda-cialotrina, H. curvispina resultó ser el más sensible (98\%) de los 31 taxones informados en la literatura (Figura 1.4). El presente estudio, según la bibliografía consultada, representaría el primer registro de la $\mathrm{LC}_{50}$ de lambda-cialotrina para H. curvispina. 


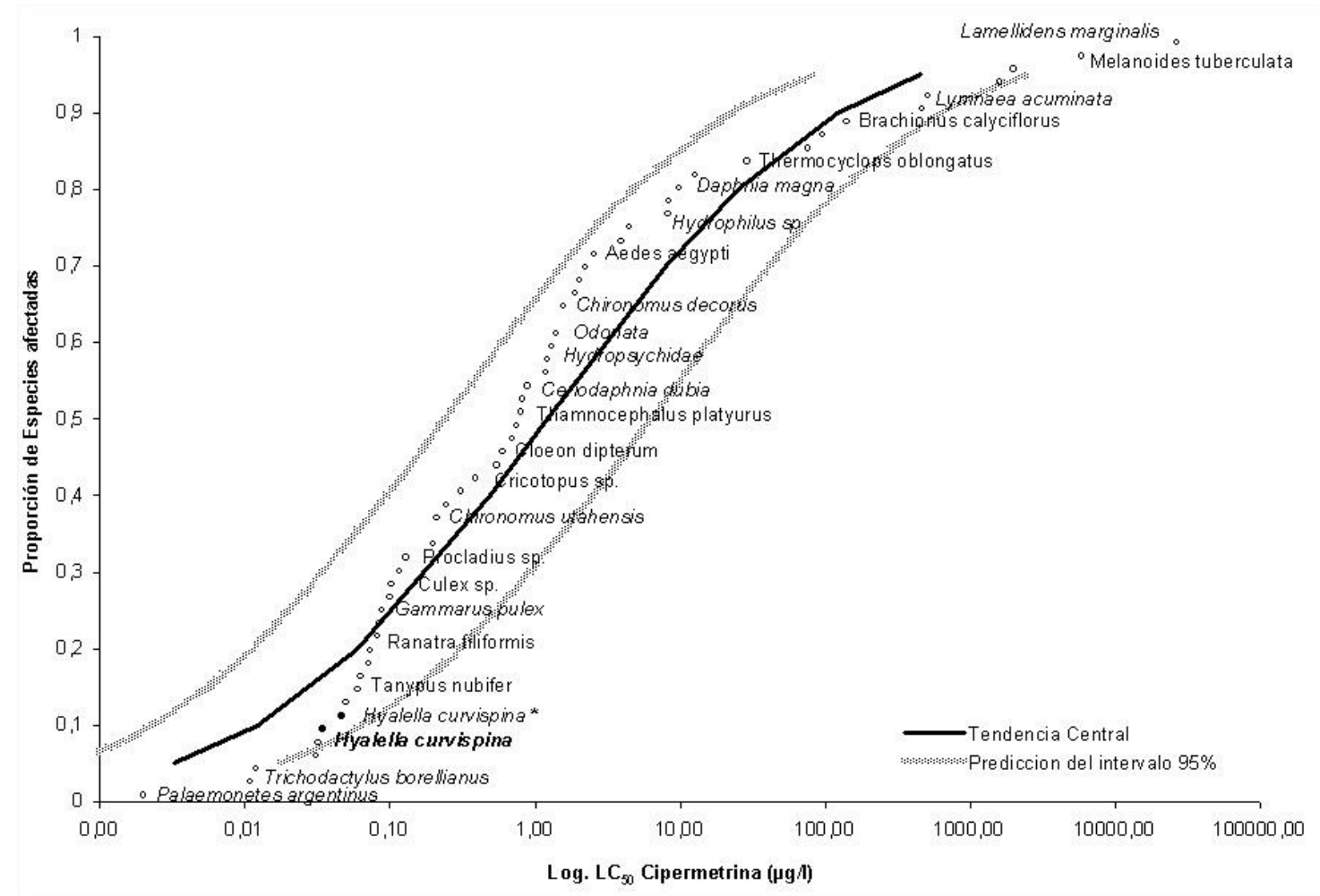

Figura 1.3 Sensibilidad de Hyalella curvispina comparada con la de otros macroinvertebrados de agua dulce para cipermetrina. Hyalella curvispina* Mugni et al., 2011b, 2012 y 2013b. (Ver Anexo Tabla A3 para los valores de $\mathrm{LC}_{50} \mathrm{y}$ valores de sensibilidad relativa para cada taxón).

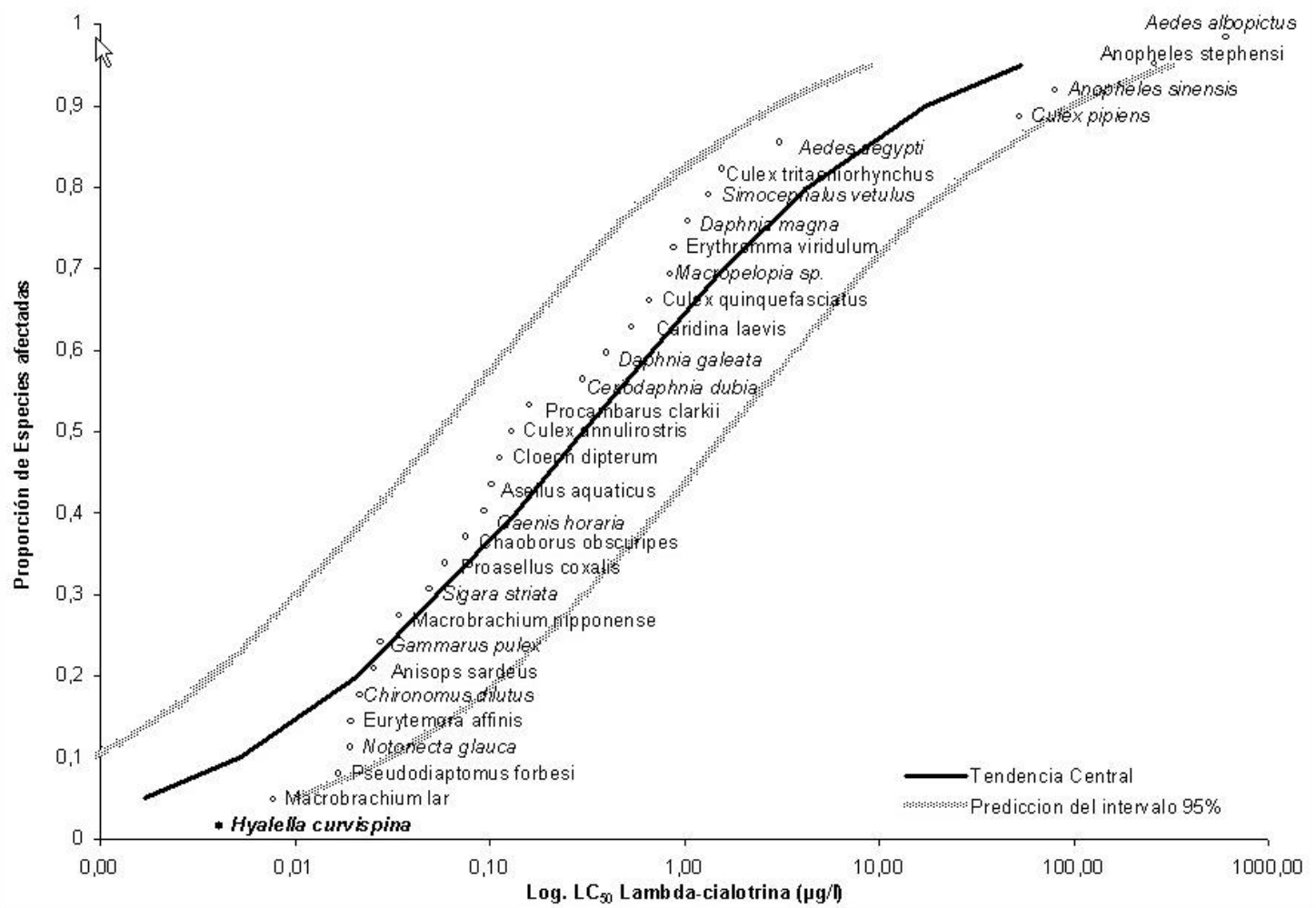

Figura 1.4 Sensibilidad de Hyalella curvispina comparada con la de otros macroinvertebrados de agua dulce para Lambda-cialotrina. (Ver Anexo Tabla A4 para los valores de $\mathrm{LC}_{50} \mathrm{y}$ valores de sensibilidad relativa para cada taxón). 


\section{DISCUSIÓN}

Los resultados del presente estudio indican que para los agrotóxicos clorpirifos y endosulfán la sensibilidad de $H$. curvispina es similar a la de $H$. azteca y que ambos organismos son más sensibles que la mayoría de los taxones de invertebrados de agua dulce. Asimismo, lo observado en este estudio concuerda con los datos previos de la sensibilidad de $H$. curvispina, aunque hubo algunas diferencias en la metodología empleada (Mugni et al. 2011b, 2012, 2013b, 2015 y Solis, 2017). Los trabajos previos utilizaron organismos adultos, más grandes (5-10 mm de longitud), por lo cual se espera que sean menos sensibles que los organismos más jóvenes utilizados en este estudio (aproximadamente 1-2 mm de longitud). Además, la duración de los ensayos anteriores fue de $48 \mathrm{~h}$ mientras que en estos se mantuvieron 96h, lo cual se presume que bioensayos con una duración más corta resulten en mayores valores de $\mathrm{LC}_{50}$. Para el agrotóxico endosulfán, los valores de $\mathrm{LC}_{50}$ de $H$. curvispina no fueron verdaderamente comparables debido a que se ensayaron diferentes isómeros; Mugni et al. (2012, 2015) utilizaron la mezcla de isómeros de endosulfán (I y II) mientras que en el presente trabajo se ensayó el isómero más tóxico, endosulfán I. No se encontraron otros estudios que determinen la $\mathrm{LC}_{50}$ de lambda-cialotrina en $H$. curvispina. Por otra parte, este anfípodo resultó ser el organismo más sensible a lambda-cialotrina con respecto a los invertebrados informados en la bibliografía.

Las curvas de sensibilidad calculada para los distintos agrotóxicos son consistentes con trabajos realizados a campo donde se analizó la composición del ensamble de invertebrados acuáticos relacionados con el efecto producido por los biocidas. Los grupos considerados más tolerantes fueron Hirudinea, Gastropoda y Oligochaeta; mientras que los más sensibles Amphipoda, Cladocera, Trichoptera y Ephemeroptera (Wogram \& Liess, 2001; Neumann \& Dudgeon, 2002; Liess \& Von der Ohe, 2005; Solis et al., 2016).

Existen algunos trabajos que informan concentraciones ambientales de agrotóxicos para nuestra región. Mugni et al. (2011a) registraron una alta concentración de endosulfán $(38 \mu \mathrm{g} / \mathrm{l})$ en coincidencia con la primera lluvia después de la aplicación en un arroyo de primer orden que atraviesa un campo cultivado en La Plata. Jergentz et al. (2005) detectaron concentraciones de $0,45 \mu \mathrm{g} / \mathrm{l}$ de clorpirifos y $0,71 \mu \mathrm{g} / \mathrm{l} \mathrm{de}$ cipermetrina en un arroyo que atraviesa parcelas cultivadas con soja en Arrecifes, 
Argentina. Asimismo, Marino \& Ronco (2005) reportaron concentraciones entre 0,4 $10,8 \mu \mathrm{g} / \mathrm{l}$ de clorpirifos y $0,2-3,6 \mu \mathrm{g} / \mathrm{l}$ de cipermetrina en arroyos pampeanos de zonas intensamente cultivadas de Pergamino. Comparando las concentraciones máximas reportada (endosulfán: $38 \mu \mathrm{g} / \mathrm{l}$; clorpirifos: $10,8 \mu \mathrm{g} / \mathrm{l}$ y cipermetrina: $0,71 \mu \mathrm{g} / \mathrm{l}$ ) con la $\mathrm{LC}_{50}$ estimada de $H$. curvispina en el presente trabajo (endosulfán: 3,26 $\mu \mathrm{g} / \mathrm{l}$; clorpirifos: $0,138 \mu \mathrm{g} / \mathrm{l}$ y cipermetrina: $0,034 \mu \mathrm{g} / \mathrm{l}$ ) se puede observar que los valores detectados en campo resultaron ser un orden de magnitud mayor, sugiriendo un importante riesgo para la biota.

En la bibliografía consultada sobre bioensayo en sedimento no se reportaron valores de $\mathrm{LC}_{50}$ de $H$. curvispina. No obstante, los valores de $\mathrm{LC}_{50}$ de $H$. azteca en sedimento han sido informados para los cuatro agrotóxicos y los resultados se corresponden bien con los determinados en $H$. curvispina en el presente estudio. Los valores de $\mathrm{LC}_{50}$ en sedimento a diez días en $H$. curvispina fueron 3101, 256 y 33342 ng/gOC de clorpirifos, lambda-cialotrina y endosulfán I respectivamente; mientras que los mismos en H. azteca fueron 4160, 450 y $51700 \mathrm{ng} / \mathrm{g}_{\mathrm{OC}}$ (You et al., 2004a; Weston et al., 2013). Sin embargo, el valor de $\mathrm{LC}_{50}$ de cipermetrina en $H$. curvispina determinada en la presenta tesis resultó un orden de magnitud mayor (2073 ng/goC) al reportado en $H$. azteca (380 ng/goC) por Weston et al. (2013).

La recomendación de la Agencia de Protección Ambiental de los Estados Unidos (USEPA, 2000) para los bioensayos de H. azteca es el uso de individuos recién nacidos, de 7 a 14 días de edad. Sin embargo, en el presente trabajo se observó que utilizar organismos tan jóvenes de $H$. curvispina no resultó práctico. Si bien el grupo de edad más pequeño de $H$. curvispina fue más sensible a los piretroides, la utilización de individuos de este tamaño resultó problemática en los ensayos de agua debido a la variabilidad en la supervivencia de los controles y en los bioensayos de sedimento, resultó sumamente difícil encontrar a los organismos al finalizar el experimento.

Este estudio añade información sobre la sensibilidad a los biocidas de una importante especie de anfípodos de América del Sur e indica que su sensibilidad es muy similar a una especie estrechamente relacionada de América del Norte. Una crítica repetida es evaluar el riesgo ecológico en los sistemas acuáticos utilizando los criterios de calidad de agua que se realizan sobre la base de especies de Europa, Estados Unidos y Canadá. Por este motivo, es importante realizar estudios sobre la fauna local para 
determinar si el uso de datos de sensibilidad de las especies del hemisferio norte es adecuadamente protector.

Hyalella curvispina es un organismo que alcanza altas densidades en aguas poco profundas y, como se observa en el presente estudio, se ubica entre las especies más sensibles a los agrotóxicos comúnmente utilizados. Por lo tanto, se propone como especie indicadora para la evaluación regional del riesgo ambiental. 


\section{Estudios de campo}




\section{MATERIALES Y MÉTODOS}

\section{Área de Estudio}

Los muestreos se realizaron durante el período de crecimiento de la soja, correspondiente a los meses de noviembre a abril en áreas agrícolas de Argentina, Paraguay y Brasil (Fig.2.1).

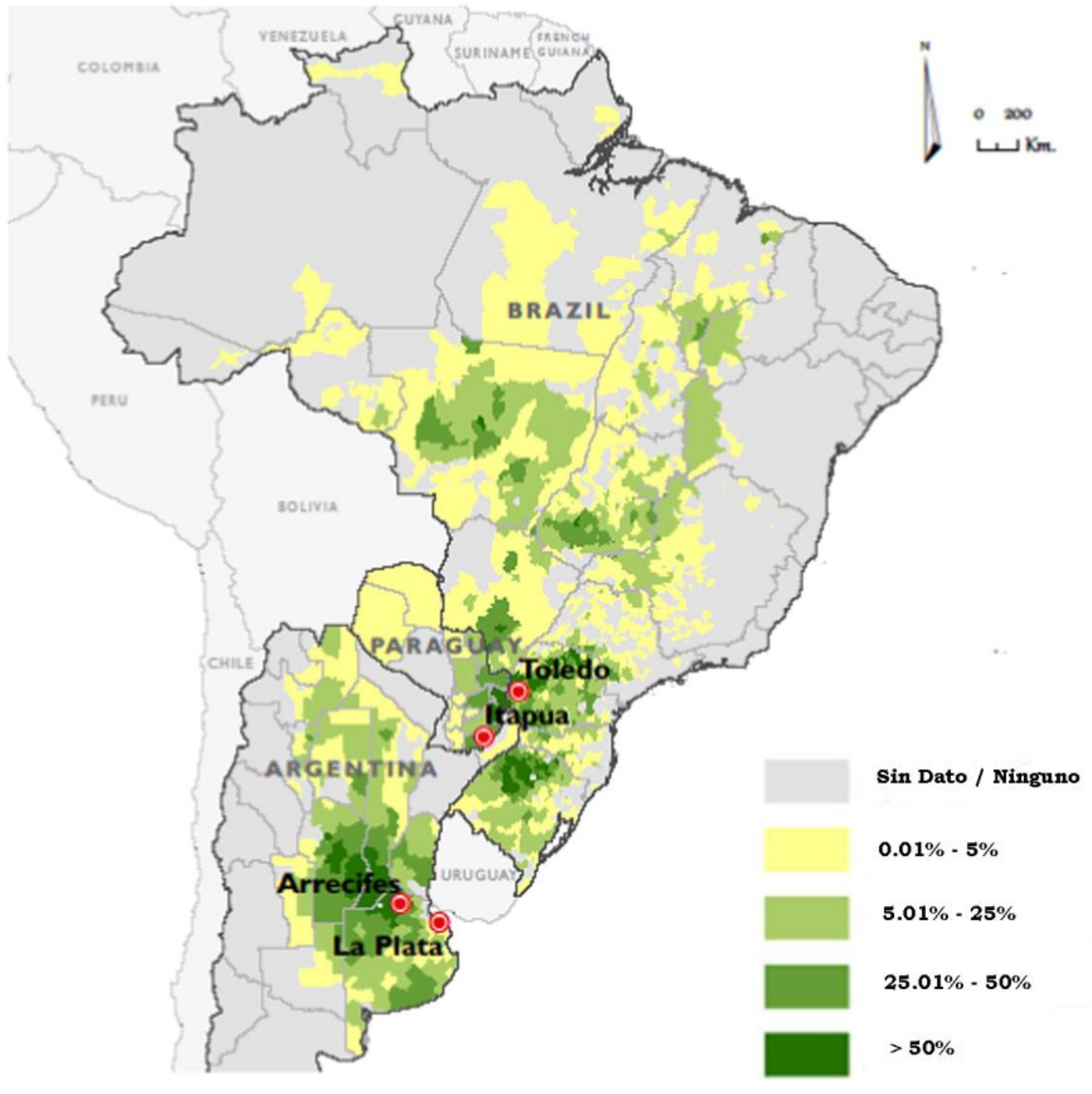

Figura 2.1. Área de estudio e intensidad de la producción de soja como porcentaje del uso del suelo por provincia/departamento en Argentina (La Plata y Arrecifes), Brasil (Toledo) y Paraguay (Itapúa).

En Argentina se llevó a cabo el estudio durante un período de tres años (noviembre 2011-febrero 2014), monitoreando 23 sitios en arroyos de primer y segundo orden, ubicados en dos regiones de la Pampa argentina, incluyendo una región de 
producción intensiva de soja, en Arrecifes, y una región mixta con agricultura y ganadería extensiva, en La Plata (Tabla 2.1).

Tabla 2.1. Ubicación y características de cada arroyo en Argentina (Arrecifes- La Plata).

\begin{tabular}{|c|c|c|c|c|c|}
\hline Argentina & Abreviatura & Coordenada (S) & Coordenada (W) & Uso del suelo & $\begin{array}{c}\text { Franja de } \\
\text { atenuación }(\mathbf{m})\end{array}$ \\
\hline \multicolumn{6}{|l|}{ Arrecifes } \\
\hline 3 Horqueta & $3 \mathrm{HQ}$ & $34^{\circ} 02^{\prime} 52.0^{\prime \prime} \mathrm{S}$ & $59^{\circ} 56^{\prime} 41.1^{\prime \prime} \mathrm{W}$ & Soja & 15 \\
\hline Cañete & $\mathrm{CA}$ & $34^{\circ} 01^{\prime} 52.6^{\prime \prime} \mathrm{S}$ & $60^{\circ} 08^{\prime} 04.9^{\prime \prime} \mathrm{W}$ & Soja + Maiz & 10 \\
\hline Contador 1 & $\mathrm{CO} 1$ & $34^{\circ} 07^{\prime} 27.6^{\prime \prime} \mathrm{S}$ & $60^{\circ} 03^{\prime} 32.0^{\prime \prime} \mathrm{W}$ & Soja & 2 \\
\hline Contador 2 & $\mathrm{CO} 2$ & $34^{\circ} 09^{\prime} 15.9^{\prime \prime} \mathrm{S}$ & $60^{\circ} 04^{\prime} 44.1^{\prime \prime} \mathrm{W}$ & Soja & 20 \\
\hline Gomez & GO & $34^{\circ} 07^{\prime} 39.3^{\prime \prime} \mathrm{S}$ & $59^{\circ} 54^{\prime} 01.5^{\prime \prime} \mathrm{W}$ & Soja & 5 \\
\hline Río Saladito Grande & $\mathrm{HB}$ & $34^{\circ} 18^{\prime} 15.9^{\prime \prime} \mathrm{S}$ & $60^{\circ} 19^{\prime} 58.5^{\prime \prime} \mathrm{W}$ & Soja & 15 \\
\hline Helves & HEL & $34^{\circ} 02^{\prime} 48.3^{\prime \prime} \mathrm{S}$ & $60^{\circ} 01^{\prime} 8.98^{\prime \prime} \mathrm{W}$ & Soja & 2 \\
\hline Horqueta 0 & HO & $34^{\circ} 08^{\prime} 31.0^{\prime \prime} \mathrm{S}$ & $59^{\circ} 50^{\prime} 31.4^{\prime \prime} \mathrm{W}$ & Soja & 8 \\
\hline Horqueta 2 & $\mathrm{H} 2$ & $34^{\circ} 10^{\prime} 19.6^{\prime \prime} \mathrm{S}$ & $59^{\circ} 50^{\prime} 42.6^{\prime \prime} \mathrm{W}$ & Soja & 10 \\
\hline Horqueta 5 & H5 & $34^{\circ} 07^{\prime} 33.8^{\prime \prime} \mathrm{S}$ & $59^{\circ} 50^{\prime} 14.2^{\prime \prime} \mathrm{W}$ & Soja + Maiz & 5 \\
\hline Las Animas & AN & $34^{\circ} 06^{\prime} 47.5^{\prime \prime} \mathrm{S}$ & $60^{\circ} 12^{\prime} 24.1^{\prime \prime} \mathrm{W}$ & Soja & 5 \\
\hline Los Ingleses & ING & $33^{\circ} 59^{\prime} 07.4^{\prime \prime} \mathrm{S}$ & $60^{\circ} 12^{\prime} 07.0^{\prime \prime} \mathrm{W}$ & Soja & $>100$ \\
\hline Luna 2 & $\mathrm{~A} 2$ & $34^{\circ} 10^{\prime} 43.2^{\prime \prime} \mathrm{S}$ & $59^{\circ} 59^{\prime} 22.9^{\prime \prime} \mathrm{W}$ & Soja & 10 \\
\hline Luna 3 & A3 & $34^{\circ} 10^{\prime} 57.6^{\prime \prime} \mathrm{S}$ & $59^{\circ} 58^{\prime} 54.4^{\prime \prime} \mathrm{W}$ & Soja & 30 \\
\hline Luna 4 & A4 & $34^{\circ} 11^{\prime} 52.5^{\prime \prime} \mathrm{S}$ & $60^{\circ} 01^{\prime} 32.0^{\prime \prime} \mathrm{W}$ & Soja + Maiz & 40 \\
\hline Maguire & MG & $33^{\circ} 58^{\prime} 00.7^{\prime \prime} \mathrm{S}$ & $60^{\circ} 16^{\prime} 25.1^{\prime \prime} \mathrm{W}$ & Soja + Maiz & 5 \\
\hline Salto2 & $\mathrm{S} 2$ & $34^{\circ} 11^{\prime} 08.5^{\prime \prime} \mathrm{S}$ & $60^{\circ} 14^{\prime} 03.5^{\prime \prime} \mathrm{W}$ & Soja + Maiz & 20 \\
\hline \multicolumn{6}{|l|}{ La Plata } \\
\hline Remes & $\mathrm{Re}$ & $35^{\circ} 01^{\prime} 31.8^{\prime \prime} \mathrm{S}$ & $57^{\circ} 59^{\prime} 38.5^{\prime \prime} \mathrm{W}$ & Soja & 1 \\
\hline Poblet & Po & $35^{\circ} 02^{\prime} 02.4^{\prime \prime} \mathrm{S}$ & $57^{\circ} 56^{\prime} 33.3^{\prime \prime} \mathrm{W}$ & Soja + Ganadería & 30 \\
\hline Arregui & $\mathrm{Ar}$ & $35^{\circ} 07^{\prime} 23.5^{\prime \prime} \mathrm{S}$ & $57^{\circ} 41^{\prime} 14.9^{\prime \prime} \mathrm{W}$ & Ganadería & 50 \\
\hline Ignacio Correa & IC & $35^{\circ} 01^{\prime} 24.9^{\prime \prime} \mathrm{S}$ & $57^{\circ} 51^{\prime} 26.4^{\prime \prime} \mathrm{W}$ & Ganadería & $>100$ \\
\hline Cajaravilla & Caj & $35^{\circ} 02^{\prime} 26.4^{\prime \prime} \mathrm{S}$ & $57^{\circ} 48^{\prime} 54.7^{\prime \prime} \mathrm{W}$ & Ganadería & $>100$ \\
\hline Juan Blanco & $\mathrm{JB}$ & $35^{\circ} 08^{\prime} 29.9^{\prime \prime} \mathrm{S}$ & $57^{\circ} 26^{\prime} 23.0^{\prime \prime} \mathrm{W}$ & Reserva & $>100$ \\
\hline
\end{tabular}

En la región de Arrecifes se muestrearon 17 sitios todos afluentes del río Arrecife, ubicados en el noroeste de la Provincia de Buenos Aires, zona comprendida entre Pergamino, Capitán Sarmiento y Salto (Figura 2.2). Esta zona es considerada núcleo de la producción agrícola de la región pampeana, donde el suelo se destina principalmente a los cultivos de soja, maíz y trigo. 


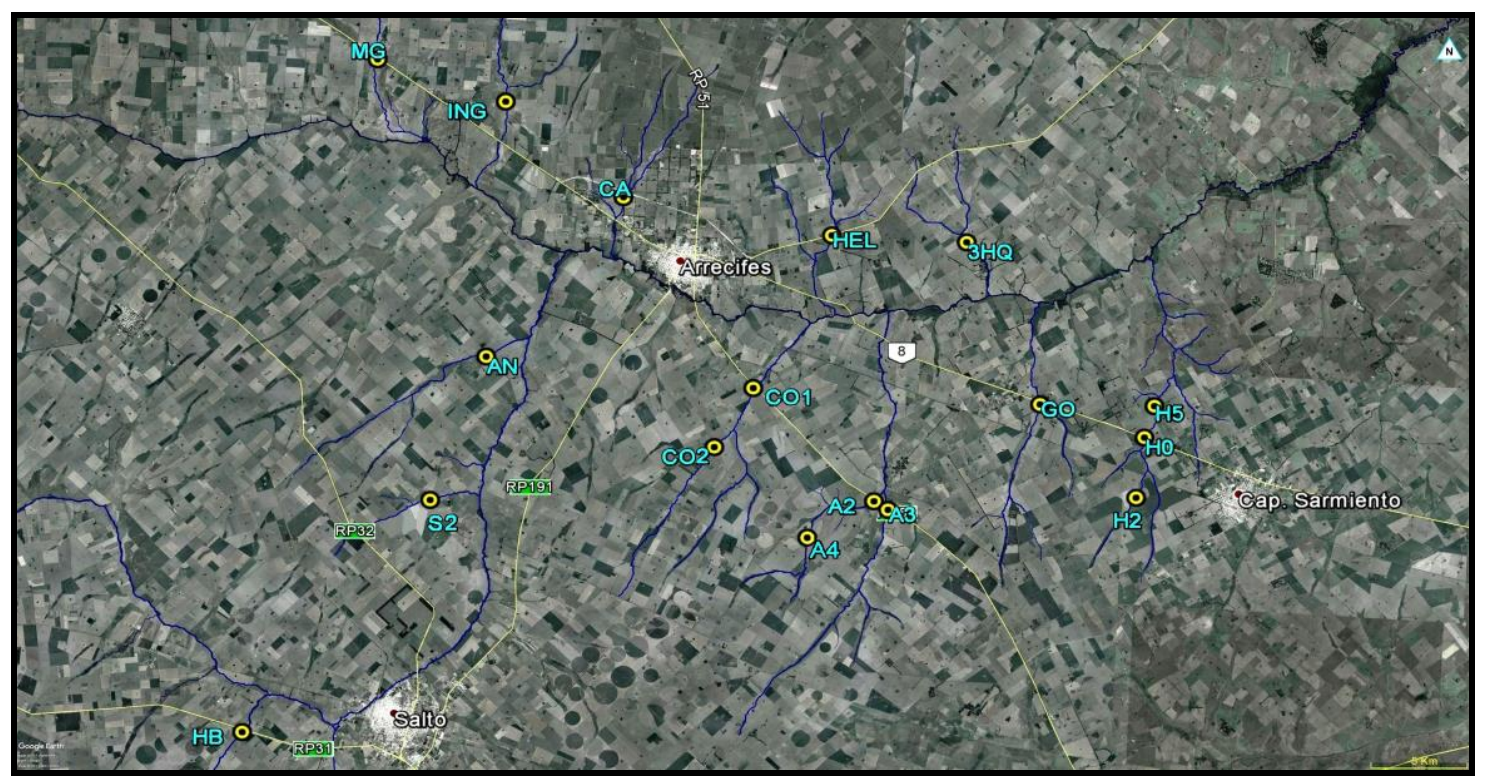

Figura 2.2. Localización de los sitios de muestreo de Arrecifes en Argentina, en una imagen satelital. (MG: Maguire, ING: Los Ingleses, CA: Cañete, HEL: Helves, 3HQ: 3Horqueta, AN: Las Animas, S2: Salto 2, HB: Río Saladito Grande, CO1: Contador 1, CO2: Contador 2, A2: Luna 2, A3: Luna 3, A4: Luna 4, GO: Gomez, H0: Horqueta 0, H2: Horqueta 2, H5: Horqueta 5).

En la región de La Plata se muestrearon seis sitios (Figura 2.3), cuatro sobre la cuenca del arroyo El Pescado (Remes (Re), Poblet (Po), Ignacio Correa (IC), Cajaravilla (Caj) y dos sobre cuencas separadas (Arregui (Ar) y Juan Blanco (JB)). El principal uso del suelo fue la ganadería extensiva sobre pasturas naturales, con parcelas dispersas de producción de soja y otros cultivos; excepto para el sitio Remes, donde el uso del suelo es exclusivamente agrícola y Poblet con ganadería y agricultura en la cuenca superior.

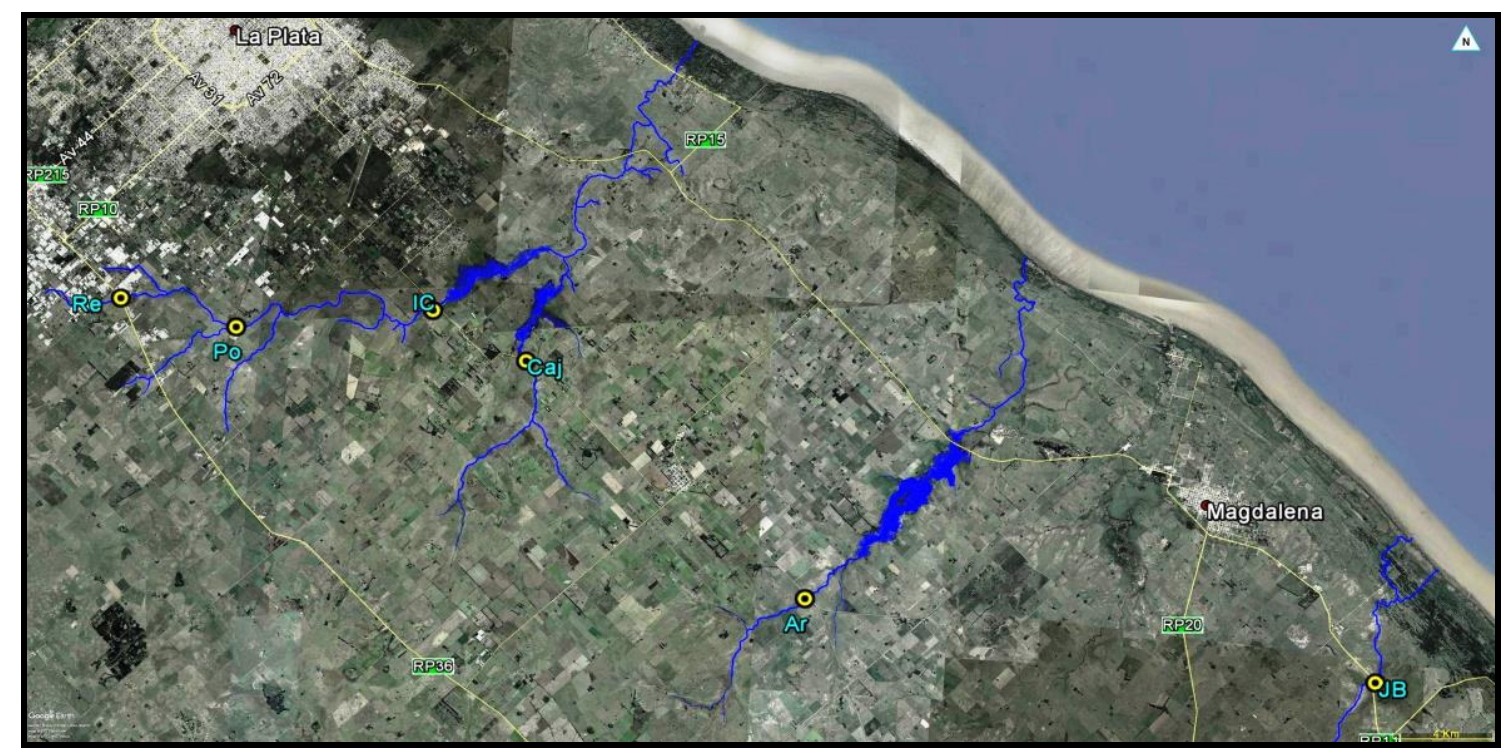

Figura 2.3. Localización de los sitios de muestreo de La Plata en Argentina, en una imagen satelital. (Re: Remes, Po: Poblet, IC: Ignacio Correa, Caj: Cajaravilla, Ar: Arregui, JB: Juan Blanco). 
En Paraguay, los 17 sitios de muestreo se ubicaron sobre la cuenca del río Pirapó, departamento de Itapúa, $440 \mathrm{~km}$ al sureste de Asunción y a $80 \mathrm{~km}$ de Posadas, Argentina (Figura 2.4, Tabla 2.2). El departamento de Itapúa es el segundo productor nacional de soja, como así también de girasol, trigo, maíz y algodón. El ganado vacuno es el de mayor importancia dentro del departamento, seguido del porcino (DGEEC, 2015).

El Ministerio de Agricultura y Ganadería de Paraguay reglamentó la aplicación de productos fitosanitarios mediante la Ley $N^{\circ} 3742 / 09$; y establece, a fin de evitar la contaminación de los cursos de agua, la obligatoriedad de utilizar franjas de atenuación. En los casos de pulverización aérea de los biocidas de uso agrícola, se establece una franja de protección de $200 \mathrm{~m}$ entre la zona de aplicación y todo asentamiento humano y cursos de agua en general. En caso de aplicación terrestre se requiere una franja de 100 $\mathrm{m}$ entre el área de tratamiento con productos fitosanitarios y todo asentamiento humano y curso de agua natural.

Los muestreos se desarrollaron en enero y diciembre de 2013. La posibilidad de realizar dicho muestreo surgió gracias a una gestión realizada ante el Dr. John Kochalka, jefe de la División de Invertebrados del Museo Nacional de Historia Natural del Paraguay. Paralelamente se logró la colaboración de la Asociación Pro Cordillera San Rafael (Pro-Cosara), una organización dedicada a la conservación de uno de los últimos restos del Bosque Atlántico en el sureste del Paraguay, que brindó alojamiento en la sede de la asociación, en la Reserva San Rafael, departamento de Itapúa. Las muestras de macroinvertebrados recolectadas fueron separadas y clasificadas in-situ hasta el nivel taxonómico de familia. Una parte de las muestras fue donada al Museo Nacional de Historia Natural del Paraguay y otra traída a la Argentina para posterior confirmación con especialistas. 
Tabla 2.2. Ubicación y características de cada sitio de muestreo en Paraguay.

\begin{tabular}{|c|c|c|c|c|}
\hline Paraguay & Coordenada $(S)$ & Coordenada $(\mathbf{W})$ & Uso del suelo & $\begin{array}{c}\text { Franja de } \\
\text { atenuación }(\mathbf{m})\end{array}$ \\
\hline P1 & $26^{\circ} 42^{\prime} 21.2^{\prime \prime} \mathrm{S}$ & $55^{\circ} 31^{\prime} 49.1^{\prime \prime} \mathrm{W}$ & Soja + Eucaliptus & $>100$ \\
\hline P2 & $26^{\circ} 45^{\prime} 48.7^{\prime \prime} \mathrm{S}$ & $55^{\circ} 33^{\prime} 34.7^{\prime \prime} \mathrm{W}$ & Soja & $>100$ \\
\hline P3 & $26^{\circ} 49^{\prime} 34.5^{\prime \prime} \mathrm{S}$ & $55^{\circ} 31^{\prime} 36.8^{\prime \prime} \mathrm{W}$ & Soja + Eucaliptus & $>100$ \\
\hline P4 & $26^{\circ} 53^{\prime} 29.8^{\prime \prime} \mathrm{S}$ & $55^{\circ} 34^{\prime} 19.1^{\prime \prime} \mathrm{W}$ & Soja & 53 \\
\hline P5 & $26^{\circ} 55^{\prime} 54.1^{\prime \prime} \mathrm{S}$ & $55^{\circ} 31^{\prime} 00.8^{\prime \prime} \mathrm{W}$ & Soja + yerba mate & 10 \\
\hline P6 & $26^{\circ} 52^{\prime} 12.5^{\prime \prime} \mathrm{S}$ & $55^{\circ} 29^{\prime} 49.7^{\prime \prime} \mathrm{W}$ & Soja & $>100$ \\
\hline P7 & $26^{\circ} 37^{\prime} 45.8^{\prime \prime} \mathrm{S}$ & $55^{\circ} 39^{\prime} 55.1^{\prime \prime} \mathrm{W}$ & Soja + Bosque & $>100$ \\
\hline P8 & $26^{\circ} 47^{\prime} 37.0^{\prime \prime} \mathrm{S}$ & $55^{\circ} 37^{\prime} 33.4^{\prime \prime} \mathrm{W}$ & Soja & 40 \\
\hline P9 & $26^{\circ} 47^{\prime} 59.4^{\prime \prime} \mathrm{S}$ & $55^{\circ} 35^{\prime} 38.0^{\prime \prime} \mathrm{W}$ & Soja & $>100$ \\
\hline P10 & $26^{\circ} 50^{\prime} 09.1^{\prime \prime} \mathrm{S}$ & $55^{\circ} 36^{\prime} 33.4^{\prime \prime} \mathrm{W}$ & Soja + Maiz & 30 \\
\hline P11 & $26^{\circ} 50^{\prime} 35.0^{\prime \prime} \mathrm{S}$ & $55^{\circ} 36^{\prime} 43.7^{\prime \prime} \mathrm{W}$ & Soja & 40 \\
\hline $\mathrm{P} 12$ & $26^{\circ} 31^{\prime} 16.6^{\prime \prime} \mathrm{S}$ & $55^{\circ} 37^{\prime} 04.3^{\prime \prime} \mathrm{W}$ & Maiz + Soja & 30 \\
\hline $\mathrm{P} 13$ & $26^{\circ} 32^{\prime} 18.1^{\prime \prime} \mathrm{S}$ & $55^{\circ} 37^{\prime} 01.7^{\prime \prime} \mathrm{W}$ & Soja & 35 \\
\hline P14 & $26^{\circ} 26^{\prime} 19.0^{\prime \prime} \mathrm{S}$ & $55^{\circ} 34^{\prime} 32.4^{\prime \prime} \mathrm{W}$ & Soja & $>100$ \\
\hline P15 & $26^{\circ} 30^{\prime} 56.5^{\prime \prime} \mathrm{S}$ & $55^{\circ} 36^{\prime} 43.3^{\prime \prime} \mathrm{W}$ & Soja & $>100$ \\
\hline P16 & $26^{\circ} 28^{\prime} 21.9^{\prime \prime} \mathrm{S}$ & $55^{\circ} 34^{\prime} 07.9^{\prime \prime} \mathrm{W}$ & Soja + Mandioca + Eucaliptus & 3 \\
\hline P17 & $26^{\circ} 28^{\prime} 27.4^{\prime \prime} \mathrm{S}$ & $55^{\circ} 33^{\prime} 57.3^{\prime \prime} \mathrm{W}$ & Soja + maiz & 5 \\
\hline
\end{tabular}

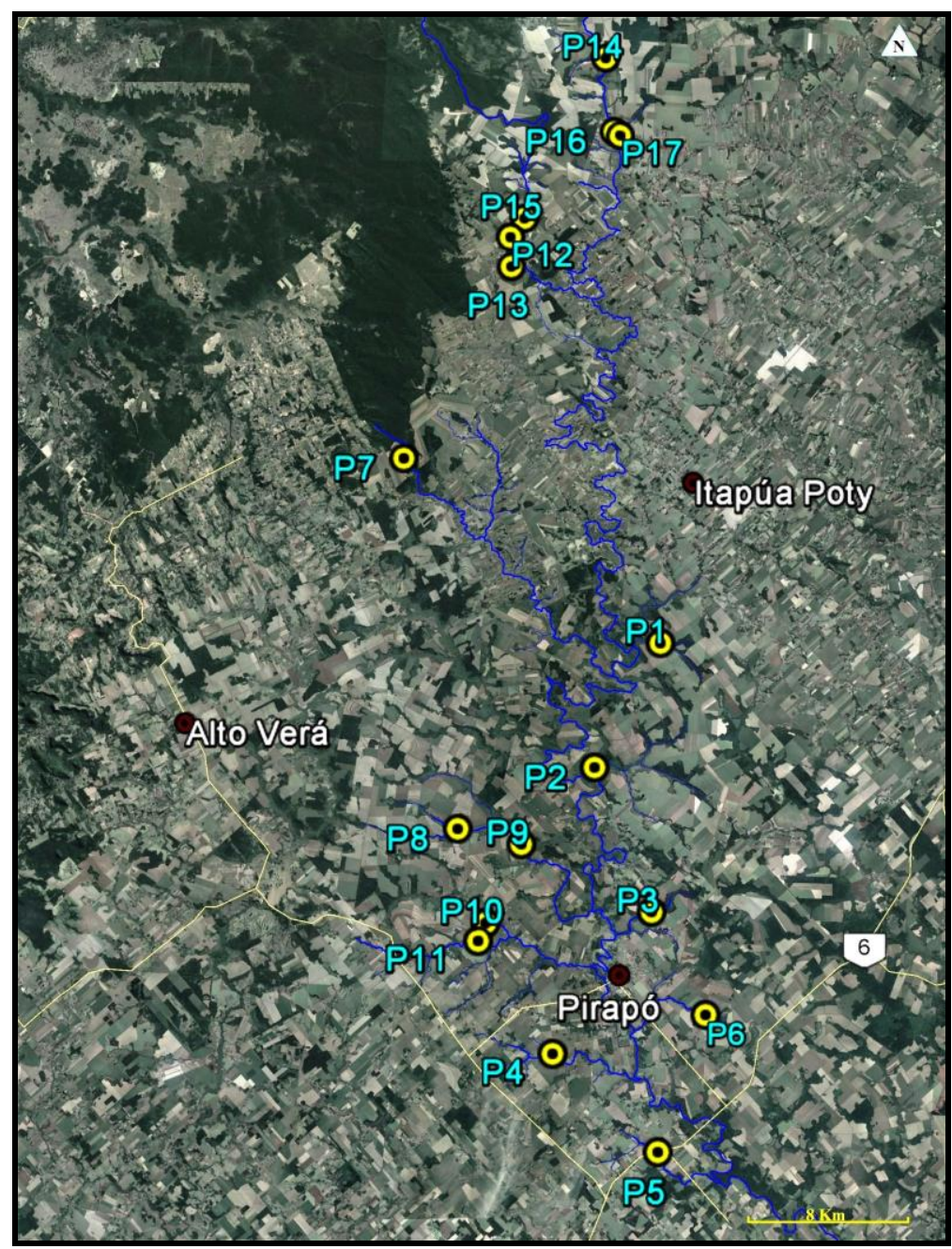

Figura 2.4. Localización de los sitios de muestreo de Itapúa, Paraguay, en una imagen satelital. 
En Brasil se tomaron muestras en 18 sitios de la localidad de Toledo, estado de Paraná, a unos $170 \mathrm{Km}$ al noroeste de Puerto Iguazú, Argentina (Figura 2.5, Tabla 2.3). El muestreo en Brasil fue posible gracias al apoyo del Dr. Daniel Buss, especialista en biodiversidad del Instituto Oswaldo Cruz, Río de Janeiro, quien mantiene un programa de monitoreo en varios estados de Brasil, que incluye el estado de Paraná. El Dr. Buss gestionó el acceso a los sitios de muestreo que él visita como parte de su programa y a las instalaciones de la universidad de Toledo. Para la clasificación taxonómica se utilizaron claves y material bibliográfico referido a la fauna regional y fue supervisada por Michelli Ferronato, docente e investigadora de la Universidad Católica de Paraná, que participa del proyecto dirigido por el Dr. Buss.

La ciudad de Toledo posee una economía agroindustrial; ocupa el primer lugar en el PIB agropecuario de la región sur de Brasil y el $11^{\circ}$ lugar en el país. El ganado porcino y los criaderos de pollo son los de mayor importancia dentro del departamento. Al igual que Paraguay, Brasil posee la obligatoriedad de mantener franjas de atenuación. En 2012 se aprobó un nuevo código forestal (Ley No 12.651 / 12) en el que se establece que los requisitos de la zona de amortiguación de ribera varían con el ancho del cuerpo de agua, la topografía del ambiente, la actividad de la cuenca, entre otras características. La legislación determina una franja de $30 \mathrm{~m}$ en arroyos con un ancho de $10 \mathrm{~m}$ o menos y una zona marginal de $50 \mathrm{~m}$ en arroyos con un ancho de 10 a $50 \mathrm{~m}$

Tabla 2.3. Ubicación y características de cada sitio en Brasil.

\begin{tabular}{|c|c|c|c|c|}
\hline Brasil & Coordenada (S) & Coordenada $(W)$ & Uso del suelo & $\begin{array}{c}\text { Franja de } \\
\text { atenuación }(\mathrm{m})\end{array}$ \\
\hline $\mathrm{B} 2$ & $24^{\circ} 48^{\prime} 44.4^{\prime \prime} \mathrm{S}$ & $53^{\circ} 42^{\prime} 31.6^{\prime \prime} \mathrm{W}$ & Soja & 10 \\
\hline B3 & $24^{\circ} 48^{\prime} 51.4^{\prime \prime} \mathrm{S}$ & $53^{\circ} 38^{\prime} 22.2^{\prime \prime} \mathrm{W}$ & Soja & $>100$ \\
\hline B7 & $24^{\circ} 57^{\prime} 31.2^{\prime \prime} \mathrm{S}$ & $53^{\circ} 40^{\prime} 53.5^{\prime \prime} \mathrm{W}$ & Soja + Maíz + Pastura & 18 \\
\hline B10 & $24^{\circ} 56^{\prime} 54.4^{\prime \prime} \mathrm{S}$ & $53^{\circ} 41^{\prime} 52.5^{\prime \prime} \mathrm{W}$ & Soja + Pastura & 15 \\
\hline B11 & $24^{\circ} 56^{\prime} 31.8^{\prime \prime} \mathrm{S}$ & $53^{\circ} 42^{\prime} 49.1^{\prime \prime} \mathrm{W}$ & Soja & 9 \\
\hline B12 & $24^{\circ} 45^{\prime} 49.1^{\prime \prime} \mathrm{S}$ & $53^{\circ} 48^{\prime} 55.7^{\prime \prime} \mathrm{W}$ & Soja & 40 \\
\hline B13 & $24^{\circ} 44^{\prime} 41.6^{\prime \prime} \mathrm{S}$ & $53^{\circ} 51^{\prime} 40.3^{\prime \prime} \mathrm{W}$ & Soja + Maíz & $>100$ \\
\hline B14 & $24^{\circ} 44^{\prime} 40.8^{\prime \prime} \mathrm{S}$ & $53^{\circ} 51^{\prime} 59.3^{\prime \prime} \mathrm{W}$ & Soja & 30 \\
\hline B15 & $24^{\circ} 45^{\prime} 28.2^{\prime \prime} \mathrm{S}$ & $53^{\circ} 52^{\prime} 55.8^{\prime \prime} \mathrm{W}$ & Soja + Pastura & 49 \\
\hline B16 & $24^{\circ} 45^{\prime} 05.2^{\prime \prime} \mathrm{S}$ & $53^{\circ} 53^{\prime} 03.6^{\prime \prime} \mathrm{W}$ & Soja & 35 \\
\hline B17 & $24^{\circ} 44^{\prime} 57.4^{\prime \prime} \mathrm{S}$ & $53^{\circ} 54^{\prime} 18.2^{\prime \prime} \mathrm{W}$ & Soja & 58 \\
\hline B18 & $24^{\circ} 47^{\prime} 43.0^{\prime \prime} \mathrm{S}$ & $53^{\circ} 54^{\prime} 11.0^{\prime \prime} \mathrm{W}$ & Soja & $>100$ \\
\hline B19 & $24^{\circ} 49^{\prime} 19.8^{\prime \prime} \mathrm{S}$ & $53^{\circ} 54^{\prime} 12.2^{\prime \prime} \mathrm{W}$ & Soja + Pastura & 90 \\
\hline B20 & $24^{\circ} 49^{\prime} 07.5^{\prime \prime} \mathrm{S}$ & $53^{\circ} 50^{\prime} 29.2^{\prime \prime} \mathrm{W}$ & Soja + Pastura & $>100$ \\
\hline B21 & $24^{\circ} 48^{\prime} 29.6^{\prime \prime} \mathrm{S}$ & $53^{\circ} 45^{\prime} 44.8^{\prime \prime} \mathrm{W}$ & Soja + Pastura & 43 \\
\hline B22 & $24^{\circ} 45^{\prime} 48.2^{\prime \prime} \mathrm{S}$ & $53^{\circ} 37^{\prime} 54.1^{\prime \prime} \mathrm{W}$ & Soja + Maíz & 30 \\
\hline B23 & $24^{\circ} 47^{\prime} 48.0^{\prime \prime} \mathrm{S}$ & $53^{\circ} 36^{\prime} 16.8^{\prime \prime} \mathrm{W}$ & Soja + Maíz & 15 \\
\hline B24 & $24^{\circ} 47^{\prime} 57.2^{\prime \prime} \mathrm{S}$ & $53^{\circ} 36^{\prime} 01.7^{\prime \prime} \mathrm{W}$ & Soja & $>100$ \\
\hline
\end{tabular}




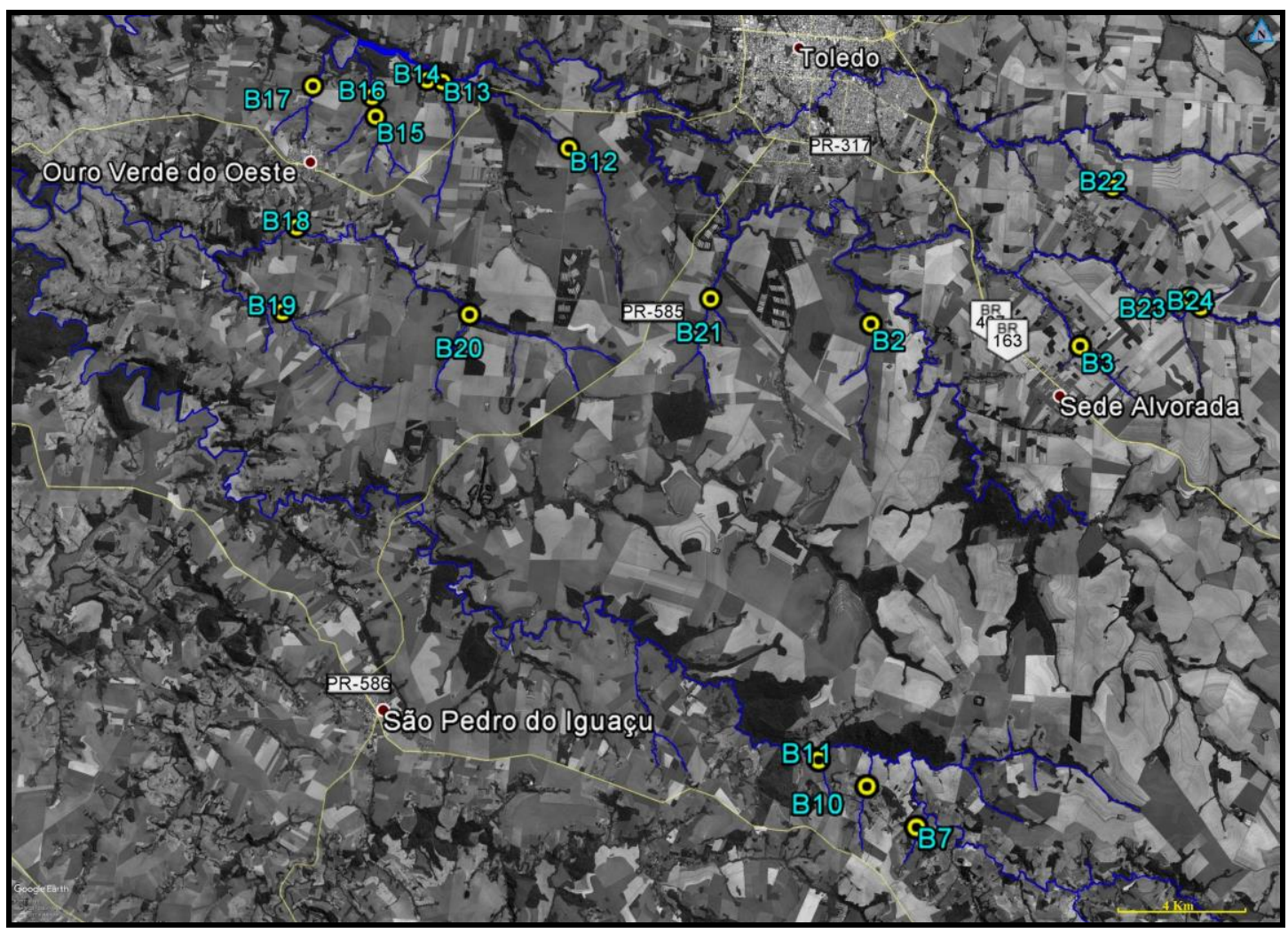

Figura 2.5 Localización de los sitios de muestreo de Toledo, Brasil, en una imagen satelital.

\section{Datos ambientales}

En cada muestreo se realizaron determinaciones in situ. El ancho y profundidad de los cauces se midieron por medio de una cinta métrica graduada. La temperatura del agua $\left(\mathrm{T}^{\circ} \mathrm{C}\right)$, conductividad, $\mathrm{pH}$, turbidez y oxígeno disuelto (OD) se midieron con un equipo multiparámetro (modelo Yellow Springs instruments si 556). En todos los sitios se tomaron muestras de agua para determinar los sólidos suspendidos (SS) en el laboratorio, por diferencia de peso después de filtrar un volumen de agua conocido a través de filtros Whatman GF/C. Los filtros fueron muflados a $550{ }^{\circ} \mathrm{C}$ por dos horas con anterioridad a su utilización (APHA 2005).

En cada uno de los sitios se midió el ancho y la profundidad máxima del arroyo. En Arrecifes (Arg.), Brasil y Paraguay se calcularon las velocidades máximas y promedio del agua con un medidor de caudal (Global Water FP311, College Station, TX, EE. UU.); en La Plata (Arg.) no fue posible la utilización del equipo por las características propias de los arroyos. En cada sitio de muestreo se midió el ancho mínimo de la franja de atenuación y se confirmó con imágenes satelitales LANDSAT. En los sitios de Argentina, la vegetación acuática se cuantificó según la riqueza de 
familias encontradas en el sitio de muestreo. Los arroyos de Brasil y Paraguay no contaban con vegetación acuática.

En la Selva Paranaense se evaluaron los componentes del sustrato, morfología del arroyo y la calidad del hábitat siguiendo el Protocolo Rápido de Bioevaluación (RBP) de la USEPA (Barbour et al., 1999). Los componentes inorgánicos del sustrato se estimaron calculando la proporción relativa de los distintos tipos presentes en la sección muestreada. El esfuerzo de muestreo correspondió a la colecta manual de una muestra por metro hasta completar un trayecto de $100 \mathrm{~m}$ en zigzag aguas arriba para cada uno de los sitios. Utilizando un marco calibrado o cinta métrica se clasificaron las 100 muestras según su diámetro en: Lecho rocoso, Bloque (> 256 mm), Adoquín (64-256 mm), Grava (4-64 mm) y Sedimento fino (<4) (Figura 2.6; ver Anexo Tabla B1).

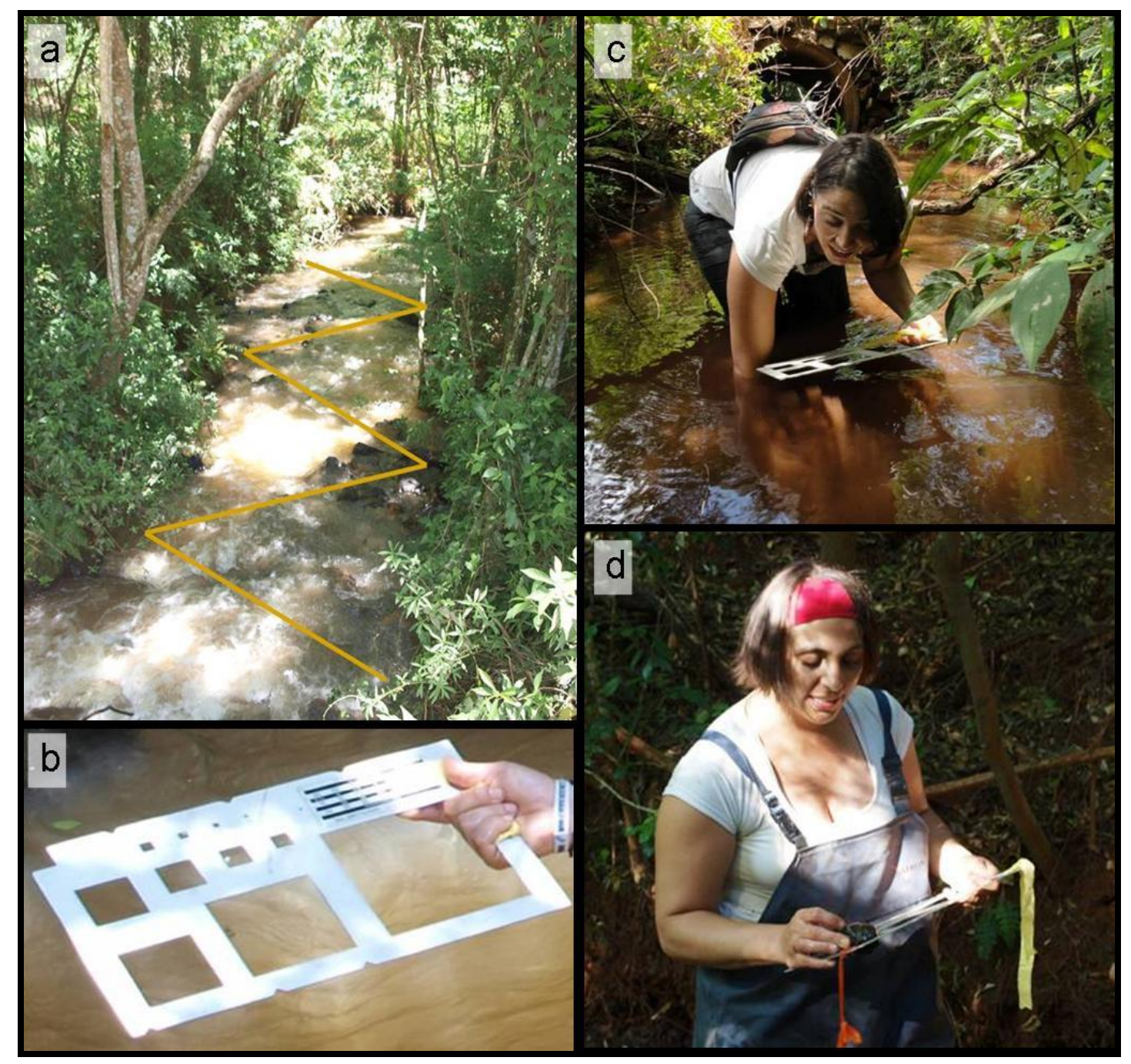

Figura 2.6. Estimación de los componentes inorgánicos del sustrato según su diámetro: a) trayecto en zigzag a lo largo de la sección del arroyo, b) marco calibrado, c) colecta de la muestra y d) medición de la muestra colectada. 
Los componentes orgánicos del sustrato se diferenciaron visualmente en dos grupos: Materia Orgánica Particulada Gruesa (MOPG: palos, maderas, fragmentos vegetales) y Materia Orgánica Particulada Fina (MOPF) y se cuantificaron según su abundancia relativa en el area muestreada. La heterogeneidad morfológica de cada arroyo (figura 2.7) se evaluó calculando la proporción representada por zonas de erosión, con flujo rápido y poco profundas (rápidos); áreas de transición, de flujo suave e ininterrumpido que conecta los rápidos con los pozones (correderas) y; zonas de deposición, donde el agua fluye lentamente y se encuentran a menudo en el exterior de las curvas (pozones).
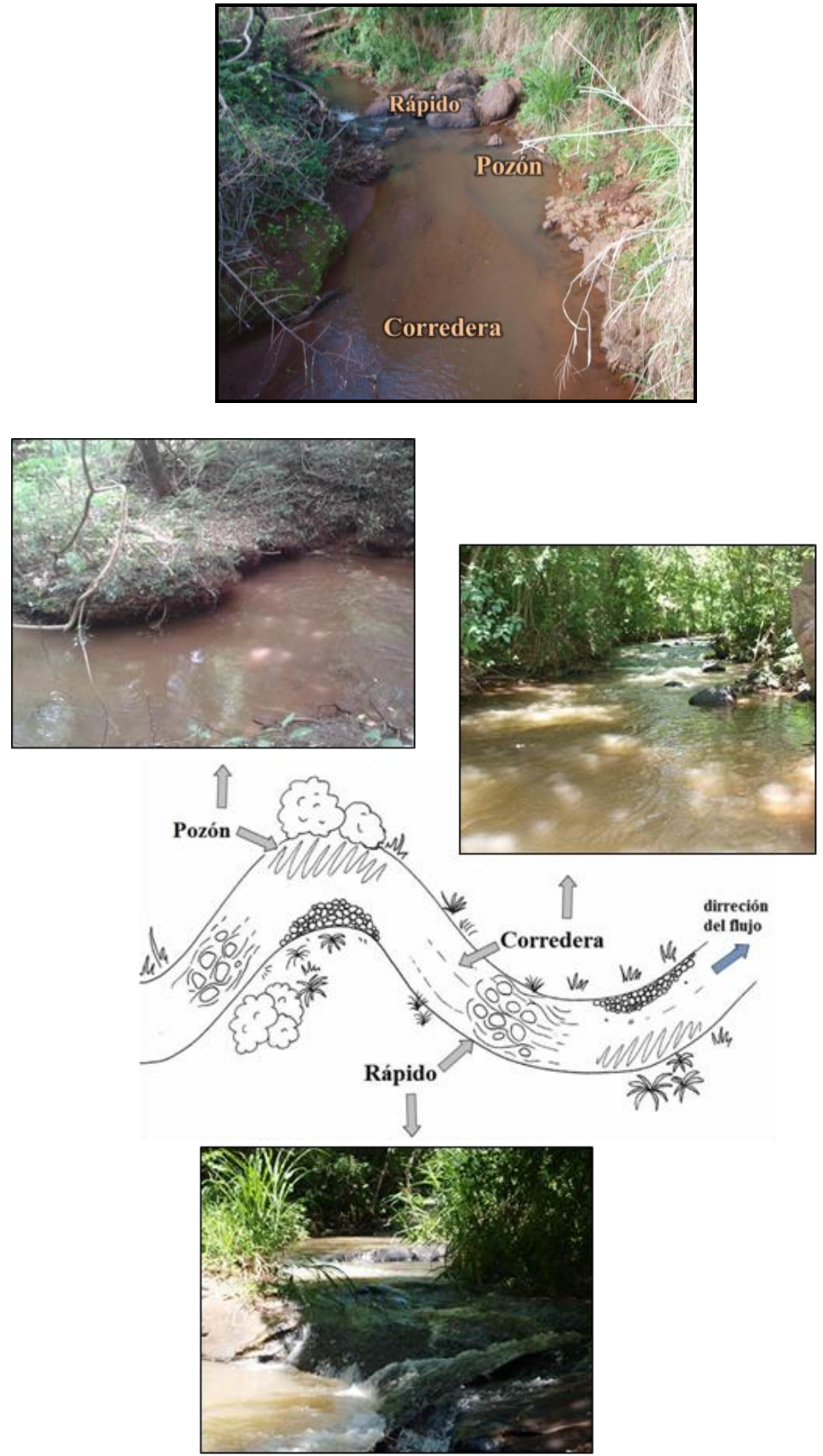

Figura 2.7. Heterogeneidad morfológica de los arroyos en pozón, corredera y rápido. 
Según Barbour et al. (1996), la calidad del hábitat se define como la evaluación de la estructura del hábitat físico circundante que influye en la calidad del recurso hídrico y la condición de la comunidad acuática residente. Un enfoque global para determinar la estructura del hábitat en los arroyos incluye: estimación de la variedad y calidad del sustrato, morfología del canal, estructura de la orilla y vegetación ribereña. Los principales parámetros para la evaluación comprenden aquellos que caracterizan el hábitat de "microescala" (estimación de nichos), las características de "macroescala" (morfología del canal) y las características estructurales de la ribera y la orilla. El proceso de evaluación implica calificar 10 parámetros: sustrato epifaunal, variabilidad del lecho, régimen de velocidad y profundidad, depositación de sedimentos, estado del flujo del canal, alteraciones del canal, frecuencia de rápidos, estabilidad de las orillas, protección vegetal y ancho de la zona ribereña vegetada. Todos los parámetros se evalúan en una escala numérica de 0 a 20 (deficiente, marginal, subóptimo u óptimo). Las calificaciones se suman y se comparan con una condición de referencia para proporcionar una clasificación final. Las puntuaciones aumentan a medida que aumenta la calidad del hábitat. La coherencia en las descripciones de los parámetros físicos y los criterios de evaluación del hábitat fueron estandarizados acorde al formulario de calificación de hábitat de Barbour et al. (1999).

\section{Análisis de Nutrientes}

En cada relevamiento se tomaron muestras de agua de los arroyos, las cuales fueron llevadas en frío al laboratorio para su análisis. Las muestras se filtraron a través de filtros de fibra de vidrio Whatman GF/C. La concentración de nutrientes disueltos en Argentina se midió siguiendo la metodología propuesta por APHA (1995). La concentración de fósforo reactivo soluble (PRS) se determinó mediante la reacción con molibdato-ascórbico, la de nitrito $\left(\mathrm{N}^{-\mathrm{NO}_{2}^{-}}\right)$por diazotización, nitrato $\left(\mathrm{N}^{-} \mathrm{NO}_{3}^{-}\right)$por reducción con hidracina seguida de diazotización y la de amonio $\left(\mathrm{N}_{-} \mathrm{NH}^{+}{ }_{4}\right)$ por la reacción del indofenol azul (límite de detección 0,005 ppm para todos los nutrientes). En Paraguay y Brasil se determinaron los nutrientes en campo utilizando Kits: PRS (CHEMetrics C-8501, Midland, VA, USA), N-NO- ${ }_{3}$ (LaMotte 3354-01, Chestertown, MD, USA) y N-NH ${ }_{4}^{+}$(Sera, Alemania), con un límite de detección 0,1 ppm, 1 ppm y 0,5 ppm respectivamente. 


\section{Análisis de Agrotóxicos}

Los sedimentos para determinar la concentración de agrotóxicos fueron colectados de las áreas de deposición dependiendo de la profundidad, el acceso y la disponibilidad. En cada sitio se tomó una muestra compuesta de sedimento utilizando una cuchara de acero inoxidable (3-5 cucharas por muestra) y se guardó en frasco de vidrio color ámbar con tapas de Teflón. Las muestras fueron transportadas en frío al laboratorio y se mantuvieron refrigeradas hasta su extracción. Después de homogeneizar completamente cada muestra en el laboratorio, se tomó una alícuota de cada una para el análisis de carbono orgánico total (COT) mediante titulación con sulfato ferroso (USDA, 1996) y se recogió una muestra separada de cada localidad para el análisis de textura.

La extracción de los biocidas se realizó siguiendo la metodología de You et al. (2004b). Después de homogeneizar manualmente cada muestra se separaron aproximadamente $20 \mathrm{~g}$ de sedimento (peso húmedo), se añadieron $100 \mathrm{ng}$ del subrogante decaclorobifenilo (DCBP), un compuesto orgánico que se utiliza para determinar el porcentaje de recuperación, y se mezclaron con $4 \mathrm{~g}$ de cobre y $\mathrm{Na}_{2} \mathrm{SO}_{4}$ anhidro en un vaso de precipitado enfriado con hielo. La extracción se realizó agregando $50 \mathrm{ml}$ de una mezcla 50:50 de acetona y cloruro de metileno y se sonicó usando un procesador ultrasónico de alta intensidad a una amplitud de 60 (modelo VCX 500; Sonics and Materials, Newtown, CT, EE. UU.). El extracto se dejó decantar y se filtró a través de un papel de filtro Whatman $n^{\circ} 41$ (Whatman, Maidstone, UK) que contenía aproximadamente $2 \mathrm{~g}$ de $\mathrm{Na}_{2} \mathrm{SO}_{4}$ anhidro. Este procedimiento se repitió dos veces. Los extractos se combinaron y concentraron a 1-2 ml aproximadamente por evaporación. A continuación se realizó un clean up mediante la extracción en fase sólida (SPE) (USEPA 2007). Todos los patrones de plaguicidas y el estándar del subrogante decachlorobifenil (DCBP) se adquirieron de Accustandard y presentaron una pureza $>93 \%$ (New Haven, CT, USA). Los solventes utilizados en las extracciones y análisis fueron grado plaguicida. El cobre granular utilizado en las extracciones de muestras se purificó cubriendo con cloruro de metileno, se agitó vigorosamente y se dejó secar en la campana durante $24 \mathrm{~h}$.

Durante el primer período 2011-2012 se utilizó cromatografía de gases acoplada a detección de captura de electrones (GC-ECD) para analizar los insecticidas más frecuentemente usados en Argentina en los cultivos de soja incluyendo cipermetrina, clorpirifos, lambda-cialotrina y endosulfán. A partir de 2013, se tuvo acceso a un método más avanzado para la cuantificación de los compuestos, un cromatógrafo de 
gases acoplado con un espectrómetro de masas (GC-MS). Este equipo permitió detectar mayor número de organoclorados, como DDT y sus derivados, piretroides adicionales y el sinérgico piperonil butóxido (PBO). Aunque el sinérgico PBO no está presente en las formulaciones de insecticidas que se venden para su uso en la producción de soja, es posible que los productores lo mezclen con plaguicidas piretroides para aumentar su eficacia o puede provenir de otras fuentes, como el control de garrapatas en la producción de animales de granja.

Todas las determinaciones de los biocidas se llevaron a cabo en la Universidad del Sur de Illinois, USA.

\section{Cálculo de Unidades Tóxicas}

Las Unidades Tóxicas (UT) de los biocidas más utilizados en el área de estudio fueron calculadas para todas las muestras de sedimentos:

$$
\mathrm{UT}=\mathrm{C}_{i} / \mathrm{LC}_{50 i}
$$

Donde $\mathrm{C}_{i}$ es la concentración del biocida $i$ en el sedimento, normalizado por la concentración de carbono orgánico total (COT), y $\mathrm{LC}_{50 i}$ es la concentración letal 50 determinada en ensayos de toxicidad en sedimento del biocida $i$.

Los valores de $\mathrm{LC}_{50}$ en sedimento utilizados para el cálculo de las UT fueron las determinadas en el presente estudio para H. curvispina (ver Cap. 1 "ensayos de toxicidad"), excepto para el endosulfán sulfato, que no fue ensayada. Para calcular la UT del endosulfán sulfato, se utilizó el valor de $\mathrm{LC}_{50}$ de Chironomus tentans, y no la del anfípodo $H$. azteca, debido a que éste díptero posee mayor sensibilidad (You et al. 2004a). La toxicidad de los biocidas en los sedimentos depende en gran medida del contenido de carbono orgánico. Con la finalidad de poder comparar resultados, las concentraciones determinadas en las muestras de los arroyos se normalizaron dividiendo las mismas por el contenido de COT en los sedimentos. Para calcular la UT-total se sumaron los valores de UT de todos los biocidas.

\section{Muestras de Macroinvertebrados}

En la región pampeana, las muestras de macroinvertebrados bentónicos se recogieron arrastrando sobre el fondo una red de mano tipo D-net de $30 \mathrm{~cm}$ de diámetro y $500 \mu \mathrm{m}$ de abertura de malla (Figura 2.8), recorriendo cinco transectas de un metro en la primera etapa (2011-2012) y nueve transectas de un metro en la segunda etapa de 
muestreo (2013-2014). Todos los organismos colectados fueron clasificados e identificados. En Paraguay y Brasil se implementó el método de muestreo conocido como "Kick-sampling". El procedimiento consiste en apoyar la red, sujeta a un mango largo, en el fondo del arroyo en dirección aguas abajo. El material del fondo que se encuentra inmediatamente aguas arriba es removido con el pie por lo que el material es llevado dentro de la red por la corriente. Este método es más eficiente cuando el sustrato es rocoso y la velocidad del agua transporta los organismos hacia el interior de la red (Barbour et al., 1999).

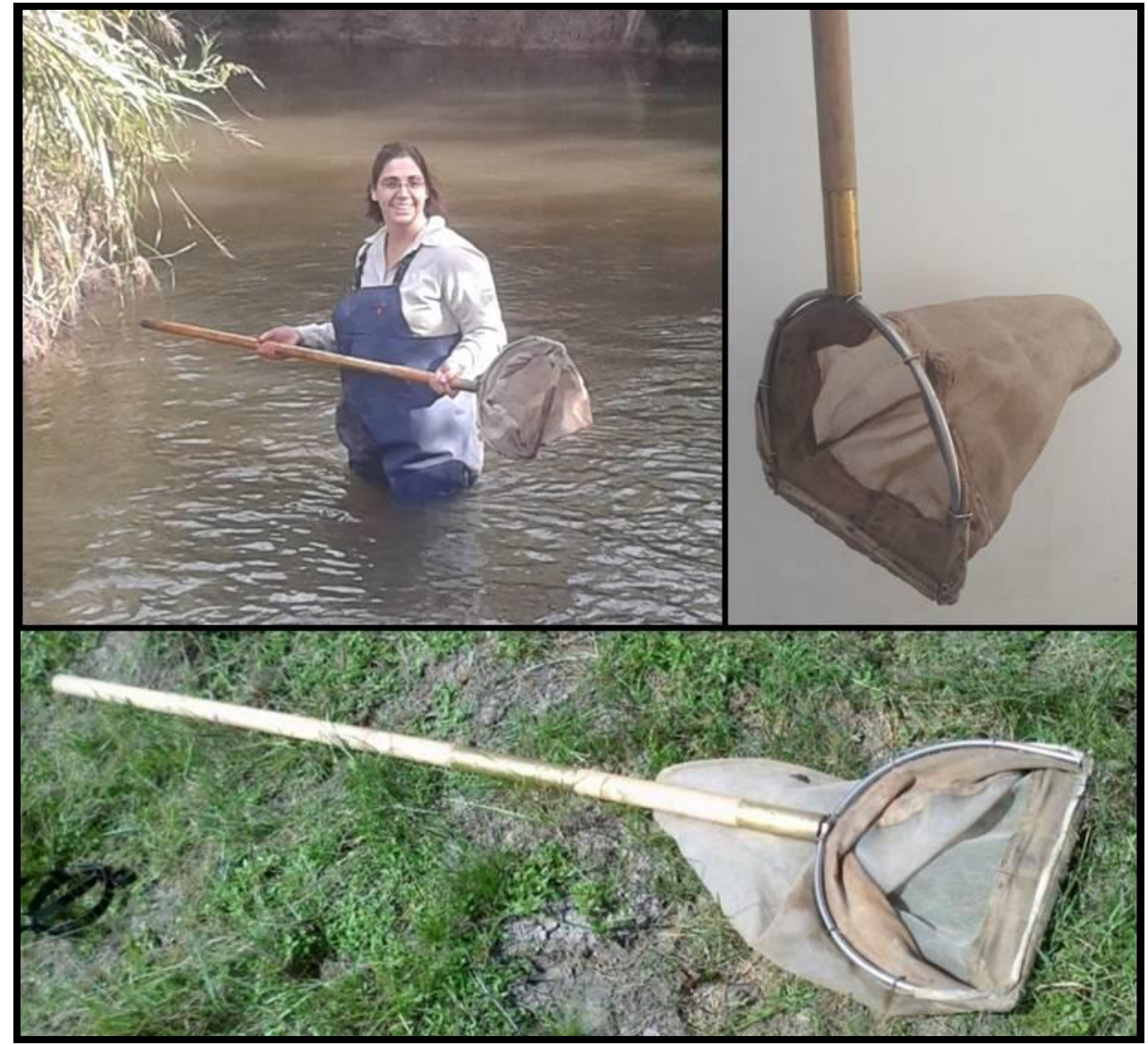

Figura 2.8. Red de mano tipo D-net

En Paraguay y Brasil, cada remoción del sustrato se efectuó a 0,5 m aguas arriba de la red. Debido a la alta variabilidad en el número de organismos obtenidos, el tamaño de la muestra se adaptó para asegurar un número suficiente de organismos en cada una. En enero de 2013, en Paraguay, se realizaron tres remociones del sustrato por un período de 30 segundos en cada sitio y todos los invertebrados de las muestras fueron clasificados e identificados. Para los muestreos de noviembre y diciembre de 2013, en Brasil y Paraguay respectivamente; el tamaño de la muestra fue mayor asegurando un 
número suficiente de organismos y se utilizó, además, un método de submuestreo. En cada sitio se realizaron 30 remociones durante un período de 20 segundos cada una, se homogeneizó el material y se dividió en 24 cuadrillas. Los organismos de los cuadrantes seleccionados aleatoriamente se clasificaron hasta que se alcanzó un recuento total de 500 organismos por muestra ó hasta que los organismos de todos los cuadrantes se hayan clasificado. Esto se aproxima al rango superior de conteo utilizado en los programas de biomonitoreo de los Estados Unidos que involucran números fijos de organismos (Barbour \& Gerritsen, 1996; Carter \& Resh, 2013). Una vez iniciada la clasificación de un cuadrante se sigue hasta completarlo, aunque ya se hayan alcanzado los 500 organismos antes de terminar el cuadrante. El análisis estadístico se realizó utilizando la abundancia relativa de cada taxón.

Las muestras recolectadas se volcaron en una bandeja plástica y fueron tamizadas para eliminar el agua excedente, luego se colocaron en frascos plásticos debidamente rotuladas (especificando fecha, sitio y número de réplica) con alcohol $70 \%$ para su posterior separación, identificación y conteo (Figura 2.9).

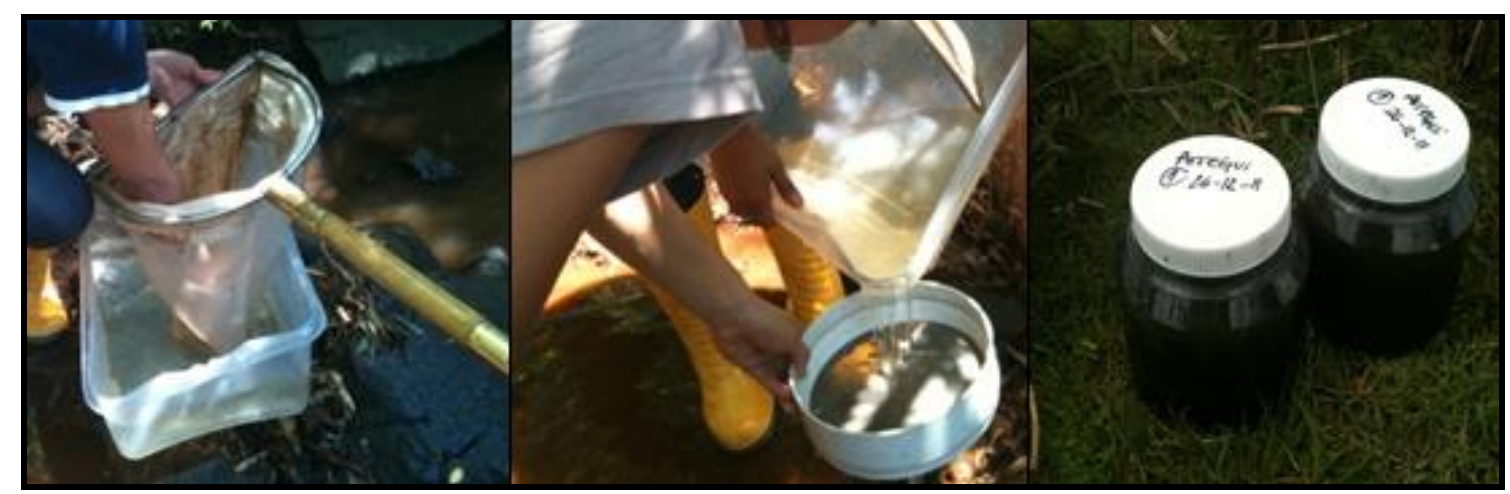

Figura 2.9. Colecta, filtrado y almacenamiento de la muestra.

En el laboratorio, las muestras fueron nuevamente tamizadas (tamiz de $500 \mu \mathrm{m}$ ) y colocadas en bandejas, donde los organismos fueron separados. El sustrato fue removido cuidadosamente hasta asegurarse de que no quede ningún individuo en él. Los macroinvertebrados fueron identificados bajo microscopio óptico estereoscópico (lupa) mediante el uso de las claves taxonómicas Nieser \& Melo (1997), Bouchard (2004), Merritt et al. (2008), Domínguez \& Fernández (2009), Mugnai et al. (2010) hasta el nivel taxonómico de familia. Lenat \& Barbour (1994) sugieren que el nivel taxonómico de familia permite una adecuada caracterización de la calidad ecológica en los sistemas fluviales. Si bien para la determinación taxonómica se puso especial énfasis en lograr la 
mayor precisión posible a través de la consulta con especialistas, en la mayoría de los casos no fue posible realizar determinaciones a nivel específico. Por lo tanto, se tomó en cuenta el nivel más bajo determinado de la unidad taxonómica: filo u orden, familia, género. Luego de la identificación las muestras fueron conservadas en tubos debidamente rotulados en alcohol 70\% (Figura 2.10).

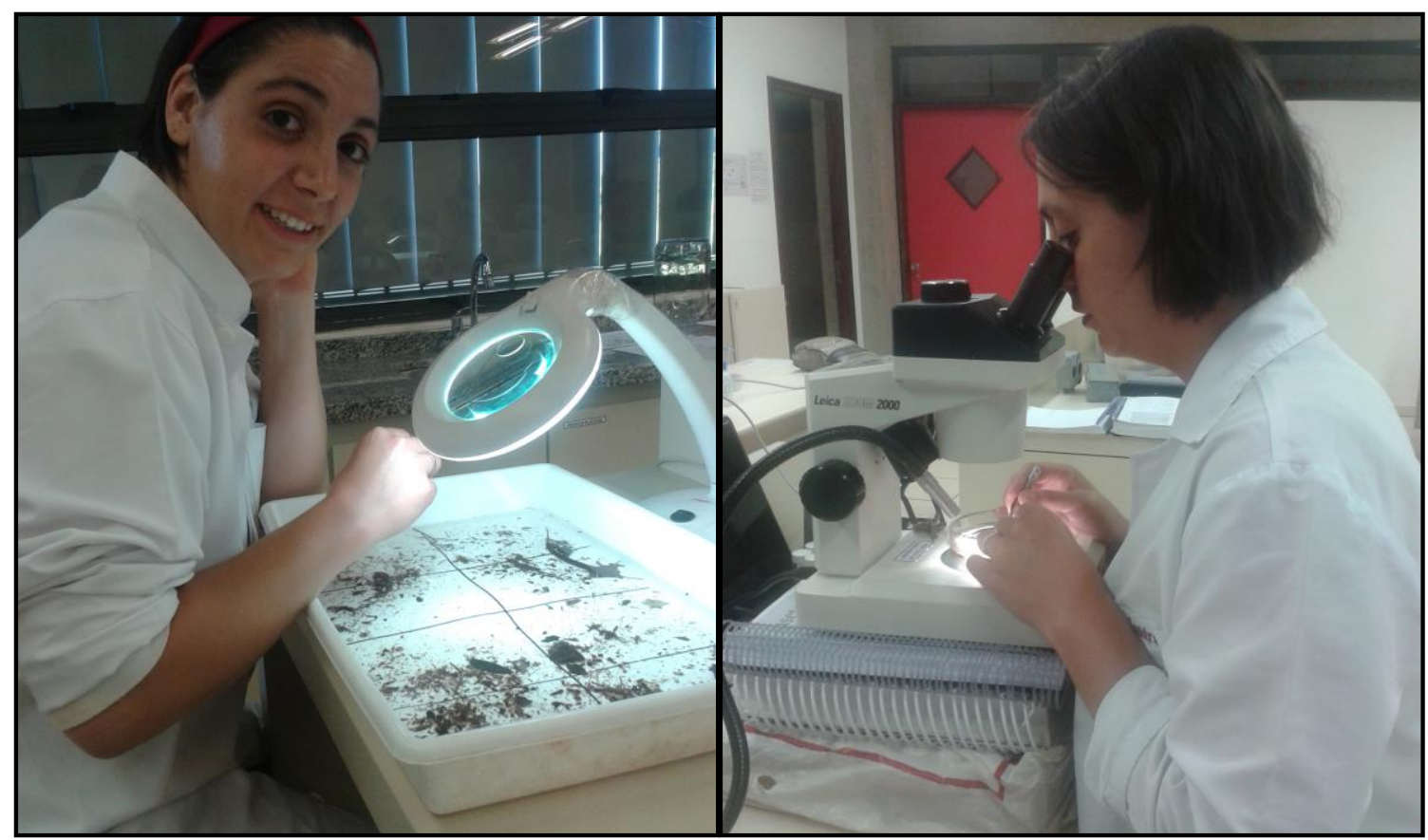

Figura 2.10. Materiales de laboratorio para el procesamiento de las muestras.

\section{Análisis Estadístico}

Los parámetros ambientales en los arroyos relevados de la pampa argentina fueron comparados, agrupándolos según el uso del suelo (agrícola, ganadero, reserva), mediante el análisis de la varianza de una vía (ANOVA). Previo a este análisis se probaron los supuestos estadísticos de homogeneidad de la varianza (Test de Levene) y normalidad (Test de Kolmogorov Smirnov). En caso de cumplirse los supuestos y observarse diferencias significativas se realizó un test a posteriori de múltiples comparaciones de pares (Test de Tukey). En los análisis que los supuestos no se cumplieron se aplicó el método de Kruskal Wallis (ANOVA no paramétrico por rangos). Cuando se detectaron diferencias significativas $(\mathrm{p}<0,05)$, para determinar entre que grupos existían diferencias, se realizó un test a posteriori de comparación múltiple de medianas (método Dunn's).

El análisis utilizado para comparar los parámetros ambientales y los índices de diversidad entre los arroyos muestreados de Paraguay y Brasil fue un test de " $t$ ". Previo 
al análisis se verificó la normalidad de los datos mediante el Test de Kolmogorov Smirnov. En los casos donde los datos no respondieron a una distribución normal se aplicó Mann-Whitney. Las concentraciones de agrotóxicos detectadas en ambas regiones, según la fecha de muestreo, fueron comparadas mediante el análisis ANOVA no paramétrico por rangos (Kruskal Wallis) debido a que los supuestos de homogeneidad y normalidad no se cumplieron. Para determinar entre que grupos existían diferencias se realizó el test a posteriori Dunn's.

Las correlaciones entre las variables ambientales, las métricas del ensamble de macroinvertebrados, las concentraciones de agrotóxicos y las unidades tóxicas, fueron analizadas mediante el coeficiente de correlación de Spearman, asumiendo en todos los casos un nivel de significancia $\mathrm{p}<0,05$.

Todos los análisis previamente mencionados se realizaron utilizando el programa SigmaStat 3.5.

Las métricas del ensamble de macroinvertebrados (riqueza, abundancias e índices de diversidad y dominancia) fueron calculados usando el programa estadístico PRIMER versión 5. La riqueza taxonómica fue determinada por el número total de taxones. La abundancia total correspondió a la suma de todos los taxones de cada sitio de muestreo y expresada como el número de individuos por unidad de superficie (ind $/ \mathrm{m}^{2}$ ). En Brasil y Paraguay se trabajó con la abundancia relativa, calculada como la proporción de individuos de un taxón dado entre el número total de taxones observados de una muestra. Asimismo, se determinaron el índice de Margalef, diversidad de ShannonWiener, dominancia de Simpson y equitatividad de Pielou.

El índice de Margalef (d) se utiliza para estimar la diversidad de una comunidad con base en la distribución numérica de los individuos de las diferentes especies en función del número de individuos existentes en la muestra analizada y se calcula como:

$$
\mathrm{d}=(\mathrm{S}-1) / \log (\mathrm{N})
$$

donde $\mathrm{S}$ es el número de taxones y $\mathrm{N}$ número total de individuos en la muestra.

El índice de diversidad de Shannon-Wiener (H'), basado en la abundancia proporcional de los taxones, se calculó mediante la ecuación:

$$
\mathrm{H}^{\prime}=-\sum(\mathrm{pi}) \times \log (\mathrm{pi})
$$

donde pi es la proporción del número total de individuos del taxón i en el ensamble.

La dominancia de Simpson fue calculada como:

$$
\mathrm{D}^{\prime}=1-\sum(\mathrm{ni}(\mathrm{ni}-1) /(\mathrm{N}(\mathrm{N}-1))
$$


donde ni es el número de individuos del taxón i de la muestra y $\mathrm{N}$ es el número total de individuos de la muestra.

La equitatividad de Pielou mide la proporción de la diversidad observada con relación a la máxima diversidad

$$
\mathrm{J}^{\prime}=\mathrm{H}^{\prime} / \log \mathrm{S}
$$

donde $H^{\prime}$ es el índice de Shannon-Wiener y $\mathrm{S}$ número de taxones en la muestra. Es decir, analiza con qué grado de igualdad están representadas las especies presentes en una muestra. Cuando las abundancias de una muestra son similares, el valor establecido por el índice es máximo (1), mientras que cuando son muy diferentes el valor del índice se acerca a cero (Magurran 1988). Además, se calculó la abundancia relativa de los grandes grupos taxonómicos (Ephemeroptera, Plecoptera, Trichoptera, Diptera, entre otros), el porcentaje de EPT (Ephemeroptera, Plecoptera y Trichoptera) y la riqueza de cada uno de estos ordenes (Riq Ephem, Riq Plec, Riq Trichop).

Los patrones de abundancia del ensamble de macroinvertebrados fueron analizados por medio de técnicas multivariadas utilizando el programa PRIMER versión 5 (Clarke \& Gorley, 2001). Con el fin de reducir la contribución de los taxones más abundantes los datos fueron transformados previamente a $\log (\mathrm{x}+1)$ y se utilizó el índice de similaridad de Bray Curtis. Un análisis de agrupamiento de CLUSTER se realizó con los datos de abundancia de cada arroyo y se aplicó el método por promedio de pares de grupos (Clarke \& Warwick, 2001). Para la primera etapa, La Plata - Arrecifes, se analizaron todos los muestreos realizados en 2011- 2012 y se utilizó como factor el uso del suelo de la cuenca. Para corroborar si existían diferencias significativas entre los distintos grupos (reserva, ganadería, agricultura La Plata y agricultura Arrecifes) se realizó el análisis de similaridad ANOSIM. Esta rutina realiza comparaciones de similitud promedio entre diferentes grupos definidos a priori mediante la realización de permutaciones. Debido a que es un análisis no paramétrico, no es necesario que las variables cumplan los supuestos de normalidad y homocedasticidad de la varianza. En esta rutina cuando los valores del estadístico $\mathrm{R}$ global son cercanos a cero indica que los ensambles son similares, mientras que valores cercanos a 1 indican grandes diferencias en la composición de los ensambles. Luego, se calculó el porcentaje de similitud (SIMPER) para determinar cuáles fueron los taxones que más contribuyeron a las diferencias de los ensambles de macroinvertebrados entre los distintos grupos (Clarke \& Warwick, 2001). Para la segunda etapa se realizó un CLUSTER analizando sólo los muestreos de Arrecifes 2011-2014 y el factor utilizado fue la fecha del muestreo. Luego 
se realizaron dos ANOSIM, uno con los grupos formados por el CLUSTER y otro definido a priori, según la fecha de muestreo. Para ambos análisis se calculó el porcentaje de similitud SIMPER. Para los muestreos en Brasil se realizó un CLUSTER y los factores utilizados fueron la franja de atenuación y la concentración de agrotóxicos totales.

Para evaluar las relaciones entre los parámetros limnológicos, concentraciones de agrotóxicos y ensambles de macroinvertebrados de los arroyos muestreados en Arrecifes se realizó un análisis multivariado con el programa CANOCO versión 4.53 (ter Braak \& Smilauer 1998). Los valores de abundancia relativa de los taxones de cada uno de los relevamientos fueron utilizados para construir una matriz. Los taxones cuya abundancia relativa total presentó una contribución menor al $0,5 \%$ fueron eliminadas del análisis para disminuir la influencia de especies raras. Debido a que las variables ambientales poseen diferentes unidades de medida, los datos fueron normalizados. Previo al ordenamiento se realizó un análisis de correspondencia detendenciado (DCA) con la matriz de taxones para determinar si la variación de los datos responde de forma unimodal o lineal. Debido a que la longitud del gradiente fue $<2$ unidades de desviación estándar para el primer eje, se llevó a cabo un análisis de redundancia (RDA) (ter Braak \& Smilauer 1998; Leps \& Smilauer 2003). Inicialmente, se incluyeron en el análisis todos los parámetros fisicoquímicos, agrotóxicos y descriptores ambientales. Aquellas variables que evidenciaron covariación (factor de inflación de la varianza >10) fueron removidas. El análisis final fue realizado sobre las variables remanentes. La significancia global para el primer eje y para la suma de todos los ejes fue testeado mediante el test permutaciones de Monte Carlo ( $p<0,05 ; 499$ permutaciones). Los dos primeros ejes fueron utilizados y se graficaron dos biplot: uno que incluyó el ordenamiento de sitios según fecha de muestreo junto con las variables ambientales seleccionadas y otro con el ordenamiento de los taxones y las mismas variables ambientales. 


\section{Región Pampeana (Argentina)}

\section{RESULTADOS}

$1^{\text {a }}$ Etapa: Arroyos con distinto uso del suelo en sus cuencas (La Plata - Arrecifes, 2011-2012).

\section{Variables ambientales}

Los resultados de las variables ambientales, determinadas en el período 20112012, no mostraron diferencias significativas entre los arroyos según el uso del suelo. Los valores medios de $\mathrm{pH}$ de cada arroyo variaron entre próximo a la neutralidad $(6,8)$ y alcalino $(9,1)$. La conductividad presentó un amplio rango de variación, el sitio Horqueta 2 (H2) de Arrecifes registró el valor más alto $(1510 \mu \mathrm{S} / \mathrm{cm})$ y Poblet (Po) en La Plata, el más bajo (220 $\mu \mathrm{S} / \mathrm{cm})$. Los sólidos suspendidos variaron considerablemente entre los distintos sitios de muestreo (Tabla 3.1).

Tabla 3.1 Valores medios y rangos de variación de las variables ambientales en los sitios de muestreo.

\begin{tabular}{|c|c|c|c|c|c|}
\hline \multirow{2}{*}{\multicolumn{2}{|c|}{$\begin{array}{l}\text { Región } \\
\text { Uso del suelo }\end{array}$}} & \multicolumn{3}{|c|}{ La Plata } & \multirow{2}{*}{$\begin{array}{c}\text { Arrecifes } \\
\text { Agricultura }\end{array}$} \\
\hline & & Reserva & Ganadería & Agricultura & \\
\hline pH & & $8,9(8,7-9,0)$ & $7,5(7,2-8,0)$ & $7,2(6,7-8,3)$ & $7,8(6,8-9,1)$ \\
\hline Cond & $(\mu \mathrm{S} / \mathrm{cm})$ & 997 (870-1124) & 904 (284-1094) & $332(220-554)$ & $842(390-1510)$ \\
\hline Sol Susp & $(\mathrm{mg} / \mathrm{l})$ & $153(29-278)$ & $11(11-11)$ & $71(4-289)$ & $25(0,2-119)$ \\
\hline $\mathrm{N}-\mathrm{NO}_{2}^{-}$ & $(\mu \mathrm{g} / \mathrm{l})$ & $10,7(9-13)$ & $7(7-7)$ & $16,9(3-23)$ & $64(10-405)$ \\
\hline $\mathrm{N}-\mathrm{NO}_{3}{ }^{-}$ & $(\mu \mathrm{g} / \mathrm{l})$ & $105(86-125)$ & $161(161-161)$ & $140(50-237)$ & $2875(572-8165)$ \\
\hline $\mathrm{N}-\mathrm{NH}_{4}^{+}$ & $(\mu \mathrm{g} / \mathrm{l})$ & $69(5-133)$ & $80(13-147)$ & $108(17-367)$ & $54(6-213)$ \\
\hline PRS & $(\mu \mathrm{g} / \mathrm{l})$ & $113(103-123)$ & $139(46-232)$ & $828(549-1170)$ & $249(46-802)$ \\
\hline COT & $\%$ & 2,1 & $5,4(2-7,3)$ & $5,8(5,5-6,1)$ & $1,0(0,4-1,9)$ \\
\hline Arena & $\%$ & 39 & $34(26-49)$ & $24(24-24)$ & $46(23-66)$ \\
\hline Limo & $\%$ & 42 & $43(35-52)$ & $44(32-55)$ & $40(29-48)$ \\
\hline Arcilla & $\%$ & 19 & $23(16-31)$ & $32(21-44)$ & $14(5-32)$ \\
\hline
\end{tabular}

Cond: conductividad, Sol Susp: sólidos suspendidos, nutrientes $\left(\mathrm{N}^{-\mathrm{NO}_{2}}{ }^{-}\right.$: nitritos, $\mathrm{N}^{-\mathrm{NO}_{3}}{ }^{-}$: nitratos, N$\mathrm{NH}_{4}{ }^{+}$: amonio y PRS: fósforo reactivo soluble), COT: carbono orgánico total y textura (porcentaje de arena, limo y arcilla). 
Las concentraciones de nutrientes registraron diferencias significativas para los distintos usos del suelo. La concentración de PRS fue significativamente mayor en la zona agrícola de La Plata respecto a los demás sitios (ANOVA, Tukey p<0,005). La concentración de nitrato $\left({\mathrm{N}-\mathrm{NO}_{3}^{-}}_{3}\right)$ resultó significativamente mayor en la zona agrícola de Arrecifes a las determinadas en los restantes sitios de muestreo (Kruskal Wallis, Dunn's p<0,005). El análisis de las concentraciones de amonio $\left(\mathrm{N}_{-} \mathrm{NH}^{+}{ }_{4}\right)$ no registró diferencias significativas para los distintos usos del suelo (Tabla 3.1). En Arrecifes, se observó que las concentraciones de nitrato resultaron significativamente mayores en el muestreo de abril (prom: $4767 \pm 2084 \mu \mathrm{g} / \mathrm{l}$ ), período en que se cosecha la soja y queda el barbecho, que las concentraciones determinadas en los muestreos de enero y marzo durante el crecimiento de la soja (prom: $2055 \pm 863 ; 2228 \pm 979 \mu \mathrm{g} / \mathrm{l}$ respectivamente) (ANOVA, Tukey $\mathrm{p}<0,005)$.

La acumulación de carbono orgánico total (COT) en los sedimentos resultó significativamente menor en los arroyos de Arrecifes que en los de La Plata (ANOVA, Tukey $\mathrm{p}<0,005)$. Asimismo, la textura del fondo resultó significativamente distinta entre ambas regiones (Kruskal Wallis, Dunn's p<0,005); donde el contenido de arena fue mayor en los sitios de Arrecifes respecto a los sitios de La Plata y, por el contrario, el porcentaje de arcilla fue menor en Arrecifes y mayor en La Plata.

\section{Agrotóxicos}

Los agrotóxicos detectados en los sedimentos de los arroyos fueron los más comúnmente utilizados en los cultivos de la región: clorpirifos, cipermetrina, lambdacialotrina, endosulfán y, su producto de degradación, endosulfán sulfato. En la reserva y los arroyos de cuencas con ganadería no se detectó la presencia de agrotóxicos, con la excepción de algunos muestreos donde se registraron bajas concentraciones de clorpirifos (< $1 \mathrm{ng} / \mathrm{g}$ peso seco) y un muestreo realizado en marzo 2012, en el arroyo ganadero Cajaravilla donde se registró $5,2 \mathrm{ng} / \mathrm{g}$ peso seco del mismo. En la Tabla 3.2 se muestran las concentraciones detectadas de los biocidas en las distintas fechas de muestreo para los arroyos agrícolas de La Plata y la zona de Arrecifes. 
Tabla 3.2. Concentraciones de los biocidas en sedimentos por muestreo para el período 2011-2012.

\begin{tabular}{|c|c|c|c|c|c|c|}
\hline \multirow{3}{*}{\multicolumn{2}{|c|}{$\begin{array}{l}\text { Lugar } \\
\text { Fecha } \\
\mathrm{N}^{\circ} \text { de muestras }\end{array}$}} & \multicolumn{2}{|c|}{ La Plata ${ }^{\#}$} & \multicolumn{3}{|c|}{ Arrecifes } \\
\hline & & dic-2011 & mar-2012 & ene-2012 & mar-2012 & abr-2012 \\
\hline & & 2 & 2 & 6 & 7 & 5 \\
\hline \multirow{4}{*}{ Clorpirifos } & Frecuencia & $100 \%$ & $67 \%$ & $100 \%$ & $100 \%$ & $100 \%$ \\
\hline & Máximo (ng/g) & 4,9 & 7,4 & 2,7 & 3,6 & 2,0 \\
\hline & Media (ng/g) & 3,6 & 5,7 & 1,4 & 1,9 & 0,8 \\
\hline & $\pm \mathrm{sd}$ & 1,8 & 2,4 & 0,9 & 1,0 & 0,7 \\
\hline \multirow{4}{*}{ Endosulfán } & Frecuencia & $100 \%$ & $50 \%$ & $100 \%$ & $43 \%$ & $40 \%$ \\
\hline & Máximo (ng/g) & 31,9 & 4,1 & 1,2 & 2,1 & 1,4 \\
\hline & Media (ng/g) & 26,4 & & 0,6 & 1,7 & 1,0 \\
\hline & $\pm \mathrm{sd}$ & 7,8 & & 0,4 & 0,7 & 0,7 \\
\hline \multirow{4}{*}{ Endosulfan Sulfato } & Frecuencia & $100 \%$ & $50 \%$ & $100 \%$ & $57 \%$ & $100 \%$ \\
\hline & Máximo (ng/g) & 155,6 & 37,6 & 5,0 & 6,2 & 1,7 \\
\hline & Media (ng/g) & 118,0 & & 1,2 & 2,4 & 0,8 \\
\hline & $\pm \mathrm{sd}$ & 53,1 & & 1,9 & 2,6 & 0,6 \\
\hline \multirow{4}{*}{ Cipermetrina } & Frecuencia & $100 \%$ & $0 \%$ & $50 \%$ & $29 \%$ & $20 \%$ \\
\hline & Máximo (ng/g) & 1,9 & & 8,3 & 4,2 & 2,7 \\
\hline & Media (ng/g) & 1,7 & & 2,9 & 3,7 & \\
\hline & $\pm \mathrm{sd}$ & 0,3 & & 4,7 & 0,7 & \\
\hline \multirow{4}{*}{ Lambda-cialotrina } & Frecuencia & \multirow{4}{*}{ NA } & \multirow[t]{4}{*}{$0 \%$} & \multirow{4}{*}{ NA } & $29 \%$ & $60 \%$ \\
\hline & Máximo (ng/g) & & & & 6,1 & 5,1 \\
\hline & Media (ng/g) & & & & 3,3 & 2,0 \\
\hline & $\pm \mathrm{sd}$ & & & & 4,0 & 2,6 \\
\hline \multirow{3}{*}{ Agrotóxicos total } & Máximo (ng/g) & 194 & 49 & 12 & 15 & 12 \\
\hline & Media (ng/g) & 150 & 27 & 5 & 6 & 4 \\
\hline & $\pm \mathrm{sd}$ & 63 & 32 & 5 & 6 & 5 \\
\hline
\end{tabular}

Limite de cuantificación: $0,5 \mathrm{ng} / \mathrm{g}$ peso seco

\# sitios agricolas

NA: No Analizado

Método: GC-ECD

Clorpirifos tuvo la mayor frecuencia de detección en las dos regiones examinadas y para casi todos los eventos de muestreo (67 a 100\%). Las concentraciones máximas oscilaron entre 2,7 y 7,4 ng/g peso seco (ps), con la mayor concentración medida en la región de La Plata.

Endosulfán y endosulfán sulfato se detectaron con frecuencia en ambas regiones. Sin embargo, en los sitios agrícolas de La Plata, se obtuvieron las concentraciones más altas $31,9 \mathrm{ng} / \mathrm{g}$ ps para el endosulfán y $155,6 \mathrm{ng} / \mathrm{g}$ ps para el endosulfán sulfato. Durante el primer período de muestreo, el biocida endosulfán fue ampliamente utilizado en la producción de soja y en muchos cultivos de Argentina (OPDS, 2013). A partir de julio 
2012, Argentina prohibió la importación del principio activo y formulados del endosulfán y, para julio 2013, su elaboración y uso.

Cipermetrina se detectó en ambas regiones, mientras que lambda-cialotrina no fue detectado en las muestras de La Plata, pero si en la región de Arrecifes. Las concentraciones máximas oscilaron entre 1,9 y $8,3 \mathrm{ng} / \mathrm{g}$ ps para la cipermetrina y entre 5,1 y $6,1 \mathrm{ng} / \mathrm{g}$ ps para lambda-cialotrina.

\section{Unidades Tóxicas (UT)}

En la zona de La Plata, de agricultura mixta, los valores máximos de UT-Totales para los muestreos de 2011 y 2012 fueron 0,55 y 0,7 respectivamente. En Arrecifes, con producción intensiva de soja, los valores máximos de UT-Totales fueron de 1,39 y 1,81 en marzo y abril 2012 respectivamente (Tabla 3.3).

Cabe destacar, que las concentraciones de agrotóxicos totales fueron mayores en La Plata (Tabla 3.2), sin embargo, las UT totales fueron mayores en Arrecifes. Esto se debe a que las dosis letales en $H$. curvispina son mucho menores para los piretroides. En Arrecifes, fueron los piretroides (cipermetrina y lambda-cialotrina) los principales contribuyentes a los altos valores de UT-totales; mientras que, en La Plata, el principal contribuyente, fue endosulfán sulfato.

Si la UT es mayor que 1 significa que la concentración resulta mayor a la dosis letal 50, sugiriendo un efecto importante en la comunidad. En la tabla 3.3 se observa que el biocida que registró mayores UT fue lambda cialotrina, a pesar de que endosulfán sulfato fue el que se determinó en mayor concentración (Tabla 3.2). 
Tabla 3.3. Unidades Tóxicas de los biocidas más utilizados calculados para cada muestreo. La Unidad Tóxica Total (UT-total) fue calculada sumando las UT de todos los agrotóxicos.

\begin{tabular}{|c|c|c|c|c|c|c|c|c|c|}
\hline Fecha & Región & Cuenca & Sitio & UT Clorp $^{a}$ & UT $\lambda$-Cialo ${ }^{a}$ & UT Ciper $^{\mathrm{a}}$ & UT Endo $^{a}$ & UT Endo-Sul $^{\text {b }}$ & UT total \\
\hline \multirow{6}{*}{ 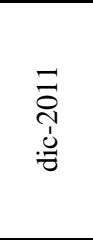 } & \multirow{6}{*}{ La Plata } & Reserva & JB & nd & NA & nd & nd & nd & nd \\
\hline & & \multirow{3}{*}{ Ganadera } & $\mathrm{Ar}$ & nd & \multirow{3}{*}{ NA } & nd & nd & nd & nd \\
\hline & & & Caj & nd & & nd & nd & nd & nd \\
\hline & & & $\mathrm{IC}$ & nd & & nd & nd & nd & nd \\
\hline & & \multirow{2}{*}{ Agrícola } & Po & 0,014 & \multirow{2}{*}{ NA } & 0,013 & 0,011 & 0,279 & 0,316 \\
\hline & & & $\operatorname{Re}$ & 0,026 & & 0,015 & 0,016 & 0,488 & 0,545 \\
\hline \multirow{5}{*}{$\begin{array}{l}\stackrel{\sim}{\delta} \\
\stackrel{\overbrace{}}{1} \\
\stackrel{0}{0}\end{array}$} & \multirow{5}{*}{ Arrecifes } & \multirow{5}{*}{ Agrícola } & $\mathrm{CO} 1$ & 0,015 & \multirow{5}{*}{ NA } & 0,013 & 0,001 & 0,004 & 0,034 \\
\hline & & & $\mathrm{CA}$ & 0,032 & & 0,211 & 0,001 & 0,012 & 0,256 \\
\hline & & & HO & 0,076 & & nd & 0,003 & 0,012 & 0,091 \\
\hline & & & $\mathrm{H} 2$ & 0,076 & & nd & 0,003 & 0,084 & 0,164 \\
\hline & & & MG & 0,012 & & nd & nd & nd & 0,012 \\
\hline \multirow{13}{*}{ 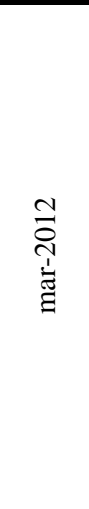 } & \multirow{7}{*}{ Arrecifes } & \multirow{7}{*}{ Agrícola } & $\mathrm{CO} 1$ & 0,047 & nd & nd & 0,005 & 0,019 & 0,071 \\
\hline & & & $\mathrm{A} 2$ & 0,065 & nd & nd & nd & nd & 0,065 \\
\hline & & & $\mathrm{A} 3$ & 0,031 & nd & nd & nd & 0,011 & 0,042 \\
\hline & & & $\mathrm{CA}$ & 0,041 & 1,252 & 0,082 & 0,001 & 0,016 & 1,393 \\
\hline & & & HO & 0,221 & nd & nd & nd & nd & 0,221 \\
\hline & & & $\mathrm{H} 2$ & 0,075 & nd & 0,178 & 0,005 & 0,105 & 0,363 \\
\hline & & & MG & 0,047 & nd & nd & nd & nd & 0,047 \\
\hline & \multirow{6}{*}{ La Plata } & Reserva & JB & 0,026 & nd & nd & nd & nd & 0,026 \\
\hline & & \multirow{3}{*}{ Ganadera } & $\mathrm{Ar}$ & nd & nd & nd & nd & nd & nd \\
\hline & & & Caj & 0,120 & nd & nd & nd & nd & 0,120 \\
\hline & & & $\mathrm{IC}$ & nd & nd & nd & nd & nd & nd \\
\hline & & \multirow{2}{*}{ Agrícola } & Po & 0,093 & nd & nd & nd & nd & 0,093 \\
\hline & & & $\mathrm{Re}$ & 0,171 & nd & nd & 0,009 & 0,516 & 0,696 \\
\hline \multirow{10}{*}{ 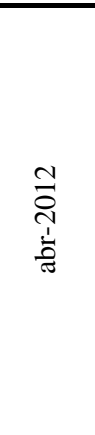 } & \multirow{5}{*}{ Arrecifes } & \multirow{5}{*}{ Agrícola } & $\mathrm{CO} 1$ & 0,054 & 1,632 & 0,107 & 0,001 & 0,021 & 1,815 \\
\hline & & & $\mathrm{A} 2$ & nd & nd & nd & 0,011 & 0,080 & 0,091 \\
\hline & & & $\mathrm{A} 3$ & nd & nd & nd & nd & 0,008 & 0,008 \\
\hline & & & $\mathrm{HO}$ & 0,027 & nd & nd & nd & 0,016 & 0,043 \\
\hline & & & MG & 0,014 & nd & nd & 0,0004 & 0,006 & 0,020 \\
\hline & \multirow{5}{*}{ La Plata } & Reserva & $\mathrm{JB}$ & 0,012 & nd & nd & nd & nd & 0,012 \\
\hline & & & $\mathrm{Ar}$ & 0,023 & nd & nd & nd & nd & 0,023 \\
\hline & & Ganadera & Caj & 0,003 & nd & nd & nd & nd & 0,003 \\
\hline & & & IC & \multicolumn{6}{|c|}{ NA } \\
\hline & & Agrícola & $\begin{array}{l}\text { Po } \\
\text { Re }\end{array}$ & \multicolumn{6}{|c|}{$\mathrm{NA}$} \\
\hline
\end{tabular}

Clorp: clorpirifos, $\lambda$-Cialo: lambda cialotrina, Ciper: cipermetrina, Endo: endosulfán, Endo-Sul: endosulfán sulfato. NA: no analizado. nd: no detectado. LP: La Plata (JB: Juan Blanco, Ar: Arregui, Caj: Cajarravilla, IC: Ignacio Correa, Po: Poblet y Re: Remes). Arrecif: Arrecifes (MG: Maguire, Ca: Cañete, H0: Horqueta0, H2: Horqueta2, CO1: Contador1, A2: Luna2 y A3: Luna3).

${ }^{\mathrm{a}}: \mathrm{LC}_{50}$ para Hyalella curvispina ${ }^{\mathrm{b}}: \mathrm{LC}_{50}$ para Chironomus tentans (You et al ., 2004a).

\section{Ensamble de macroinvertebrados}

En la Tabla 3.4 se muestran las 48 entidades taxonómicas identificadas. En la región de La Plata, el arroyo ubicado en la reserva, Juan Blanco (JB), se caracterizó por ser el único donde se registró una elevada abundancia de Paleomonidae (decapoda); el cual estuvo ausente o en baja densidad en los demás arroyos. Los sitios de cuencas ganaderas (IC, Ar y Caj) presentaron variaciones entre ellos, aunque todos registraron una alta abundancia del orden Amphipoda (Hyalella). Ignacio Correa (IC) se caracterizó por la abundancia de Hirudinea, Arregui (Ar) por el efemeróptero Caenidae y, 
Cajaravilla (Caj) por la gran densidad de Hyalella. En la cuenca agrícola del arroyo Pescado, los sitios Remes $(\mathrm{Re})$ y Poblet $(\mathrm{Po})$, los taxones pertenecientes a la clase Hirudinea, Oligochaeta, Bivalvia y el filo Nematoda fueron los grupos taxonómicos mejor representados. Los arroyos de Arrecifes presentaron una amplia variabilidad entre ellos. Al igual que en los arroyos agrícolas de La Plata, se registraron entre los grupos más abundantes la clase Hirudinea y Oligochaeta, aunque a diferencia de los primeros se observó también una mayor densidad de Gastropoda y del orden Diptera (Chironomidae); además, en algunos sitios se encontraron bien representados los ordenes Amphipoda (Hyalella), Decapoda (Aeglidae) y Ephemeroptera (Baetidae y Caenidae). 
Tabla 3.4. Abundancia (ind $/ \mathrm{m}^{2}$ ) media de cada taxón durante el período 2011-2012 para cada uno de los sitios muestreados en La Plata y Arrecifes.

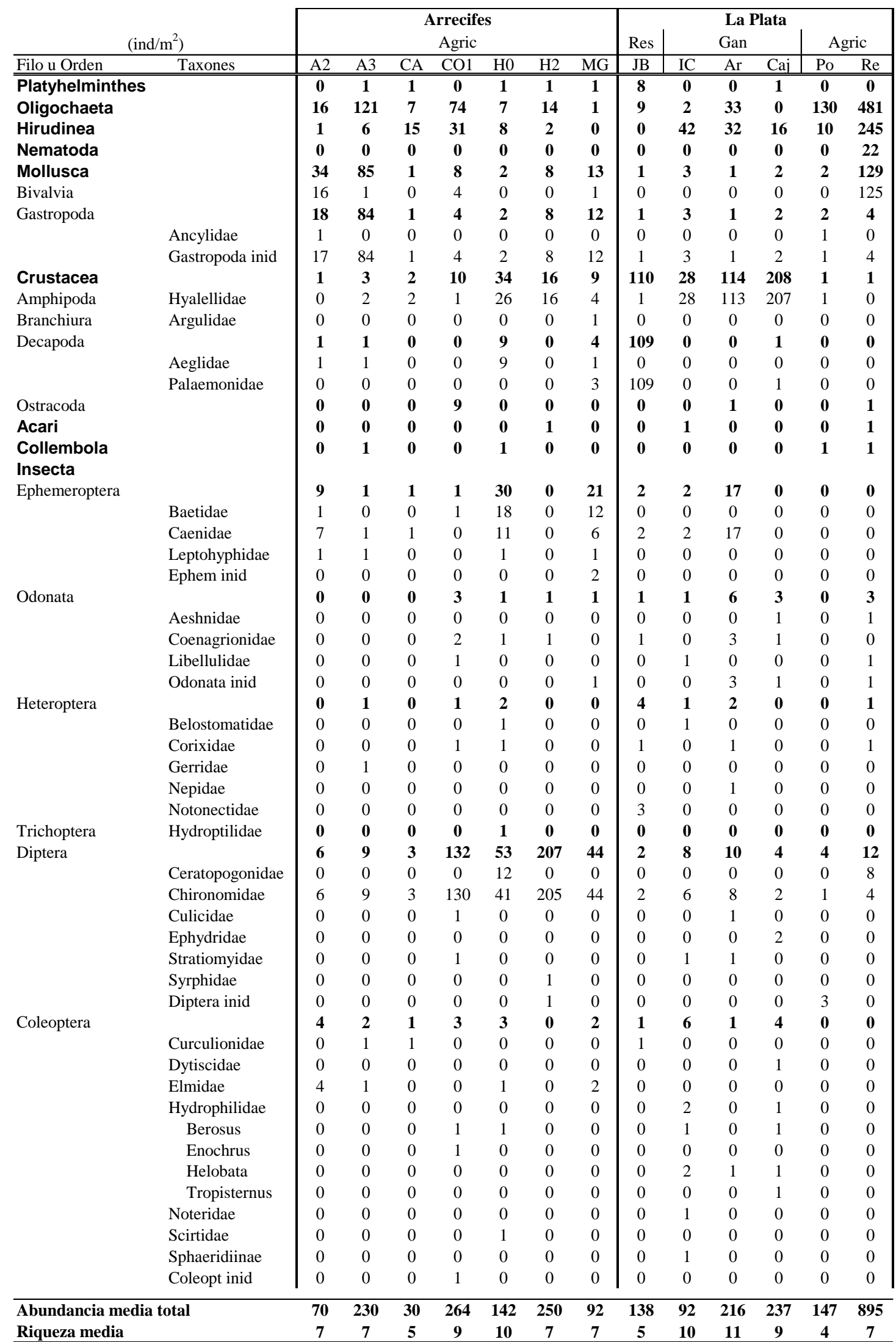

Arrecifes (A2: Luna2, A3: Luna3, CO1: Contador1, Ca: Cañete, H0: Horqueta 0, H2: Horqueta 2, MG: Maguire)

La Plata (JB: Juan Blanco, IC: Ignacio Correa, Ar: Arregui, Caj: Cajarravilla, Po: Poblet y Re: Remes)

inid: inidentificado Agric: agricultura Res: reserva Gan: ganadería 
El análisis CLUSTER (Figura 3.1) mostró agrupamientos entre los ensambles de macroinvertebrados en arroyos con distinto uso del suelo. Los muestreos del arroyo situado en la reserva se segregaron en un único grupo (A) como asi también los de sitios con ganadería (B). A su vez, los arroyos agrícolas de La Plata y Arrecifes forman los grupos C, D, E y F. Los grupos C, D y E están formados fundamentalmente por los arroyos de Arrecifes, con la excepción de un muestreo en Remes. El grupo F, está conformado principalmente por los sitios Remes y Poblet de la zona de La Plata, si bien incorpora algunos de los arroyos de Arrecifes.

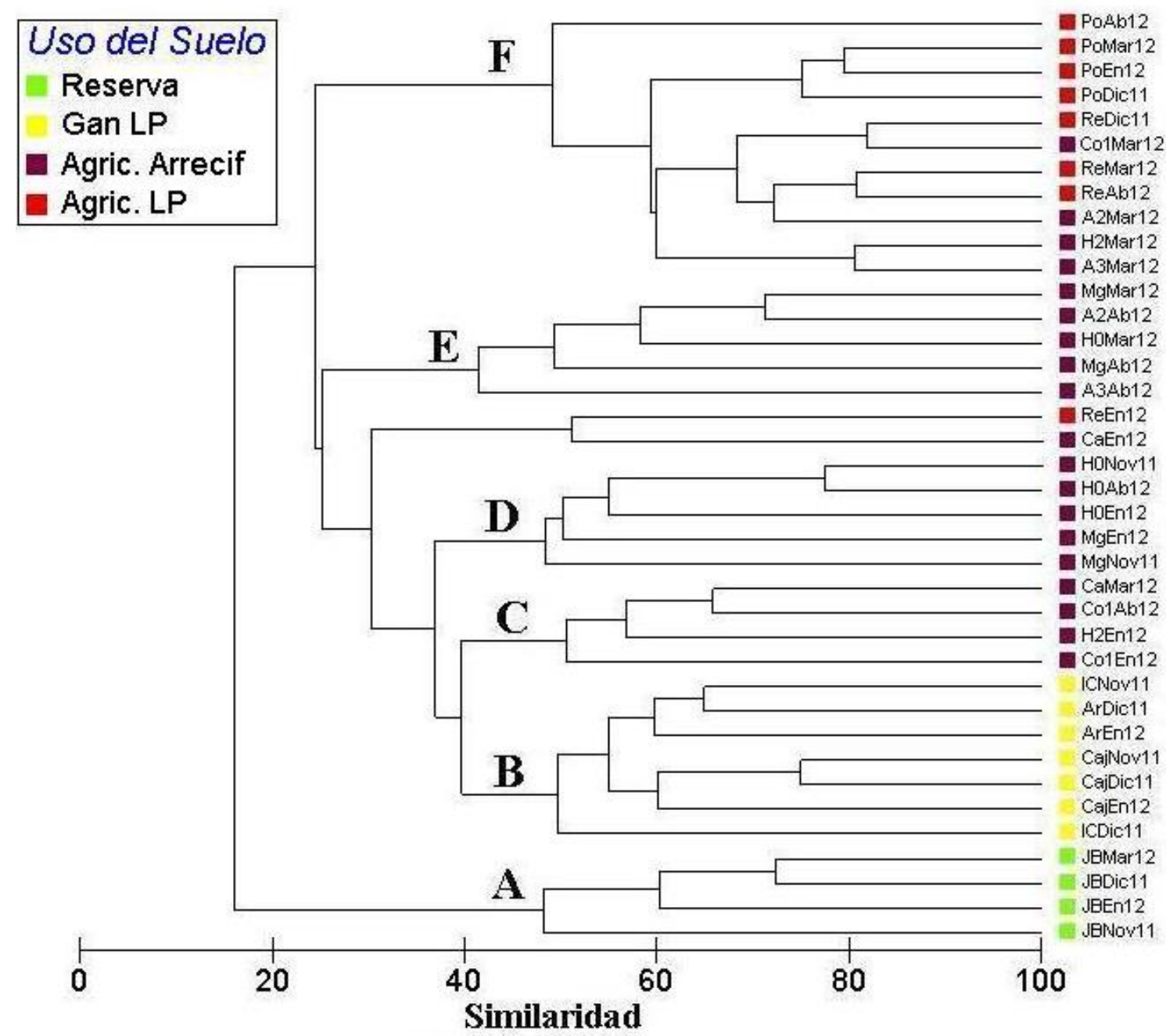

Figura. 3.1. Cluster del ensamble de macroinvertebrados durante el período muestreado 2011-2012 (Nov11, Dic11, En12, Mar12 y Ab12) para los sitios de La Plata (JB: Juan Blanco, Ar: Arregui, Caj: Cajarravilla, IC: Ignacio Correa, Po: Poblet y Re: Remes) y Arrecifes (Mg: Maguire, Ca: Cañete, H0: Horqueta0, H2: Horqueta2, Co1: Contador1, A2: Luna2 y A3: Luna3). 
El análisis ANOSIM muestra que existen diferencias significativas entre los ensambles de los arroyos con distinto uso del suelo en sus cuencas (Global R: 0,51; p: 0,001). El ensamble del arroyo de la reserva resultó significativamente distinto de todos los demas usos del suelo (Tabla 3.5). Los ensambles de los arroyos agrícolas de La Plata mostraron diferencias significativas con los de Arrecifes, como así también entre estos y los arroyos de cuencas con ganadería.

Tabla 3.5. Valores del análisis ANOSIM para los test de a pares que resultaron significativamente distintos. Se informa el R de cada par y el nivel de significancia.

\begin{tabular}{lcc}
\hline Pares & Estadístico R & Significancia \\
\hline \hline Agric. Arrecifes vs. Ganadería LP & 0,28 & 0,003 \\
Agric. Arrecifes vs. Agric. LP & 0,40 & 0,002 \\
Agric. Arrecifes vs. Reserva & 0,61 & 0,001 \\
Ganadería LP vs. Reserva & 0,98 & 0,003 \\
Ganadería LP vs. Agric. LP & 0,93 & 0,001 \\
Reserva vs. Agric. LP & 0,93 & 0,002 \\
\hline
\end{tabular}

En el análisis SIMPER se identificaron 12 taxones como principales contribuyentes a la disimilitud entre los pares que presentaron diferencias significativas en el ANOSIM, representados por los taxones Aeglidae, Baetidae, Bivalvia, Caenidae, Chironomidae, Coenagrionidae, Gastropoda, Helobata, Hirudinea, Hyalella, Oligochaeta y Palaemonidae. En la Tabla 3.6 se muestran los taxones que contribuyeron aproximadamente en un $70 \%$ a la disimilitud entre los sitios.

Los Palaemonidae constribuyeron a la mayor diferencia entre la composición del ensamble en la reserva y los demas usos del suelo. Para las cuencas ganaderas, el principal aporte a la diferencia fue el anfípodo Hyalella, Chironomidae y Oligochaeta representaron la mayor contribución a la disimilitud en los usos del suelo agrícola, además de Bivalvia para las cuencas agrícolas de La Plata y Gastropada en Arrecifes. 
Tabla 3.6. Resultado del análisis SIMPER. Se muestra el promedio de la abundancia relativa porcentual (\%Abund.) y el porcentaje de contribución (\%Contrib) de los taxones que aportaron en mayor medida a la disimilitud de los sitios (Agric. Arrecif: agricultura Arrecifes, Gan LP: ganadería La Plata, Agric. LP: agricultura La Plata, reserva)

\begin{tabular}{|c|c|c|c|c|c|c|c|}
\hline Taxones & $\% \mathrm{Abu}$ & & \% Contrib & Taxones & $\% \mathrm{~A}$ & bund & \% Contrib \\
\hline$\%$ Disimilaridad $=81,69$ & Agric. Arrecif & Reserva & & $\%$ Disimilaridad $=85,43$ & Gan LP & Reserva & \\
\hline Palaemonidae & 0,27 & $\overline{4,33}$ & 22,35 & Palaemonidae & 0,09 & 4,33 & 21,44 \\
\hline Chironomidae & 2,77 & 0,57 & 12,72 & Hyalella & 4,06 & 0,58 & 18,02 \\
\hline Oligochaeta & 1,51 & 0,94 & 9,35 & Hirudinea & 2,72 & 0,00 & 13,42 \\
\hline Gastropoda & $\mathbf{1 , 5 3}$ & 0,44 & 8,12 & Oligochaeta & 0,78 & 0,94 & 6,24 \\
\hline Hyalella & 1,24 & 0,58 & 6,37 & Chironomidae & 1,12 & 0,57 & 5,05 \\
\hline Hirudinea & 1,10 & 0,00 & 6,29 & Gastropoda & $\mathbf{0 , 8 2}$ & 0,44 & 4,24 \\
\hline Caenidae & 1,26 & 0,86 & 6,21 & Caenidae & 0,68 & $\mathbf{0 , 8 6}$ & 4,19 \\
\hline$\%$ Disimilaridad $=69,04$ & Agric. Arrecif & Gan LP & & $\%$ Disimilaridad $=76,14$ & Gan LP & Agric. LP & \\
\hline Hyalella & 1,24 & 4,06 & 15,36 & Hyalella & 4,06 & 0,05 & 23,25 \\
\hline Hirudinea & 1,10 & 2,72 & 10,28 & Oligochaeta & 0,78 & 4,11 & 19,61 \\
\hline Chironomidae & 2,77 & 1,12 & 10,25 & Hirudinea & 2,72 & 1,72 & 8,55 \\
\hline Oligochaeta & 1,51 & 0,78 & 8,34 & Bivalvia & 0,00 & 1,13 & 6,26 \\
\hline Gastropoda & 1,53 & 0,82 & 7,29 & Chironomidae & 1,12 & 0,43 & 5,12 \\
\hline Caenidae & 1,26 & 0,68 & 6,46 & Gastropoda & $\mathbf{0 , 8 2}$ & 0,40 & 3,93 \\
\hline Baetidae & 0,94 & 0,00 & 4,54 & Helobata & 0,74 & 0,00 & 3,60 \\
\hline Helobata & 0,00 & 0,74 & 3,41 & & & & \\
\hline Coenagrionidae & 0,12 & 0,55 & 2,90 & & & & \\
\hline Aeglidae & 0,56 & 0,00 & 2,57 & & & & \\
\hline Bivalvia & $\mathbf{0 , 4 7}$ & 0,00 & 2,45 & & & & \\
\hline$\%$ Disimilaridad $=73,82$ & Agric. Arrecif & Agric. LP & & $\%$ Disimilaridad $=88,54$ & Reserva & Agric. LP & \\
\hline Oligochaeta & 1,51 & 4,11 & 16,49 & Palaemonidae & 4,33 & 0,00 & 27,05 \\
\hline Chironomidae & 2,77 & 0,43 & 14,50 & Oligochaeta & 0,94 & 4,11 & 21,09 \\
\hline Hirudinea & 1,10 & 1,72 & 9,62 & Hirudinea & 0,00 & 1,72 & 10,35 \\
\hline Gastropoda & 1,53 & 0,40 & 8,78 & Bivalvia & 0,00 & 1,13 & 6,75 \\
\hline Bivalvia & 0,47 & 1,13 & 7,58 & Caenidae & 0,86 & 0,00 & 5,46 \\
\hline Hyalella & 1,24 & 0,05 & 7,16 & & & & \\
\hline Caenidae & 1,26 & 0,00 & 6,90 & & & & \\
\hline
\end{tabular}

\section{Relaciones del ensamble de macroinvertebrados con los agrotóxicos y parámetros físico-químicos}

En la Tabla 3.7 se muestran las correlaciones entre las concentraciones de agrotóxicos y la abundancia de los distintos taxones de macroinvertebrados (ind $/ \mathrm{m}^{2}$ ). Dos familias, Palaemonidae y Caenidae, presentaron una correlación negativa con la mayoría de los biocidas estudiados (clorpirifos, cipermetrina, endosulfán, endosulfán sulfato y agrotóxicos totales), al igual que los ordenes a los cuales pertenecen, Decapoda y Ephemeroptera respectivamente. Seis grupos taxonómicos registraron correlación positiva con la concentración de uno o más agrotóxicos, estos son Hirudinea, Oligochaeta, Gastropoda (Ancylidae), Odonata (Coenagrionidae), Coleoptera (Curculionidae) y Heteroptera. Los taxones que muestran correlación con las concentraciones de los biocidas son los que contribuyen a las diferencias entre los ensambles, detectadas por el análisis SIMPER. 
Tabla 3.7. Correlaciones entre la abundancia de los macroinvertebrados (ind $/ \mathrm{m}^{2}$ ) y la concentración de los agrotóxicos determinados para el período de muestreo 2011-2012 en la región de La Plata y Arrecifes.

\begin{tabular}{|c|c|c|c|c|c|c|c|}
\hline & & Clorp & $\lambda$-Cialo & Ciper & Endo & Endo-Sul & \begin{tabular}{|l|} 
Agrotóx. T \\
\end{tabular} \\
\hline \multirow{2}{*}{ Crustacea } & $\mathrm{r}$ & $-0,58$ & \multirow[t]{2}{*}{ * } & \multirow[t]{2}{*}{ * } & $-0,43$ & \multirow{2}{*}{$*$} & $-0,61$ \\
\hline & $\mathrm{p}$ & 0,002 & & & 0,030 & & 0,001 \\
\hline \multirow{2}{*}{ Decapoda } & $\mathrm{r}$ & $-0,52$ & \multirow{2}{*}{$*$} & $-0,46$ & $-0,47$ & $-0,42$ & $-0,50$ \\
\hline & $\mathrm{p}$ & 0,007 & & 0,020 & 0,016 & 0,033 & 0,009 \\
\hline \multirow{2}{*}{ Palaemonidae } & $\mathrm{r}$ & $-0,58$ & \multirow{2}{*}{$*$} & \multirow{2}{*}{$*$} & $-0,48$ & $-0,50$ & $-0,58$ \\
\hline & $\mathrm{p}$ & 0,002 & & & 0,014 & 0,010 & 0,002 \\
\hline \multirow{2}{*}{ Ephemeroptera } & $\mathrm{r}$ & $-0,54$ & \multirow{2}{*}{$*$} & $-0,49$ & $-0,62$ & $-0,51$ & $-0,59$ \\
\hline & $\mathrm{p}$ & 0,005 & & 0,011 & 0,000 & 0,008 & 0,002 \\
\hline \multirow{2}{*}{ Caenidae } & $\mathrm{r}$ & $-0,42$ & \multirow[t]{2}{*}{ * } & $-0,47$ & $-0,48$ & $-0,50$ & $-0,48$ \\
\hline & $\mathrm{p}$ & 0,035 & & 0,017 & 0,014 & 0,010 & 0,013 \\
\hline \multirow{2}{*}{ Oligochaeta } & $\mathrm{r}$ & 0,64 & \multirow{2}{*}{$*$} & \multirow{2}{*}{$*$} & \multirow{2}{*}{$*$} & 0,40 & 0,58 \\
\hline & $\mathrm{p}$ & 0,000 & & & & 0,041 & 0,002 \\
\hline \multirow{2}{*}{ Hirudinea } & $\mathrm{r}$ & \multirow[t]{2}{*}{$*$} & \multirow{2}{*}{ * } & 0,47 & 0,49 & \multirow{2}{*}{$*$} & \multirow{2}{*}{$*$} \\
\hline & $\mathrm{p}$ & & & 0,016 & 0,011 & & \\
\hline \multirow[t]{2}{*}{ Ancylidae } & $\mathrm{r}$ & \multirow[t]{2}{*}{$*$} & \multirow[t]{2}{*}{$*$} & \multirow[t]{2}{*}{$*$} & 0,39 & \multirow[t]{2}{*}{$*$} & \multirow[t]{2}{*}{$*$} \\
\hline & $\mathrm{p}$ & & & & & & \\
\hline Coenagrionidae & $\begin{array}{l}r \\
p\end{array}$ & $*$ & $\begin{array}{c}0,55 \\
0,033\end{array}$ & $*$ & * & $*$ & $*$ \\
\hline Heteroptera & $\mathrm{r}$ & $*$ & 0,55 & $*$ & $*$ & $*$ & $*$ \\
\hline & $\mathrm{p}$ & & 0,033 & & & & \\
\hline Curculionidae & $\mathrm{r}$ & $*$ & 0,52 & $*$ & $*$ & $*$ & $*$ \\
\hline Curctumomatae & $\mathrm{p}$ & & 0,046 & & & & \\
\hline
\end{tabular}

Clorp: clorpirifos, $\lambda$-Cialo: lambda cialotrina, Ciper: cipermetrina, Endo: endosulfán,

Endo-Sul: endosulfán sulfato, Agrotóx. T: agrotóxicos totales, * : no significativo

\section{Relaciones con las características del hábitat}

En la Tabla 3.8 se muestra las correlaciones determinadas entre la abundancia de macroinvertebrados con las características del hábitat. Se observó que Chironomidae (Diptera), dos familias del orden Ephemeroptera (Baetidae y Leptohyphidae) y la clase Gastropoda se correlacionaron de forma positiva con la concentración de nitratos, mientras siete grupos taxonómicos se correlacionaron negativamente con la concentración de PRS (Hyalella, Palaemonidae, Crustacea, Stratiomyidae, Baetidae, Caenidae y Ephemeroptera) y sólo Oligochaeta lo hizo de forma positiva. 
Trece grupos taxonómicos se correlacionaron con el contenido de COT en sedimentos. La abundancia aumentó con la materia orgánica sólo en cuatro taxones (Ephydridae, Hydrophilidae, Aeshnidae, Hirudinea) mientras que en los restantes la abundancia disminuyó, entre ellos se encuentran Ephemeroptera (Baetidae, Caenidae y Leptohyphidae) y Decapoda (Aeglidae). La abundancia de varios grupos taxonómicos se relacionó con la textura del sedimento, diez grupos con la proporción de arena y 11 con la de arcilla. Decapoda (Aeglidae), Coleoptera (Elmidae), Diptera (Chironomidae) y Ephemeroptera (Baetidae, Caenidae, Leptohyphidae) registraron una correlación negativa con el contenido de arcillas, mientras que tres taxones (Acari, Hirudinea y Oligochaeta) se correlacionaron de forma positiva. La abundancia de ocho taxones aumentó con el aumento de la proporción de arena (Crustacea (Decapoda: Aeglidae) Coleoptera, Ephemeroptera y dentro de este último, las familias Baetidae, Caenidae y Leptohyphidae), mientras que Acari y Oligochaeta disminuyeron. Seis taxones registraron correlación simultánea, positiva con la arena y negativa con la arcilla y, dos taxones registraron la condición inversa (Acari y Oligochaeta). A su vez, ocho grupos taxonómicos mostraron correlación negativa simultánea con el contenido de COT y arcilla.

La abundancia de los taxones Crustacea (Hyalella), Diptera (Stratiomyidae) y Odonata se correlacionó positivamente con la riqueza de familias de la vegetación acuática y Gastropoda negativamente. Asimismo, se puede observar que la abundancia de Hydrophilidae, Crustacea y dentro de este último Hyalella se correlacionaron positivamente con la franja de atenuación. 
Tabla 3.8. Relaciones entre la abundancia de los macroinvertebrados y las variables ambientales determinadas para el período de muestreo 2011-2012 en La Plata y Arrecifes.

\begin{tabular}{|c|c|c|c|c|c|c|c|c|c|c|}
\hline & & $\mathrm{N}-\mathrm{NO}_{2}^{-}$ & $\mathrm{N}-\mathrm{NO}_{3}^{-}$ & PRS & COT & Arena & Limo & Arcilla & Franja & Veg \\
\hline Oligochaeta & $\begin{array}{l}\mathrm{r} \\
\mathrm{p}\end{array}$ & * & $*$ & $\begin{array}{c}0,64 \\
0,000\end{array}$ & $*$ & $\begin{array}{l}-0,41 \\
0,011\end{array}$ & $*$ & $\begin{array}{c}0,40 \\
0,014\end{array}$ & $\begin{array}{r}-0,32 \\
0,048\end{array}$ & $*$ \\
\hline Hirudinea & $\begin{array}{l}\mathrm{r} \\
\mathrm{p}\end{array}$ & $*$ & $*$ & $*$ & $\begin{array}{c}0,50 \\
0,002 \\
\end{array}$ & * & $*$ & $\begin{array}{r}0,38 \\
0,019 \\
\end{array}$ & $*$ & $*$ \\
\hline Bivalvia & $\begin{array}{l}\mathrm{r} \\
\mathrm{p}\end{array}$ & $*$ & $*$ & $*$ & $*$ & $*$ & $*$ & $*$ & $\begin{array}{l}-0,57 \\
0,000\end{array}$ & $*$ \\
\hline Gastropoda & $\begin{array}{l}\mathrm{r} \\
\mathrm{p}\end{array}$ & $*$ & $\begin{array}{c}0,43 \\
0,025 \\
\end{array}$ & $*$ & $*$ & $*$ & $*$ & $*$ & $*$ & $\begin{array}{r}-0,40 \\
0,013 \\
\end{array}$ \\
\hline Crustacea & $\begin{array}{l}\mathrm{r} \\
\mathrm{p}\end{array}$ & $*$ & $*$ & $\begin{array}{l}-0,62 \\
0,000\end{array}$ & $*$ & $\begin{array}{c}0,36 \\
0,026\end{array}$ & $*$ & $*$ & $\begin{array}{c}0,60 \\
0,000\end{array}$ & $\begin{array}{c}0,59 \\
0,000\end{array}$ \\
\hline Hyalella & $\begin{array}{l}\mathrm{r} \\
\mathrm{p}\end{array}$ & $*$ & $*$ & $\begin{array}{l}-0,44 \\
0,021 \\
\end{array}$ & $*$ & $*$ & $*$ & $*$ & $\begin{array}{c}0,42 \\
0,009 \\
\end{array}$ & $\begin{array}{c}0,59 \\
0,000 \\
\end{array}$ \\
\hline Decapoda & $\begin{array}{l}\mathrm{r} \\
\mathrm{p}\end{array}$ & $*$ & $*$ & $\begin{array}{l}-0,58 \\
0,002 \\
\end{array}$ & $\begin{array}{l}-0,37 \\
0,021 \\
\end{array}$ & $\begin{array}{c}0,50 \\
0,002 \\
\end{array}$ & $*$ & $\begin{array}{r}-0,47 \\
0,003 \\
\end{array}$ & $*$ & $*$ \\
\hline Aeglidae & $\begin{array}{l}\mathrm{r} \\
\mathrm{p}\end{array}$ & $*$ & $*$ & $*$ & $\begin{array}{l}-0,60 \\
0,000\end{array}$ & $\begin{array}{c}0,56 \\
0,000\end{array}$ & $\begin{array}{l}-0,47 \\
0,003\end{array}$ & $\begin{array}{l}-0,60 \\
0,000\end{array}$ & $*$ & $*$ \\
\hline Palaemonidae & $\begin{array}{l}\mathrm{r} \\
\mathrm{p}\end{array}$ & $*$ & $*$ & $\begin{array}{l}-0,38 \\
0,049 \\
\end{array}$ & $*$ & $*$ & $*$ & $*$ & $*$ & $*$ \\
\hline Acari & $\begin{array}{l}\mathrm{r} \\
\mathrm{p}\end{array}$ & $*$ & $*$ & $*$ & $*$ & $\begin{array}{l}-0,34 \\
0,039\end{array}$ & $*$ & $\begin{array}{c}0,35 \\
0,034\end{array}$ & $*$ & $*$ \\
\hline Ephemeroptera & $\begin{array}{l}\mathrm{r} \\
\mathrm{p}\end{array}$ & $*$ & $\begin{array}{c}0,46 \\
0,017\end{array}$ & $\begin{array}{l}-0,51 \\
0,006\end{array}$ & $\begin{array}{l}-0,60 \\
0,000\end{array}$ & $\begin{array}{c}0,52 \\
0,000\end{array}$ & $*$ & $\begin{array}{l}-0,59 \\
0,000\end{array}$ & $*$ & $*$ \\
\hline Baetidae & $\begin{array}{l}\mathrm{r} \\
\mathrm{p}\end{array}$ & $*$ & $\begin{array}{c}0,38 \\
0,048\end{array}$ & $\begin{array}{l}-0,55 \\
0,003\end{array}$ & $\begin{array}{l}-0,61 \\
0,000\end{array}$ & $\begin{array}{c}0,48 \\
0,002\end{array}$ & $*$ & $\begin{array}{l}-0,58 \\
0,000\end{array}$ & $*$ & $*$ \\
\hline Caenidae & $\begin{array}{l}\mathrm{r} \\
\mathrm{p}\end{array}$ & $*$ & $*$ & $\begin{array}{l}-0,42 \\
0,030 \\
\end{array}$ & $\begin{array}{l}-0,52 \\
0,000 \\
\end{array}$ & $\begin{array}{c}0,45 \\
0,005 \\
\end{array}$ & $*$ & $\begin{array}{r}-0,48 \\
0,002 \\
\end{array}$ & $*$ & $*$ \\
\hline Leptohyphidae & $\begin{array}{l}\mathrm{r} \\
\mathrm{p}\end{array}$ & $*$ & $\begin{array}{c}0,45 \\
0,020\end{array}$ & $*$ & $\begin{array}{l}-0,46 \\
0,004 \\
\end{array}$ & $\begin{array}{c}0,43 \\
0,008 \\
\end{array}$ & $*$ & $\begin{array}{l}-0,47 \\
0,003\end{array}$ & $*$ & $*$ \\
\hline Odonata & $\begin{array}{l}\mathrm{r} \\
\mathrm{p}\end{array}$ & $*$ & $*$ & $*$ & $*$ & $*$ & $*$ & $*$ & $*$ & $\begin{array}{c}0,34 \\
0,037 \\
\end{array}$ \\
\hline Aeshnidae & $\begin{array}{l}\mathrm{r} \\
\mathrm{p}\end{array}$ & $*$ & $*$ & $*$ & $\begin{array}{c}0,43 \\
0,007 \\
\end{array}$ & $*$ & $*$ & $*$ & $*$ & $*$ \\
\hline Diptera & $\begin{array}{l}\mathrm{r} \\
\mathrm{p}\end{array}$ & $\begin{array}{c}0,53 \\
0,004 \\
\end{array}$ & $\begin{array}{c}0,52 \\
0,006\end{array}$ & $*$ & $\begin{array}{l}-0,32 \\
0,049 \\
\end{array}$ & $*$ & $*$ & $*$ & $*$ & $*$ \\
\hline Ceratopogonidae & $\begin{array}{l}\mathrm{r} \\
\mathrm{p}\end{array}$ & $*$ & $*$ & $*$ & $*$ & $*$ & $\begin{array}{l}-0,37 \\
0,024 \\
\end{array}$ & $*$ & $*$ & $*$ \\
\hline Chironomidae & $\begin{array}{l}\mathrm{r} \\
\mathrm{p}\end{array}$ & $\begin{array}{c}0,49 \\
0,010 \\
\end{array}$ & $\begin{array}{c}0,60 \\
0,001 \\
\end{array}$ & $*$ & $\begin{array}{l}-0,46 \\
0,004 \\
\end{array}$ & $*$ & $*$ & $\begin{array}{r}-0,34 \\
0,037 \\
\end{array}$ & $*$ & $*$ \\
\hline Ephydridae & $\begin{array}{l}\mathrm{r} \\
\mathrm{p}\end{array}$ & $*$ & $*$ & $*$ & $\begin{array}{r}0,33 \\
0,040 \\
\end{array}$ & $*$ & $*$ & $*$ & $*$ & $*$ \\
\hline Stratiomyidae & $\begin{array}{l}\mathrm{r} \\
\mathrm{p}\end{array}$ & $*$ & $*$ & $\begin{array}{l}-0,40 \\
0,038 \\
\end{array}$ & $*$ & $*$ & $*$ & $*$ & $*$ & $\begin{array}{c}0,35 \\
0,034 \\
\end{array}$ \\
\hline Coleoptera & $\begin{array}{l}\mathrm{r} \\
\mathrm{p}\end{array}$ & $*$ & $*$ & $*$ & $*$ & $\begin{array}{c}0,35 \\
0,030 \\
\end{array}$ & $*$ & $*$ & $*$ & $*$ \\
\hline Elmidae & $\begin{array}{l}\mathrm{r} \\
\mathrm{p}\end{array}$ & $*$ & $*$ & $*$ & $\begin{array}{l}-0,44 \\
0,006 \\
\end{array}$ & $*$ & $*$ & $\begin{array}{l}-0,41 \\
0,012 \\
\end{array}$ & $*$ & $*$ \\
\hline Hydrophilidae & $\begin{array}{l}\mathrm{r} \\
\mathrm{p}\end{array}$ & $*$ & $*$ & $*$ & $\begin{array}{c}0,53 \\
0,000\end{array}$ & $*$ & $*$ & $*$ & $\begin{array}{c}0,46 \\
0,004\end{array}$ & $*$ \\
\hline
\end{tabular}

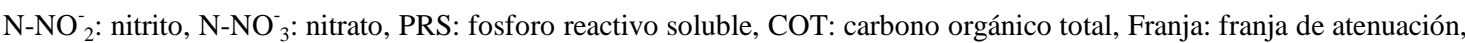
Veg: riqueza de familias de la vegetación. * : no significativo. 
El contenido de COT se correlacionó positivamente con el contenido de arcilla (r: $0,69$ у $\mathrm{p}<0,0001)$ y negativamente con el de arena $(\mathrm{r}:-0,50 ; \mathrm{p}<0,002)$. La materia orgánica presentó correlación negativa tanto con el $\mathrm{N}_{-N^{-}}^{-}(\mathrm{r}:-0,40 ; \mathrm{p}<0,041)$ como con el $\mathrm{N}^{-N^{-}}{ }_{3}(\mathrm{r}:-0,65 ; \mathrm{p}<0,0001)$ y una relación positiva con el PRS (r: 0,44; $\mathrm{p}<$ 0,023). El porcentaje de arena en sedimento se correlacionó positivamente con la concentración de $\mathrm{N}_{-\mathrm{NO}_{3}^{-}}$(r: 0,55; p < 0,003) y negativamente con el PRS (r: -0,61; p < 0,0001). La arcilla registró la tendencia opuesta, positiva para el PRS (r: 0,58; p < $0,002)$ y negativa para el $\mathrm{N}^{-\mathrm{NO}_{3}^{-}}(\mathrm{r}:-0,66 ; \mathrm{p}<0,0001)$.

En la Tabla 3.9 se observa que el contenido de arena se correlacionó negativamente con la concentración total de agrotóxicos, clorpirifos y la unidad tóxica del endosulfán sulfato. Por el contrario, la proporción de arcilla se correlacionó positivamente con estos mismos parámetros. El PRS se correlacionó de forma positiva con la concentración de clorpirifos, agrotóxicos totales, sus respectivas unidades tóxicas y la UT de endosulfán sulfato. Resulta de interés destacar que las concentraciones del clorpirifos, endosulfán y los agrotóxicos totales se correlacionaron negativamente con la franja de atenuación (Tabla 3.9).

Tabla 3.9. Relaciones entre las características físicas y químicas del hábitat y la concentración de los agrotóxicos determinadas para el período de muestreo 2011-2012 en la región de La Plata y Arrecifes.

\begin{tabular}{|lc|c|c|c|c|}
\hline \multicolumn{5}{|c|}{ PRS } & \multicolumn{2}{c|}{ Arena } & \multicolumn{2}{c|}{ Arcilla } & Franja \\
\hline \hline \multirow{2}{*}{ Clorpirifos } & $\mathrm{r}$ & 0,75 & $-0,48$ & 0,42 & $-0,42$ \\
& $\mathrm{p}$ & 0,000 & 0,014 & 0,032 & 0,034 \\
\hline \multirow{2}{*}{ Endosulfán } & $\mathrm{r}$ & $*$ & $*$ & $*$ & $-0,42$ \\
& $\mathrm{p}$ & & & & 0,031 \\
\hline \multirow{2}{*}{ Agrotóxicos totales } & $\mathrm{r}$ & 0,65 & $-0,43$ & $*$ & $-0,42$ \\
& $\mathrm{p}$ & 0,002 & 0,030 & & 0,034 \\
\hline \multirow{2}{*}{ UT Clorpirifos } & $\mathrm{r}$ & 0,65 & $*$ & $*$ & $*$ \\
\hline \multirow{2}{*}{ UT Endosulfán-Sulfato } & $\mathrm{p}$ & 0,003 & & & \\
& $\mathrm{p}$ & 0,041 & 0,034 & 0,021 & $*$ \\
\hline \multirow{2}{*}{ UT total } & $\mathrm{r}$ & 0,55 & $*$ & $*$ & $*$ \\
& $\mathrm{p}$ & 0,012 & & & \\
\hline
\end{tabular}

PRS: fosforo reactivo soluble, Franja: franja de atenuación.

$*$ : no significativo 


\section{$2^{\mathrm{a}}$ Etapa: Arroyos de cuencas agrícolas (Arrecifes 2011-2014)}

En la primera etapa se estudiaron arroyos con distinto uso del suelo en sus cuencas. En la segunda etapa se decidió profundizar en el conocimiento de los arroyos con uso de suelo agrícola. Por lo tanto, se suspendieron los muestreos en la reserva y los arroyos ganaderos y se incrementó el número de arroyos en cuencas agrícolas (de siete a diecisiete arroyos), todos en la denominada "zona núcleo" (Pengue, 2000) con intensa agricultura.

\section{Variables ambientales}

En la tabla 3.10 se resume los resultados de las variables ambientales determinadas en el período 2011-2014 de todos los arroyos muestreados en Arrecifes. Los valores medios de $\mathrm{pH}$ de los arroyos variaron en un rango alcalino $(7,5-9,1)$. La conductividad presentó una amplia variación, el sitio Río Saladito Grande (HB) registró el valor más alto $(1796 \mu \mathrm{S} / \mathrm{cm})$ y Horqueta $2(\mathrm{H} 2)$ el más bajo $(549 \mu \mathrm{S} / \mathrm{cm})$. Los sólidos suspendidos variaron considerablemente entre los distintos arroyos, al igual que la turbidez. El ancho mínimo fue de $1 \mathrm{~m}$ y máximo de $12 \mathrm{~m}$. La profundidad osciló entre 0,1 y 1,2 m. Las concentraciones de $\mathrm{N}^{-} \mathrm{NH}_{4}{ }^{+}$y PRS resultaron un orden de magnitud menor que las concentraciones de $\mathrm{N}_{-} \mathrm{NO}_{3}{ }^{-}$, los valores máximos registrados fueron 281, 802 y $9808 \mu \mathrm{g} / \mathrm{l}$ respectivamente. 
Tabla 3.10. Valores medios, mínimos y máximos de las variables ambientales de los arroyos muestreados en Arrecifes 2011-2014.

\begin{tabular}{|c|c|c|c|c|c|c|c|c|c|c|c|c|c|c|c|c|c|c|}
\hline & & 3HQ & A2 & A3 & A4 & AN & CA & CO1 & $\mathrm{CO2}$ & GO & Ho & H2 & H5 & HB & HEL & ING & MG & S2 \\
\hline \multirow{3}{*}{ pH } & prom & $\overline{77,7}$ & $7 \overline{7,8}$ & 8,1 & 99,1 & 8,0 & 8,0 & 8,1 & 8,4 & $7,7,5$ & $7,7,5$ & 7,2 & $\overline{77,7}$ & 8,0 & 8,2 & 8,1 & $8,8,0$ & 8,2 \\
\hline & mín & 7,2 & 7,6 & 8,1 & & 7,6 & 7,5 & 7,5 & & 7,1 & 6,8 & 7,0 & & 7,4 & & & 7,0 &, 1 \\
\hline & máx & 8,3 & 8,1 & 8,1 & & 8,4 & 8,3 & 8,7 & & 7,9 & 8,1 & 7,4 & & 8,6 & & & 9,1 & 3 \\
\hline \multirow{3}{*}{$\begin{array}{c}\text { Cond } \\
(\mu \mathrm{S} / \mathrm{cm})\end{array}$} & prom & 873 & 803 & 951 & 956 & 897 & 807 & 808 & 1277 & 922 & 886 & 1030 & 785 & 1282 & 847 & 920 & 917 & 931 \\
\hline & mín & 867 & 759 & 951 & & 844 & 673 & 688 & 956 & 892 & 843 & 549 & 663 & 768 & 818 & 891 & 589 & 895 \\
\hline & máx & 879 & 847 & 951 & & 949 & 897 & 927 & 1597 & 951 & 929 & 1510 & 906 & 1796 & 876 & 949 & 1133 & 967 \\
\hline \multirow{3}{*}{$\begin{array}{c}\text { SS } \\
(\mathrm{mg} / \mathrm{l}) \\
\end{array}$} & prom & 11 & 15 & 21 & 11 & 11 & 9 & 10 & 3 & 17 & 9 & 116 & 11 & 32 & 3 & 100 & 20 & 6 \\
\hline & mín & 5 & 2 & 9 & & 9 & 7 & 3 & 3 & 13 & 0,2 & 113 & 6 & 17 & 1 & 18 & 5 & 6 \\
\hline & máx & 16 & 34 & 33 & & 14 & 10 & 17 & 4 & 21 & 18 & 119 & 17 & 47 & 6 & 182 & 42 & 7 \\
\hline \multirow{3}{*}{$\begin{array}{c}\mathbf{N}-\mathrm{NO}_{2}{ }^{-} \\
(\mu \mathrm{g} / \mathrm{l})\end{array}$} & prom & 169 & 10 & 19 & 31 & 53 & 51 & 55 & 60 & 18 & 61 & 217 & 17 & 39 & 35 & 27 & 27 & 17 \\
\hline & mín & 77 & 4 & 17 & & 43 & 10 & 20 & 16 & 14 & 23 & 29 & 7 & 29 & 26 & 15 & 2 & 2 \\
\hline & máx & 261 & 17 & 21 & & 64 & 142 & 91 & 104 & 22 & 104 & 405 & 27 & 50 & 45 & 39 & 48 & 32 \\
\hline \multirow{3}{*}{$\begin{array}{c}\mathbf{N}-\mathrm{NO}_{3}{ }^{-} \\
(\mu \mathrm{g} / \mathrm{l})\end{array}$} & prom & 3735 & 3172 & 3177 & 1495 & 5239 & 4034 & 4871 & 3933 & 4514 & 2258 & 1401 & 3635 & 4314 & 3202 & 4527 & 2800 & 3581 \\
\hline & mín & 2697 & 1687 & 2096 & & 2060 & 1180 & 2921 & 2008 & 1977 & 1932 & 984 & 1683 & 1329 & 1579 & 1743 & 572 & 1788 \\
\hline & máx & 4773 & 4971 & 4257 & & 8418 & 9808 & 8166 & 5857 & 7051 & 2614 & 1818 & 5587 & 7300 & 4824 & 7311 & 6886 & 5373 \\
\hline \multirow{3}{*}{$\begin{array}{c}\mathbf{N}-\mathbf{N H}_{4}{ }^{+} \\
(\mu \mathrm{g} / \mathrm{l})\end{array}$} & prom & 113 & 50 & 25 & 24 & 60 & 98 & 52 & 65 & 131 & 60 & 113 & 114 & 35 & 166 & 54 & 58 & 25 \\
\hline & mín & 31 & 6 & 22 & & 24 & 24 & 13 & 44 & 31 & 28 & 13 & 57 & 25 & 51 & 30 & 13 & 24 \\
\hline & máx & 196 & 135 & 28 & & 95 & 183 & 113 & 85 & 231 & 101 & 213 & 171 & 44 & 281 & 77 & 161 & 25 \\
\hline \multirow{3}{*}{$\begin{array}{c}\text { PRS } \\
(\mu \mathrm{g} / \mathrm{l}) \\
\end{array}$} & prom & 173 & 226 & 186 & 135 & 254 & 180 & 171 & 165 & 94 & 120 & 695 & 120 & 313 & 348 & 126 & 208 & 89 \\
\hline & mín & 135 & 111 & 154 & & 169 & 117 & 75 & 111 & 67 & 46 & 588 & 5 & 69 & 169 & 117 & 46 & 67 \\
\hline & máx & 211 & 308 & 218 & & 339 & 321 & 308 & 219 & 120 & 218 & 802 & 236 & 558 & 526 & 136 & 588 & 111 \\
\hline \multirow{3}{*}{$\begin{array}{c}\text { Ancho } \\
(\mathrm{m})\end{array}$} & prom & 3 & 7 & 4 & 2 & 3 & 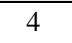 & 11 & 3 & 5 & 3 & 7 & 3 & 4 & 4 & 3 & 4 & 2 \\
\hline & mín & 3 & 5 & 3 & & 3 & 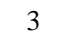 & 10 & 3 & 5 & 2 & & 3 & 6 & 4 & 3 & 3 & 2 \\
\hline & máx & 3 & 8 & 5 & & 4 & 4 & 12 & 4 & 5 & 5 & & 3 & 6 & 4 & 4 & 5 & 3 \\
\hline \multirow{4}{*}{$\begin{array}{c}\text { Prof } \\
(\mathrm{m})\end{array}$} & prom & 0,4 & 0,8 & 0,6 & 0,2 & 0,4 & 0,6 & 10 & 0,4 & 0,4 & 0,3 & 0,3 & 0,3 & 0,5 & 0,4 & 0,3 & 0,6 & 0,3 \\
\hline & mín & 0,4 & 0,5 & 0,1 & & 0, & 0,4 & 0, & 0,4 & 0,4 & 0,3 & 0, & 0,3 & 0,5 & 0,4 & 0,3 & 0,2 &, 3 \\
\hline & máx & 0,4 & 1,0 & 1,0 & & 0,4 & 1,0 & 1,2 & 0,5 & 0,4 & 0,3 & 0,3 & 0,3 & 0,5 & 0,4 & 0,3 & 1,0 & 0,3 \\
\hline & prom & 13 & 20 & & 9 & 15 & 11 & & 7 & 15 & & & 12 & 30 & 7,1 & 62 & 38 & 12 \\
\hline \multirow{3}{*}{$\begin{array}{c}\text { Turb } \\
\text { (NTU) }\end{array}$} & mín & 9 & & - & & 15 & 8 & - & 4 & 14 & - & - & 9 & 16 & 6,8 & 27 & 28 & 11 \\
\hline & máx & 16 & & & & 15 & 13 & & 10 & 15 & & & 15 & 45 & 7,4 & 96 & 47 & 14 \\
\hline & prom & 1,4 & 0,8 & 1,2 & 0,9 & 0,7 & 1,9 & 1,2 & 0,6 & 1,2 & 0,5 & 1,1 & 0,9 & 0,3 & 1,9 & 0,9 & 0,8 & 1,5 \\
\hline \multirow{2}{*}{$\begin{array}{c}\text { COT } \\
(\%) \\
\end{array}$} & mín & 1,3 & 0,4 & & & 0,4 & 1,8 & & 0,4 & 1,1 & & & & & 1,6 & 0,6 & 0,6 & 1,1 \\
\hline & máx & 1,5 & 1,6 & & & 1,0 & 2,0 & & 0,8 & 1,3 & & & & & 2,2 & 1,3 & 0,9 & 1,9 \\
\hline Arena & $\%$ & 25 & 66 & 56 & 47 & 30 & 32 & 41 & 38 & 42 & 64 & 23 & 46 & 34 & 22 & 27 & 38 & 37 \\
\hline Arcilla & $\%$ & 21 & 5 & 9 & 15 & - & - & 13 & 17 & 17 & 5 & 32 & 15 & 19 & 36 & 17 & 15 & 24 \\
\hline Limo & $\%$ & 54 & 29 & 36 & 38 & 48 & 47 & 46 & 46 & 40 & 31 & 44 & 39 & 47 & 42 & 56 & 47 & 40 \\
\hline
\end{tabular}

\section{Agrotóxicos}

Los agrotóxicos clorpirifos, cipermetrina, lambda-cialotrina, endosulfán y, su producto de degradación, endosulfán sulfato fueron detectados en casi todos los sitios de muestreo de Arrecifes, durante el período 2011-2014 (Tabla 3.11).

Clorpirifos tuvo una frecuencia de detección del $100 \%$ en todos los muestreos y la concentración máxima fue de 3,6 ng/g ps. Cipermetrina fue determinada en el $50 \%$ de las muestras, mientras que lambda-cialotrina en $60 \%$ de las mismas. Las concentraciones máximas oscilaron entre 8,3 y $6,1 \mathrm{ng} / \mathrm{g}$ ps respectivamente. La 
frecuencia de detección del endosulfán fue del $40 \%$ y del endosulfán sulfato $80 \%$ y la concentración máxima detectada fue 2,1 y $12,0 \mathrm{ng} / \mathrm{g}$ ps respectivamente.

Tabla 3.11 Concentraciones máximas, media y desviación de los biocidas en ng/g de peso seco de sedimentos por arroyo, para el período 2011-2014 en Arrecifes.

\begin{tabular}{|c|c|c|c|c|c|c|c|c|c|c|c|c|c|c|c|c|c|c|}
\hline$(\mathrm{ng} / \mathrm{g} \mathrm{pc}$ & seco) & 3HQ & A2 & A3 & A4 & AN & $\mathrm{CA}$ & CO1 & $\mathrm{CO2}$ & GO & HO & H2 & H5 & HB & HEL & ING & MG & S2 \\
\hline \multirow{3}{*}{ Clorp } & máx & $1,4,45$ & 2,61 & 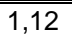 & $\begin{array}{ll}1,07 \\
\end{array}$ & $\begin{array}{l}2,18 \\
\end{array}$ & 2,43 & 2,02 & $\begin{array}{l}0,71 \\
\end{array}$ & 11,19 & $\begin{array}{l}3,56 \\
\end{array}$ & $\begin{array}{l}2,67 \\
\end{array}$ & $\begin{array}{ll}1,03 \\
\end{array}$ & $\begin{array}{ll}1,02 \\
\end{array}$ & $\begin{array}{l}1,21 \\
\end{array}$ & 2,50 & $\begin{array}{ll}1,29 \\
\end{array}$ & $\overline{0,83}$ \\
\hline & media & 1,05 & 1,31 & 0,81 & - & 1,35 & 1,51 & 1,44 & 0,56 & 0,89 & 1,74 & 2,65 & 0,81 & 0,72 & 1,12 & 2,21 & 0,70 & - \\
\hline & $\pm \mathrm{sd}$ & 0,57 & 1,14 & 0,44 & - & 1,18 & 0,78 & 0,78 & 0,21 & 0,42 & 1,63 & 0,03 & 0,30 & 0,43 & 0,13 & 0,42 & 41 & - \\
\hline \multirow{3}{*}{$\lambda$-Cialo } & máx & 0,27 & 0,50 & 0,50 & & 0,41 & 6,09 & 5,05 & 0,25 & 0,25 & & & 0,25 & & 0,58 & 0,42 & 0,56 & \\
\hline & media & 0,26 & 0,46 & - & BRL & 0,34 & 2,35 & 2,78 & 0,23 & 0,24 & nd & nd & 0,24 & BRL & 0,51 & 0,35 & 0,39 & BRL \\
\hline & $\pm \mathrm{sd}$ & 0,01 & 0,06 & - & & 0,11 & 3,24 & 1,09 & 0,03 & 0,01 & & & 0,01 & & 0,09 & 0,10 & 0,24 & \\
\hline \multirow{3}{*}{ Ciper } & máx & 0,35 & & & 0,42 & 1,11 & 8,32 & 2,68 & 0,42 & 0,47 & & 4,16 & 0,48 & 0,34 & 0,37 & 1,85 & & 0,78 \\
\hline & media & 0,30 & nd & nd & . & 0,62 & 3,36 & 1,51 & 0,34 & 0,39 & nd & - & 0,30 & 0,30 & 0,31 & 1,02 & BRL & - \\
\hline & $\pm \mathrm{sd}$ & 0,07 & & & - & 0,69 & 3,48 & 1,66 & 0,12 & 0,11 & & - & 0,25 & 0,07 & 0,08 & 1,17 & & - \\
\hline \multirow{3}{*}{ Endo } & máx & & 1,42 & & & & 0,88 & 2,12 & 0,33 & 0,25 & 0,45 & 1,95 & & & 1,99 & 0,40 & 0,25 & 1,05 \\
\hline & media & BRL & 1,24 & nd & BRL & BRL & 0,55 & 1,01 & 0,29 & 0,23 & - & 1,57 & BRL & BRL & 1,12 & 0,29 & 0,21 & - \\
\hline & $\pm \mathrm{sd}$ & & 0,25 & & & & 0,34 & 0,96 & 0,06 & 0,03 & - & 0,54 & & & 1,23 & 0,15 & 0,07 & - \\
\hline \multirow{3}{*}{ Endo-Sul } & máx & 0,76 & 1,67 & 0,63 & 0,46 & 0,68 & 1,61 & 1,33 & 0,58 & 0,58 & 0,44 & 6,19 & 0,63 & & 3,69 & 0,78 & 0,30 & 12,03 \\
\hline & media & 0,55 & 1,51 & 0,54 & . & 0,44 & 0,92 & 0,94 & 0,42 & 0,55 & 0,39 & 5,59 & 0,49 & BRL & 2,64 & 0,55 & 0,26 & - \\
\hline & $\pm \mathrm{sd}$ & 0,30 & 0,23 & 0,12 & - & 0,34 & 0,57 & 0,57 & 0,23 & 0,05 & 0,08 & 0,86 & 0,20 & & 1,50 & 0,33 & 0,04 & - \\
\hline
\end{tabular}

Clorp: clorpirifos, $\lambda$-Cialo: lambda cialotrina, Ciper: cipermetrina, Endo: endosulfán, Endo-Sul: endosulfán sulfato, nd: no detectado, BRL: por debajo del límite de cuantificación, 3HQ: 3Horqueta, A2: Luna 2, A3: Luna 3, A4: Luna 4, AN: Las Animas, CA: Cañete, CO1: Contador 1, CO2: Contador 2, GO: Gomez, H0: Horqueta 0, H2: Horqueta 2, H5: Horqueta 5, HB: Río Saladito Grande, HEL: Helves, ING: Los Ingleses, MG: Maguire, S2: Salto 2.

En 2013 y 2014, se amplió sustancialmente la cantidad de agrotóxicos analizados, se incrementó los organoclorados, piretroides y el sinérgico piperonil butóxido (Tabla 3.12). Dentro de los piretroides se detectaron ocasionalmente y en bajas concentraciones bifentrina, flútrina, esfenvalerato, deltametrina y permetrina. Teflutrina fue el único piretroide analizado que no se detectó. Piperonil butóxido (PBO), sinérgico de piretroides, se detectó en el 70\% de las muestras y las concentraciones variaron entre 0,98 a 3,31 ng/g peso seco. Diclorodifeniltricloroetano (DDT) se detectó sólo en el sitio Luna 2 en baja concentración (0,29 ng/g peso seco). Su producto de degradación DDE se detectó en Helves (0,28 ng/g peso seco) y el DDD en los arroyos Luna 2, 3 Horqueta y Cañete en concentraciones de 1,2; 4,4 y 7,3 ng/g peso seco respectivamente. Otros agrotóxicos organoclorados prohibidos que se detectaron en el arroyo Luna 2 incluyeron clordano (gamma y alfa) y el epóxido de heptacloro $(0,32 ; 0,33$ y $0,23 \mathrm{ng} / \mathrm{g}$ peso seco respectivamente). Los organoclorados que se analizaron, pero no se detectaron fueron el lindano, heptacloro, dieldrina, endrina y aldrina. 
Tabla 3.12. Concentraciones detectadas de los compuestos adicionales analizados en sedimentos para los muestreos en Arrecifes, 2013-2014.

\begin{tabular}{|c|c|c|c|c|c|c|c|c|c|c|c|c|c|c|c|c|c|}
\hline \multirow{3}{*}{ Concentracion ng/g ps } & \multicolumn{17}{|c|}{ Arrecifes } \\
\hline & \multicolumn{11}{|c|}{ feb-2013 } & \multicolumn{6}{|c|}{ feb-2014 } \\
\hline & 3HQ & $\mathbf{A N}$ & CA & $\mathrm{CO} 2$ & GO & H5 & HB & HEL & A4 & MG & S2 & $3 H Q$ & A2 & CA & GO & ING & HEL \\
\hline PBO & 1,79 & 3,20 & 3,18 & 1,67 & 1,83 & 2,18 & 1,99 & 2,20 & 3,31 & 1,61 & 1,99 & 1,99 & 0,98 & 2,91 & 1,32 & - & - \\
\hline Permetrina & - & & & & 0,47 & - & - & - & - & - & - & - & - & - & - & - & 0,27 \\
\hline Ciflutrina & - & - & - & - & BRL & - & - & - & - & - & - & - & - & - & - & - & - \\
\hline Deltametrina & - & - & - & - & BRL & - & - & - & - & - & - & - & - & - & - & - & - \\
\hline Esfenvalerato & - & - & - & - & BRL & - & - & - & - & - & - & - & - & - & - & - & - \\
\hline Bifentrina & - & - & - & - & - & - & - & - & - & - & - & - & 2,96 & - & - & BRL & - \\
\hline DDD & - & - & - & - & - & - & - & - & - & - & - & 4,42 & 1,16 & 7,26 & - & - & - \\
\hline DDE & - & - & - & - & - & - & - & - & - & - & - & - & - & - & - & - & 0,28 \\
\hline DDT & - & - & - & - & - & - & - & - & - & - & - & - & 0,29 & - & - & - & - \\
\hline Alpha Clordano & - & - & - & - & - & - & - & - & - & - & - & - & 0,33 & - & - & - & - \\
\hline Gamma Clordano & - & - & - & - & - & - & - & - & - & - & - & - & 0,32 & - & - & - & - \\
\hline Epoxido de Heptacloro & - & - & - & - & - & - & - & - & - & - & - & - & 0,23 & - & - & - & - \\
\hline
\end{tabular}

\section{Unidades Tóxicas (UT)}

En los muestreos realizados en Arrecifes 2013 y 2014, se puede observar que los valores máximos de UT-Totales fueron 0,46 y 0,34 respectivamente (Tabla 3.13). Los piretroides, principalmente lambda-cialotrina, son los que más contribuyen a los valores de UT-totales, seguido por los valores de clorpirifos. Las UT de endosulfán y su producto de degradación, endosulfán sulfato, mayormente resultaron inferiores a 0,003. En este período, ninguna concentración de los agrotóxicos superó la mitad de la dosis letal 50 para H. curvispina. 
Tabla 3.13. Unidades Tóxicas de los biocidas más utilizados calculados para cada arroyo muestreado en Arrecifes 2013-2014.

\begin{tabular}{|c|c|c|c|c|c|c|c|}
\hline Fecha & Sitio & UT Clorp $^{a}$ & UT $\lambda$-Cialo $^{a}$ & UT Ciper $^{a}$ & UT Endo $^{a}$ & UT Endo-Sul ${ }^{b}$ & UT total \\
\hline \multirow{12}{*}{ 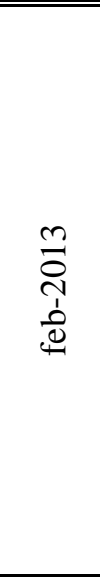 } & $3 \mathrm{HQ}$ & 0,032 & nd & 0,011 & nd & 0,010 & 0,05 \\
\hline & A4 & 0,037 & nd & 0,022 & nd & 0,009 & 0,07 \\
\hline & AN & 0,068 & 0,156 & 0,052 & nd & 0,013 & 0,29 \\
\hline & CA & 0,016 & 0,123 & 0,024 & nd & 0,004 & 0,17 \\
\hline & $\mathrm{CO} 2$ & 0,030 & nd & 0,027 & nd & nd & 0,06 \\
\hline & GO & 0,029 & nd & 0,017 & nd & 0,007 & 0,05 \\
\hline & H5 & 0,038 & nd & 0,027 & nd & 0,014 & 0,08 \\
\hline & HB & 0,127 & nd & 0,064 & nd & nd & 0,19 \\
\hline & HEL & 0,025 & 0,111 & 0,011 & nd & 0,019 & 0,17 \\
\hline & ING & 0,063 & 0,127 & 0,069 & 0,001 & 0,012 & 0,27 \\
\hline & MG & 0,055 & 0,397 & nd & nd & 0,010 & 0,46 \\
\hline & S2 & 0,014 & nd & 0,020 & 0,002 & 0,124 & 0,16 \\
\hline \multirow{12}{*}{ 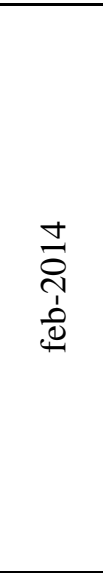 } & $3 \mathrm{HQ}$ & 0,016 & 0,081 & nd & nd & 0,005 & 0,10 \\
\hline & $\mathbf{A 2}$ & 0,053 & 0,102 & nd & 0,002 & 0,016 & 0,17 \\
\hline & AN & 0,046 & 0,282 & nd & nd & 0,010 & 0,34 \\
\hline & CA & 0,014 & 0,070 & 0,024 & nd & 0,005 & 0,11 \\
\hline & $\mathrm{CO} 2$ & 0,035 & 0,210 & nd & 0,003 & 0,029 & 0,28 \\
\hline & GO & 0,018 & 0,088 & 0,014 & 0,001 & 0,010 & 0,13 \\
\hline & H5 & 0,021 & 0,102 & nd & nd & 0,007 & 0,13 \\
\hline & HB & 0,053 & nd & nd & nd & nd & 0,05 \\
\hline & HEL & 0,015 & 0,101 & nd & 0,003 & 0,032 & 0,15 \\
\hline & ING & 0,110 & 0,193 & 0,017 & 0,001 & 0,011 & 0,33 \\
\hline & MG & 0,028 & 0,139 & nd & nd & 0,007 & 0,17 \\
\hline & $\mathbf{S 2}$ & \multicolumn{6}{|c|}{ NA } \\
\hline \multicolumn{8}{|c|}{${ }^{\mathrm{a}}: \mathrm{LC}_{50}$ para Hyalella curvispina } \\
\hline do & 2 & $\begin{array}{l}\text { UT to } \\
\text { Horque }\end{array}$ & IDda & 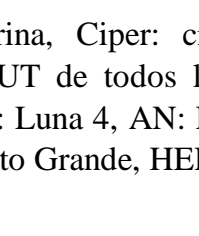 & rmetrina, & do: endosulfán & Endo- \\
\hline
\end{tabular}

\section{Ensamble de macroinvertebrados}

Los macroinvertebrados identificados corresponden a 64 entidades taxonómicas diferentes (Tabla 3.14). Los ensambles de los arroyos exhibieron diferencias entre ellos, aunque todos registraron una elevada abundancia de la clase Oligochaeta, Gastropoda, Bivalvia y del orden Diptera (Chironomidae), Ephemeroptera (Baetidae y Caenidae) y Odonata (Coenagrionidae). Algunos arroyos se encontraron bien representados por Hirudinea, el anfípodo Hyalella y el coleóptero Elmidae. 
Tabla 3.14. Abundancia (ind $/ \mathrm{m}^{2}$ ) media de cada taxón colectado durante el período 2011-2014 para cada uno de los arroyos muestreados en Arrecifes.

\begin{tabular}{|c|c|c|c|c|c|c|c|c|c|c|c|c|c|c|c|c|c|c|}
\hline \multicolumn{2}{|c|}{$\left(\right.$ ind $\left./ \mathrm{m}^{2}\right)$} & \multicolumn{17}{|c|}{ Arrecifes } \\
\hline Filo u Orden & Taxones & $3 \mathrm{HQ}$ & $\mathbf{A 2}$ & $\mathbf{A 3}$ & A4 & $\mathbf{A N}$ & $\mathbf{C A}$ & $\mathrm{CO1}$ & $\mathrm{CO2}$ & GO & Ho & $\mathbf{H 2}$ & H5 & HB & HEL & ING & MG & S2 \\
\hline Platyhelminthes & & 2 & 1 & 1 & 82 & $\mathbf{0}$ & 2 & $\mathbf{0}$ & 2 & 1 & $\mathbf{0}$ & 1 & 1 & $\mathbf{0}$ & 1 & 1 & 2 & 6 \\
\hline Oligochaeta & & 25 & 75 & 178 & 48 & 7 & 4 & 74 & 27 & 12 & 7 & 14 & 47 & 38 & 28 & 28 & 20 & $\mathbf{5 0}$ \\
\hline Hirudinea & & 10 & 1 & 2 & 1 & 1 & 8 & 31 & 2 & 2 & 10 & 2 & 1 & $\mathbf{0}$ & 1 & 1 & $\mathbf{0}$ & 98 \\
\hline Nematoda & & 3 & $\mathbf{0}$ & $\mathbf{0}$ & $\mathbf{0}$ & $\mathbf{0}$ & $\mathbf{0}$ & $\mathbf{0}$ & 2 & 2 & $\mathbf{0}$ & $\mathbf{0}$ & 3 & 1 & 1 & $\mathbf{0}$ & 1 & 41 \\
\hline Nemertea & & $\mathbf{0}$ & $\mathbf{0}$ & $\mathbf{0}$ & $\mathbf{0}$ & $\mathbf{0}$ & $\mathbf{0}$ & $\mathbf{0}$ & 6 & $\mathbf{0}$ & $\mathbf{0}$ & $\mathbf{0}$ & 1 & $\mathbf{0}$ & $\mathbf{0}$ & 1 & 1 & 6 \\
\hline Mollusca & & 184 & 27 & 127 & 1 & 6 & 194 & 8 & 21 & 31 & 2 & 8 & 60 & 1 & 25 & 53 & 565 & 684 \\
\hline Bivalvia & & 172 & 11 & 1 & 1 & 1 & 13 & 4 & 1 & 18 & 0 & 0 & 55 & 0 & 13 & 8 & 27 & 28 \\
\hline \multirow[t]{3}{*}{ Gastropoda } & & 12 & 16 & 126 & 0 & 5 & 182 & 4 & 20 & 13 & 2 & 8 & 6 & 1 & 12 & 45 & 538 & 656 \\
\hline & Ancylidae & 0 & 1 & 0 & 0 & 0 & 137 & 0 & 19 & 0 & 0 & 0 & 0 & 0 & 1 & 0 & 3 & 2 \\
\hline & Gastropoda inid & 12 & 15 & 126 & 0 & 5 & 45 & 4 & 2 & 13 & 2 & 8 & 6 & 1 & 11 & 45 & 535 & 654 \\
\hline Crustacea & & 111 & 2 & 3 & 40 & 5 & 93 & 10 & 7 & 5 & 25 & 16 & 6 & 1 & 68 & 7 & 8 & 4 \\
\hline Amphipoda & Hyalellidae & 95 & 1 & 2 & 33 & 3 & 92 & 1 & 5 & 4 & 19 & 16 & 1 & 0 & 65 & 6 & 2 & 1 \\
\hline \multirow[t]{3}{*}{ Decapoda } & & 0 & 1 & 1 & 0 & 2 & 0 & 0 & 1 & 1 & 6 & 0 & 1 & 0 & 1 & 1 & 6 & 1 \\
\hline & Aeglidae & 0 & 1 & 1 & 0 & 0 & 0 & 0 & 1 & 1 & 6 & 0 & 1 & 0 & 0 & 0 & 0 & 1 \\
\hline & Palaemonidae & 0 & 0 & 0 & 0 & 2 & 0 & 0 & 0 & 0 & 0 & 0 & 0 & 0 & 1 & 1 & 6 & 0 \\
\hline Ostracoda & & 15 & 0 & 0 & 7 & 0 & 1 & 9 & 1 & 1 & 0 & 0 & 5 & 1 & 2 & 0 & 0 & 1 \\
\hline Acari & & 3 & 1 & $\mathbf{0}$ & 1 & $\mathbf{0}$ & 1 & $\mathbf{0}$ & 2 & 11 & $\mathbf{0}$ & 1 & 1 & 1 & 1 & 1 & $\mathbf{0}$ & 1 \\
\hline \multirow[t]{4}{*}{ Collembola } & & $\mathbf{0}$ & $\mathbf{0}$ & 1 & 8 & 1 & $\mathbf{0}$ & $\mathbf{0}$ & $\mathbf{0}$ & 2 & 1 & $\mathbf{0}$ & 1 & 1 & 2 & $\mathbf{0}$ & 1 & 1 \\
\hline & Entomobryidae & 0 & 0 & 0 & 1 & 1 & 0 & 0 & 0 & 2 & 0 & 0 & 1 & 0 & 1 & 0 & 0 & 0 \\
\hline & Poduridea & 0 & 0 & 0 & 0 & 0 & 0 & 0 & 0 & 0 & 0 & 0 & 0 & 1 & 1 & 0 & 1 & 0 \\
\hline & Collembola ind. & 0 & 0 & 1 & 7 & 0 & 0 & 0 & 0 & 0 & 1 & 0 & 0 & 0 & 0 & 0 & 0 & 1 \\
\hline \multicolumn{19}{|l|}{ Insecta } \\
\hline \multirow[t]{5}{*}{ Ephemeroptera } & & 963 & 55 & 2 & 740 & 42 & 55 & 1 & 439 & 133 & 35 & $\mathbf{0}$ & 17 & 14 & 59 & 34 & 38 & 53 \\
\hline & Baetidae & 926 & 1 & 0 & 666 & 15 & 40 & 1 & 359 & 112 & 20 & 0 & 2 & 1 & 6 & 10 & 21 & 28 \\
\hline & Caenidae & 32 & 52 & 1 & 63 & 14 & 13 & 0 & 76 & 21 & 13 & 0 & 11 & 1 & 52 & 24 & 14 & 20 \\
\hline & Leptohyphidae & 1 & 1 & 1 & 11 & 13 & 2 & 0 & 4 & 1 & 2 & 0 & 5 & 11 & 0 & 0 & 1 & 5 \\
\hline & Ephemerop inid. & 4 & 1 & 0 & 0 & 0 & 0 & 0 & 0 & 0 & 0 & 0 & 0 & 1 & 0 & 0 & 2 & 0 \\
\hline \multirow[t]{6}{*}{ Odonata } & & 23 & $\mathbf{0}$ & $\mathbf{0}$ & 54 & 33 & 25 & 3 & 23 & 2 & $\mathbf{0}$ & 1 & $\mathbf{0}$ & 16 & 7 & 12 & 3 & 23 \\
\hline & Calopterygidae & 1 & 0 & 0 & 1 & 1 & 0 & 0 & 0 & 0 & 0 & 0 & 0 & 0 & 0 & 0 & 1 & 0 \\
\hline & Coenagrionidae & 21 & 0 & 0 & 53 & 32 & 8 & 2 & 14 & 1 & 0 & 1 & 0 & 9 & 7 & 9 & 1 & 13 \\
\hline & Libellulidae & 0 & 0 & 0 & 0 & 0 & 0 & 1 & 0 & 0 & 0 & 0 & 0 & 0 & 0 & 1 & 0 & 0 \\
\hline & Anisoptera inid. & 0 & 0 & 0 & 0 & 0 & 1 & 0 & 0 & 0 & 0 & 0 & 0 & 0 & 0 & 0 & 0 & 0 \\
\hline & Zygoptera inid. & 1 & 0 & 0 & 0 & 0 & 15 & 0 & 9 & 1 & 0 & 0 & 0 & 7 & 0 & 2 & 1 & 11 \\
\hline Heteroptera & & 1 & $\mathbf{0}$ & 1 & 4 & 2 & 2 & 1 & 1 & $\mathbf{0}$ & $\mathbf{0}$ & $\mathbf{0}$ & $\mathbf{0}$ & 1 & 2 & 4 & $\mathbf{0}$ & 2 \\
\hline & Belostomatidae & 0 & 0 & 0 & 1 & 1 & 1 & 0 & 0 & 0 & 0 & 0 & 0 & 1 & 1 & 1 & 0 & 0 \\
\hline & Corixidae & 0 & 0 & 0 & 0 & 0 & 0 & 1 & 0 & 0 & 0 & 0 & 0 & 0 & 0 & 1 & 0 & 0 \\
\hline & Gerridae & 0 & 0 & 1 & 0 & 0 & 0 & 0 & 1 & 0 & 0 & 0 & 0 & 0 & 0 & 0 & 0 & 0 \\
\hline & Hebridae & 0 & 0 & 0 & 1 & 0 & 0 & 0 & 0 & 0 & 0 & 0 & 0 & 0 & 0 & 1 & 0 & 0 \\
\hline & Helotrephidae & 0 & 0 & 0 & 0 & 0 & 0 & 0 & 0 & 0 & 0 & 0 & 0 & 0 & 0 & 1 & 0 & 0 \\
\hline & Mesoveliidae & 0 & 0 & 0 & 1 & 0 & 0 & 0 & 0 & 0 & 0 & 0 & 0 & 0 & 0 & 0 & 0 & 0 \\
\hline & Naucoridae & 0 & 0 & 0 & 0 & 0 & 0 & 0 & 0 & 0 & 0 & 0 & 0 & 0 & 0 & 0 & 0 & 1 \\
\hline & Notonectidae & 0 & 0 & 0 & 0 & 0 & 0 & 0 & 0 & 0 & 0 & 0 & 0 & 0 & 1 & 0 & 0 & 0 \\
\hline & Pleidae & 1 & 0 & 0 & 1 & 1 & 1 & 0 & 0 & 0 & 0 & 0 & 0 & 0 & 0 & 1 & 0 & 1 \\
\hline Trichoptera & & 4 & $\mathbf{0}$ & $\mathbf{0}$ & 6 & $\mathbf{0}$ & 2 & $\mathbf{0}$ & 10 & 3 & $\mathbf{0}$ & $\mathbf{0}$ & $\mathbf{0}$ & 4 & 1 & 20 & 2 & 5 \\
\hline & Hydropsychidae & 3 & 0 & 0 & 5 & 0 & 1 & 0 & 5 & 2 & 0 & 0 & 0 & 1 & 0 & 20 & 2 & 1 \\
\hline & Hydroptilidae & 1 & 0 & 0 & 1 & 0 & 1 & 0 & 6 & 1 & 0 & 0 & 0 & 3 & 1 & 0 & 0 & 3 \\
\hline & Trichoptera inid. & 0 & 0 & 0 & 0 & 0 & 0 & 0 & 0 & 0 & 0 & 0 & 0 & 0 & 0 & 0 & 0 & 1 \\
\hline Lepidoptera & & 2 & $\mathbf{0}$ & $\mathbf{0}$ & 1 & 2 & 2 & $\mathbf{0}$ & 6 & $\mathbf{0}$ & $\mathbf{0}$ & $\mathbf{0}$ & $\mathbf{0}$ & $\mathbf{0}$ & $\mathbf{0}$ & 1 & $\mathbf{0}$ & 1 \\
\hline & Crambidae & 1 & 0 & 0 & 1 & 1 & 2 & 0 & 0 & 0 & 0 & 0 & 0 & 0 & 0 & 1 & 0 & 1 \\
\hline & Noctuidae & 0 & 0 & 0 & 0 & 1 & 0 & 0 & 0 & 0 & 0 & 0 & 0 & 0 & 0 & 0 & 0 & 0 \\
\hline & Lepidoptera inid. & 1 & 0 & 0 & 0 & 0 & 0 & 0 & 6 & 0 & 0 & 0 & 0 & 0 & 0 & 0 & 0 & 0 \\
\hline Diptera & & 81 & 22 & 13 & 115 & 33 & 67 & 132 & 106 & 41 & 50 & 206 & 169 & 168 & 35 & 28 & 39 & 144 \\
\hline & Ceratopogonidae & 1 & 1 & 0 & 1 & 0 & 1 & 0 & 4 & 1 & 16 & 0 & 1 & 1 & 0 & 1 & 1 & 4 \\
\hline & Chironomidae & 78 & 21 & 13 & 105 & 33 & 54 & 130 & 94 & 37 & 35 & 205 & 169 & 165 & 33 & 23 & 37 & 135 \\
\hline & Culicidae & 0 & 0 & 0 & 1 & 0 & 0 & 1 & 1 & 0 & 0 & 0 & 0 & 0 & 1 & 0 & 0 & 0 \\
\hline & Empididae & 0 & 0 & 0 & 0 & 0 & 0 & 0 & 1 & 0 & 0 & 0 & 0 & 1 & 0 & 1 & 0 & 1 \\
\hline & Ephydridae & 1 & 0 & 0 & 0 & 0 & 11 & 0 & 0 & 0 & 0 & 0 & 0 & 0 & 0 & 1 & 0 & 1 \\
\hline & Muscidae & 0 & 0 & 0 & 0 & 0 & 0 & 0 & 1 & 0 & 0 & 0 & 0 & 0 & 1 & 0 & 0 & 0 \\
\hline & Simuliidae & 1 & 0 & 0 & 0 & 0 & 0 & 0 & 5 & 3 & 0 & 0 & 0 & 1 & 0 & 1 & 1 & 1 \\
\hline & Stratiomyidae & 0 & 0 & 0 & 8 & 0 & 1 & 1 & 0 & 0 & 0 & 0 & 0 & 0 & 0 & 1 & 0 & 1 \\
\hline & Syrphidae & 0 & 0 & 0 & 0 & 0 & 0 & 0 & 0 & 0 & 0 & 1 & 0 & 0 & 0 & 0 & 0 & 0 \\
\hline
\end{tabular}




\begin{tabular}{llccccccccccccccccc} 
Coleoptera & & $\mathbf{8}$ & $\mathbf{5}$ & $\mathbf{1}$ & $\mathbf{1 0}$ & $\mathbf{5}$ & $\mathbf{1 1}$ & $\mathbf{2}$ & $\mathbf{0}$ & $\mathbf{3 1}$ & $\mathbf{2}$ & $\mathbf{0}$ & $\mathbf{1 2}$ & $\mathbf{2}$ & $\mathbf{6}$ & $\mathbf{1 8}$ & $\mathbf{5}$ & $\mathbf{5 8}$ \\
& Curculionidae & 0 & 0 & 0 & 0 & 0 & 1 & 0 & 0 & 0 & 0 & 0 & 0 & 0 & 0 & 0 & 0 & 0 \\
& Dytiscidae & 1 & 0 & 0 & 2 & 1 & 1 & 0 & 0 & 0 & 0 & 0 & 0 & 0 & 0 & 0 & 0 & 2 \\
& Elmidae & 4 & 5 & 1 & 0 & 1 & 7 & 0 & 0 & 29 & 0 & 0 & 2 & 1 & 5 & 15 & 5 & 47 \\
& Hexacylloepus & 1 & 0 & 0 & 0 & 1 & 0 & 0 & 0 & 2 & 0 & 0 & 11 & 0 & 0 & 0 & 0 & 0 \\
& Hydrophilidae & 0 & 0 & 0 & 1 & 0 & 0 & 0 & 0 & 0 & 0 & 0 & 0 & 0 & 0 & 1 & 0 & 3 \\
& Berossus & 0 & 0 & 0 & 1 & 0 & 0 & 1 & 0 & 0 & 1 & 0 & 0 & 1 & 0 & 0 & 0 & 0 \\
& Deralus & 0 & 0 & 0 & 0 & 0 & 0 & 0 & 0 & 0 & 0 & 0 & 0 & 0 & 0 & 0 & 0 & 1 \\
& Enochrus & 0 & 0 & 0 & 2 & 0 & 0 & 1 & 0 & 0 & 0 & 0 & 0 & 0 & 0 & 0 & 0 & 0 \\
& Helobata & 0 & 0 & 0 & 0 & 1 & 1 & 0 & 0 & 0 & 0 & 0 & 0 & 0 & 0 & 0 & 0 & 0 \\
& Tropisternus & 0 & 0 & 0 & 1 & 0 & 0 & 0 & 0 & 0 & 0 & 0 & 0 & 0 & 0 & 0 & 0 & 1 \\
& Noteridae & 1 & 0 & 0 & 3 & 1 & 1 & 0 & 0 & 0 & 0 & 0 & 0 & 0 & 1 & 2 & 0 & 1 \\
& Scarabaeidae & 0 & 0 & 0 & 0 & 0 & 0 & 0 & 0 & 0 & 0 & 0 & 0 & 0 & 0 & 0 & 0 & 1 \\
& Scirtidae & 1 & 0 & 0 & 0 & 1 & 0 & 0 & 0 & 0 & 1 & 0 & 0 & 0 & 0 & 0 & 0 & 0 \\
& Sphaeriusidae & 0 & 0 & 0 & 0 & 0 & 0 & 0 & 0 & 0 & 0 & 0 & 0 & 0 & 0 & 0 & 0 & 1 \\
\hline Abundancia media total & $\mathbf{1 4 1 7}$ & $\mathbf{1 8 8}$ & $\mathbf{3 2 7}$ & $\mathbf{1 1 0 9}$ & $\mathbf{1 3 5}$ & $\mathbf{4 6 5}$ & $\mathbf{2 6 2}$ & $\mathbf{6 4 7}$ & $\mathbf{2 7 5}$ & $\mathbf{1 3 3}$ & $\mathbf{2 4 9}$ & $\mathbf{3 2 1}$ & $\mathbf{2 4 7}$ & $\mathbf{2 3 5}$ & $\mathbf{2 0 8}$ & $\mathbf{6 8 5}$ & $\mathbf{1 1 7 6}$ \\
Riqueza media & & $\mathbf{3 0}$ & $\mathbf{1 6}$ & $\mathbf{1 3}$ & $\mathbf{3 1}$ & $\mathbf{2 3}$ & $\mathbf{2 9}$ & $\mathbf{1 6}$ & $\mathbf{2 7}$ & $\mathbf{2 3}$ & $\mathbf{1 3}$ & $\mathbf{1 0}$ & $\mathbf{1 9}$ & $\mathbf{2 1}$ & $\mathbf{2 4}$ & $\mathbf{3 1}$ & $\mathbf{2 2}$ & $\mathbf{3 9}$ \\
\hline
\end{tabular}

3HQ: 3Horqueta, A2: Luna 2, A3: Luna 3, A4: Luna 4, AN: Las Animas, CA: Cañete, CO1: Contador 1, CO2: Contador 2, GO: Gomez, H0: Horqueta 0, H2: Horqueta 2, H5: Horqueta 5, HB: Río Saladito Grande, HEL: Helves, ING: Los Ingleses, MG: Maguire, S2: Salto 2. inid: inidentificado.

En el análisis CLUSTER realizado con los datos de abundancia (ind $/ \mathrm{m}^{2}$ ) de los macroinvertebrados, se observan agrupamientos relacionados por la fecha de muestreo (Figura 3.2). Los relevamientos realizados en marzo de 2012 se concentraron en el grupo B, los de febrero 2013 en el grupo E y los de febrero 2014 en D. Los arroyos analizados en enero y abril 2012 mostraron un agrupamiento por sitio. El grupo A, está formado por el sitio Contador 1 (CO1) y Horqueta $2(\mathrm{H} 2)$ mientras que el grupo F contiene a Maguire (MG) y Horqueta $0(\mathrm{H} 0)$, que también aparecen agrupados en otros muestreos, en el grupo C. 


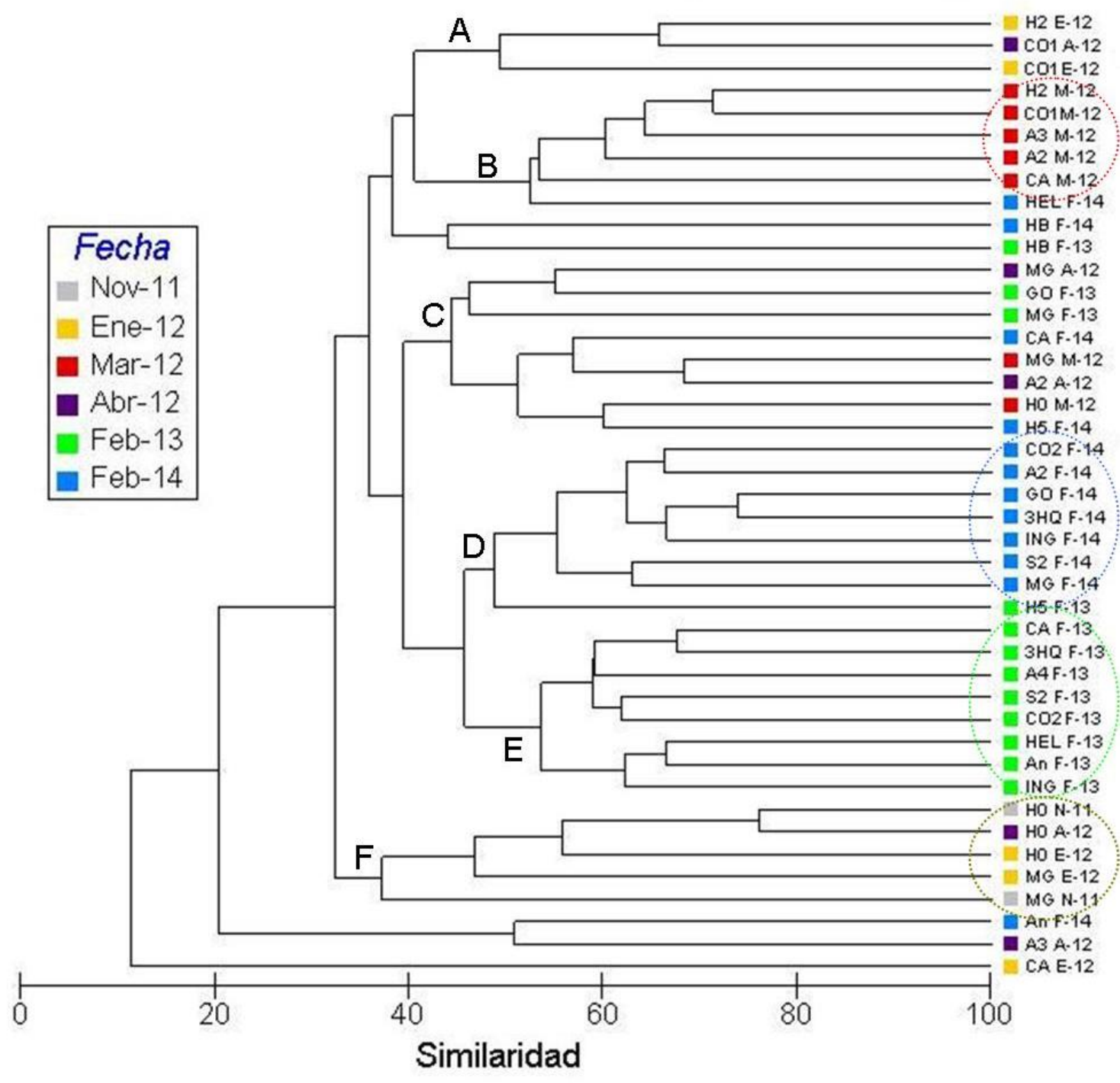

Figura. 3.2. Cluster del ensamble de macroinvertebrados durante el período muestreado 2011-2014 (N-11, E-12, M-12, A-12, F-13 y F-14) para los sitios de Arrecifes (MG: Maguire, ING: Los Ingleses, CA: Cañete, HEL: Helves, 3HQ: 3Horqueta, AN: Las Animas, S2: Salto 2, HB: Río Saladito Grande, CO1: Contador 1, CO2: Contador 2, A2: Luna 2, A3: Luna 3, A4: Luna 4, GO: Gómez, H0: Horqueta 0, H2: Horqueta 2, H5: Horqueta 5).

El análisis ANOSIM realizado para los grupos formados por el CLUSTER, muestra que existen diferencias significativas entre ellos (Global R:0,76; p:0,001). Todos los grupos resultaron significativamente distintos entre sí (Tabla 3.15). 
Tabla 3.15. Valores del análisis ANOSIM para los test de a pares que resultaron significativamente distintos. Se informa el R de cada par y el nivel de significancia.

\begin{tabular}{lcc}
\hline Pares & Estadístico R & Significancia \\
\hline \hline Grupo A vs. Grupo B & 0,69 & 0,012 \\
Grupo A vs. Grupo C & 0,89 & 0,006 \\
Grupo A vs. Grupo D & 0,84 & 0,006 \\
Grupo A vs. Grupo E & 0,99 & 0,006 \\
Grupo A vs. Grupo F & 0,58 & 0,018 \\
Grupo B vs. Grupo C & 0,71 & 0,001 \\
Grupo B vs. Grupo D & 0,75 & 0,001 \\
Grupo B vs. Grupo E & 0,99 & 0,001 \\
Grupo B vs. Grupo F & 0,94 & 0,002 \\
Grupo C vs. Grupo D & 0,58 & 0,001 \\
Grupo C vs. Grupo E & 0,76 & 0,001 \\
Grupo C vs. Grupo F & 0,56 & 0,002 \\
Grupo D vs. Grupo E & 0,72 & 0,001 \\
Grupo D vs. Grupo F & 0,90 & 0,002 \\
Grupo E vs. Grupo F & 0,84 & 0,002 \\
\hline
\end{tabular}

En el análisis SIMPER se identificaron 22 grupos taxonómicos como principales contribuyentes a la disimilitud entre las fechas de muestreo. Se observa que la contribución de cada uno de los taxones Oligochaeta, Hirudinea, Nematoda, Platyhelminthes, Acari, Bivalvia, Gastropoda (Ancylidae), Ostracoda, Decapoda (Aeglidae, Paleomonidae), Amphipoda (Hyalellidae), Ephemeroptera (Caenidae, Baetidae, Leptohyphidae), Diptera (Ceratopogonidae, Chironomidae), Odonata (Coenagrionidae y una familia indeterminada del Suborden Zygoptera), Trichoptera (Hydropsychidae) y Coleoptera (Elmidae, Noteridae), difieren entre los distintos grupos. En la Tabla 3.16 se muestran los taxones que contribuyeron aproximadamente en un $70 \%$ a la disimilitud entre los grupos.

Los taxones que constribuyeron a la mayor diferencia en la composición del ensamble del grupo A fueron Hirudinea y Chironomidae. Para el grupo B, el principal aporte a la diferencia fueron Oligochaeta, Gastropoda y Bivalvia. La mayor contribución a la disimilitud en el grupo C estuvo dada por los efemeroptera Caenidae y Baetidae y, el coleóptera Elmidae. Los ensambles del grupo D, formado principalmente por los muestreos de febrero 2014, estuvieron representados por Diptera (Chironomidae, Ceratopogonidae), Oligochaeta, Gastropoda, Bivalvia, Hirudinea y 
Nematoda. Mientras que el grupo E, relevamientos de febrero 2013, se diferenció por los taxones Baetidae, Caenidae, Coenagrionidae y Hyalella. El grupo F, formado por los arroyos Maguire (MG) y Horqueta 0 (H0) con distintas fechas de muestro, se caracterizó por la abundancia de los taxones Crustacea (Hyalella y Aeglidae) y Ephemeroptera (Caenidae y Baetidae).

Tabla 3.16. Resultado del análisis SIMPER. Se muestra el promedio de la abundancia relativa porcentual (\% Abund.) y el porcentaje de contribución (Contrib. \%) de los taxones que aportaron en mayor medida a la disimilitud entre los grupos del CLUSTER.

\begin{tabular}{|c|c|c|c|}
\hline Taxones & \multicolumn{2}{|c|}{ \% Abund } & \% Contrib \\
\hline$\%$ Disimilaridad $=59,4$ & Grupo A & Grupo B & \\
\hline Chironomidae & 5,41 & 2,05 & 18,27 \\
\hline Oligochaeta & 1,94 & 4,00 & 11,89 \\
\hline Hirudinea & 3,02 & 1,06 & 10,75 \\
\hline Gastropoda & 1,08 & 2,42 & 9,66 \\
\hline Hyalella & 1,78 & 0,41 & 8,33 \\
\hline Bivalvia & 0,45 & 1,70 & 8,22 \\
\hline$\%$ Disimilaridad $=72,8$ & Grupo A & Grupo C & \\
\hline Chironomidae & 5,41 & 2,34 & 12,82 \\
\hline Hirudinea & 3,02 & 0,14 & 11,43 \\
\hline Caenidae & 0,00 & 2,12 & 8,72 \\
\hline Baetidae & 0,17 & 2,15 & 7,43 \\
\hline Oligochaeta & 1,94 & 1,11 & 7,42 \\
\hline Elmidae & 0,00 & 1,62 & 6,61 \\
\hline Hyalella & 1,78 & 0,34 & 6,10 \\
\hline Gastropoda & 1,08 & 2,43 & 6,06 \\
\hline$\%$ Disimilaridad $=62,5$ & Grupo A & Grupo D & \\
\hline Caenidae & 0,0 & 3,8 & 11,9 \\
\hline Gastropoda & 1,1 & 3,8 & 8,0 \\
\hline Bivalvia & 0,5 & 3,1 & 7,7 \\
\hline Hirudinea & 3,0 & 1,5 & 6,7 \\
\hline Oligochaeta & 1,9 & 3,9 & 6,5 \\
\hline Elmidae & 0,0 & 2,1 & 6,1 \\
\hline Chironomidae & 5,4 & 4,0 & 4,5 \\
\hline Hyalella & 1,8 & 1,0 & 4,4 \\
\hline Ostracoda & 1,1 & 0,6 & 4,2 \\
\hline Nematoda & 0,0 & 1,4 & 3,8 \\
\hline Ceratopogonidae & 0,0 & 1,2 & 3,7 \\
\hline$\%$ Disimilaridad $=64,8$ & Grupo A & Grupo $\mathbf{E}$ & \\
\hline Baetidae & 0,17 & 4,83 & 10,96 \\
\hline Caenidae & 0,00 & 3,27 & 8,12 \\
\hline Hirudinea & 3,02 & 0,70 & 5,94 \\
\hline Coenagrionidae & 1,10 & 3,46 & 5,80 \\
\hline Hyalella & 1,78 & 3,37 & 5,14 \\
\hline Gastropoda & 1,08 & 2,52 & 4,37 \\
\hline Oligochaeta & 1,94 & 2,50 & 3,86 \\
\hline Ostracoda & 1,12 & 1,16 & 3,72 \\
\hline Leptohyphidae & 0,00 & 1,56 & 3,63 \\
\hline Bivalvia & 0,45 & 1,86 & 3,59 \\
\hline Zygoptera & 0,00 & 1,55 & 3,46 \\
\hline Elmidae & 0,00 & 1,35 & 3,24 \\
\hline Chironomidae & 5,41 & 4,40 & 3,19 \\
\hline Ancylidae & 0,00 & 1,46 & 2,95 \\
\hline
\end{tabular}

\begin{tabular}{|c|c|c|c|}
\hline Taxones & $\% \mathrm{~A}$ & und & $\%$ Contrib \\
\hline$\%$ Disimilaridad $=58,2$ & Grupo C & Grupo D & \\
\hline Oligochaeta & 1,11 & 3,89 & 10,09 \\
\hline Bivalvia & 0,65 & 3,08 & 8,12 \\
\hline Gastropoda & 2,43 & 3,80 & 7,42 \\
\hline Chironomidae & 2,34 & 3,98 & 7,09 \\
\hline Baetidae & 2,15 & 0,86 & 6,36 \\
\hline Caenidae & 2,12 & 3,81 & 6,17 \\
\hline Elmidae & 1,62 & 2,12 & 5,11 \\
\hline Hirudinea & 0,14 & 1,50 & 4,40 \\
\hline Nematoda & 0,23 & 1,37 & 4,13 \\
\hline Ceratopogonidae & 0,08 & 1,21 & 3,86 \\
\hline Acari & 0,19 & 0,95 & 3,32 \\
\hline Hydropsychidae & 0,25 & 0,93 & 3,20 \\
\hline$\%$ Disimilaridad $=62,9$ & Grupo $\mathbf{C}$ & Grupo E & \\
\hline Coenagrionidae & 0,17 & 3,46 & 8,61 \\
\hline Hyalella & 0,34 & 3,37 & 7,74 \\
\hline Baetidae & 2,15 & 4,83 & 7,70 \\
\hline Chironomidae & 2,34 & 4,40 & 5,89 \\
\hline Oligochaeta & 1,11 & 2,50 & 5,47 \\
\hline Gastropoda & 2,43 & 2,52 & 4,48 \\
\hline Bivalvia & 0,65 & 1,86 & 3,87 \\
\hline Caenidae & 2,12 & 3,27 & 3,67 \\
\hline Zygoptera & 0,04 & 1,55 & 3,64 \\
\hline Leptohyphidae & 0,76 & 1,56 & 3,42 \\
\hline Elmidae & 1,62 & 1,35 & 3,28 \\
\hline Ancylidae & 0,17 & 1,46 & 3,27 \\
\hline Noteridae & 0,00 & 1,09 & 2,92 \\
\hline Ostracoda & 0,00 & 1,16 & 2,75 \\
\hline Platyhelminthes & 0,16 & 1,16 & 2,51 \\
\hline$\%$ Disimilaridad $=63,7$ & Grupo $\mathbf{C}$ & Grupo $\mathbf{F}$ & \\
\hline Hyalella & 0,34 & 2,97 & 12,90 \\
\hline Gastropoda & 2,43 & 0,26 & 10,81 \\
\hline Baetidae & 2,15 & 1,98 & 8,57 \\
\hline Chironomidae & 2,34 & 2,76 & 8,38 \\
\hline Elmidae & 1,62 & 0,10 & 8,08 \\
\hline Aeglidae & 0,45 & 1,55 & 6,10 \\
\hline Oligochaeta & 1,11 & 0,52 & 5,87 \\
\hline Caenidae & 2,12 & 1,76 & 5,09 \\
\hline Palaemonidae & 0,55 & 0,36 & 3,75 \\
\hline
\end{tabular}




\begin{tabular}{|c|c|c|c|}
\hline Taxones & $\% \mathrm{~A}$ & und & \% Contrib \\
\hline$\%$ Disimilaridad $=66,6$ & Grupo A & Grupo $\mathbf{F}$ & \\
\hline Chironomidae & 5,41 & 2,76 & 12,87 \\
\hline Hirudinea & 3,02 & 0,79 & 11,63 \\
\hline Baetidae & 0,17 & 1,98 & 8,25 \\
\hline Caenidae & 0,00 & 1,76 & 7,88 \\
\hline Oligochaeta & 1,94 & 0,52 & 7,78 \\
\hline Hyalella & 1,78 & 2,97 & 7,12 \\
\hline Aeglidae & 0,00 & 1,55 & 6,40 \\
\hline Ostracoda & 1,12 & 0,00 & 5,43 \\
\hline$\%$ Disimilaridad $=64,0$ & Grupo B & Grupo $\mathbf{C}$ & \\
\hline Oligochaeta & 4,00 & 1,11 & 16,37 \\
\hline Baetidae & 0,00 & 2,15 & 10,28 \\
\hline Gastropoda & 2,42 & 2,43 & 9,46 \\
\hline Caenidae & 0,52 & 2,12 & 9,05 \\
\hline Elmidae & 0,23 & 1,62 & 8,13 \\
\hline Bivalvia & 1,70 & 0,65 & 8,01 \\
\hline Chironomidae & 2,05 & 2,34 & 7,32 \\
\hline$\%$ Disimilaridad $=56,3$ & Grupo B & Grupo D & \\
\hline Caenidae & 0,52 & 3,81 & 12,71 \\
\hline Gastropoda & 2,42 & 3,80 & 8,70 \\
\hline Chironomidae & 2,05 & 3,98 & 7,83 \\
\hline Bivalvia & 1,70 & 3,08 & 7,38 \\
\hline Elmidae & 0,23 & 2,12 & 7,03 \\
\hline Ceratopogonidae & 0,00 & 1,21 & 4,55 \\
\hline Nematoda & 0,15 & 1,37 & 4,49 \\
\hline Hirudinea & 1,06 & 1,50 & 4,43 \\
\hline Oligochaeta & 4,00 & 3,89 & 4,24 \\
\hline Hyalella & 0,41 & 1,01 & 3,67 \\
\hline Acari & 0,12 & 0,95 & 3,55 \\
\hline$\%$ Disimilaridad $=70,1$ & Grupo B & Grupo $\mathbf{E}$ & \\
\hline Baetidae & 0,00 & 4,83 & 11,42 \\
\hline Coenagrionidae & 0,09 & 3,46 & 8,35 \\
\hline Hyalella & 0,41 & 3,37 & 7,23 \\
\hline Caenidae & 0,52 & 3,27 & 6,90 \\
\hline Chironomidae & 2,05 & 4,40 & 5,77 \\
\hline Gastropoda & 2,42 & 2,52 & 4,75 \\
\hline Bivalvia & 1,70 & 1,86 & 4,58 \\
\hline Oligochaeta & 4,00 & 2,50 & 3,96 \\
\hline Leptohyphidae & 0,00 & 1,56 & 3,63 \\
\hline Zygoptera & 0,00 & 1,55 & 3,45 \\
\hline Elmidae & 0,23 & 1,35 & 3,00 \\
\hline Ancylidae & 0,09 & 1,46 & 2,99 \\
\hline Noteridae & 0,00 & 1,09 & 2,77 \\
\hline$\%$ Disimilaridad $=74,5$ & Grupo B & Grupo $\mathbf{F}$ & \\
\hline Oligochaeta & 4,00 & 0,52 & 16,48 \\
\hline Hyalella & 0,41 & 2,97 & 11,98 \\
\hline Gastropoda & 2,42 & 0,26 & 10,50 \\
\hline Baetidae & 0,00 & 1,98 & 9,16 \\
\hline Chironomidae & 2,05 & 2,76 & 7,64 \\
\hline Bivalvia & 1,70 & 0,26 & 7,49 \\
\hline Aeglidae & 0,09 & 1,55 & 6,50 \\
\hline
\end{tabular}

\begin{tabular}{|c|c|c|c|}
\hline \multirow{2}{*}{$\begin{array}{c}\text { Taxones } \\
\% \text { Disimilaridad }=54,3\end{array}$} & \multicolumn{2}{|c|}{$\%$ Abund } & \multirow[t]{2}{*}{$\%$ Contrib } \\
\hline & Grupo D & Grupo E & \\
\hline Baetidae & 0,86 & 4,83 & 9,20 \\
\hline Coenagrionidae & 0,28 & 3,46 & 7,38 \\
\hline Hyalella & 1,01 & 3,37 & 5,78 \\
\hline Gastropoda & 3,80 & 2,52 & 5,50 \\
\hline Bivalvia & 3,08 & 1,86 & 5,22 \\
\hline Elmidae & 2,12 & 1,35 & 3,93 \\
\hline Oligochaeta & 3,89 & 2,50 & 3,51 \\
\hline Zygoptera & 0,00 & 1,55 & 3,31 \\
\hline Leptohyphidae & 0,40 & 1,56 & 3,29 \\
\hline Ancylidae & 0,32 & 1,46 & 3,15 \\
\hline Nematoda & 1,37 & 0,11 & 2,93 \\
\hline Hirudinea & 1,50 & 0,70 & 2,88 \\
\hline Hydropsychidae & 0,93 & 1,01 & 2,81 \\
\hline Platyhelminthes & 1,09 & 1,16 & 2,74 \\
\hline Ostracoda & 0,64 & 1,16 & 2,63 \\
\hline Chironomidae & 3,98 & 4,40 & 2,61 \\
\hline Noteridae & 0,00 & 1,09 & 2,56 \\
\hline$\%$ Disimilaridad $=68,3$ & Grupo D & Grupo $\mathbf{F}$ & \\
\hline Oligochaeta & $3,8,89$ & 0,52 & $\overline{10,04}$ \\
\hline Gastropoda & 3,80 & 0,26 & 9,79 \\
\hline Bivalvia & 3,08 & 0,26 & 7,94 \\
\hline Caenidae & 3,81 & 1,76 & 6,37 \\
\hline Hyalella & 1,01 & 2,97 & 5,96 \\
\hline Elmidae & 2,12 & 0,10 & 5,72 \\
\hline Chironomidae & 3,98 & 2,76 & 5,28 \\
\hline Baetidae & 0,86 & 1,98 & 5,24 \\
\hline Hirudinea & 1,50 & 0,79 & 4,45 \\
\hline Ceratopogonidae & 1,21 & 0,88 & 4,09 \\
\hline Aeglidae & 0,28 & 1,55 & 3,97 \\
\hline$\%$ Disimilaridad $=64,4$ & Grupo E & Grupo F & \\
\hline Coenagrionidae & 3,46 & 0,10 & 8,74 \\
\hline Baetidae & 4,83 & 1,98 & 7,24 \\
\hline Gastropoda & 2,52 & 0,26 & 5,79 \\
\hline Oligochaeta & 2,50 & 0,52 & 5,54 \\
\hline Chironomidae & 4,40 & 2,76 & 4,93 \\
\hline Bivalvia & 1,86 & 0,26 & 4,20 \\
\hline Caenidae & 3,27 & 1,76 & 4,11 \\
\hline Aeglidae & 0,00 & 1,55 & 3,87 \\
\hline Hyalella & 3,37 & 2,97 & 3,83 \\
\hline Leptohyphidae & 1,56 & 0,22 & 3,72 \\
\hline Zygoptera & 1,55 & 0,17 & 3,55 \\
\hline Elmidae & 1,35 & 0,10 & 3,29 \\
\hline Ancylidae & 1,46 & 0,00 & 3,08 \\
\hline Noteridae & 1,09 & 0,00 & 2,91 \\
\hline Turbellaria & 1,16 & 0,47 & 2,80 \\
\hline
\end{tabular}

Los arroyos Horqueta (H0) y Maguire (MG) muestran características distintivas. El arroyo Horqueta registra abundante vegetación ribereña y ha sido represado, aguas arriba del sitio de muestreo, con fines recreativos en el camping de Capitán Sarmiento. Asimismo, las margenes del arroyo se encuentran densamente forestados aguas arriba de la represa (Figura 3.3 y 3.4). 


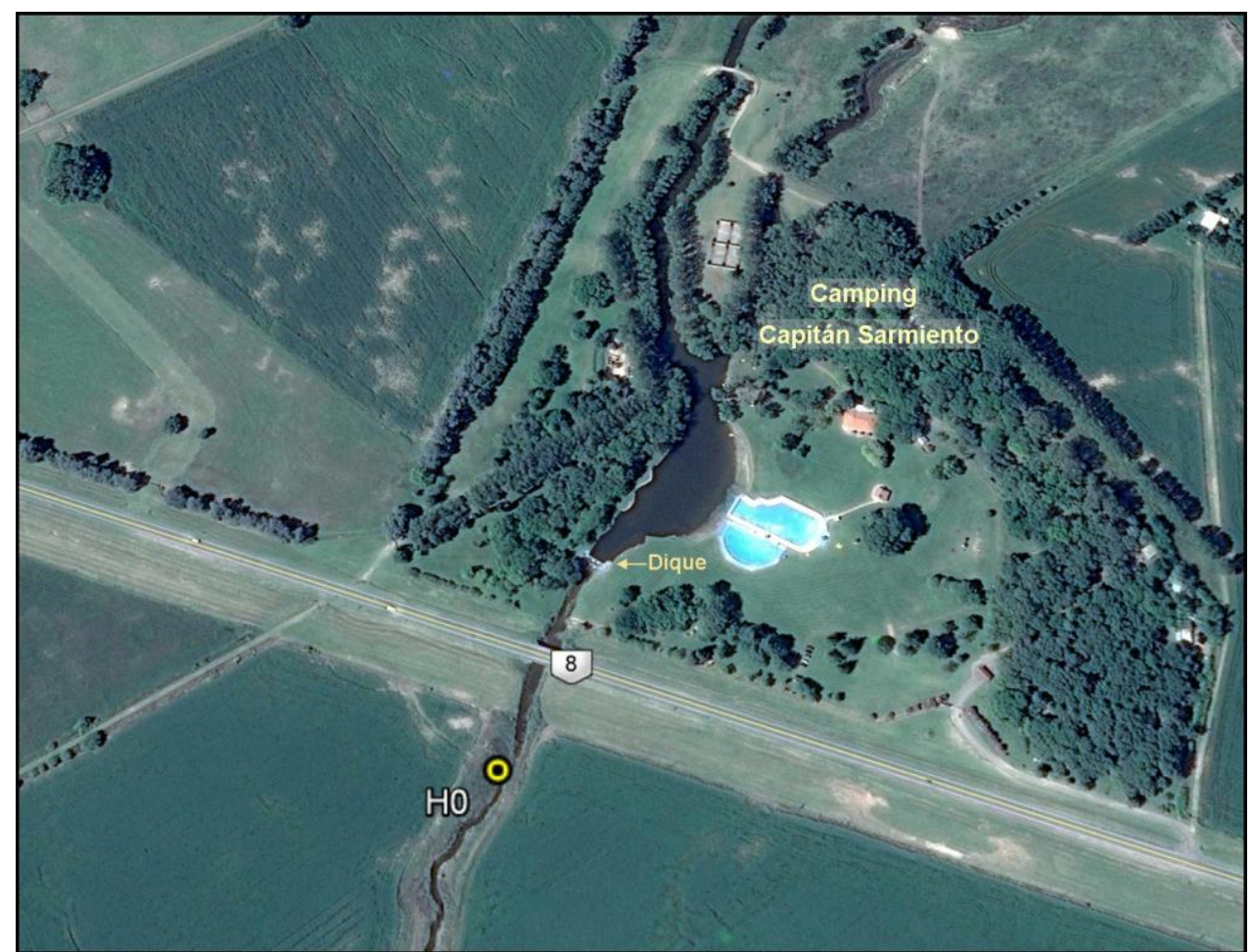

Figura 3.3. Foto satelital del sitio de muestreo en el arroyo Horqueta (H0).

Horqueta presentó comparativamente bajas concentraciones de agrotóxicos y una composición caracterizada por una mayor proporción de taxones sensibles a los mismos, como los crustáceos Aeglidae y Hyalellidae y los efemeropteros Caenidae y Baetidae.



Figura 3.4. Arroyo Horqueta (H0) en enero, marzo y abril de 2012. 
El arroyo Maguire es distinto a los demas porque desarrolla un humedal a poca distancia aguas arriba del sitio de muestreo y cuenta con un valle aluvial desarrollado con abundante vegetación (Figura 3.5 y 3.6).

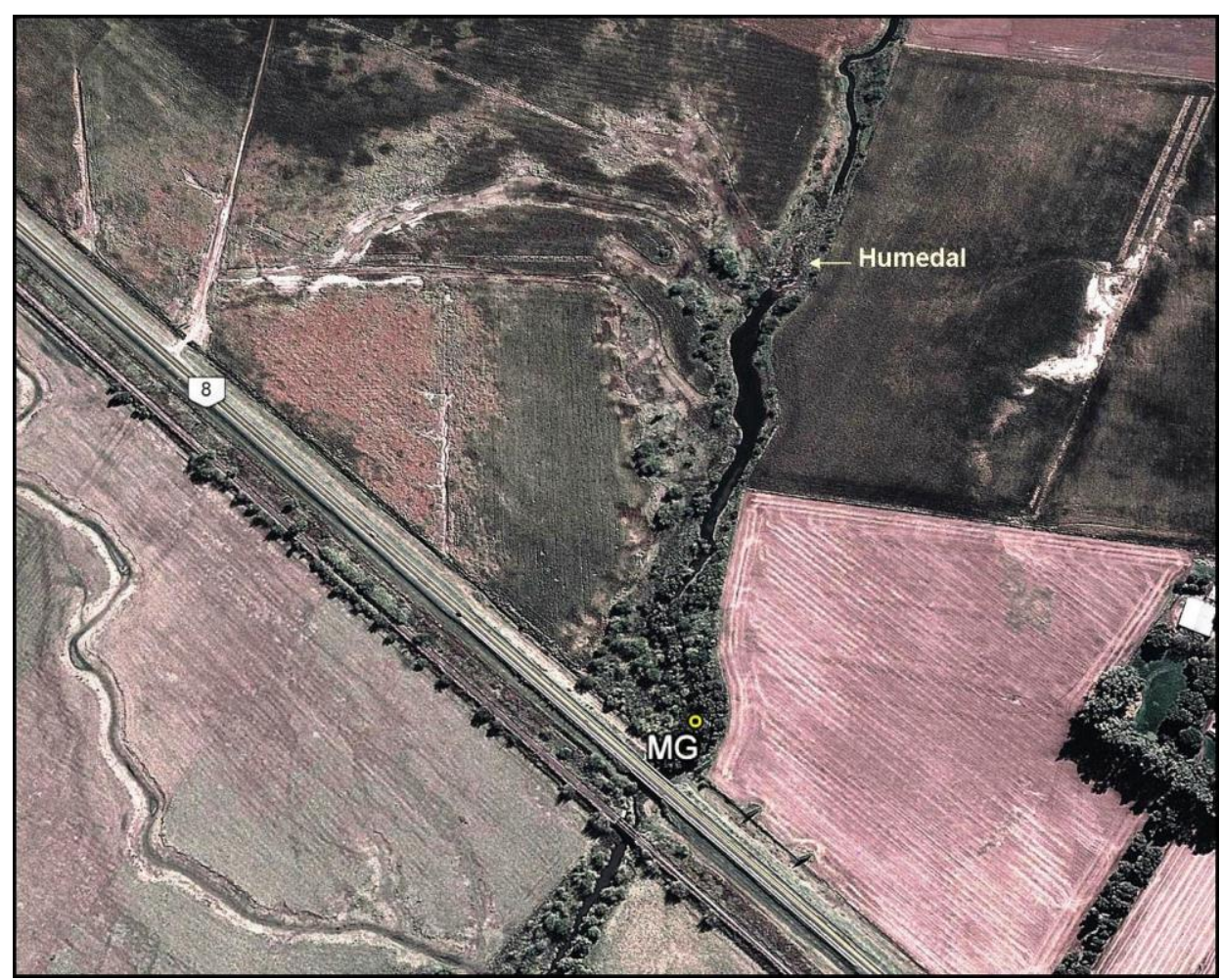

Figura 3.5. Foto satelital del sitio de muestreo en el arroyo Maguire (MG).

El arroyo Maguire mostró también bajas concentraciones de agrotóxicos en varios muestreos de 2011 y 2012, junto a una elevada proporción de taxones consideradas sensibles: Hyalellidae y Paleomonidae (Crustacea); Baetidae y Caenidae (Ephemeroptera) y Elmidae (Coleoptera). No obstante, en los muestreos realizados en febrero 2013 y 2014 Gastropoda fue el grupo taxonómico predominante.

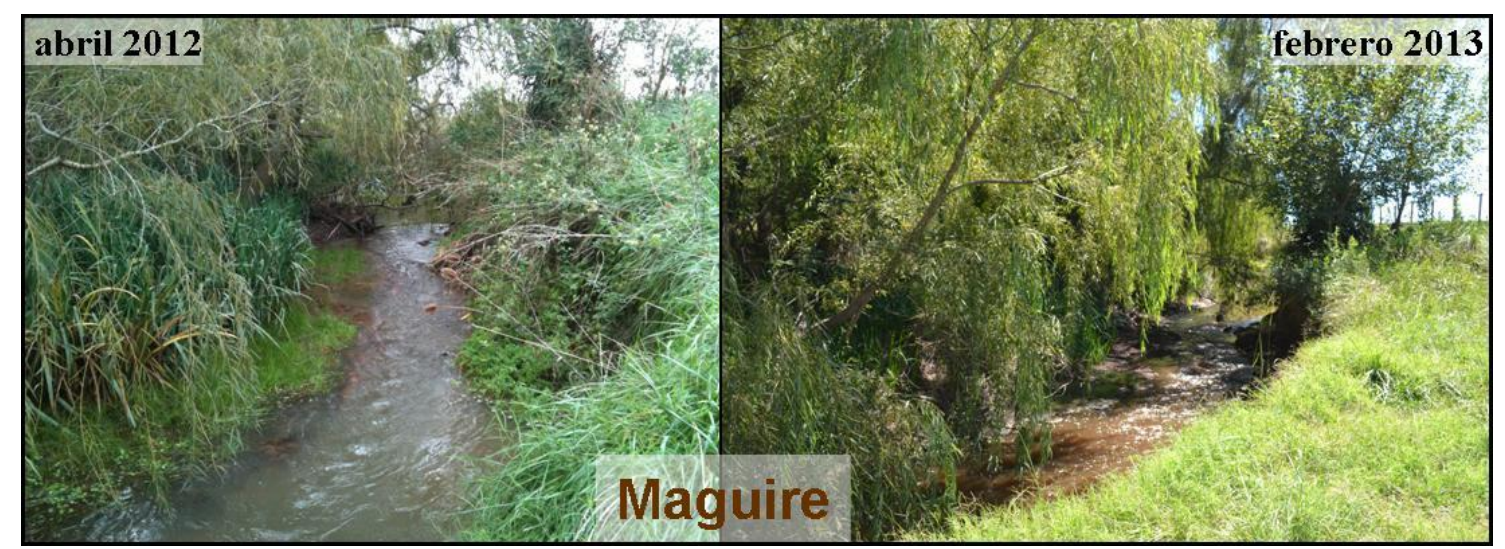

Figura 3.6. Arroyo Maguire (MG) en abril de 2012 y febrero de 2013. 
Las características particulares en ambos arroyos, $\mathrm{H} 0$ y MG, favorecerían la presencia de taxones sensibles, los cuales contribuyen a las diferencias entre los ensambles detectadas por el análisis SIMPER.

Con la finalidad de poder comparar entre los distintos años de muestreo, se realizó un ANOSIM agrupando los ensambles de los arroyos sólo teniendo en cuenta la fecha de relevamiento. El análisis mostró que existen diferencias significativas entre ellos (Global R:0,44; p:0,001). El ensamble del muestreo de febrero 2013 resultó significativamente distinto de todos los demás; al igual que el realizado en febrero 2014 (Tabla 3.17). El relevamiento de enero 2012 mostró diferencias significativas con el de marzo 2012.

Tabla 3.17. Valores del análisis ANOSIM para los test de a pares que resultaron significativamente distintos. Se informa el R de cada par y el nivel de significancia.

\begin{tabular}{lcc}
\hline Pares & Estadístico R & Significancia \\
\hline \hline Ene12 vs. Mar12 & 0,517 & 0,004 \\
Feb13 vs. Nov11 & 0,596 & 0,022 \\
Feb13 vs. Ene12 & 0,701 & 0,001 \\
Feb13 vs. Mar12 & 0,645 & 0,001 \\
Feb13 vs. Abr12 & 0,486 & 0,001 \\
Feb13 vs. Feb14 & 0,362 & 0,001 \\
Feb14 vs. Nov11 & 0,555 & 0,044 \\
Feb14 vs. Ene12 & 0,629 & 0,003 \\
Feb14 vs. Mar12 & 0,241 & 0,020 \\
Feb14 vs. Abr12 & 0,427 & 0,010 \\
\hline
\end{tabular}

En el análisis SIMPER se identificaron 20 grupos taxonómicos como principales contribuyentes a la disimilitud entre las fechas de muestreo. Se observa que la contribución de cada uno de los taxones Oligochaeta, Hirudinea, Nematoda, Platyhelminthes, Acari, Bivalvia, Gastropoda, Ostracoda, Decapoda (Aeglidae, Paleomonidae) Amphipoda (Hyalellidae) y los ordenes Ephemeroptera (Caenidae, Baetidae, Leptohyphidae), Diptera (Chironomidae), Odonata (Coenagrionidae y una familia indeterminada del Suborden Zygoptera), Trichoptera (Hydropsychidae) y Coleoptera (Elmidae), difieren entre las distintas fechas de muestreo. En la Tabla 3.18 se muestran los taxones que contribuyeron aproximadamente en un $70 \%$ a la disimilitud entre los sitios.

Los taxones que constribuyeron a la mayor diferencia en la composición del ensamble del grupo A fueron Hirudinea y Chironomidae. El principal aporte a la diferencia en la composición del ensamble de los muestreos de febrero 2013 fueron 
Chironomidae, Baetidae, Caenidae y Coenagrionidae. La mayor contribución a la disimilitud en los relevamientos de febrero 2014 estuvo dada por Oligochaeta, Gastropoda, Bivalvia y Elmidae. Los taxones que constribuyeron a la mayor diferencia en los ensambles de noviembre 2011 fueron los crustáceos Hyalella y Aeglidae; los de enero 2012 por Hyalella e Hirudinea y, los muestreos de marzo 2012 Oligochaeta y Gastropoda. Los ensambles de los muestreos de abril 2012 fueron distintos entre ellos, por lo cual no hay taxones que predominen es este grupo.

Tabla 3.18. Resultado del análisis SIMPER. Se muestra el promedio de la abundancia relativa porcentual (\% Abund.) y el porcentaje de contribución (Contrib. \%) de los taxones que aportaron en mayor medida a la disimilitud entre fechas de muestreo.

\begin{tabular}{|c|c|c|c|c|c|c|c|}
\hline Taxones & \multicolumn{2}{|c|}{ \%Abund } & \multirow[t]{2}{*}{ Contrib\% } & Taxones & \multicolumn{2}{|c|}{ \%Abund } & \multirow[t]{2}{*}{ Contrib\% } \\
\hline$\%$ Disimilaridad $=66,82$ & feb-13 & nov-11 & & $\%$ Disimilaridad $=67,54$ & feb-14 & nov-11 & \\
\hline Baetidae & 3,77 & 1,23 & 8,48 & Oligochaeta & 3,27 & 0,87 & 9,74 \\
\hline Gastropoda & 2,45 & 0,00 & 7,30 & Gastropoda & 2,93 & 0,00 & 9,60 \\
\hline Coenagrionidae & 2,66 & 0,26 & 6,81 & Hyalella & 0,81 & 2,85 & 8,49 \\
\hline Hyalella & 2,32 & 2,85 & 5,96 & Caenidae & 2,85 & 1,29 & 7,18 \\
\hline Chironomidae & 4,27 & 2,93 & 5,79 & Aeglidae & 0,26 & 1,84 & 5,98 \\
\hline Oligochaeta & 2,29 & 0,87 & 5,53 & Bivalvia & 2,14 & 0,65 & 5,98 \\
\hline Aeglidae & 0,05 & 1,84 & 5,05 & Elmidae & 1,93 & 0,26 & 5,79 \\
\hline Leptohyphidae & 1,59 & 0,00 & 4,65 & Chironomidae & 2,80 & 2,93 & 5,73 \\
\hline Caenidae & 2,70 & 1,29 & 4,41 & Baetidae & 0,84 & 1,23 & 4,73 \\
\hline Bivalvia & $\mathbf{1 , 8 1}$ & 0,65 & 4,31 & Platyhelminthes & 0,91 & 1,18 & 3,93 \\
\hline Platyhelminthes & 0,77 & 1,18 & 3,76 & Nematoda & 1,20 & 0,00 & 3,85 \\
\hline Zygoptera & 1,28 & 0,00 & 3,37 & & & & \\
\hline Elmidae & 1,16 & 0,26 & 3,06 & & & & \\
\hline \% Disimilaridad =72,97 & feb-13 & ene-12 & & $\%$ Disimilaridad $=74,56$ & feb-14 & ene-12 & \\
\hline Baetidae & 3,77 & 0,85 & 8,23 & Oligochaeta & 3,27 & 0,44 & 10,13 \\
\hline Chironomidae & 4,27 & 2,87 & 7,55 & Chironomidae & 2,80 & 2,87 & 8,60 \\
\hline Coenagrionidae & 2,66 & 0,34 & 6,33 & Caenidae & 2,85 & 0,98 & 8,01 \\
\hline Gastropoda & 2,45 & 0,52 & 6,19 & Gastropoda & 2,93 & 0,52 & 7,98 \\
\hline Hirudinea & 0,47 & 2,35 & 6,17 & Hirudinea & 1,14 & 2,35 & 7,86 \\
\hline Oligochaeta & 2,29 & 0,44 & 5,85 & Hyalella & 0,81 & 2,26 & 6,69 \\
\hline Caenidae & 2,70 & 0,98 & 5,57 & Bivalvia & 2,14 & 0,10 & 6,30 \\
\hline Hyalella & 2,32 & 2,26 & 5,43 & Elmidae & 1,93 & 0,00 & 5,92 \\
\hline Bivalvia & 1,81 & 0,10 & 4,56 & & & & \\
\hline Leptohyphidae & 1,59 & 0,22 & 4,20 & & & & \\
\hline Ostracoda & $\mathbf{0 , 9 8}$ & 0,67 & 3,27 & & & & \\
\hline Elmidae & 1,16 & 0,00 & 3,22 & & & & \\
\hline Zygoptera & 1,28 & 0,17 & 3,22 & & & & \\
\hline$\%$ Disimilaridad $=67,60$ & feb-13 & mar-12 & & $\%$ Disimilaridad $=57,89$ & feb-14 & mar-12 & \\
\hline Baetidae & 3,77 & 0,43 & 9,86 & Caenidae & 2,85 & 1,20 & 9,90 \\
\hline Chironomidae & 4,27 & 2,04 & 7,62 & Oligochaeta & 3,27 & 3,35 & 9,83 \\
\hline Coenagrionidae & 2,66 & 0,07 & 7,42 & Gastropoda & 2,93 & 2,45 & 8,99 \\
\hline Oligochaeta & 2,29 & 3,35 & 6,30 & Bivalvia & 2,14 & 1,02 & 8,24 \\
\hline Gastropoda & 2,45 & 2,45 & 5,91 & Elmidae & 1,93 & 0,40 & 7,44 \\
\hline Hyalella & 2,32 & 0,38 & 5,75 & Chironomidae & 2,80 & 2,04 & 7,43 \\
\hline Caenidae & 2,70 & 1,20 & 5,50 & Nematoda & 1,20 & 0,00 & 4,76 \\
\hline Bivalvia & 1,81 & 1,02 & 5,43 & Hirudinea & 1,14 & 0,83 & 4,72 \\
\hline Leptohyphidae & 1,59 & 0,19 & 4,65 & Baetidae & 0,84 & 0,43 & 4,44 \\
\hline Zygoptera & 1,28 & 0,00 & 3,49 & Acari & 0,86 & 0,00 & 3,80 \\
\hline Elmidae & 1,16 & 0,40 & 3,42 & & & & \\
\hline Ostracoda & 0,98 & 0,00 & 2,54 & & & & \\
\hline Hirudinea & 0,47 & $\mathbf{0 , 8 3}$ & 2,39 & & & & \\
\hline
\end{tabular}




\begin{tabular}{|c|c|c|c|c|c|c|c|}
\hline Taxones & \multicolumn{2}{|c|}{ \%Abund } & Contrib\% & Taxones & \multicolumn{2}{|c|}{ \%Abund } & Contrib\% \\
\hline$\%$ Disimilaridad $=65,42$ & feb-13 & abr-12 & & $\%$ Disimilaridad $=65,88$ & feb-14 & abr-12 & \\
\hline Baetidae & ב,77 & 1,72 & 8,47 & Oligochaeta & 3 & 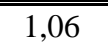 & 9,98 \\
\hline Coenagrionidae & 2,66 & 0,32 & 7,03 & Caenidae & 2,85 & 0,95 & 8,40 \\
\hline Hyalella & 2,32 & 0,90 & 5,90 & Chironomidae & 2,80 & 3,72 & 8,02 \\
\hline Oligochaeta & 2,29 & 1,06 & 5,90 & Gastropoda & 2,93 & 1,89 & 7,14 \\
\hline Chironomidae & 4,27 & 3,72 & 5,89 & Bivalvia & 2,14 & 0,27 & 6,62 \\
\hline Caenidae & 2,70 & 0,95 & 5,73 & Baetidae & 0,84 & 1,72 & 6,50 \\
\hline Gastropoda & 2,45 & 1,89 & 5,54 & Elmidae & 1,93 & 0,67 & 6,09 \\
\hline Bivalvia & 1,81 & 0,27 & 4,73 & Hirudinea & 1,14 & 0,90 & 5,06 \\
\hline Leptohyphidae & 1,59 & 0,42 & 4,05 & Hyalella & 0,81 & 0,90 & 4,35 \\
\hline Elmidae & 1,16 & 0,67 & 3,51 & Nematoda & 1,20 & 0,00 & 3,99 \\
\hline Zygoptera & 1,28 & 0,00 & 3,47 & Acari & $\mathbf{0 , 8 6}$ & 0,00 & 3,17 \\
\hline Hirudinea & 0,47 & 0,90 & 2,95 & & & & \\
\hline Ostracoda & 0,98 & 0,00 & 2,53 & & & & \\
\hline Palaemonidae & 0,44 & 0,47 & 2,44 & & & & \\
\hline Ancylidae & $\mathbf{1 , 0 2}$ & 0,10 & 2,40 & & & & \\
\hline$\%$ Disimilaridad $=60,73$ & feb-13 & feb-14 & & $\%$ Disimilaridad $=73,71$ & ene-12 & mar-12 & \\
\hline Baetidae & 3,77 & 0,84 & 8,37 & Oligochaeta & 0,44 & ב,35 & 15,87 \\
\hline Coenagrionidae & 2,66 & 0,19 & 6,51 & Chironomidae & 2,87 & 2,04 & 12,43 \\
\hline Gastropoda & 2,45 & 2,93 & 5,99 & Gastropoda & 0,52 & 2,45 & 10,90 \\
\hline Chironomidae & 4,27 & 2,80 & 5,76 & Hirudinea & 2,35 & 0,83 & 10,65 \\
\hline Oligochaeta & 2,29 & 3,27 & 5,23 & Hyalella & 2,26 & 0,38 & 10,42 \\
\hline Bivalvia & 1,81 & 2,14 & 5,10 & Caenidae & 0,98 & 1,20 & 7,38 \\
\hline Hyalella & 2,32 & 0,81 & 5,09 & Baetidae & $\mathbf{0 , 8 5}$ & 0,43 & 5,52 \\
\hline Caenidae & 2,70 & 2,85 & 4,87 & & & & \\
\hline Elmidae & 1,16 & 1,93 & 4,10 & & & & \\
\hline Leptohyphidae & $\mathbf{1 , 5 9}$ & 0,43 & 3,81 & & & & \\
\hline Zygoptera & 1,28 & 0,00 & 3,14 & & & & \\
\hline Nematoda & 0,08 & 1,20 & 2,88 & & & & \\
\hline Platyhelminthes & 0,77 & 0,91 & 2,59 & & & & \\
\hline Hirudinea & 0,47 & 1,14 & 2,55 & & & & \\
\hline Ostracoda & 0,98 & 0,36 & 2,52 & & & & \\
\hline Hydropsychidae & 0,77 & 0,73 & 2,52 & & & & \\
\hline
\end{tabular}

El muestreo realizado en febrero 2014 fue inmediatamente posterior a un período de lluvias intensas. En los siete días con anterioridad al muestreo las precipitaciones alcanzaron un total de $185 \mathrm{~mm}$. Estas lluvias causaron el desborde del río Arrecifes e inundaciones en varios sectores que debieron ser evacuados. Como consecuencia, se puede observar que aunque las concentraciones de los agrotóxicos fueron bajas, el ensamble de macroinvertebrados es característico de un ambiente disturbado, donde predominan Oligochaeta, Gastropoda, Bivalvia, Hirudinea y Platyhelminthes. En los muestreos de noviembre 2011 las lluvias alcanzaron un máximo de $32 \mathrm{~mm}$ dos días antes del muestreo, en enero 2012 llovió $37 \mathrm{~mm}$ la semana anterior, en marzo y abril de 2012 precipitaron 25 y $17 \mathrm{~mm}$ el día previo, respectivamente y, en febrero 2013 llovieron $45 \mathrm{~mm}$ cinco días antes del muestreo (tabla 3.19). 
Tabla 3.19. Precipitaciones en milimetros $(\mathrm{mm})$ de Arrecifes y alrededores, para los días previos a los muestreos realizados en noviembre 2011; enero, marzo y abril 2012; febrero 2013 y 2014.

\begin{tabular}{ccc} 
Muestreo & Precipitación $(\mathrm{mm})$ & Días previos \\
\hline \hline nov-2011 & 32 & 2 \\
\hline \multirow{2}{*}{ ene-2012 } & 37 & 6 \\
& 30 & 7 \\
\hline \multirow{2}{*}{ mar-2012 } & 25 & 1 \\
& 32 & 3 \\
\hline abr-2012 & 17 & 1 \\
\hline \multirow{2}{*}{ feb-2013 } & 5 & 2 \\
& 45 & 5 \\
\hline \multirow{3}{*}{ feb-2014 } & 6 & 1 \\
& 20 & 2 \\
& 44 & 4 \\
& 63 & 6 \\
\hline
\end{tabular}

\section{Relaciones del ensamble de macroinvertebrados con los agrotóxicos y variables ambientales}

En la Tabla 3.20 se observa las relaciones entre los agrotóxicos y la abundancia de los macroinvertebrados $\left(\mathrm{ind} / \mathrm{m}^{2}\right)$. Catorce taxones presentaron correlación negativa con la concentración de uno o más biocidas o sus unidades tóxicas: Platyhelminthes, Nematoda, Bivalvia, Gastropoda (Ancylidae), Decapoda (Aeglidae, Palaemonidae), Ostracoda, Ephemeroptera (Baetidae y Caenidae), Trichoptera (Hydropsychidae), Coleoptera (Elmidae) y Diptera (Simuliidae). Nueve grupos taxonómicos registraron correlación positiva, ocho de ellos con cipermetrina y uno, Hirudinea, con endosulfán y endosulfán sulfato. 
Tabla 3.20. Relaciones entre el ensamble de macroinvertebrados, agrotóxicos y sus respectivas unidades tóxicos (UT) determinados para el período de muestreo 2011-2014 en la región de Arrecifes.

\begin{tabular}{|c|c|c|c|c|c|c|c|c|c|c|c|}
\hline & & Clorp & $\lambda$-Cialo & Ciper & Endo & Endo-Sul & $\begin{array}{c}\text { UT } \\
\text { Clorp }\end{array}$ & $\begin{array}{c}\mathbf{U T} \\
\lambda \text {-Cialo }\end{array}$ & $\begin{array}{c}\text { UT } \\
\text { Ciper }\end{array}$ & $\begin{array}{c}\text { UT } \\
\text { Endo }\end{array}$ & $\begin{array}{c}\text { UT } \\
\text { Endo-Sul }\end{array}$ \\
\hline Platyhelminthes & $\begin{array}{l}\mathrm{r} \\
\mathrm{p}\end{array}$ & $*$ & $*$ & $*$ & $*$ & $*$ & $\begin{array}{l}-0,41 \\
0,010\end{array}$ & $\begin{array}{l}-0,57 \\
0,018\end{array}$ & $*$ & $*$ & $*$ \\
\hline Nematoda & $\begin{array}{l}\mathrm{r} \\
\mathrm{p}\end{array}$ & $\begin{array}{l}-0,40 \\
0,010 \\
\end{array}$ & $\begin{array}{c}-0,44 \\
0,009\end{array}$ & $*$ & $*$ & $*$ & $\begin{array}{l}-0,37 \\
0,023 \\
\end{array}$ & * & $*$ & $*$ & $*$ \\
\hline Bivalvia & $\begin{array}{l}\mathrm{r} \\
\mathrm{p}\end{array}$ & $*$ & $*$ & $*$ & * & * & $\begin{array}{l}-0,32 \\
0,049\end{array}$ & $\begin{array}{l}-0,52 \\
0,033\end{array}$ & $\begin{array}{l}-0,62 \\
0,005\end{array}$ & $*$ & $*$ \\
\hline Gastropoda & $\begin{array}{l}\mathrm{r} \\
\mathrm{p}\end{array}$ & $*$ & $*$ & $*$ & $\begin{array}{l}-0,32 \\
0,048 \\
\end{array}$ & $*$ & $*$ & $*$ & $*$ & $*$ & $*$ \\
\hline Ancylidae & $\begin{array}{l}\mathrm{r} \\
\mathrm{p}\end{array}$ & $*$ & $*$ & $*$ & $*$ & * & $\begin{array}{l}-0,38 \\
0,020\end{array}$ & * & $*$ & $*$ & $*$ \\
\hline Aeglidae & $\begin{array}{l}\mathrm{r} \\
\mathrm{p}\end{array}$ & $*$ & $\begin{array}{l}-0,35 \\
0,039 \\
\end{array}$ & $*$ & $*$ & $*$ & $*$ & $*$ & $*$ & $*$ & $*$ \\
\hline Palaemonidae & $\begin{array}{l}\mathrm{r} \\
\mathrm{p}\end{array}$ & $*$ & $*$ & $*$ & * & $*$ & $*$ & * & $*$ & $\begin{array}{l}-0,53 \\
0,030 \\
\end{array}$ & $*$ \\
\hline Ostracoda & $\begin{array}{l}\mathrm{r} \\
\mathrm{p}\end{array}$ & $*$ & $*$ & $*$ & $*$ & $*$ & $\begin{array}{l}-0,33 \\
0,043 \\
\end{array}$ & * & $\begin{array}{l}-0,57 \\
0,010 \\
\end{array}$ & $*$ & $*$ \\
\hline Ephemeroptera & $\begin{array}{l}\mathrm{r} \\
\mathrm{p}\end{array}$ & $*$ & $*$ & $*$ & $\begin{array}{l}-0,42 \\
0,007\end{array}$ & * & $*$ & * & $\begin{array}{l}-0,63 \\
0,004\end{array}$ & $*$ & $*$ \\
\hline Baetidae & $\begin{array}{l}\mathrm{r} \\
\mathrm{p}\end{array}$ & $*$ & $*$ & $*$ & $\begin{array}{l}-0,41 \\
0,009 \\
\end{array}$ & * & * & * & $\begin{array}{l}-0,55 \\
0,015 \\
\end{array}$ & $*$ & $\begin{array}{l}-0,37 \\
0,037 \\
\end{array}$ \\
\hline Caenidae & $\begin{array}{l}\mathrm{r} \\
\mathrm{p}\end{array}$ & $*$ & $*$ & $*$ & $\begin{array}{l}-0,33 \\
0,036\end{array}$ & $*$ & $*$ & $*$ & $\begin{array}{l}-0,58 \\
0,009\end{array}$ & $*$ & $*$ \\
\hline Hydropsychidae & $\begin{array}{l}\mathrm{r} \\
\mathrm{p} \\
\end{array}$ & $*$ & $*$ & $*$ & $\begin{array}{l}-0,40 \\
0,011 \\
\end{array}$ & * & $*$ & * & $\begin{array}{l}-0,52 \\
0,023\end{array}$ & $*$ & $\begin{array}{l}-0,38 \\
0,031\end{array}$ \\
\hline Simuliidae & $\begin{array}{l}\mathrm{r} \\
\mathrm{p} \\
\end{array}$ & $*$ & $*$ & $*$ & $\begin{array}{l}-0,44 \\
0,005 \\
\end{array}$ & $*$ & $*$ & $*$ & $*$ & $*$ & $\begin{array}{l}-0,36 \\
0,038\end{array}$ \\
\hline Elmidae & $\begin{array}{l}\mathrm{r} \\
\mathrm{p}\end{array}$ & $*$ & $*$ & $*$ & $\begin{array}{l}-0,32 \\
0,043 \\
\end{array}$ & $*$ & $*$ & $\begin{array}{l}-0,52 \\
0,031\end{array}$ & $\begin{array}{l}-0,60 \\
0,007\end{array}$ & $*$ & $*$ \\
\hline Hirudinea & $\begin{array}{l}\mathrm{r} \\
\mathrm{p} \\
\end{array}$ & $*$ & $*$ & $*$ & $\begin{array}{c}0,43 \\
0,006 \\
\end{array}$ & $\begin{array}{c}0,38 \\
0,016\end{array}$ & $*$ & $*$ & $*$ & $*$ & $*$ \\
\hline Coenagrionidae & $\begin{array}{l}\mathrm{r} \\
\mathrm{p}\end{array}$ & $*$ & $*$ & $\begin{array}{c}0,47 \\
0,002 \\
\end{array}$ & $*$ & $*$ & $*$ & $*$ & $*$ & $*$ & $*$ \\
\hline Heteroptera & $\begin{array}{l}\mathrm{r} \\
\mathrm{p}\end{array}$ & $*$ & $*$ & $\begin{array}{c}0,52 \\
0,000 \\
\end{array}$ & * & $*$ & $*$ & $*$ & $*$ & $*$ & $*$ \\
\hline Belostomatidae & $\begin{array}{l}\mathrm{r} \\
\mathrm{p}\end{array}$ & $*$ & $*$ & \begin{tabular}{|c|}
0,41 \\
0,009 \\
\end{tabular} & $*$ & $*$ & $*$ & $*$ & $*$ & $*$ & $*$ \\
\hline Corixidae & $\begin{array}{l}\mathrm{r} \\
\mathrm{p}\end{array}$ & $*$ & $*$ & \begin{tabular}{|c|}
0,34 \\
0,034
\end{tabular} & $*$ & $*$ & $*$ & $*$ & $*$ & $*$ & $*$ \\
\hline Pleidae & $\begin{array}{l}\mathrm{r} \\
\mathrm{p}\end{array}$ & $*$ & $*$ & \begin{tabular}{|c|}
0,43 \\
0,005
\end{tabular} & $*$ & $*$ & $*$ & $*$ & $*$ & $*$ & $*$ \\
\hline Stratiomyidae & $\begin{array}{l}\mathrm{r} \\
\mathrm{p}\end{array}$ & $*$ & $*$ & $\begin{array}{c}0,35 \\
0,027 \\
\end{array}$ & $*$ & $*$ & $*$ & $*$ & $*$ & $*$ & $*$ \\
\hline Dytiscidae & $\begin{array}{l}\mathrm{r} \\
\mathrm{p}\end{array}$ & $*$ & $*$ & \begin{tabular}{|c|}
0,36 \\
0,022 \\
\end{tabular} & $*$ & $*$ & $*$ & $*$ & $*$ & $*$ & $*$ \\
\hline Noteridae & $\begin{array}{l}\mathrm{r} \\
\mathrm{p}\end{array}$ & $*$ & $*$ & $\begin{array}{c}0,45 \\
0,003 \\
\end{array}$ & $*$ & * & $*$ & $*$ & $*$ & $*$ & $*$ \\
\hline
\end{tabular}

Clorp: clorpirifos, $\lambda$-Cialo: lambda cialotrina, Ciper: cipermetrina, Endo: endosulfán, Endo-Sul: endosulfán sulfato, $*$ : no significativo 


\section{Relaciones con las características del hábitat}

En la Tabla 3.21 se observa cuatro grupos taxonómicos que se correlacionaron con el contenido de COT en sedimentos, tres de ellos aumentaron su abundancia (Bivalvia, Hirudinea y Platyhelminthes), y uno disminuyó (Decapoda) con el aumento de la materia orgánica. La densidad de los individuos también se correlacionó con la textura del sedimento. La abundancia de Decapoda aumentó al aumentar la proporción de arena, mientras que Lepidoptera y Acari disminuyeron. De forma opuesta, estos dos últimos grupos y la abundancia de Platyhelminthes registraron una correlacionó positiva con el contenido de arcillas. Odonata y Lepidoptera se correlacionaron positivamente con el aumento de la proporción de limo.

Decapoda y Ephemeroptera se correlacionaron de forma negativa con el PRS, mientras que Odonata, Heteroptera y Diptera se correlacionaron positivamente con la

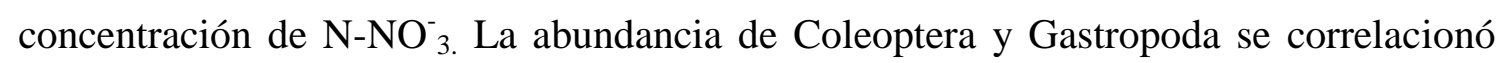
negativamente con la concentración de $\mathrm{N}^{-\mathrm{NO}_{2}}$ y de forma positiva Odonata. La densidad de Acari y Nematoda aumentó con el aumento del N-NH${ }_{4}^{+}$. 
Tabla 3.21. Coeficiente de correlación entre la abundancia de los grupos taxonómicos y características físicas y químicas del hábitat determinadas para el período de muestreo 2011-2014 en la región de Arrecifes.

\begin{tabular}{|c|c|c|c|c|c|c|c|c|c|}
\hline & & COT & Arena & Limo & Arcilla & $\mathrm{N}-\mathrm{NO}_{2}^{-}$ & $\mathrm{N}-\mathrm{NO}_{3}^{-}$ & $\mathbf{N}-\mathrm{NH}^{+}{ }_{4}$ & PRS \\
\hline Platyhelminthes & $\begin{array}{l}\mathrm{r} \\
\mathrm{p}\end{array}$ & \begin{tabular}{|c|}
0,35 \\
0,027
\end{tabular} & $*$ & $*$ & $\begin{array}{c}0,31 \\
0,048\end{array}$ & $*$ & $*$ & $*$ & $*$ \\
\hline Hirudinea & $\begin{array}{l}\mathrm{r} \\
\mathrm{p}\end{array}$ & \begin{tabular}{|c|}
0,37 \\
0,017
\end{tabular} & $*$ & $*$ & $*$ & $*$ & $*$ & $*$ & $*$ \\
\hline Nematoda & $\begin{array}{l}\mathrm{r} \\
\mathrm{p}\end{array}$ & $*$ & $*$ & $*$ & $*$ & $*$ & $*$ & $\begin{array}{c}0,32 \\
0,042\end{array}$ & $*$ \\
\hline Bivalvia & $\begin{array}{l}\mathrm{r} \\
\mathrm{p}\end{array}$ & \begin{tabular}{|c|}
0,32 \\
0,041 \\
\end{tabular} & * & $*$ & $*$ & $*$ & $*$ & $*$ & $*$ \\
\hline Gastropoda & $\begin{array}{l}\mathrm{r} \\
\mathrm{p}\end{array}$ & $*$ & $*$ & $*$ & $*$ & $\begin{array}{r}-0,36 \\
0,023\end{array}$ & $*$ & $*$ & $*$ \\
\hline Decapoda & $\begin{array}{l}\mathrm{r} \\
\mathrm{p}\end{array}$ & \begin{tabular}{|l|}
$-0,32$ \\
0,039 \\
\end{tabular} & $\begin{array}{c}0,31 \\
0,049\end{array}$ & $*$ & $*$ & $*$ & $*$ & $*$ & $\begin{array}{l}-0,34 \\
0,029 \\
\end{array}$ \\
\hline Acari & $\begin{array}{l}\mathrm{r} \\
\mathrm{p}\end{array}$ & $*$ & $\begin{array}{l}-0,37 \\
0,019\end{array}$ & $*$ & $\begin{array}{c}0,38 \\
0,014\end{array}$ & $*$ & $*$ & $\begin{array}{c}0,33 \\
0,033\end{array}$ & * \\
\hline Ephemeroptera & $\begin{array}{l}\mathrm{r} \\
\mathrm{p}\end{array}$ & $*$ & $*$ & $*$ & $*$ & $*$ & $*$ & $*$ & $\begin{array}{l}-0,33 \\
0,038 \\
\end{array}$ \\
\hline Odonata & $\begin{array}{l}\mathrm{r} \\
\mathrm{p}\end{array}$ & $*$ & $*$ & $\begin{array}{c}0,33 \\
0,037 \\
\end{array}$ & $*$ & $\begin{array}{c}0,37 \\
0,019 \\
\end{array}$ & $\begin{array}{c}0,52 \\
0,000 \\
\end{array}$ & $*$ & $*$ \\
\hline Heteroptera & $\begin{array}{l}\mathrm{r} \\
\mathrm{p}\end{array}$ & $*$ & $*$ & $*$ & $*$ & $*$ & $\begin{array}{c}0,56 \\
0,000 \\
\end{array}$ & $*$ & $*$ \\
\hline Lepidoptera & $\begin{array}{l}\mathrm{r} \\
\mathrm{p}\end{array}$ & $*$ & $\begin{array}{l}-0,37 \\
0,019\end{array}$ & $\begin{array}{c}0,43 \\
0,006 \\
\end{array}$ & $\begin{array}{c}0,35 \\
0,027\end{array}$ & $*$ & $*$ & $*$ & $*$ \\
\hline Diptera & $\begin{array}{l}\mathrm{r} \\
\mathrm{p}\end{array}$ & $*$ & $*$ & $*$ & $*$ & $*$ & $\begin{array}{c}0,38 \\
0,014 \\
\end{array}$ & $*$ & $*$ \\
\hline Coleoptera & $\begin{array}{l}\mathrm{r} \\
\mathrm{p}\end{array}$ & $*$ & $*$ & $*$ & $*$ & $\begin{array}{c}-0,41 \\
0,009\end{array}$ & $*$ & $*$ & $*$ \\
\hline
\end{tabular}

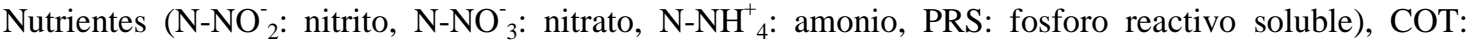
carbono orgánico total, * : no significativo

Es importante destacar que la concentración de todos los agrotóxicos se correlacionó positivamente con el contenido de COT en los sedimentos de fondo y, la unidad tóxica total se relacionó positivamente con el porcentaje de arcilla y de forma inversa, con el contenido de arena. La concentración de $\mathrm{N}^{-\mathrm{NO}^{-}}{ }_{3}$ se correlacionó de forma positiva con la concentración de lambda-cialotrina y cipermetrina (Tabla 3.22). 
Tabla 3.22. Relaciones entre las características físicas y químicas del hábitat y la concentración de los agrotóxicos determinadas para el período de muestreo 2011-2014 en la región de Arrecifes.

\begin{tabular}{|l|c|c|c|c|}
\hline & COT & Arena & Arcilla & $\mathbf{N - N O}_{3}^{-}$ \\
\hline \hline Clorpirifos & $\begin{array}{c}0,38 \\
0,015\end{array}$ & $*$ & $*$ & $*$ \\
\hline$\lambda$-Cialotrina & $\begin{array}{c}0,50 \\
0,002\end{array}$ & $*$ & $*$ & 0,39 \\
\hline Cipermetrina & $\begin{array}{c}0,54 \\
0,000\end{array}$ & $*$ & $\begin{array}{c}0,37 \\
0,019\end{array}$ & $\begin{array}{c}0,43 \\
0,006\end{array}$ \\
\hline Endosulfán & $\begin{array}{c}0,35 \\
0,029\end{array}$ & $*$ & $*$ & $*$ \\
\hline Endosulfán-Sulfato & $\begin{array}{c}0,62 \\
0,000\end{array}$ & $*$ & $*$ & $*$ \\
\hline Agrotóxicos totales & $\begin{array}{c}0,59 \\
0,000\end{array}$ & $*$ & $*$ & $*$ \\
\hline UT total & $*$ & $-0,34$ & 0,36 & $*$ \\
\hline
\end{tabular}

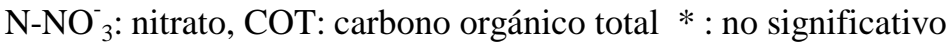

El análisis de redundancia (RDA) utilizando las variables clorpirifos, lambda-

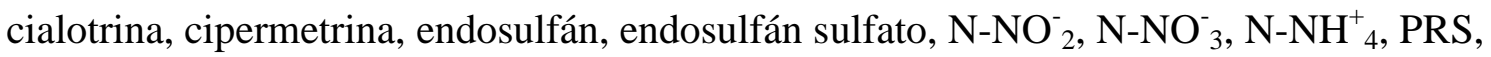
COT y el ancho de la franja de atenuación resultó significativo según el test de permutaciones de Monte Carlo. Utilizando estas variables el primer y segundo eje explicaron el $68 \%$ de la variación total. En la tabla 3.23 se observan todos los valores obtenidos del análisis de redundancia.

Tabla 3.23. Resumen de los autovalores del RDA y el porcentaje acumulado de la varianza explicada, el porcentaje de la varianza acumulada de los primeros cuatro ejes y el test de Monte Carlo.

\begin{tabular}{lcccc} 
Ejes & $\mathbf{1}$ & $\mathbf{2}$ & $\mathbf{3}$ & $\mathbf{4}$ \\
\hline \hline Autovalores & 0,17 & 0,07 & 0,04 & 0,03 \\
Correlaciones taxa - ambiente & 0,74 & 0,71 & 0,68 & 0,59 \\
Porcentaje acumulado de varianza & & & & \\
$\quad$ de taxa & 17,4 & 24,7 & 28,4 & 31,7 \\
$\quad$ de relación taxa - ambiente & 47,8 & 68,1 & 78,3 & 87,4 \\
\hline Test de significancia de Monte Carlo & & & & \\
10 eje canónico & & F: 5,882 & p: 0,040 \\
$\quad$ todos los ejes canónicos & F: 1,451 & p: 0,030 \\
\hline
\end{tabular}


En la figura 3.7 se puede observar muestreos caracterizados por altas concentración de agrotóxicos, PRS y nitritos correspondientes a los meses enero y marzo de 2012 principalmente. El muestreo de febrero 2013 se caracteriza por altas concentraciones de nitratos, COT y endosulfán sulfato; y febrero 2014 altas concentraciones de amonio. Además, se puede observar una tendencia inversa entre los agrotóxicos y la franja de atenuación, donde al aumentar la distancia del cultivo al arroyo parecería disminuir la concentración de los biocidas.

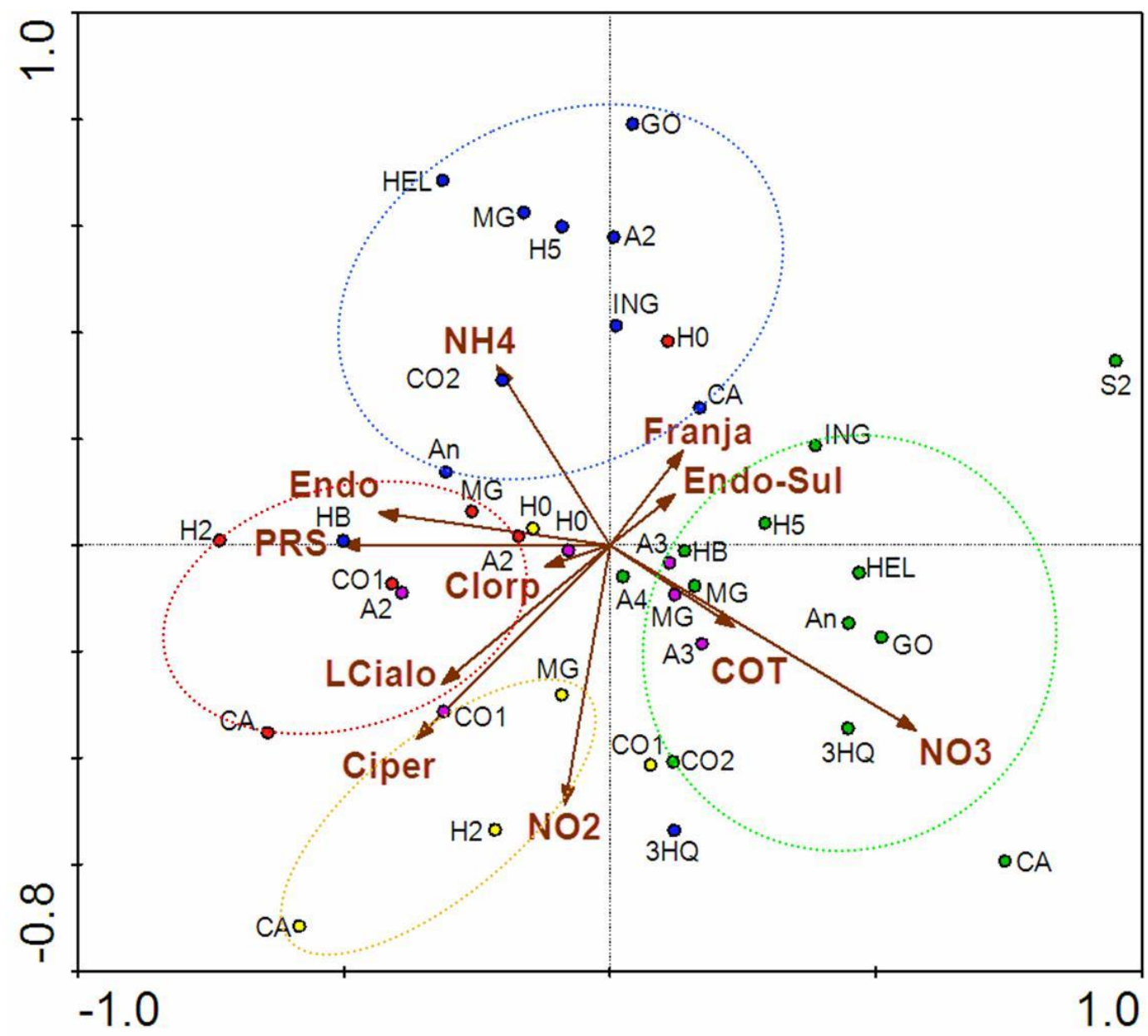

Figura 3.7. Representación del análisis de redundancia (RDA) para los sitios muestreados en el período 2012-2014 de Arrecifes reflejando las relaciones ambientales. Enero 2012 (amarillo), marzo 2012 (rojo), abril 2012 (violeta), febrero 2013 (verde) y febrero 2014 (azul). Clorp: clorpirifos, LCialo: lambda cialotrina, Ciper: cipermetrina, Endo: endosulfán, Endo-Sul: endosulfán sulfato, NO2: nitrito, NO3: nitrato, NH4: amonio, PRS: fosforo reactivo soluble, COT: carbono orgánico total, Franja: ancho de la franja de atenuación. 
La fig. 3.8 muestra la influencia de los agrotóxicos en la composición taxonómica de los ensambles. La mayoría de los grupos taxonómicos se ubican en los cuadrantes opuestos al sector donde predomina la mayor concentración de biocidas, con la única excepción de Hirudinea. Un grupo importante de taxones muestra relación con la abundancia de materia orgánica (COT) y nitratos $\left(\mathrm{NO}_{3}^{-}\right)$y; otro grupo, con la magnitud de la franja de atenuación y el producto de degradación del endosulfán (Endo-Sul). Los muestreos caracterizados por mayores concentraciones de $\mathrm{NH}_{4}^{+}$estuvieron dominados por Oligoquetos. El PRS tuvo un comportamiento similar a los agrotóxicos.

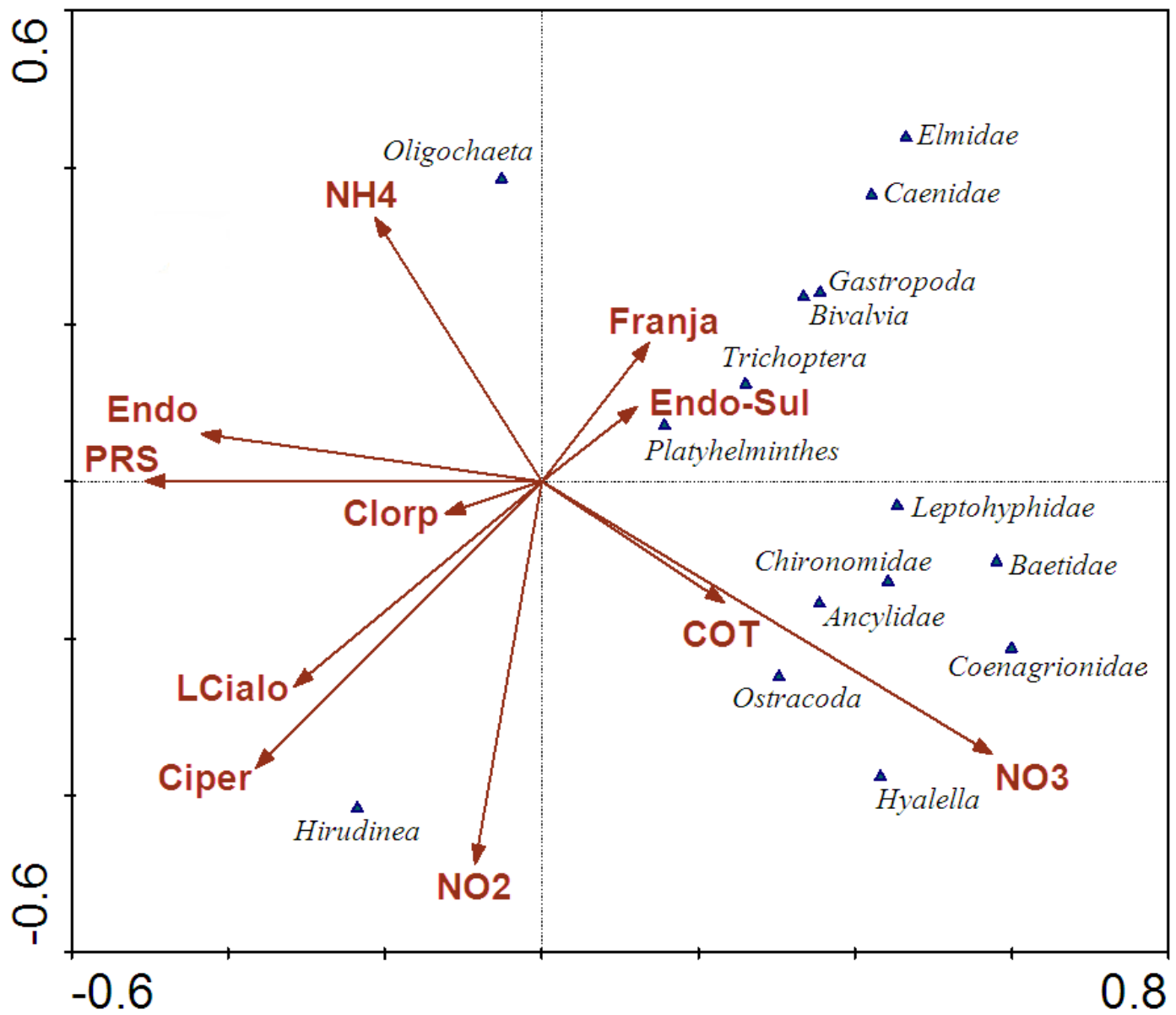

Figura 3.8. Representación del análisis de redundancia (RDA) para los sitios muestreados en el período 2012-2014 de Arrecifes reflejando las asociaciones de invertebrados. Clorp: clorpirifos, LCialo: lambda cialotrina, Ciper: cipermetrina, Endo: endosulfán, Endo-Sul: endosulfán sulfato, NO2: nitrito, NO3: nitrato, NH4: amonio, PRS: fosforo reactivo soluble, COT: carbono orgánico total, Franja: ancho de la franja de atenuación. 


\section{DISCUSIÓN}

En la primera etapa de muestreos se demostró que los ensambles de macroinvertebrados registraron diferencias significativas entre arroyos con distinto uso del suelo en sus cuencas (agrícolas, ganaderos y reserva). Las mayores concentraciones de nutrientes y la presencia de agrotóxicos se registraron en los arroyos de cuencas donde la agricultura fue la actividad dominante. La concentración de PRS fue significativamente mayor en la zona agrícola de La Plata y la concentración de $\mathrm{N}_{-} \mathrm{NO}_{3}^{-}$ lo fue en la zona agrícola de Arrecifes. Estas observaciones son coincidentes con lo informado por otros autores; Mugni et al. (2013a) observaron que las concentraciones de PRS determinadas en un arroyo de primer orden de una parcela donde se cultivó trigo, fertilizado con $120 \mathrm{~kg} / \mathrm{ha}$ de fosfato diamónico, seguido de soja fueron significativamente más altas que en la parcela que se ubicaba aguas abajo con soja sin fertilizar. De igual modo, Gabellone et al. (2005) observaron que en la cuenca alta del río Salado donde predomina la agricultura intensiva las concentraciones de nutrientes fueron mayores que en la cuenca baja donde prevalece la actividad ganadera. Solis et al. (2016) compararon arroyos de cuencas con distinto uso del suelo en la región Pampeana, Argentina. Las mayores concentraciones de nutrientes y agrotóxicos se determinaron en los sitios agrícolas y de ganadería intensiva. Miller et al. (1997), en la cuenca del río Potomac Estados Unidos, registraron las mayores concentraciones de nitratos en aquellos arroyos que drenan cuencas con agricultura, disminuyendo a concentraciones intermedias los que drenan pasturas y las menores en cuencas que drenan bosques. Las concentraciones de nutrientes en los arroyos están relacionadas con el uso del suelo en la cuenca (Omernik 1977). Estudios realizados en Sudamérica indican que las practicas agrícolas se han intensificado y a menudo se extienden hasta los márgenes de los arroyos afectando negativamente la calidad del agua (Ribbe et al., 2008; Hunke et al., 2015). Cooper (1993) ha identificado a la actividad agrícola como unas de los factores que más contribuyen al impacto ambiental, afectando distintos componentes del ecosistema. Los arroyos que drenan cuencas agrícolas se caracterizan por elevados niveles de nutrientes, conductividad y sólidos suspendidos (Stefanidis et al., 2016; Gerth et al., 2017). Los resultados disponibles confirman que el uso del suelo en la cuenca influye en las concentraciones de nutrientes, los cuales aumentan en los arroyos adyacentes a cultivos fertilizados. 
Wogram \& Liess (2001) elaboraron un ranking basado en la sensibilidad de distintos órdenes de macroinvertebrados en comparación con la tolerancia a la toxicidad de Daphnia magna. A partir de la base de datos AQUIRE - USEPA, recopilaron los datos de toxicidad de 211 sustancias y mostraron la tolerancia fisiológica relativa de distintos órdenes. Cada concentración de $\mathrm{LC}_{50}$ ó $\mathrm{EC}_{50}$ para una determinada especie fue dividida por la concentración correspondiente a D. magna. El logaritmo de esta ecuación, calculado para cada especie, se denominó tolerancia fisiológica relativa de esa especie con respecto a D. magna. Entre los órdenes más tolerantes se encuentran Hirudinea, Gastropoda y Oligochaeta; mientras que los más sensibles fueron Amphipoda, Ostracoda, Cladócera y Ephemeroptera. Estos resultados son coincidentes con lo observado en este trabajo de tesis y en otros estudios de bioindicadores (Rodrigues Capítulo et al., 2001; Ocon et al., 2004). Los taxones considerados tolerantes por Wogram \& Liess (2001), caracterizaron los ensambles de los sitios impactados con agrotóxicos, y los sensibles se encontraron en baja densidad o han desaparecido. Los ensambles de los arroyos con uso del suelo ganadero o reserva estuvieron bien representados por estos últimos (Amphipoda, Ephemeroptera).

Liess \& Von der Ohe (2005) estudiaron la composición del ensamble de invertebrados acuáticos relacionados con el efecto producido por los agrotóxicos en 20 arroyos de Alemania y estimaron las unidades toxicas (UT) en D. magna en cada muestreo. Los autores observaron que los biocidas causan cambios sobre la composición de la comunidad aun con unidades tóxicas bajas (UT > 0,01), equivalentes a 1/100 de la $\mathrm{CL}_{50} 48 \mathrm{~h}$ de D. magna. En el presente estudio, se determinaron las UT en H. curvispina utilizando las $\mathrm{LC}_{50}$ estimadas en el primer capítulo. Los arroyos agrícolas alcanzaron valores de UT total mayores a 0,01 en casi todos los muestreos y, en algunos sitios de Arrecifes (Cañete y Contador 1) alcanzaron valores extremos mayores a 1. Cuando la concentración de biocidas es mayor a la dosis letal se presume que habrá una drástica disminución de taxones por la desaparición de los grupos más sensibles. Los cambios en el uso del suelo tienen consecuencias ecológicas en los ecosistemas acuáticos (Bruno et al., 2014; Lammert \& Allan, 1999) y los ensambles de macroinvertebrados son excelentes indicadores de la calidad del agua debido a que poseen distinta tolerancia a la contaminación (Fierro et al., 2012). Cooper (1993) sostiene que los biocidas provenientes de la agricultura al ingresar a los arroyos pueden causar efectos tóxicos agudos sobre los organismos acuáticos. Del mismo modo 
sostiene que los efectos subletales o crónicos son menos notorios y pueden producir un importante daño a la biota por períodos de tiempo más prolongados.

Liess \& Von der Ohe (2005) clasificaron las especies de invertebrados de arroyos alemanes en dos grandes grupos según su sensibilidad a los biocidas, especies en riesgo ó sensibles (SPEAR $=$ Species at Risk) y especies no en riesgo ó tolerantes (SPEnotAR). En el presente estudio dos familias consideradas sensibles, Palaemonidae y Caenidae, como así también los órdenes a los cuales pertenecen Decapoda y Ephemeroptera respectivamente, registraron una correlación negativa con casi todos los biocidas estudiados. Asimismo, Crustacea registró correlación negativa con la concentración de varios biocidas. Dada la elevada toxicidad de los agrotóxicos se asume que las correlaciones indican una relación causa efecto, la disminución de la abundancia estaría determinada por la toxicidad de los agrotóxicos determinados en mayor concentración. Seis grupos taxonómicos registraron correlación positiva con la concentración de uno o más agrotóxicos. Algunos de los cuales representan organismos considerados tolerantes, Hirudinea, Oligochaeta, Gastropoda (Ancylidae) y Coleoptera (Curculionidae). Se presume que los grupos tolerantes muestran un incremento de la abundancia con el aumento de la concentración de los biocidas debido a que se ven favorecidos en algunos casos por la desaparición de los más sensibles en términos de menor competencia por el hábitat o bien, por el incremento de la oferta alimentaria por enriquecimiento de nutrientes, los cuales llegan al arroyo junto con los agrotóxicos. Los ancílidos y curculiónidos, generalmente asociados a la vegetación emergente, podrían no verse afectados debido a su hábito, que no se encuentran en contacto con el sedimento. No obstante, debe tenerse en cuenta que la exposición a los biocidas en el momento de la escorrentía siempre es mayor que la determinada en los sedimentos de la muestra. Neumann \& Dudgeon (2002) estudiaron tres pequeños arroyos de Hong Kong, China. En cada arroyo muestrearon aguas arriba y aguas abajo de una zona cultivada y compararon los macroinvertebrados bentónicos. Observaron que después de una lluvia intensa que generó una escorrentía proveniente del campo cultivado, los sitios aguas abajo presentaron una disminución significativa del número de taxones sensibles (Ephemeroptera, Trichoptera) y un incremento de taxones tolerantes (Hirudinea, Oligochaeta, Platyhelminthes, Gastropoda). Los estudios previos, muestran coincidencia en cuanto a las consideraciones de los grupos como tolerantes o sensibles con el trabajo desarrollado en la presente tesis, demostrando que los ensambles de macroinvertebrados 
de los arroyos relacionados con cuencas agrícolas son distintos de los arroyos de cuencas con otros usos del suelo.

El CLUSTER mostró una agrupación según el uso del suelo en la cuenca, agrícola ganadera y reserva, lo cual concuerda con las diferencias detectadas en las concentraciones de nutrientes. El análisis ANOSIM confirmó que existen diferencias significativas entre los ensambles de los arroyos con distinto uso del suelo. El SIMPER reveló que los taxones que contribuyeron a la disimilud y resultaron dominantes en los sitios agrícolas fueron Chironomidae, Oligochaeta, Gastropoda y Bivalvia, los cuales son considerados tolerantes (Liess \& Von der Ohe, 2005); mientras que Crustacea (Paleomonidae y Hyalella), dominantes en la reserva y en los sitios ganaderos son considerados sensibles. Los resultados que se muestran en el presente trabajo son consistentes con los resultados informados por Solis et al. (2016). Ellos compararon el ensamble de macroinvertebrados asociados a la vegetación en arroyos de cuencas con distinto uso del suelo y observaron que en los sitios agrícolas y de ganadería intensiva la composición del ensamble de macroinvertebrados era distinta que en las cuencas de ganadería extensiva y en la reserva. Fierro et al. (2017) investigaron los efectos del uso del suelo sobre la calidad del agua y los ensambles de macroinvertebrados bentónicos en las regiones de Araucanía y Los Ríos de Chile. En los sitios con cuencas agrícolas y de plantaciones forestales exóticas observaron que la diversidad de los macroinvertebrados fue la más baja, con una menor abundancia de insectos en los ensambles. Contrariamente, los sitios de muestreo en áreas de influencia de bosques prístinos tuvieron la mayor diversidad de macroinvertebrados y especies consideradas sensibles. Estos resultados son similares a los informados en otros estudios (Miserendino \& Masi, 2010; Egler et al., 2012; Fierro et al., 2015; Gerth et al., 2017) que indican que la fauna de macroinvertebrados se relaciona con el uso del suelo. En el presente trabajo de tesis, en los sitios menos disturbados la dominancia correspondió al anfípodo $H$. curvispina, considerado sensible, mientras que en los disturbados Gastropoda, Oligochaeta e Hirudinea, considerados tolerantes, fueron los taxones mejor representados.

La abundancia de numerosos taxones mostró relación con las características del hábitat. Grupos taxonómicos como Hirudinea, Platyhelminthes, Hydrophilidae (Coleoptera) y Aeshnidae (Odonata) se correlacionaron positivamente con el porcentaje de COT. Estudios sobre la calidad del agua, registran que Hirudinea es moderadamente 
tolerante o tolerante al enriquecimiento orgánico y la contaminación (Pizzolón \& Miserendino, 2001). La mayoría de los Platyhelminthes se caracterizan por vivir en aguas bien oxigenadas, pero muchas especies pueden resistir altos grados de contaminación orgánica (Roldán Pérez \& Ramírez Restrepo, 2008). Pérez \& Roldán (1978) reportaron una gran abundancia de Platyhelminthes en un río de Antioquia, Colombia, en zonas de alta contaminación orgánica. La mayoría de los adultos de la familia Hydrophilidae, son organismos omnívoros y consumidores primarios de materia orgánica, se alimentan de tejido vegetal y/o animal en descomposición (Spangler, 1982; Merritt et al., 2008; Domínguez \& Fernández, 2009; Cruz Miranda et al., 2015). Por el contrario, la abundancia de Decapoda (Aeglidae), Ephemeroptera (Baetidae, Caenidae, Leptohyphidae) y Elmidae disminuyó con el aumento del COT. En ambientes bien oxigenados y con bajo contenido de materia orgánica se espera encontrar poblaciones de Ephemeroptera y Crustacea (Roldán Pérez, 1999). Elmidae es una familia de coleópteros frecuente en ambientes lóticos, sensible al déficit de oxígeno y al incremento de la carga orgánica residual (González-Córdoba et al., 2015). El contenido de materia orgánica se correlacionó con la concentración de los biocidas cipermetrina, clorpirifos, endosulfán, endosulfán sulfato y lambda-cialotrina (Tabla 3.22). Algunos de los taxones que registraron correlación positiva con el contenido de COT corresponden a grupos considerados tolerantes a los agrotóxicos mientras que los que registraron correlaciones negativas resultaron mayoritariamente grupos sensibles, sugiriendo que el efecto de la materia orgánica estaría también relacionado con la interacción con los agrotóxicos.

Varios taxones se correlacionaron positivamente con la riqueza de la vegetación acuática. Los nutrientes fósforo y nitrógeno son esenciales para la biota. La vegetación acuática absorbe estos compuestos tanto de la columna de agua como del sedimento y, a mayor disponibilidad, mayor producción primaria y biomasa vegetal. En principio, este aumento en la biomasa permitiría un mayor recurso alimentario para los niveles tróficos siguientes como así también de un sustrato y refugio para muchos invertebrados. Ferreiro et al. (2014) llevaron a cabo experimentos de colonización de macrófitas y observaron que la complejidad de las mismas se asociaba con una mayor abundancia y riqueza de macroinvertebrados. Duggan et al. (2001), consideran que el tipo de vegetación, arquitectura y forma de crecimiento determina la distribución de macroinvertebrados. En este contexto, no sorprende la correlación positiva entre la 
abundancia de algunos grupos taxonómicos con la cantidad de vegetación y concentración de nitratos.

Por el contrario, resultó inesperado que varios taxones registraran correlación negativa con la concentración de PRS. El PRS no tiene efecto tóxico sobre la fauna. En experimentos de enriquecimiento con nutrientes en un arroyo Pampeano, Armendariz et al. (2012) observaron un aumento en la abundancia y biomasa de oligoquetos tanto en los sedimentos como en la vegetación, especialmente las subfamilias Naidinae y Pristininae durante la fase de reproducción asexual. También se observó un aumento de algas y bacterias asociadas al sedimento, por lo que se interpretó el aumento de oligoquetos como resultado del incremento de la oferta alimentaria. En un trabajo posterior Cortelezzi et al. (2015) registraron que de todos los macroinvertebrados estudiados sólo dos taxones tuvieron diferencias significativas en su abundancia después de la fertilización: Corbicula fluminea y ostrácodos. Los ambientes pampeanos presentan elevadas concentraciones basales de PRS por la riqueza del material loessico originario (Quirós \& Drago, 1999; Mugni, 2009). En el presente estudio la correlación negativa entre el PRS y la abundancia de algunos taxones no estaría indicando una relación causa-efecto, más bien parece sugerir la ocurrencia simultánea de mayores concentraciones de PRS con la presencia de altas concentraciones de agrotóxicos. En efecto, el PRS registró correlación positiva con la concentración de clorpirifos, agrotóxicos totales y las respectivas UT. En el arroyo de la reserva, el PRS resultó menor que en los sitios de zonas agrícolas. Los fertilizantes se aplican con la siembra, pero si en ese momento se observa la presencia de plagas, se hacen aplicaciones simultáneas con agrotóxicos. Ambos se incorporan a los arroyos con las lluvias posteriores a la aplicación, en coincidencia con episodios de escurrimiento superficial (Mugni et al., 2013a). La mayoría de los agrotóxicos utilizados en nuestro medio son fuertemente hidrofóbicos y se asocian a la materia orgánica del suelo. El fósforo aplicado como fertilizante, generalmente en la forma de superfosfato, se asocia a los coloides de hierro y aluminio en el suelo y es arrastrado a los arroyos también por los eventos de escorrentía superficial, principalmente en la fracción particulada. La concentración de PRS en el agua se correlacionó positivamente con el contenido de COT y arcilla y negativamente con el contenido de arena en los sedimentos. Los taxones que se relacionaron negativamente con el PRS son aquellos considerados sensibles a los agrotóxicos: Crustacea (Hyalella, Palaemonidae), Diptera 
(Stratiomyidae), Ephemeroptera (Baetidae, Caenidae) y sólo Oligochaeta, clasificado como tolerante por Liess \& Von der Ohe (2005), se correlacionó de forma positiva. La concentración de PRS resultó un indicador sensible y confiable de impacto agrícola por su utilización en la práctica agrícola y por su comportamiento ambiental similar al de los pesticidas aun cuando sea un nutriente esencial y no presente toxicidad.

El ancho de la franja de atenuación se correlacionó negativamente con la concentración de varios biocidas y con la suma total de los mismos (agrotóxicos totales) y positivamente con la abundancia de algunos taxones sensibles a los agrotóxicos. Esto concuerda con varios estudios (FOCUS 2007, Reichenberger et al., 2007, Schulz et al., 2009) que muestran la efectividad de las franjas de atenuación para mitigar y reducir el riesgo de entrada de biocidas en los ecosistemas acuáticos. Aunque las eficiencias informadas en la reducción de la cantidad de agrotóxicos transportados en la escorrentía variaron mucho según el diseño del estudio, la mayoría informó una eficiencia superior al 60\% (Reichenberger et al., 2007; Zhang et al., 2010). Generalmente, la efectividad es mayor para los agrotóxicos hidrofóbicos que se transportan adsorbidos a la fracción particulada que para los solubles que se encuentran en fase acuosa. En promedio, la reducción observada de carga de biocidas fue del $50 \%$ para un ancho de franja de atenuación de $5 \mathrm{~m}, 90 \%$ para un ancho de $10 \mathrm{~m}$ y 97,5\% para un ancho de $20 \mathrm{~m}$ (Reichenberger et al., 2007). Estas observaciones se tienen en cuenta en el modelo de exposición a escorrentías, EXPOSIT, desarrollado en Alemania en base a la recopilación de estudios sobre la reducción de la contaminación utilizando franjas de atenuación cubiertas de vegetación. Para los biocidas débilmente absorbidos, el modelo asume eficiencias de reducción del 40\%, 60\% y 80\% para un ancho de amortiguación de $5 \mathrm{~m}, 10 \mathrm{~m}$ y $20 \mathrm{~m}$, respectivamente. Para los biocidas altamente absorbidos, se asumen eficiencias del 40\%, 85\% y 95\%, respectivamente (Bereswill et al., 2014). Borin et al. (2010) presentaron un análisis de las diferentes funciones de las zonas buffer y revisaron los datos de investigaciones realizados durante la última década en la región de Veneto, Italia. Entre otras cosas, demostraron que la franja de atenuación es una barrera útil para los herbicidas y, disminuye las concentraciones en un $60 \%$ a $90 \%$, dependiendo de la sustancia química y el tiempo transcurrido desde la aplicación. Aguiar et al. (2015), investigaron la capacidad de la vegetación ribereña como zona buffer para retener los agrotóxicos, en 27 sitios sobre la cuenca del río Cará-Cará (Paraná, Brasil). Los sitios de muestreo presentaban franjas con diferente estructura 
vegetal (leñosa, árboles de 15-20m; arbustiva, plantas de hasta $3 \mathrm{~m}$ y pastura) y distinto ancho (12, 36 y 60m). Analizaron tres herbicidas (Atrazina, Fluazifop-p-butyl, Lactofen) y dos insecticidas (Lambda-cialotrina y Clorpirifos) y observaron que la efectividad del filtrado fue influenciada en gran medida por el ancho y el tipo de vegetación de la zona buffer. En general, la disminución de los agrotóxicos siguió en este orden árboles > arbustos > pastura. La zona de amortiguamiento forestal de $60 \mathrm{~m}$ fue la más eficaz en la eliminación de todos los biocidas. La pérdida de las márgenes con vegetación natural y zonas de ribera acelera los efectos de la contaminación y deben ser tenidos en cuenta a la hora de evaluar el daño en la vida acuática. La protección de estos hábitats es una manera simple y efectiva de conservar la diversidad biológica.

En el primer período de muestreos (2011-2012) se mostró que los ensambles de invertebrados en arroyos de cuencas agrícolas son distintos a los de zonas ganaderas y de reserva y, que la aplicación de agroquímicos en los cultivos contribuye a la diferencia. En el segundo período se concentró el esfuerzo de muestreo en los arroyos de la zona considerada como núcleo de mayor intensidad agrícola del país (Pengue, 2000) con el objeto de profundizar la comprensión del efecto de la práctica agrícola en los ensambles.

Considerando sólo los arroyos agrícolas de Arrecifes-Pergamino se confirman varias de las observaciones llevadas a cabo cuando se compararon los distintos usos del suelo. Fundamentalmente se observaron correlaciones entre algunos grupos taxonómicos y la concentración de biocidas, y la correlación entre grupos taxonómicos y algunas variables ambientales como la cantidad de materia orgánica o composición granulométrica del sedimento. El conjunto de arroyos de la zona en la región comprendida entre Capitán Sarmiento, Pergamino y Salto representan un grupo ambientalmente homogéneo, todos reciben impacto y todos registran la presencia de agrotóxicos en los sedimentos. Considerando sólo este grupo, en todo el período de muestreo, surge que la variabilidad temporal es mayor que la espacial. La aplicación de agrotóxicos no se repite de igual forma año tras año, se aplican distintos pesticidas en función de las plagas observadas en los cultivos. Los biocidas ingresan a los arroyos en coincidencia con las primeras lluvias posteriores a la aplicación (Mugni et al., 2013a). El efecto en los ensambles resultará de pulsos que producen toxicidad diferencial en los grupos que componen los ensambles, que a su vez varían en años sucesivos por la variabilidad climática. Por este motivo, si bien los resultados del segundo período 
confirman los del primero, mostrando correlaciones entre la abundancia de diferentes taxones y la concentración de agrotóxicos; el efecto de un pulso de toxicidad sobre la composición de los ensambles de macroinvertebrados que varían entre años sucesivos no repite los mismos resultados.

El análisis de RDA muestra que los relevamientos realizados en 2012 se segregan del resto, en el cuadrante caracterizado por la mayor concentración de agrotóxicos y PRS (Figura 3.7). Además, se puede observar, que esta mayor concentración tiene una influencia determinante sobre la composición de los ensambles. Hirudinea, es el único grupo presente, considerado tolerante a los biocidas, que se relaciona positivamente con este entorno; mientras que todos los demás taxones se sitúan en los cuadrantes opuestos (Figura 3.8). Los muestreos realizados en febrero 2013 y febrero 2014, que son los grupos mejor definidos en el análisis CLUSTER, aparecen como dos nubes de puntos claramente segregados en el RDA; asociados a bajas concentraciones de biocidas. Se observa que dos características ambientales parecen influir, el contenido de materia orgánica y la franja de atenuación entre el cultivo y el arroyo. Ambos tienden a amortiguar el efecto de la exposición a los agrotóxicos. La franja de atenuación actúa interceptando y reteniendo los agroquímicos, y por tal motivo disminuyendo la cantidad de biocidas que ingresa a los arroyos. La materia orgánica representa un recurso alimentario para muchos grupos y un factor adverso para otros, registrándose tanto correlaciones negativas como positivas con distintos grupos taxonómicos. Una causa que podría producir el efecto negativo sería que, la acumulación de materia orgánica puede generar déficit de oxígeno intersticial en los sedimentos afectando selectivamente a diferentes taxones. Además, el contenido de COT tiene interacción con los agrotóxicos y, esta relación tiene efectos contrapuestos. Los biocidas más utilizados en nuestro medio son hidrofóbicos y se asocian a la materia orgánica, ya sea en el suelo o en el sedimento de los ambientes acuáticos; por lo cual hay correlación positiva entre el COT y la concentración de los agrotóxicos. Sustratos que poseen abundante materia orgánica representan un ambiente de mayor exposición para los organismos asociados al sedimento. Sin embargo, también existe el efecto contrapuesto, la materia orgánica adsorbe y acompleja los agrotóxicos disminuyendo su biodisponibilidad y, por consiguiente, la toxicidad de los mismos. El resultado neto resulta difícil de predecir. Los taxones que registraron correlación positiva con la materia orgánica, Bivalvia, Hirudinea y Platyhelminthes, son considerados tolerantes a los agrotóxicos (Tabla 3.21). 
En el presente estudio se observó que algunas características de la cuenca como la presencia de una represa (Horqueta 0) o un humedal (Maguire) tienen influencia en la composición de los ensambles, presumiblemente porque en ambos casos existiría retención de los biocidas en esos ambientes, favoreciendo a las especies sensibles del ensamble. Mugni (2009) determinó que las concentraciones de nitratos en Maguire y Horqueta resultaron significativamente menores que en otros arroyos de la región y lo adjudicó a la asimilación y desnitrificación en los ambientes ribereños de estos arroyos.

La composición de los ensambles resultó significativamente distinta con posterioridad a un período con eventos de lluvias excepcionales. Este tipo de lluvias, representan un estrés para los ensambles debido a que una mayor velocidad de corriente puede arrastrar aguas abajo una fracción variable de la población. En el presente trabajo, se observó que el muestreo de febrero de 2014 resultó bien representado por Chironomidae, Oligochaeta, Gastropoda, Bivalvia, Hirudinea y Nematoda, considerados tolerantes. Al iniciarse un evento de lluvia, el agua percola a través del suelo y, cuando este se satura, comienza el flujo superficial de la escorrentía arrastrando partículas de suelo con los contaminantes asociados. La escorrentía superficial se forma en la región pampeana con una lluvia de aproximadamente $26 \mathrm{~mm}$ (Jergentz et al., 2004). Todo evento de escorrentía implica la ocurrencia de un pulso de toxicidad cuya intensidad está asociada al tiempo transcurrido entre la aplicación de agrotóxico en el cultivo y la primer lluvia con posterioridad que posea una intensidad suficiente para producir escorrentía (Mugni et al., 2012, Paracampo et al., 2012). Si la lluvia es excepcionalmente fuerte, puede arrastrar aguas abajo no sólo a los organismos sino también el material transportado por la propia escorrentía y el material previamente depositado en el cauce de los arroyos; de esta forma, puede no detectarse la presencia de agrotóxicos en los sedimentos muestreados en la fecha posterior aun cuando existió el pulso de toxicidad. El efecto combinado del arrastre y la toxicidad resulta en un ensamble más empobrecido como el que se detectó en febrero del 2014. En situaciones donde el arroyo comienza a mostrar signos de contaminación, o por el contrario que comienzan a recuperarse, es común encontrar poblaciones dominantes de Platyhelminthes, Oligochaeta, Hirudinea, Chironomidae y ciertos Mollusca, mezclados en menor proporción con ciertos Ephemeroptera y Trichoptera (Roldán Pérez, 1999). Mugni (2009) estudió la concentración de nutrientes en arroyos de la zona y, observó que, con posterioridad a un período de lluvia excepcional, alcanzando una precipitación 
de $228 \mathrm{~mm}$ en cinco días, el aumento de nivel de agua en el río Arrecifes creó condiciones que impedían el desagüe de sus tributarios, cesando el flujo momentáneamente. En esa condición, se produjo una drástica disminución del oxígeno disuelto que alcanzó $0,4 \mathrm{mg} / \mathrm{l}$ en el arroyo Luna, también muestreado en el presente estudio. La reducción del oxígeno disuelto impide el proceso de nitrificación y aumenta la desnitrificación, compatible con la disminución del nitrato y el aumento de amonio que caracterizó el muestreo de febrero de 2014 en el presente trabajo de tesis.

Los macroinvertebrados acuáticos han adquirido una creciente importancia en el análisis de la calidad del agua, debido a que no sólo revelan las condiciones ambientales actuales, sino que actúan como reveladores de las condiciones en el tiempo (AlbaTercedor, 1996). Por lo tanto, los ensambles pueden ser usados para evaluar ecosistemas acuáticos y sus respuestas a los cambios en el uso del suelo de las tierras adyacentes. Los ensambles de macroinvertebrados en los arroyos resultan de una combinación de diferentes parámetros ambientales. En los sitios no disturbados, las características del arroyo tales como la morfología (Probst et al., 2005), química (Gibbins et al., 2001) y vegetación ribereña (Potter et al., 2005) determinan la ocurrencia y abundancia de diferentes taxones y, pueden proveer de adecuados indicadores de la composición del ensamble (Clarke et al., 2003). Adicionalmente, estos ensambles pueden verse afectados por compuestos orgánicos y agrotóxicos (Liess \& Von der Ohe 2005). 


\section{Selva Paranaense (Paraguay y Brasil)}

\section{RESULTADOS}

\section{Variables ambientales}

Los resultados de las determinaciones de nutrientes indicaron que las concentraciones fueron menores al límite de detección del método utilizado $\left(\mathrm{N}_{-} \mathrm{NH}_{4}^{+}\right.$

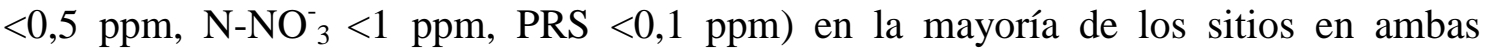
regiones. Cuatro sitios en Brasil (B11, B16, B17 y B23) y cinco en Paraguay (P1, P2, P9, P10, P11) tenían concentraciones de nitratos de 1-2 ppm, y dos sitios en Brasil (B10, B12) tenían concentraciones de PRS entre 0,1-0,2 ppm. Las concentraciones de nutrientes fueron medidas mediante un kit y los valores estimados por rango, resultando generalmente bajas y con poca variabilidad entre los sitios, por lo que no fueron incluidos como variables en los análisis estadísticos.

El análisis estadístico de los parámetros ambientales (ANOVA - test de t ó Mann-Whitney, según corresponda) mostró diferencias significativas entre los arroyos de Brasil y Paraguay. Los arroyos de Brasil registraron mayor porcentaje de Materia Orgánica Particulada Fina (MOPF), Materia Orgánica Particulada Gruesa (MOPG), Carbono Orgánico Total (COT) y porcentaje de limo, y una mayor velocidad de corriente. Los sitios de Paraguay presentaron arroyos más anchos y profundos, con mayor conductividad. Sin embargo, la calificación general de la calidad del hábitat siguiendo el Protocolo Rápido de Bioevaluación (RBP) de la USEPA (Barbour et al. 1999) fue similar (Tabla 4.1). 
Tabla 4.1. Las características ambientales de los arroyos estudiados en Brasil y Paraguay (prom: promedio, desv: desvío, máx: máximos y mín: mínimos).

\begin{tabular}{|c|c|c|c|c|c|c|c|}
\hline Parámetro & & Paraguay $^{\text {a }}$ & Brasil & Parámetro & & Paraguay $^{\text {a }}$ & Brasil \\
\hline \multirow{4}{*}{$\mathrm{T}\left({ }^{\circ} \mathrm{C}\right)$} & prom & 20,5 & 20,4 & \multirow{4}{*}{$\%$ Arcilla } & prom & 30 & 31 \\
\hline & \pm desv & 1,4 & 1,0 & & \pm desv & 10 & 7 \\
\hline & máx & 23 & 23 & & máx & 44 & 43 \\
\hline & mín & 18 & 19 & & mín & 12 & 21 \\
\hline \multirow{4}{*}{ Cond $* *$} & prom & 69 & 32 & \multirow{4}{*}{$\%$ Limo $* *$} & prom & 6 & 35 \\
\hline & \pm desv & 22 & 13 & & \pm desv & 3 & 7 \\
\hline & máx & 111 & 60 & & máx & 14 & 48 \\
\hline & mín & 24 & 14 & & mín & 2 & 23 \\
\hline \multirow{4}{*}{$\mathrm{pH} * *$} & prom & 6,7 & 7,2 & \multirow{4}{*}{$\%$ Arena $* *$} & prom & 64 & 34 \\
\hline & \pm desv & 0,3 & 0,3 & & \pm desv & 10 & 12 \\
\hline & máx & 7,2 & 7,6 & & máx & 86 & 55 \\
\hline & mín & 6,3 & 6,7 & & mín & 49 & 17 \\
\hline \multirow{4}{*}{$\begin{array}{c}\text { OD } \\
(\mathrm{mg} / \mathrm{l})\end{array}$} & prom & 8,4 & 8,4 & \multirow{4}{*}{ \% Rápidos } & prom & 28 & 39 \\
\hline & \pm desv & 0,4 & 0,2 & & \pm desv & 16 & 26 \\
\hline & máx & 9,2 & 8,7 & & máx & 60 & 90 \\
\hline & mín & 7,6 & 7,9 & & mín & 0 & 5 \\
\hline \multirow{4}{*}{$\begin{array}{l}\text { Turbidez } \\
\text { (NTU) }\end{array}$} & prom & 15 & 17 & \multirow{4}{*}{$\%$ Correderas } & prom & 66 & 57 \\
\hline & \pm desv & 7 & 8 & & \pm desv & 18 & 24 \\
\hline & máx & 38 & 31 & & máx & 100 & 90 \\
\hline & mín & 5 & 3 & & mín & 30 & 10 \\
\hline \multirow{4}{*}{$\% \mathrm{COT} * *$} & prom & 0,94 & 2,32 & \multirow{4}{*}{$\%$ Pozones } & prom & 5 & 4 \\
\hline & \pm desv & 0,62 & 0,68 & & \pm desv & 7 & 4 \\
\hline & máx & 2,80 & 3,24 & & máx & 20 & 10 \\
\hline & mín & 0,22 & 1,37 & & mín & 0 & 0 \\
\hline \multirow{4}{*}{$\begin{array}{c}\text { Franja de } \\
\text { atenuación } \\
(\mathrm{m})\end{array}$} & prom & 86 & 66 & \multirow{4}{*}{$\begin{array}{l}\% \text { Sedimento } \\
\text { fino }\end{array}$} & prom & 30 & 21 \\
\hline & \pm desv & 115 & 79 & & \pm desv & 34 & 19 \\
\hline & máx & 500 & 350 & & máx & 100 & 70 \\
\hline & mín & 1 & 9 & & mín & 0 & 0 \\
\hline \multirow{4}{*}{$\mathrm{RBP}$} & prom & 154 & 162 & \multirow{4}{*}{$\begin{array}{l}\text { \% Lecho } \\
\text { rocoso }\end{array}$} & prom & 33 & 17 \\
\hline & \pm desv & 24 & 12 & & \pm desv & 34 & 18 \\
\hline & máx & 182 & 180 & & máx & 95 & 50 \\
\hline & mín & 79 & 134 & & mín & 0 & 0 \\
\hline \multirow{4}{*}{$\begin{array}{c}\text { Velocidad } \\
\text { maxima } * * \\
(\mathrm{~m} / \mathrm{s})\end{array}$} & prom & 0,5 & 1,8 & \multirow{4}{*}{$\% \mathrm{MOPF} * *$} & prom & 2 & 7 \\
\hline & \pm desv & 0,2 & 0,5 & & \pm desv & 1 & 4 \\
\hline & máx & 0,9 & 2,8 & & máx & 5 & 20 \\
\hline & mín & 0,2 & 0,8 & & mín & 2 & 2 \\
\hline \multirow{4}{*}{$\begin{array}{c}\text { Ancho } \\
\text { máximo** } \\
(\mathrm{m})\end{array}$} & prom & 5,3 & 3,7 & \multirow{4}{*}{$\% \mathrm{MOPG} *$} & prom & 6 & 11 \\
\hline & \pm desv & 1,8 & 1,4 & & \pm desv & 3 & 7 \\
\hline & máx & 10 & 8 & & máx & 10 & 35 \\
\hline & mín & 3 & 2 & & mín & 2 & 5 \\
\hline \multirow{4}{*}{$\begin{array}{l}\text { Profundidad } \\
\text { máxima** } \\
\text { (m) }\end{array}$} & prom & 0,48 & 0,29 & \multirow{4}{*}{$\begin{array}{l}\text { Caudal } \\
\left(\mathrm{m}^{3} / \mathrm{S}\right)\end{array}$} & prom & 0,21 & 0,11 \\
\hline & \pm desv & 0,22 & 0,16 & & \pm desv & 0,22 & 0,12 \\
\hline & máx & 1,2 & 0,7 & & máx & 1,05 & 0,41 \\
\hline & mín & 0,2 & 0,1 & & mín & 0,01 & 0,01 \\
\hline
\end{tabular}

T: temperatura, Cond: conductividad, OD: oxígeno disuelto, COT: carbono orgánico total, RBP: calidad del hábitat mediante el protocolo rápido de bioevaluación, MOPF: materia orgánica particulada fina, MOPG: materia orgánica particulada gruesa. ${ }^{a}$ Para los parámetros que se midieron en ambos muestreos de Paraguay, se promediaron los valores. $* * \mathrm{p}<0,001 * \mathrm{p}<0,004$ 


\section{Agrotóxicos}

En ambas regiones, el insecticida más comúnmente detectado fue clorpirifos, seguido de los piretroides cipermetrina y lambda-cialotrina y, ocasionalmente, endosulfán y endosulfán sulfato (Tabla 4.2). También fueron analizados otros agrotóxicos piretroides y organoclorados (Tabla 4.3).

Clorpirifos tuvo la mayor frecuencia de detección en casi todos los muestreos. Las concentraciones máximas oscilaron entre 1,26 y 1,47 ng/g de peso seco (ps), con la mayor concentración medida en la región de Brasil. En ambas regiones, endosulfán y su producto de degradación, endosulfán sulfato, se detectaron con baja frecuencia y concentración. En Paraguay las concentraciones máximas fueron 0,85 y 0,58 ng/g ps y en Brasil 0,49 y 0,47 ng/g ps respectivamente. Cipermetrina se detectó con frecuencias similares en los tres muestreos y la concentración máxima fue 1,18 ng/g ps en Paraguay y 4,94 ng/g ps en Brasil. Las concentraciones de este piretroide en Brasil resultaron significativamente mayores que las concentraciones detectadas en Paraguay en diciembre 2013 (Kruskal Wallis, Dunn's p<0,023). Asimismo, las concentraciones para lambda-cialotrina resultaron significativamente mayores en los arroyos de Brasil que en los de Paraguay (Kruskal Wallis, Dunn's p $<0,001$ ), analizando tanto los datos por región como por fecha de muestreo. Sin embargo, cabe destacar que en el arroyo P16 muestreado en enero 2013, en Paraguay, se detectó la máxima concentración de lambdacialotrina $(16,57 \mathrm{ng} / \mathrm{g} \quad \mathrm{ps})$. La concentración de agrotóxicos totales fue significativamente mayor en la región de Brasil (Kruskal Wallis, Dunn’s p<0,023). 
Tabla 4.2 Concentraciones de los biocidas en sedimentos por muestreos en Paraguay y Brasil, 2013.

\begin{tabular}{|ll|cc|c|}
\hline Región & & \multicolumn{2}{|c|}{ Paraguay } & Brasil \\
Fecha & & ene-2013 & dic-2013 & nov-2013 \\
$\mathrm{N}^{\circ}$ de muestras & & 16 & 14 & 18 \\
\hline \hline \multirow{5}{*}{ Clorpirifos } & Frecuencia & $75 \%$ & $100 \%$ & $94 \%$ \\
& Máximo (ng/g) & 1,26 & 1,24 & 1,47 \\
& Media (ng/g) & 0,48 & 0,66 & 0,72 \\
& \pm sd & 0,30 & 0,26 & 0,31 \\
\hline \multirow{5}{*}{ Endosulfán } & Frecuencia & $44 \%$ & $14 \%$ & $11 \%$ \\
& Máximo (ng/g) & 0,85 & 0,25 & 0,49 \\
& Media (ng/g) & 0,36 & 0,14 & 0,15 \\
& \pm sd & 0,21 & 0,04 & 0,09 \\
\hline Endosulfán Sulfato & Frecuencia & $6 \%$ & $64 \%$ & $44 \%$ \\
& Máximo (ng/g) & 0,58 & 0,52 & 0,47 \\
& Media (ng/g) & 0,20 & 0,24 & 0,21 \\
& \pm sd & 0,12 & 0,13 & 0,12 \\
\hline Cipermetrina & Frecuencia & $75 \%$ & $64 \%$ & $78 \%$ \\
& Máximo (ng/g) & 1,18 & 0,90 & 4,94 \\
& Media (ng/g) & 0,44 & 0,26 & 0,89 \\
& \pm sd & 0,33 & 0,20 & 1,20 \\
\hline Agrotóxicos total & Frecuencia & $44 \%$ & $29 \%$ & $94 \%$ \\
& Máximo (ng/g) & 16,57 & 0,86 & 1,32 \\
& Media (ng/g) & 1,21 & 0,23 & 0,50 \\
& \pm sd & 4,10 & 0,21 & 0,29 \\
\hline & Media (ng/g) & $88 \%$ & $100 \%$ & $100 \%$ \\
& \pm sd & 18,10 & 2,85 & 7,29 \\
& Frecuencia & 4,26 & 1,30 & 2,26 \\
& Máximo (ng/g) & 0,62 & 1,55 \\
\hline
\end{tabular}

Limite de cuantificación: $0,25 \mathrm{ng} / \mathrm{g}$ peso seco.

Método: GC-MS

En las dos regiones también se detectaron ocasionalmente los piretroides: bifentrina, permetrina, ciflutrina, deltametrina y esfenvalerato en concentraciones menores. La presencia de piperonil butóxido (PBO) se determinó frecuentemente, compuesto que se utiliza como sinérgico de los piretroides, con concentraciones máximas de 1,87 a 11,14 ng/g ps. El DDT y sus productos de degradación, DDE y DDD se detectaron en ambas regiones, pero con mayor frecuencia en Brasil (100\% de frecuencia de detección de DDT y DDE, con concentraciones máximas de 1,06 y 5,67 $\mathrm{ng} / \mathrm{g}$ ps, respectivamente). Otros organoclorados prohibidos que se detectaron rara vez, generalmente por debajo del límite de cuantificación, incluyeron endrina, clordano, 
aldrin y dieldrin. No se detectó la presencia de los organoclorados, epóxido de heptacloro y lindano (Tabla 4.3).

Tabla 4.3 Concentraciones máximas (máx.) y frecuencia porcentual de detección (\%) de los compuestos adicionales analizados en sedimentos para los muestreos en Paraguay y Brasil, 2013.

\begin{tabular}{|c|c|c|c|c|c|c|}
\hline Región & \multicolumn{4}{|c|}{ Paraguay } & \multirow{2}{*}{\multicolumn{2}{|c|}{$\begin{array}{c}\text { Brasil } \\
\text { nov-2013 }\end{array}$}} \\
\hline Fecha & \multirow{2}{*}{\multicolumn{2}{|c|}{$\begin{array}{c}\text { ene- } 2013 \\
8 \\
\end{array}$}} & \multirow{2}{*}{\multicolumn{2}{|c|}{$\begin{array}{c}\text { dic-2013 } \\
13\end{array}$}} & & \\
\hline $\mathrm{N}^{\circ}$ de muestras & & & & & 1 & \\
\hline Concentracion ng/g ps & max. & $(\%)$ & max. & $(\%)$ & max. & $(\%)$ \\
\hline $\mathrm{PBO}$ & 1,87 & $(88)$ & 1,23 & $(8)$ & 11,14 & (94) \\
\hline Bifentrina & 0,37 & $(38)$ & 0,63 & $(31)$ & 1,44 & (44) \\
\hline Permetrina & 2,56 & $(13)$ & 0,47 & (23) & 2,07 & (33) \\
\hline Ciflutrina & $<0,25$ & (13) & 0,40 & (38) & $<0,25$ & (11) \\
\hline Deltametrina & $<0,25$ & $(13)$ & nd & & 0,87 & (11) \\
\hline Esfenvalerato & $<0,25$ & $(38)$ & nd & & 0,29 & (22) \\
\hline Teflutrina & nd & & nd & & $<0,25$ & (22) \\
\hline DDD & nd & & nd & & 3,97 & (33) \\
\hline DDE & nd & & 1,88 & $(15)$ & 5,67 & $(100)$ \\
\hline DDT & nd & & 0,49 & $(23)$ & 1,06 & $(100)$ \\
\hline Cetona de Endrina & $<0,25$ & (13) & nd & & 0,34 & $(6)$ \\
\hline Endrina & nd & & $<0,25$ & $(8)$ & $<0,25$ & (17) \\
\hline Aldrin & nd & & nd & & 0,42 & (11) \\
\hline Dieldrin & nd & & nd & & $<0,25$ & (6) \\
\hline Alpha Clordano & nd & & $<0,25$ & $(8)$ & $<0,25$ & (6) \\
\hline Gamma Clordano & nd & & nd & & nd & \\
\hline Lindano & nd & & nd & & nd & \\
\hline Epoxido de Heptacloro & nd & & nd & & nd & \\
\hline
\end{tabular}

nd: no detectado (límite de cuantificación 0,25 ng/g peso seco)

PBO: piperonil butóxido

DDT: dicloro difenil tricloroetano

DDD: dicloro difenil dicloroetano

DDE: dicloro difenil dicloroetileno

\section{Unidades Tóxicas (UT)}

En la tabla 4.4 se muestran las unidades toxicas (UT) calculadas para los arroyos de Paraguay y Brasil. Los valores de UT totales calculadas para Paraguay variaron entre 0,02 a 0,81 (excepto el arroyo P16 que presentó un valor de 3,62 en el muestreo de enero 2013) y para Brasil entre 0,01 a 0,36; no evidenciándose diferencias significativas entre ambas regiones. La contribución correspondiente a los piretroides representa $88 \%$ y $90 \%$ de la toxicidad total en Paraguay y Brasil respectivamente. 
Tabla 4.4 Unidades Tóxicas de los Agrotóxicos más utilizados calculados para cada arroyo muestreado en Paraguay y Brasil 2013.

\begin{tabular}{|c|c|c|c|c|c|c|c|c|c|}
\hline Región & Fecha & Sitio & $\begin{array}{c}\text { UT } \\
\text { Clorp }^{\text {a }} \\
\end{array}$ & $\begin{array}{c}\text { UT } \\
\lambda \text {-Cialo }{ }^{a}\end{array}$ & $\begin{array}{c}\text { UT } \\
\text { Ciper }^{\text {a }} \\
\end{array}$ & $\begin{array}{c}\text { UT } \\
\text { Endo }^{\text {a }} \\
\end{array}$ & $\begin{array}{c}\text { UT } \\
\text { Endo-Sul }^{b} \\
\end{array}$ & $\begin{array}{c}\text { UT } \\
\text { Piret }\end{array}$ & $\begin{array}{l}\text { UT } \\
\text { total }\end{array}$ \\
\hline \multirow{27}{*}{ 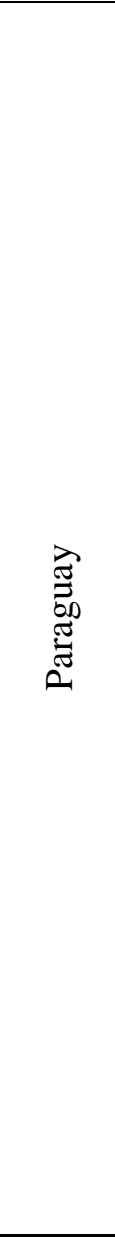 } & \multirow{14}{*}{ ene-2013 } & P1 & 0,051 & - & 0,018 & 0,0021 & - & 0,02 & 0,07 \\
\hline & & P2 & 0,008 & 0,052 & 0,016 & 0,0004 & 0,004 & 0,07 & 0,08 \\
\hline & & P3 & 0,037 & 0,127 & 0,045 & 0,0033 & - & 0,17 & 0,21 \\
\hline & & P4 & - & 0,093 & - & - & - & 0,09 & 0,09 \\
\hline & & P5 & 0,015 & 0,063 & 0,017 & - & - & 0,08 & 0,10 \\
\hline & & P6 & 0,010 & - & 0,011 & 0,0016 & - & 0,01 & 0,02 \\
\hline & & P7 & 0,034 & - & - & - & - & . & 0,03 \\
\hline & & P9 & 0,038 & 0,271 & 0,129 & - & - & 0,40 & 0,44 \\
\hline & & P10 & 0,031 & - & 0,080 & - & - & 0,08 & 0,11 \\
\hline & & P11 & 0,050 & 0,054 & 0,042 & 0,0059 & - & 0,10 & 0,15 \\
\hline & & P12 & 0,023 & - & 0,023 & 0,0021 & - & 0,02 & 0,05 \\
\hline & & P13 & 0,010 & - & 0,011 & - & - & 0,01 & 0,02 \\
\hline & & P14 & 0,015 & - & 0,016 & - & - & 0,02 & 0,03 \\
\hline & & P16 & - & 3,597 & 0,018 & 0,0014 & - & 3,61 & 3,62 \\
\hline & \multirow{13}{*}{ dic-2013 } & P1 & 0,033 & 0,312 & - & - & - & 0,31 & 0,35 \\
\hline & & P4 & 0,016 & - & 0,016 & - & - & 0,02 & 0,03 \\
\hline & & P5 & 0,021 & - & 0,017 & - & - & 0,02 & 0,04 \\
\hline & & P6 & 0,030 & - & 0,031 & - & 0,018 & 0,03 & 0,08 \\
\hline & & P7 & 0,061 & - & - & - & - & - & 0,06 \\
\hline & & P8 & 0,061 & - & 0,049 & - & 0,011 & 0,05 & 0,12 \\
\hline & & P9 & 0,040 & 0,759 & - & - & 0,008 & 0,76 & 0,81 \\
\hline & & P10 & 0,040 & 0,276 & 0,018 & - & 0,007 & 0,29 & 0,34 \\
\hline & & P13 & 0,024 & - & 0,011 & - & 0,005 & 0,01 & 0,04 \\
\hline & & P14 & 0,037 & 0,157 & 0,011 & 0,0008 & 0,007 & 0,17 & 0,21 \\
\hline & & P15 & 0,027 & - & 0,017 & - & 0,005 & 0,02 & 0,05 \\
\hline & & P16 & 0,026 & - & - & - & 0,007 & - & 0,03 \\
\hline & & P17 & 0,019 & - & 0,021 & 0,0004 & 0,004 & 0,02 & 0,04 \\
\hline \multirow{18}{*}{ 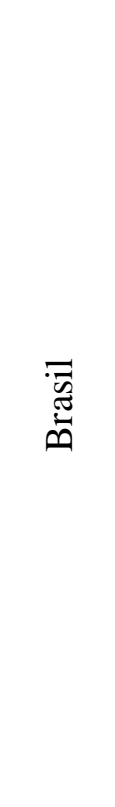 } & \multirow{18}{*}{ nov-2013 } & B2 & 0,016 & 0,285 & 0,027 & - & 0,004 & 0,31 & 0,33 \\
\hline & & B3 & 0,006 & 0,056 & 0,007 & - & - & 0,06 & 0,07 \\
\hline & & B7 & 0,019 & 0,185 & 0,153 & 0,0004 & 0,006 & 0,34 & 0,36 \\
\hline & & B10 & 0,009 & 0,069 & 0,019 & - & 0,002 & 0,09 & 0,10 \\
\hline & & B11 & 0,014 & 0,075 & 0,015 & - & 0,004 & 0,09 & 0,11 \\
\hline & & B12 & 0,009 & 0,178 & - & - & - & 0,18 & 0,19 \\
\hline & & B13 & 0,009 & 0,060 & 0,008 & - & - & 0,07 & 0,08 \\
\hline & & B14 & 0,011 & 0,065 & - & - & 0,002 & 0,06 & 0,08 \\
\hline & & B15 & 0,015 & 0,063 & 0,034 & - & - & 0,10 & 0,11 \\
\hline & & B16 & 0,021 & 0,138 & 0,030 & - & - & 0,17 & 0,19 \\
\hline & & B17 & 0,017 & 0,087 & 0,007 & - & - & 0,09 & 0,11 \\
\hline & & B18 & 0,016 & 0,117 & - & - & - & 0,12 & 0,13 \\
\hline & & B19 & 0,011 & 0,095 & - & - & - & 0,09 & 0,11 \\
\hline & & B20 & 0,008 & - & 0,005 & - & - & 0,01 & 0,01 \\
\hline & & B21 & 0,008 & 0,069 & 0,007 & - & - & 0,08 & 0,08 \\
\hline & & B22 & 0,007 & 0,046 & 0,007 & 0,0005 & 0,003 & 0,05 & 0,06 \\
\hline & & B23 & 0,002 & 0,040 & 0,037 & - & 0,002 & 0,08 & 0,08 \\
\hline & & B24 & . & 0,040 & 0,011 & - & 0,001 & 0,05 & 0,05 \\
\hline
\end{tabular}

Clorp: clorpirifos, $\lambda$-Cialo: lambda cialotrina, Ciper: cipermetrina, Endo: endosulfán, Endo-Sul: endosulfán sulfato, Piret: piretroides. ${ }^{a}: \mathrm{LC}_{50}$ para Hyalella curvispina. ${ }^{\mathrm{b}}: \mathrm{LC}_{50}$ para Chironomus tentans (You et al., 2004a). - : menor al limite de cuantificación ( $0,25 \mathrm{ng} / \mathrm{g} \mathrm{ps})$. 


\section{Ensamble de macroinvertebrados}

La composición de los ensambles de macroinvertebrados en ambas regiones registró diferencias en la abundancia relativa de ciertos grupos y en la presencia de algunas familias (Figura 4.1, Tabla 4.6 y 4.7).

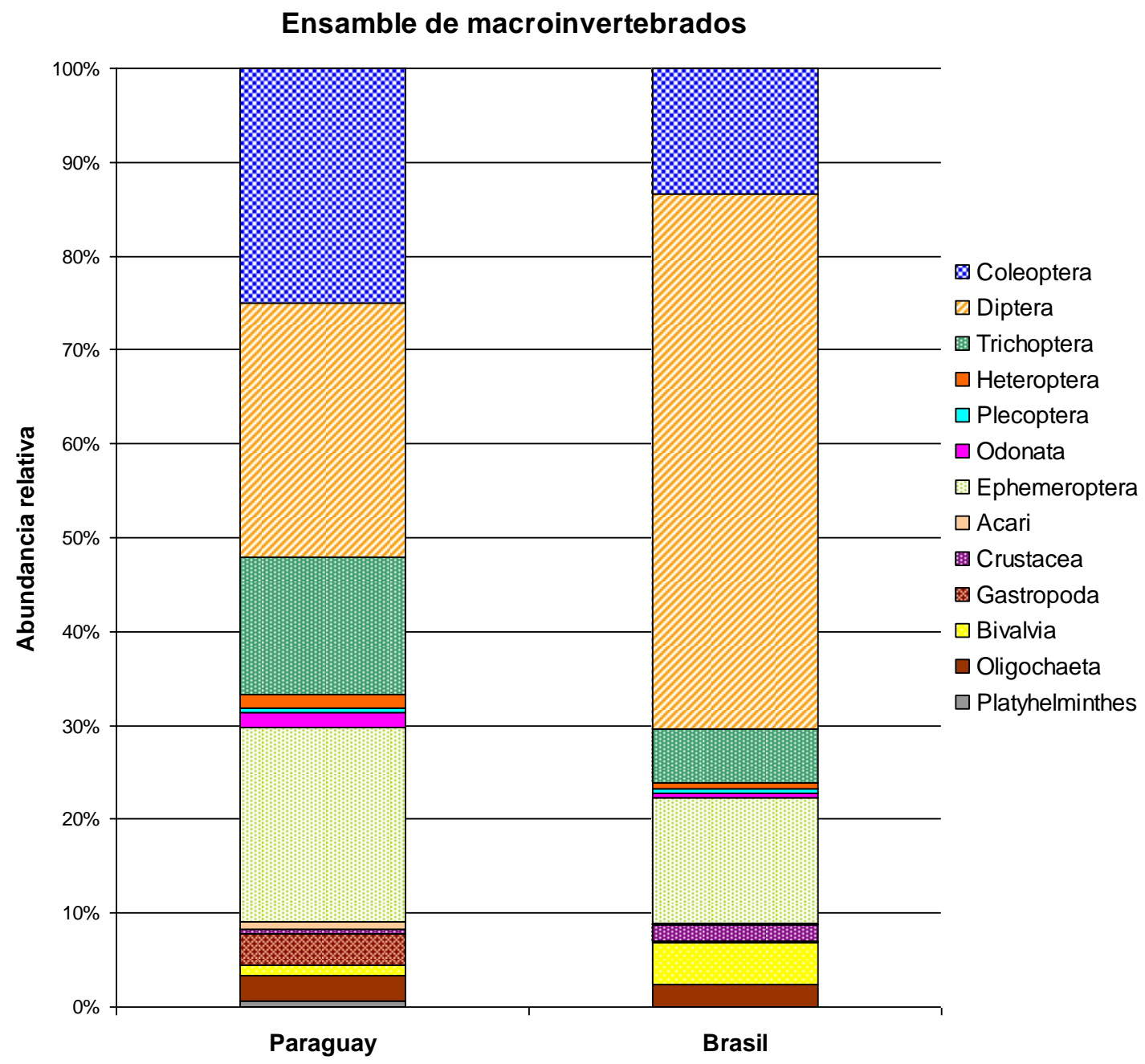

Figura 4.1: Contribución relativa en función de la abundancia de grandes grupos taxonómicos en Brasil y Paraguay.

La riqueza taxonómica fue significativamente mayor en Paraguay (26) que en Brasil (19) (Mann-Whitney p<0,001). De igual manera, el índice de Margalef (MannWhitney $\mathrm{p}<0,001$ ), equitatividad de Pielou (test de $\mathrm{p}<<0,001$ ), diversidad de ShannonWiener (test de $\mathrm{t}$ p<0,001) e índice de dominancia de Simpson (Mann-Whitney $\mathrm{p}<0,001)$ fueron significativamente mayores para los arroyos de Paraguay (Tabla 4.5). 
Tabla 4.5. Promedio de la riqueza taxonómica, índice de Margalef, equitatividad de Pielou, diversidad de Shannon-Wiener e índice de dominancia de Simpson de los muestreos realizados en Paraguay y Brasil.

\begin{tabular}{lcc} 
& Paraguay & Brasil \\
\hline \hline Riqueza & 26 & 19 \\
Indice de Margalef & 5,41 & 3,98 \\
Equitatividad de Pielou & 0,69 & 0,54 \\
Indice de Shannon-Wiener & 0,96 & 0,70 \\
Indice de Simpson & 0,82 & 0,66 \\
\hline
\end{tabular}

En las muestras de Paraguay se identificaron un total de 67 taxones (Tabla 4.6), mientras que en Brasil sólo 53 taxones (Tabla 4.7). En Paraguay, se determinaron 46 familias de insectos y en Brasil 39. De las familias de insectos identificadas en Paraguay, diez no estaban presentes en Brasil. Mientras que sólo tres familias de insectos determinadas en Brasil no estuvieron presentes en Paraguay. Todas las familias de insectos que se encontraron en una de las regiones, pero no en la otra, tuvieron una baja frecuencia de detección y abundancia relativa menor al 1\%. En Paraguay, el único decápodo identificado fue de la familia Trichodactylidae, y en Brasil el único decápodo fue de la familia Aeglidae. No se encontraron ostrácodos en las muestras de Paraguay, pero sí se encontraron en dos arroyos de Brasil, en muy baja abundancia.

En ambas regiones, la familia dominante fue Chironomidae (Diptera), pero la abundancia relativa fue significativamente mayor en Brasil (Mann-Whitney $\mathrm{p}<0,001$ ). La segunda familia dominante en ambas regiones fue Elmidae (Coleoptera), y en este caso la abundancia relativa fue significativamente mayor en Paraguay (test de $\mathrm{t}$ p <0,001). Del orden Ephemeroptera, la familia Leptohyphidae fue la más común en Paraguay; mientras que en Brasil fue la familia Leptophlebiidae. En Paraguay, el orden Trichoptera tuvo la mayor abundancia relativa y presentó más familias que en Brasil. Los plecópteros y Megaloptera fueron raros en ambas regiones. 
Tabla 4.6. La abundancia relativa media porcentual de los taxones de macroinvertebrados en los 17 sitios estudiados de Paraguay (inid: inidentificado).

\begin{tabular}{|c|c|c|c|c|c|c|c|c|c|c|c|c|c|c|c|c|c|c|}
\hline \multirow{2}{*}{\multicolumn{2}{|c|}{\begin{tabular}{ll}
\multicolumn{2}{c}{ Abundancia relativa media \% } \\
Filo u Orden $\quad$ taxones
\end{tabular}}} & \multirow[b]{2}{*}{ P1 } & \multirow[b]{2}{*}{ P2 } & \multirow[b]{2}{*}{ P3 } & \multirow[b]{2}{*}{ P4 } & \multirow[b]{2}{*}{ P5 } & \multirow[b]{2}{*}{ P6 } & \multirow[b]{2}{*}{ P7 } & \multicolumn{3}{|c|}{ Paraguay } & \multirow[b]{2}{*}{ P11 } & \multirow[b]{2}{*}{ P12 } & \multirow[b]{2}{*}{ P13 } & \multirow[b]{2}{*}{ P14 } & & & \\
\hline & & & & & & & & & P8 & P9 & P10 & & & & & P15 & P16 & P17 \\
\hline Platyhelminthes & & 0 & 1 & 1 & 0 & 0 & 1 & 0 & 2 & 1 & 1 & 1 & 0 & 1 & 1 & 1 & 1 & 0 \\
\hline Oligochaeta & & 1 & 1 & 6 & 1 & 1 & 3 & 1 & 2 & 1 & 1 & 1 & 0 & 2 & 2 & 17 & 1 & 2 \\
\hline Hirudinea & & 0 & 0 & 0 & 1 & 1 & 1 & 0 & 0 & 0 & 1 & 0 & 0 & 0 & 0 & 1 & 1 & 1 \\
\hline Nematoda & & 1 & 1 & 1 & 1 & 0 & 1 & 1 & 1 & 1 & 0 & 0 & 1 & 0 & 1 & 1 & 1 & 1 \\
\hline Nemertea & & 0 & 0 & 1 & 0 & 0 & 1 & 0 & 0 & 0 & 0 & 1 & 0 & 0 & 0 & 1 & 1 & 0 \\
\hline Mollusca & & & & & & & & & & & & & & & & & & \\
\hline Bivalvia & & 0 & 1 & 1 & 1 & 2 & 1 & 1 & 1 & 0 & 1 & 0 & 0 & 0 & 1 & 8 & 1 & 3 \\
\hline Gastropoda & & 2 & 3 & 2 & 29 & 9 & 3 & 1 & 2 & 1 & 2 & 2 & 0 & 0 & 1 & 1 & 2 & 2 \\
\hline & Ancylidae & 1 & 1 & 1 & 0 & 0 & 1 & 0 & 1 & 0 & 1 & 1 & 0 & 0 & 1 & 0 & 1 & 1 \\
\hline & Gastropoda inid & 1 & 2 & 1 & 29 & 9 & 2 & 1 & 2 & 1 & 1 & 1 & 0 & 0 & 0 & 1 & 1 & 1 \\
\hline Crustacea & & 1 & 0 & 1 & 1 & 1 & 1 & 1 & 1 & 1 & 1 & 0 & 1 & 0 & 1 & 1 & 1 & 0 \\
\hline Decapoda & Trichodactylidae & 1 & 0 & 1 & 0 & 1 & 1 & 1 & 0 & 0 & 1 & 0 & 1 & 0 & 1 & 1 & 1 & 0 \\
\hline Amphipoda & Hyalellidae & 0 & 0 & 0 & 1 & 0 & 0 & 0 & 1 & 1 & 0 & 0 & 0 & 0 & 0 & 0 & 0 & 0 \\
\hline Acari & & 1 & 1 & 2 & 1 & 3 & 0 & 1 & 1 & 1 & 1 & 1 & 0 & 1 & 2 & 0 & 1 & 1 \\
\hline Collembola & Entomobryonidae & 1 & 0 & 0 & 0 & 1 & 0 & 1 & 1 & 0 & 1 & 1 & 3 & 0 & 0 & 1 & 0 & 0 \\
\hline Insecta & & & & & & & & & & & & & & & & & & \\
\hline Ephemeroptera & & 22 & 33 & 13 & 18 & 24 & 6 & 22 & 34 & 32 & 37 & 22 & 14 & 12 & 24 & 10 & 26 & 15 \\
\hline & Baetidae & 10 & 6 & 3 & 5 & 11 & 1 & 4 & 6 & 8 & 10 & 8 & 9 & 6 & 13 & 3 & 11 & 7 \\
\hline & Caenidae & 1 & 0 & 1 & 1 & 1 & 1 & 3 & 1 & 0 & 1 & 1 & 0 & 0 & 1 & 2 & 0 & 1 \\
\hline & Leptohyphidae & 9 & 21 & 4 & 11 & 9 & 2 & 13 & 25 & 12 & 24 & 12 & 4 & 4 & 9 & 4 & 15 & 6 \\
\hline & Leptophlebiidae & 2 & 5 & 5 & 1 & 2 & 1 & 2 & 3 & 4 & 2 & 1 & 1 & 1 & 1 & 1 & 1 & 1 \\
\hline & Ephemeroptera inid & 0 & 1 & 0 & 0 & 1 & 0 & 0 & 0 & 7 & 0 & 0 & 0 & 1 & 0 & 0 & 0 & 0 \\
\hline Odonata & & 3 & 3 & 3 & 3 & 3 & 4 & 4 & 2 & 4 & 5 & 5 & 0 & 1 & 2 & 2 & 4 & 3 \\
\hline & Calopterygidae & 0 & 0 & 0 & 0 & 0 & 0 & 1 & 0 & 0 & 1 & 1 & 0 & 0 & 0 & 0 & 0 & 0 \\
\hline & Coenagrionidae & 0 & 1 & 1 & 1 & 0 & 1 & 0 & 0 & 1 & 1 & 0 & 0 & 0 & 1 & 0 & 1 & 0 \\
\hline & Corduliidae & 0 & 0 & 0 & 0 & 1 & 1 & 1 & 0 & 0 & 0 & 1 & 0 & 0 & 0 & 0 & 1 & 1 \\
\hline & Gomphidae & 1 & 1 & 1 & 1 & 1 & 1 & 1 & 1 & 2 & 1 & 1 & 0 & 1 & 1 & 2 & 1 & 1 \\
\hline & $\begin{array}{l}\text { Megapodagrionidae } \\
\text { Libellulidae }\end{array}$ & 0 & 0 & 1 & 0 & 0 & 0 & 0 & 0 & 0 & 1 & 0 & 0 & 0 & 0 & 0 & 0 & 0 \\
\hline & Libellulidae inid & 1 & 1 & 0 & 1 & 1 & 1 & 1 & 1 & 1 & 1 & 1 & 0 & 0 & 0 & 0 & 0 & 0 \\
\hline & Libellulinae & 1 & 0 & 0 & 1 & 0 & 0 & 0 & 0 & 0 & 0 & 1 & 0 & 0 & 0 & 0 & 1 & 1 \\
\hline Plecoptera & & 1 & 2 & 2 & 0 & 1 & 0 & 1 & 1 & 1 & 1 & 1 & 0 & 0 & 1 & 0 & 0 & 0 \\
\hline & Grypopterygidae & 0 & 1 & 0 & 0 & 1 & 0 & 0 & 1 & 0 & 0 & 0 & 0 & 0 & 1 & 0 & 0 & 0 \\
\hline & Perlidae & 1 & 1 & 2 & 0 & 0 & 0 & 1 & 0 & 1 & 1 & 1 & 0 & 0 & 0 & 0 & 0 & 0 \\
\hline Heteroptera & & 2 & 1 & 0 & 1 & 2 & 0 & 8 & 3 & 1 & 4 & 2 & 0 & 2 & 3 & 1 & 0 & 0 \\
\hline & Gerridae & 0 & 0 & 0 & 0 & 0 & 0 & 1 & 0 & 0 & 0 & 1 & 0 & 0 & 0 & 0 & 0 & 0 \\
\hline & Helotrephidae & 1 & 0 & 0 & 0 & 0 & 0 & 4 & 0 & 0 & 0 & 0 & 0 & 0 & 1 & 0 & 0 & 0 \\
\hline & Naucoridae & 1 & 0 & 0 & 1 & 2 & 0 & 1 & 1 & 1 & 4 & 1 & 0 & 1 & 1 & 1 & 0 & 0 \\
\hline & Pleidae & 0 & 0 & 0 & 0 & 0 & 0 & 2 & 1 & 0 & 0 & 0 & 0 & 0 & 1 & 0 & 0 & 0 \\
\hline & Veliidae & 0 & 1 & 0 & 0 & 0 & 0 & 0 & 1 & 0 & 0 & 0 & 0 & 1 & 0 & 0 & 0 & 0 \\
\hline Megaloptera & Corydalidae & 1 & 1 & 0 & 0 & 1 & 0 & 0 & 1 & 1 & 0 & 1 & 0 & 0 & 0 & 0 & 0 & 1 \\
\hline Trichoptera & & 15 & 25 & 17 & 8 & 12 & 6 & 13 & 12 & 24 & 12 & 19 & 22 & 31 & 26 & 6 & 12 & 16 \\
\hline & Calamoceratidae & 1 & 1 & 1 & 0 & 1 & 0 & 1 & 1 & 0 & 1 & 0 & 0 & 0 & 0 & 0 & 1 & 1 \\
\hline & Glossosomatidae & 1 & 2 & 1 & 2 & 1 & 1 & 1 & 6 & 4 & 1 & 1 & 1 & 4 & 1 & 0 & 3 & 3 \\
\hline & Helicopsychidae & 0 & 0 & 0 & 1 & 0 & 0 & 0 & 0 & 0 & 0 & 0 & 0 & 0 & 0 & 0 & 0 & 0 \\
\hline & Hydrobiosidae & 0 & 0 & 0 & 1 & 0 & 0 & 0 & 0 & 1 & 0 & 1 & 0 & 0 & 0 & 0 & 1 & 0 \\
\hline & Hydropsychidae & 8 & 19 & 7 & 3 & 5 & 3 & 7 & 1 & 10 & 2 & 10 & 19 & 9 & 2 & 3 & 2 & 12 \\
\hline & Hydroptilidae & 1 & 1 & 1 & 1 & 0 & 1 & 1 & 0 & 1 & 1 & 1 & 0 & 2 & 2 & 0 & 1 & 0 \\
\hline & Leptoceridae & 1 & 1 & 0 & 0 & 1 & 1 & 0 & 1 & 1 & 1 & 1 & 0 & 0 & 1 & 1 & 1 & 0 \\
\hline & Odontoceridae & 1 & 1 & 0 & 0 & 3 & 0 & 1 & 2 & 5 & 2 & 0 & 1 & 0 & 1 & 1 & 1 & 0 \\
\hline & Philopotamidae & 2 & 1 & 7 & 1 & 0 & 1 & 0 & 1 & 1 & 1 & 1 & 1 & 0 & 1 & 0 & 1 & 1 \\
\hline & Polycentropodidae & 0 & 0 & 0 & 0 & 0 & 0 & 1 & 1 & 1 & 1 & 3 & 0 & 1 & 0 & 0 & 0 & 0 \\
\hline & Sericostomatidae & 0 & 1 & 0 & 0 & 1 & 0 & 1 & 0 & 1 & 1 & 0 & 0 & 16 & 19 & 1 & 1 & 0 \\
\hline
\end{tabular}




\begin{tabular}{|c|c|c|c|c|c|c|c|c|c|c|c|c|c|c|c|c|c|c|}
\hline Lepidoptera & Crambidae & 0 & 1 & 0 & 1 & 0 & 0 & 1 & 0 & 1 & 1 & 1 & 1 & 1 & 0 & 0 & 2 & 0 \\
\hline \multirow[t]{9}{*}{ Diptera } & & 26 & 17 & 34 & 36 & 18 & 56 & 27 & 16 & 15 & 31 & 42 & 27 & 14 & 17 & 32 & 35 & 47 \\
\hline & Ceratopogonidae & 0 & 1 & 1 & 0 & 1 & 1 & 1 & 0 & 1 & 1 & 1 & 0 & 0 & 1 & 1 & 0 & 1 \\
\hline & Chironomidae & 24 & 12 & 31 & 35 & 12 & 51 & 23 & 15 & 11 & 26 & 34 & 27 & 13 & 15 & 29 & 30 & 40 \\
\hline & Empididae & 0 & 0 & 1 & 0 & 0 & 1 & 0 & 0 & 0 & 0 & 1 & 0 & 0 & 0 & 1 & 1 & 1 \\
\hline & Muscidae & 0 & 0 & 0 & 0 & 0 & 0 & 1 & 0 & 0 & 0 & 0 & 0 & 0 & 0 & 0 & 0 & 0 \\
\hline & Psychodidae & 0 & 1 & 0 & 0 & 1 & 1 & 1 & 0 & 0 & 1 & 1 & 0 & 0 & 0 & 0 & 0 & 1 \\
\hline & Simuliidae & 2 & 2 & 1 & 1 & 4 & 1 & 1 & 0 & 2 & 1 & 4 & 0 & 0 & 1 & 1 & 4 & 3 \\
\hline & Tabanidae & 0 & 1 & 0 & 0 & 0 & 0 & 0 & 0 & 0 & 0 & 0 & 0 & 0 & 0 & 0 & 0 & 0 \\
\hline & Tipulidae & 0 & 0 & 0 & 0 & 1 & 1 & 0 & 1 & 1 & 2 & 1 & 0 & 1 & 0 & 0 & 0 & 1 \\
\hline \multirow[t]{16}{*}{ Coleoptera } & & 33 & 25 & 26 & 12 & 32 & 29 & 37 & 27 & 31 & 21 & 20 & 31 & 40 & 32 & 22 & 26 & 18 \\
\hline & Dryiopidae & 0 & 0 & 0 & 0 & 0 & 0 & 0 & 0 & 0 & 0 & 0 & 0 & 0 & 0 & 0 & 0 & 1 \\
\hline & Hydrophilidae & 0 & 0 & 0 & 0 & 0 & 0 & 0 & 0 & 0 & 0 & 1 & 0 & 0 & 0 & 0 & 0 & 0 \\
\hline & Lutrochidae & 0 & 1 & 0 & 0 & 0 & 0 & 0 & 0 & 1 & 0 & 0 & 1 & 0 & 0 & 0 & 1 & 0 \\
\hline & Psephenidae & 1 & 1 & 1 & 1 & 1 & 1 & 2 & 2 & 1 & 1 & 0 & 0 & 1 & 1 & 0 & 0 & 0 \\
\hline & Scarabaeidae & 0 & 0 & 0 & 0 & 1 & 0 & 0 & 0 & 0 & 0 & 0 & 0 & 0 & 0 & 0 & 0 & 0 \\
\hline & $\begin{array}{l}\text { Staphylinidae } \\
\text { Elmidae }\end{array}$ & 0 & 0 & 0 & 0 & 0 & 0 & 0 & 0 & 1 & 0 & 0 & 0 & 0 & 0 & 0 & 0 & 0 \\
\hline & Elmidae inid & 17 & 12 & 17 & 3 & 9 & 24 & 6 & 12 & 12 & 11 & 3 & 0 & 14 & 13 & 10 & 9 & 10 \\
\hline & Cylloepus & 0 & 0 & 0 & 0 & 0 & 0 & 1 & 1 & 0 & 1 & 1 & 0 & 0 & 0 & 1 & 1 & 0 \\
\hline & Heterelmis & 7 & 1 & 3 & 1 & 1 & 0 & 1 & 0 & 1 & 1 & 4 & 3 & 0 & 0 & 1 & 1 & 7 \\
\hline & Hexacylloepus & 4 & 2 & 1 & 1 & 2 & 2 & 7 & 6 & 3 & 1 & 1 & 27 & 16 & 7 & 10 & 7 & 0 \\
\hline & Hexanchorus & 0 & 1 & 0 & 1 & 2 & 0 & 1 & 0 & 1 & 0 & 1 & 0 & 0 & 0 & 0 & 0 & 0 \\
\hline & Macrelmis & 1 & 1 & 1 & 0 & 1 & 0 & 1 & 0 & 1 & 1 & 1 & 0 & 0 & 1 & 0 & 0 & 0 \\
\hline & Microcylloepus & 2 & 4 & 1 & 1 & 11 & 1 & 1 & 1 & 1 & 1 & 3 & 1 & 4 & 1 & 0 & 2 & 0 \\
\hline & Neoelmis & 1 & 1 & 2 & 1 & 0 & 1 & 2 & 1 & 1 & 1 & 3 & 0 & 0 & 0 & 0 & 1 & 0 \\
\hline & Xenelmis & 1 & 1 & 1 & 3 & 4 & 1 & 15 & 5 & 8 & 2 & 2 & 0 & 5 & 9 & 1 & 4 & 1 \\
\hline
\end{tabular}


Tabla 4.7. La abundancia relativa porcentual de los taxones de macroinvertebrados en los 18 arroyos estudiados de Brasil.

\begin{tabular}{|c|c|c|c|c|c|c|c|c|c|c|c|c|c|c|c|c|c|c|c|}
\hline \multirow{2}{*}{\multicolumn{2}{|c|}{$\begin{array}{l}\text { Abundancia relativa \% } \\
\text { Filo u Orden taxones }\end{array}$}} & \multirow[b]{2}{*}{ B2 } & \multirow[b]{2}{*}{ B3 } & \multirow[b]{2}{*}{ B7 } & \multirow[b]{2}{*}{ B10 } & \multirow[b]{2}{*}{ B11 } & \multirow[b]{2}{*}{ B12 } & & & Bra & & & & & & & & & \\
\hline & & & & & & & & B13 & B14 & B15 & B16 & B17 & B18 & B19 & B20 & B21 & B22 & B23 & B24 \\
\hline Platyhelminthes & & 0 & 0 & 0 & 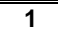 & 0 & 0 & 0 & 0 & 0 & 1 & 0 & 0 & 0 & 1 & 0 & 0 & 0 & 0 \\
\hline Oligochaeta & & 3 & 1 & 3 & 1 & 2 & 3 & 2 & 1 & 1 & 5 & 1 & 3 & 3 & 3 & 4 & 3 & 1 & 2 \\
\hline Hirudinea & & 0 & 0 & 0 & 0 & 0 & 0 & 0 & 0 & 0 & 0 & 1 & 1 & 0 & 0 & 0 & 0 & 0 & 1 \\
\hline Mollusca & & & & & & & & & & & & & & & & & & & \\
\hline Bivalvia & & 2 & 0 & 1 & 1 & 1 & 1 & 25 & 1 & 1 & 0 & 43 & 7 & 0 & 0 & 1 & 1 & 0 & 0 \\
\hline Gastropoda & & 0 & 0 & 1 & 1 & 0 & 0 & 1 & 1 & 1 & 1 & 1 & 0 & 0 & 0 & 0 & 1 & 0 & 0 \\
\hline & Ancylidae & 0 & 0 & 0 & 0 & 0 & 0 & 0 & 0 & 0 & 0 & 1 & 0 & 0 & 0 & 0 & 0 & 0 & 0 \\
\hline & Planorbidae & 0 & 0 & 1 & 0 & 0 & 0 & 0 & 1 & 1 & 0 & 0 & 0 & 0 & 0 & 0 & 1 & 0 & 0 \\
\hline Crustacea & & 1 & 2 & 1 & 1 & 1 & 1 & 1 & 0 & 1 & 1 & 3 & 3 & 6 & 1 & 5 & 0 & 0 & 8 \\
\hline Decapoda & Aeglidae & 1 & 2 & 1 & 1 & 1 & 1 & 0 & 0 & 1 & 1 & 2 & 3 & 4 & 1 & 5 & 0 & 0 & 8 \\
\hline Amphipoda & Hyalellidae & 0 & 0 & 0 & 0 & 0 & 0 & 0 & 0 & 0 & 0 & 1 & 0 & 1 & 0 & 0 & 0 & 0 & 0 \\
\hline Ostracoda & & 0 & 0 & 0 & 0 & 0 & 0 & 1 & 0 & 0 & 0 & 0 & 0 & 1 & 0 & 0 & 0 & 0 & 0 \\
\hline Acari & & 0 & 0 & 0 & 1 & 0 & 0 & 1 & 0 & 0 & 0 & 1 & 0 & 0 & 0 & 0 & 0 & 0 & 0 \\
\hline Collembola & & 1 & 0 & 0 & 0 & 0 & 0 & 1 & 0 & 0 & 0 & 0 & 0 & 0 & 1 & 0 & 0 & 0 & 0 \\
\hline Insecta & & & & & & & & & & & & & & & & & & & \\
\hline Ephemeroptera & & 11 & 8 & 16 & 25 & 31 & 6 & 2 & 2 & 12 & 7 & 7 & 38 & 30 & 35 & 18 & 0 & 1 & 2 \\
\hline & Baetidae & 1 & 1 & 6 & 21 & 30 & 1 & 1 & 2 & 7 & 6 & 4 & 9 & 7 & 8 & 1 & 0 & 0 & 1 \\
\hline & Caenidae & 0 & 0 & 0 & 0 & 0 & 0 & 0 & 0 & 1 & 0 & 1 & 1 & 0 & 0 & 0 & 0 & 0 & 0 \\
\hline & Leptohyphidae & 1 & 0 & 0 & 0 & 0 & 0 & 0 & 0 & 0 & 0 & 1 & 1 & 1 & 0 & 0 & 0 & 0 & 0 \\
\hline & Leptophlebiidae & 9 & 7 & 10 & 4 & 1 & 6 & 1 & 0 & 4 & 1 & 1 & 27 & 21 & 27 & 17 & 0 & 1 & 1 \\
\hline Odonata & & 1 & 1 & 1 & 1 & 1 & 1 & 3 & 1 & 3 & 2 & 2 & 1 & 0 & 1 & 1 & 1 & 0 & 1 \\
\hline & Calopterygidae & 1 & 0 & 0 & 0 & 0 & 0 & 1 & 1 & 1 & 0 & 1 & 0 & 0 & 0 & 0 & 0 & 0 & 0 \\
\hline & Gomphidae & 0 & 1 & 0 & 0 & 1 & 1 & 1 & 0 & 1 & 1 & 0 & 1 & 0 & 1 & 1 & 0 & 0 & 1 \\
\hline & Libellulidae & 0 & 0 & 1 & 1 & 0 & 0 & 1 & 0 & 0 & 1 & 1 & 0 & 0 & 0 & 0 & 1 & 0 & 0 \\
\hline & Megapodagrionidae & 0 & 0 & 0 & 0 & 0 & 0 & 0 & 0 & 1 & 0 & 0 & 0 & 0 & 0 & 0 & 0 & 0 & 0 \\
\hline Plecoptera & & 3 & 0 & 1 & 2 & 0 & 1 & 0 & 1 & 0 & 0 & 1 & 2 & 3 & 1 & 0 & 1 & 0 & 0 \\
\hline & Grypopterygidae & 2 & 0 & 0 & 1 & 0 & 0 & 0 & 0 & 0 & 0 & 0 & 0 & 0 & 0 & 0 & 1 & 0 & 0 \\
\hline & Perlidae & 1 & 0 & 1 & 1 & 0 & 1 & 0 & 1 & 0 & 0 & 1 & 2 & 3 & 1 & 0 & 0 & 0 & 0 \\
\hline Heteroptera & & 1 & 2 & 0 & 1 & 1 & 1 & 0 & 2 & 0 & 1 & 1 & 0 & 2 & 1 & 2 & 1 & 0 & 2 \\
\hline & Belostomatidae & 0 & 0 & 0 & 0 & 0 & 0 & 0 & 0 & 0 & 0 & 0 & 0 & 0 & 0 & 1 & 0 & 0 & 0 \\
\hline & Gerridae & 0 & 0 & 0 & 0 & 0 & 1 & 0 & 0 & 0 & 0 & 0 & 0 & 1 & 0 & 0 & 0 & 0 & 0 \\
\hline & Helotrephidae & 0 & 0 & 0 & 0 & 0 & 0 & 0 & 0 & 0 & 0 & 0 & 0 & 1 & 0 & 0 & 0 & 0 & 0 \\
\hline & Naucoridae & 0 & 1 & 0 & 0 & 0 & 0 & 0 & 0 & 0 & 0 & 0 & 0 & 0 & 1 & 0 & 0 & 0 & 0 \\
\hline & Veliidae & 1 & 1 & 0 & 1 & 1 & 0 & 0 & 2 & 0 & 1 & 1 & 0 & 0 & 0 & 1 & 1 & 0 & 2 \\
\hline Megaloptera & Corydalidae & 1 & 0 & 0 & 0 & 0 & 0 & 0 & 0 & 0 & 0 & 1 & 1 & 0 & 0 & 1 & 0 & 0 & 1 \\
\hline Trichoptera & & 10 & 3 & 10 & 17 & 13 & 4 & 7 & 10 & 3 & 8 & 4 & 2 & 4 & 4 & 5 & 4 & 8 & 4 \\
\hline & Calamoceratidae & 2 & 1 & 0 & 1 & 1 & 0 & 2 & 7 & 0 & 1 & 0 & 0 & 1 & 0 & 0 & 0 & 4 & 0 \\
\hline & Glossosomatidae & 0 & 0 & 0 & 1 & 0 & 1 & 1 & 0 & 0 & 1 & 0 & 0 & 0 & 0 & 0 & 0 & 0 & 0 \\
\hline & Hydrobiosidae & 0 & 0 & 1 & 1 & 1 & 0 & 0 & 0 & 0 & 0 & 0 & 0 & 0 & 0 & 0 & 0 & 0 & 0 \\
\hline & Hydropsychidae & 5 & 1 & 8 & 11 & 9 & 2 & 2 & 1 & 1 & 4 & 2 & 2 & 2 & 2 & 5 & 3 & 3 & 4 \\
\hline & Hydroptilidae & 1 & 1 & 1 & 1 & 0 & 0 & 1 & 2 & 1 & 1 & 1 & 0 & 0 & 2 & 0 & 0 & 0 & 0 \\
\hline & Leptoceridae & 1 & 0 & 0 & 0 & 0 & 1 & 1 & 0 & 1 & 0 & 1 & 0 & 0 & 0 & 0 & 1 & 0 & 0 \\
\hline & Limnephilidae & 0 & 0 & 0 & 0 & 0 & 0 & 0 & 0 & 0 & 0 & 0 & 0 & 0 & 0 & 0 & 0 & 1 & 0 \\
\hline & Odontoceridae & 0 & 0 & 0 & 0 & 0 & 0 & 0 & 0 & 0 & 0 & 0 & 0 & 0 & 0 & 0 & 0 & 1 & 0 \\
\hline & Philopotamidae & 0 & 0 & 0 & 3 & 2 & 0 & 0 & 0 & 0 & 1 & 0 & 0 & 1 & 0 & 0 & 0 & 0 & 0 \\
\hline Diptera & & 57 & 78 & 55 & 50 & 53 & 84 & 51 & 81 & 60 & 73 & 32 & 28 & 34 & 33 & 47 & 75 & 82 & 70 \\
\hline & Ceratopogonidae & 1 & 1 & 1 & 1 & 1 & 1 & 1 & 0 & 4 & 2 & 1 & 0 & 1 & 1 & 1 & 0 & 2 & 1 \\
\hline & Chironomidae & 49 & 71 & 45 & 40 & 39 & 80 & 46 & 76 & 53 & 65 & 28 & 26 & 27 & 20 & 41 & 66 & 62 & 66 \\
\hline & Empididae & 1 & 2 & 3 & 4 & 2 & 1 & 2 & 2 & 2 & 2 & 1 & 1 & 3 & 3 & 2 & 6 & 7 & 1 \\
\hline & Muscidae & 0 & 0 & 0 & 0 & 0 & 0 & 0 & 1 & 0 & 1 & 0 & 0 & 0 & 0 & 0 & 0 & 0 & 0 \\
\hline & Psychodidae & 0 & 0 & 1 & 1 & 0 & 0 & 0 & 1 & 0 & 0 & 0 & 0 & 0 & 0 & 0 & 0 & 0 & 0 \\
\hline & Simuliidae & 4 & 3 & 5 & 3 & 10 & 1 & 1 & 1 & 1 & 1 & 1 & 0 & 1 & 8 & 2 & 2 & 11 & 1 \\
\hline & Tabanidae & 0 & 0 & 0 & 0 & 0 & 0 & 1 & 0 & 0 & 1 & 0 & 0 & 0 & 0 & 0 & 0 & 0 & 0 \\
\hline & Tipulidae & 1 & 1 & 0 & 1 & 1 & 1 & 0 & 0 & 0 & 1 & 1 & 1 & 2 & 0 & 1 & 1 & 0 & 1 \\
\hline Coleoptera & & 17 & 9 & 17 & 7 & 3 & 5 & 15 & 4 & 25 & 10 & 15 & 17 & 24 & 24 & 20 & 15 & 9 & 13 \\
\hline & Dryiopidae & 0 & 0 & 0 & 0 & 0 & 0 & 0 & 0 & 0 & 0 & 1 & 0 & 0 & 1 & 0 & 0 & 0 & 0 \\
\hline & Dytiscidae & 0 & 0 & 0 & 0 & 0 & 0 & 0 & 1 & 0 & 0 & 0 & 0 & 0 & 0 & 1 & 0 & 0 & 0 \\
\hline & Elmidae & 17 & 7 & 13 & 6 & 2 & 5 & 15 & 2 & 25 & 10 & 14 & 17 & 23 & 21 & 15 & 14 & 9 & 11 \\
\hline & Gyrinidae & 0 & 0 & 0 & 0 & 0 & 0 & 0 & 0 & 0 & 0 & 0 & 0 & 0 & 1 & 0 & 0 & 0 & 0 \\
\hline & Lutrochidae & 0 & 1 & 0 & 0 & 0 & 0 & 0 & 0 & 0 & 0 & 0 & 0 & 0 & 1 & 1 & 1 & 0 & 0 \\
\hline & Psephenidae & 0 & 1 & 4 & 1 & 1 & 0 & 0 & 1 & 0 & 0 & 1 & 0 & 1 & 0 & 3 & 0 & 0 & 1 \\
\hline Abundancia & & 506 & 494 & 469 & 596 & 541 & 494 & 463 & 492 & 475 & 485 & 518 & 421 & 595 & 478 & 475 & 318 & 470 & 479 \\
\hline Riqueza media & & 22 & 18 & 18 & 26 & 19 & 17 & 22 & 18 & 18 & 23 & 27 & 16 & 20 & 19 & 20 & 15 & 13 & 17 \\
\hline
\end{tabular}




\section{Influencia de la franja de atenuación}

El análisis de CLUSTER mostró que en Brasil el ancho de la franja de atenuación tiene relación con la concentración de los agrotóxicos totales determinados en los arroyos adyacentes. En la figura 4.2 se puede observar que aquellos sitios que presentan franjas mayores a 50 metros, la concentración de la sumatoria de los agrotóxicos (clorpirifos, cipermetrina, lambda-cialotrina, endosulfán y endosulfán sulfato) fue menor a $1,5 \mathrm{ng} / \mathrm{g}$ ps. Mientras que en los sitios con franjas menores a 30 metros presentan concentraciones más elevadas. Por el contrario, no se observó relación entre la franja de atenuación y la concentración de biocidas en los arroyos muestreados de Paraguay, donde la mayoría presentaba franjas de atenuación mayor a 100 metros.

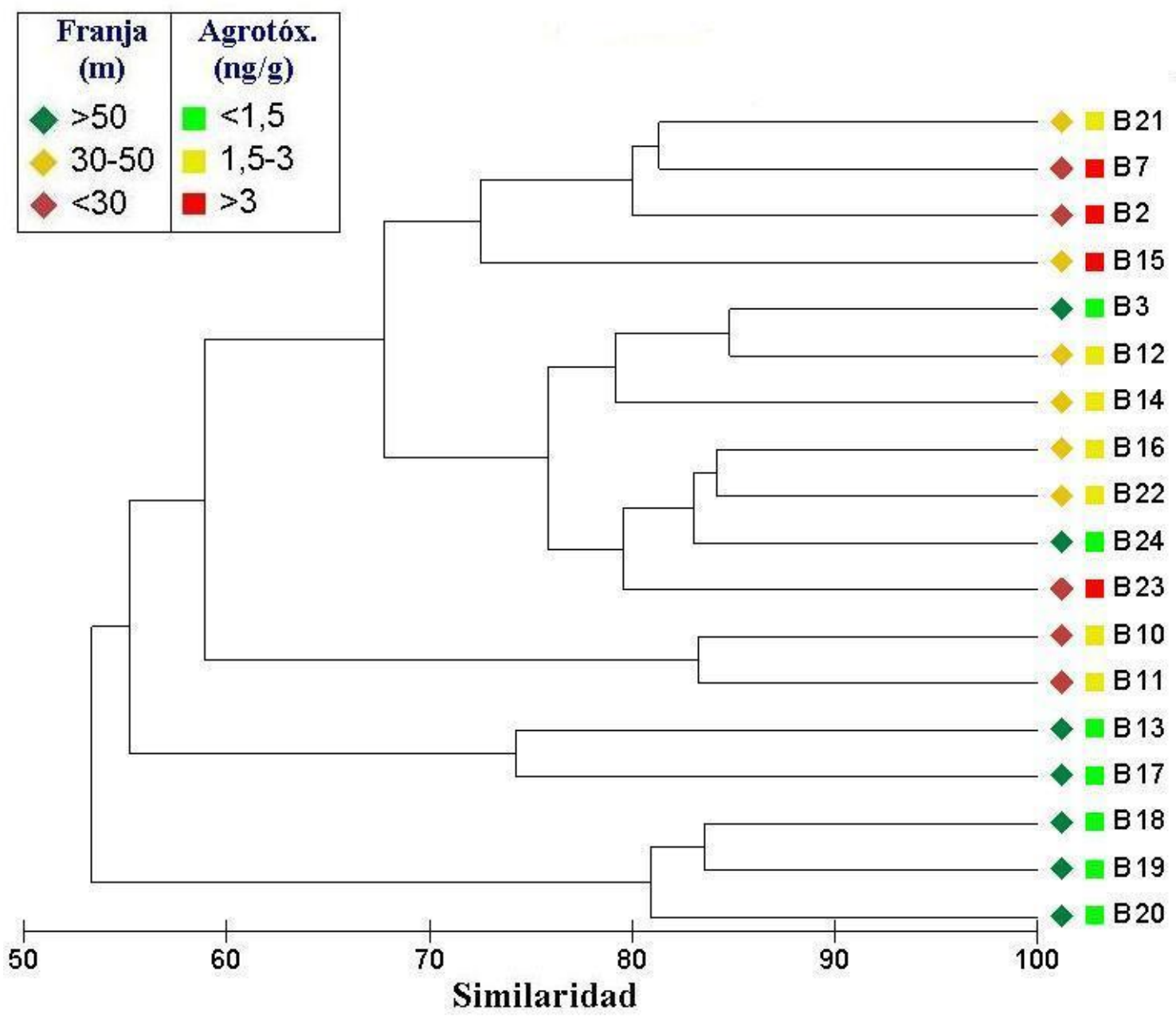

Figura. 4.2. CLUSTER del ensamble de macroinvertebrados para los arroyos de Brasil. 
En Brasil, el ancho de la franja de atenuación registró correlación inversa con la concentración de cipermetrina (r: $-0,64$ p: 0,013) y agrotóxicos totales (r: $-0,79$ $\mathrm{p}<0,0001$ ) determinados en los sedimentos de los arroyos (Figura 4.3); lo cual ratifica lo observado en el análisis de CLUSTER.
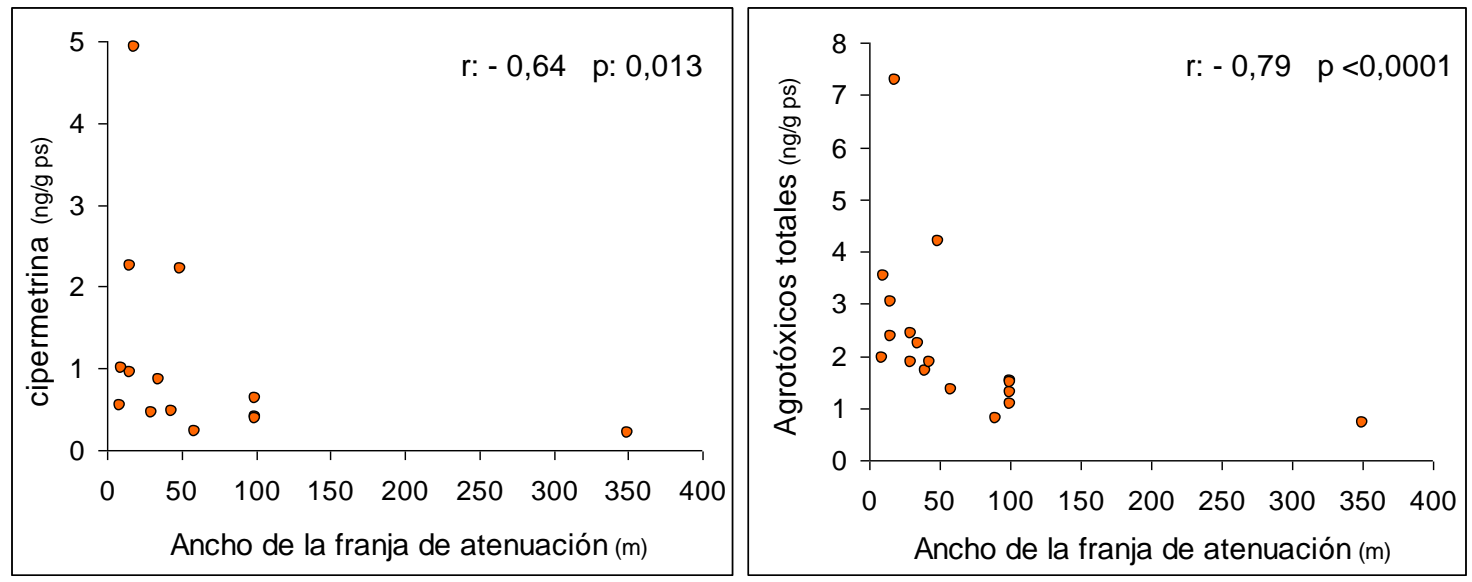

Figura 4.3. Correlación entre la concentración de cipermetrina (ng/g ps) y los agrotóxicos totales (ng/g ps) con el ancho de la franja de atenuación (m) de los arroyos de Brasil.

\section{Relaciones del ensamble de macroinvertebrados con el RBP}

En general, la evaluación de la calidad del hábitat, RBP, fue un parámetro importante en Paraguay. El RBP, en Paraguay, se correlacionó significativamente con algunas métricas de respuesta, siempre en la dirección esperada. De manera positiva para las métricas de respuesta consideradas sensibles al disturbio: abundancia relativa y riqueza de Ephemeroptera y Trichoptera, y, porcentaje de Ephemeroptera-PlecopteraTrichoptera (\% EPT). Mientras que la correlación fue de manera inversa para la abundancia relativa de tres taxones considerados tolerantes al disturbio: Hirudinea, Oligochaeta y Bivalvia (Tabla 4.8). Sin embargo, la puntuación del RBP no tuvo un efecto significativo para las métricas Brasil. Los resultados de la evaluación de la calidad del hábitat de ambas regiones se encuentran en la Tabla B2 del anexo. 
Tabla 4.8. Relaciones entre el ensamble de macroinvertebrados y el RBP en Paraguay.

\begin{tabular}{|c|c|c|c|c|c|}
\hline \multicolumn{6}{|c|}{ RBP } \\
\hline \multirow{2}{*}{ Ephemeroptera $^{(\#)}$} & $\mathrm{r}$ & 0,40 & \multirow{2}{*}{ Hirudinea $^{(\#)}$} & $\mathrm{r}$ & $-0,66$ \\
\hline & $\mathrm{p}$ & 0,026 & & $\mathrm{p}$ & 0,000 \\
\hline \multirow{2}{*}{ Trichoptera $^{(\#)}$} & $\mathrm{r}$ & 0,40 & \multirow{2}{*}{ Oligochaeta $^{(\#)}$} & $\mathrm{r}$ & $-0,62$ \\
\hline & $\mathrm{p}$ & 0,026 & & $\mathrm{p}$ & 0,000 \\
\hline \multirow{2}{*}{$\%$ EPT } & $\mathrm{r}$ & 0,57 & \multirow{2}{*}{ Bivalvia $^{(\#)}$} & $\mathrm{r}$ & $-0,71$ \\
\hline & $\mathrm{p}$ & 0,001 & & $\mathrm{p}$ & 0,000 \\
\hline \multirow{2}{*}{ Riq Trichoptera } & $r$ & 0,49 & & & \\
\hline & $\mathrm{p}$ & 0,005 & & & \\
\hline \multirow{2}{*}{ Riq Plecoptera } & $\mathrm{r}$ & 0,39 & & & \\
\hline & $\mathrm{p}$ & 0,029 & & & \\
\hline
\end{tabular}

\%EPT: porcentaje de Ephemeroptera-Plecoptera-Trichoptera, Riq: riqueza, (\#): abundancia relativa.

\section{Relaciones del ensamble de macroinvertebrados con los agrotóxicos}

En la Tabla 4.9 se presentan las correlaciones entre los agrotóxicos y la abundancia de los macroinvertebrados, utilizando los datos en conjunto de ambas regiones. Se observa que 21 taxones y la riqueza de Ephemeroptera registraron una correlación negativa con la concentración de uno o más agrotóxicos y 10 lo hicieron de manera positiva. Lambda-cialotrina registró correlación negativa con 13 taxones y la riqueza de Ephemeroptera y cipermetrina con ocho. 
Tabla 4.9. Correlaciones entre el ensamble de macroinvertebrados y la concentración de agrotóxicos para Brasil y Paraguay.

\begin{tabular}{|c|c|c|c|c|c|}
\hline Grupos Taxonómicos & & Clorp & A-Cialo & Ciper & Agrotóx. T \\
\hline Nematoda & $\begin{array}{l}\mathrm{r} \\
\mathrm{p}\end{array}$ & $*$ & $\begin{array}{l}-0,32 \\
0,028 \\
\end{array}$ & * & $*$ \\
\hline Ancylidae & $\begin{array}{l}r \\
p\end{array}$ & $*$ & $*$ & $\begin{array}{l}-0,31 \\
0,037 \\
\end{array}$ & $*$ \\
\hline Trichodactylidae & $\begin{array}{l}\mathrm{r} \\
\mathrm{p}\end{array}$ & $*$ & $\begin{array}{l}-0,39 \\
0,007 \\
\end{array}$ & $*$ & $*$ \\
\hline Acari & $\begin{array}{l}\mathrm{r} \\
\mathrm{p}\end{array}$ & $*$ & $*$ & $\begin{array}{l}-0,29 \\
0,045 \\
\end{array}$ & * \\
\hline Entomobrydae & $\begin{array}{l}\mathrm{r} \\
\mathrm{p}\end{array}$ & $*$ & $\begin{array}{l}-0,39 \\
0,006\end{array}$ & $*$ & $*$ \\
\hline Caenidae & $\begin{array}{l}\mathrm{r} \\
\mathrm{p}\end{array}$ & $*$ & $\begin{array}{l}-0,38 \\
0,008\end{array}$ & $*$ & $*$ \\
\hline Leptohyphidae & $\begin{array}{l}\mathrm{r} \\
\mathrm{p}\end{array}$ & $*$ & $\begin{array}{l}-0,37 \\
0,011\end{array}$ & $\begin{array}{l}-0,33 \\
0,026 \\
\end{array}$ & $\begin{array}{l}-0,31 \\
0,036\end{array}$ \\
\hline Libellulinae & $\begin{array}{l}\mathrm{r} \\
\mathrm{p}\end{array}$ & $*$ & $*$ & $\begin{array}{l}-0,31 \\
0,036 \\
\end{array}$ & $*$ \\
\hline Heteroptera & $\begin{array}{l}\mathrm{r} \\
\mathrm{p}\end{array}$ & $*$ & $*$ & $\begin{array}{l}-0,30 \\
0,041 \\
\end{array}$ & $\begin{array}{l}-0,44 \\
0,002 \\
\end{array}$ \\
\hline Helotrephidae & $\begin{array}{l}r \\
p\end{array}$ & $*$ & $*$ & $\begin{array}{l}-0,29 \\
0,045\end{array}$ & $\begin{array}{l}-0,29 \\
0,045\end{array}$ \\
\hline Naucoridae & $\begin{array}{l}r \\
p\end{array}$ & $*$ & $\begin{array}{l}-0,41 \\
0,005 \\
\end{array}$ & $\begin{array}{l}-0,38 \\
0,008 \\
\end{array}$ & $\begin{array}{l}-0,50 \\
0,000 \\
\end{array}$ \\
\hline Glossosomatidae & $\mathrm{p}$ & $*$ & $*$ & $\begin{array}{l}-0,29 \\
0,047\end{array}$ & $*$ \\
\hline Odontoceridae & $\begin{array}{l}r \\
p\end{array}$ & $*$ & $\begin{array}{l}-0,30 \\
0,041 \\
\end{array}$ & $*$ & $*$ \\
\hline Crambidae & $\begin{array}{l}r \\
p\end{array}$ & $\begin{array}{l}-0,30 \\
0,038\end{array}$ & $*$ & $*$ & $*$ \\
\hline Cylloepus & $\begin{array}{l}r \\
p\end{array}$ & $\begin{array}{l}-0,42 \\
0,004\end{array}$ & $*$ & $*$ & $*$ \\
\hline Heterelmis & $\begin{array}{l}r \\
p\end{array}$ & $*$ & $\begin{array}{l}-0,39 \\
0,008 \\
\end{array}$ & $*$ & $*$ \\
\hline Hexacylloepus & $\begin{array}{l}\mathrm{r} \\
\mathrm{p}\end{array}$ & $\begin{array}{l}-0,40 \\
0,005\end{array}$ & $\begin{array}{l}-0,50 \\
0,000 \\
\end{array}$ & $*$ & $*$ \\
\hline Macrelmis & $\begin{array}{l}\mathrm{r} \\
\mathrm{p}\end{array}$ & $*$ & $\begin{array}{l}-0,31 \\
0,033\end{array}$ & $*$ & * \\
\hline Microcylloepus & $\begin{array}{l}\mathrm{r} \\
\mathrm{p}\end{array}$ & $*$ & $\begin{array}{l}-0,40 \\
0,006 \\
\end{array}$ & $*$ & $*$ \\
\hline Neoelmis & $\begin{array}{l}\mathrm{r} \\
\mathrm{p}\end{array}$ & $\begin{array}{c}-0,31 \\
0,033 \\
\end{array}$ & $\begin{array}{r}-0,36 \\
0,015 \\
\end{array}$ & $*$ & $*$ \\
\hline Xenelmis & $\begin{array}{l}r \\
p\end{array}$ & $*$ & $\begin{array}{l}-0,34 \\
0,018 \\
\end{array}$ & $*$ & $\begin{array}{l}-0,37 \\
0,011 \\
\end{array}$ \\
\hline Riq Ephemeroptera & $\mathrm{p}$ & $*$ & $\begin{array}{r}-0,40 \\
0,005 \\
\end{array}$ & $*$ & $*$ \\
\hline
\end{tabular}

\begin{tabular}{|c|c|c|c|c|}
\hline Grupos Taxonómicos & \multicolumn{2}{|c|}{ Clorp $\lambda$-Cialo } & \multicolumn{2}{|c|}{ Ciper Agrotóx. T } \\
\hline Mollusca & \begin{tabular}{|c|}
0,31 \\
0,034
\end{tabular} & $*$ & $*$ & $*$ \\
\hline Bivalvia & $\begin{array}{c}0,45 \\
0,002 \\
\end{array}$ & * & * & * \\
\hline Planorbidae & \begin{tabular}{|c|}
0,34 \\
0,022 \\
\end{tabular} & $\begin{array}{c}0,33 \\
0,022 \\
\end{array}$ & $*$ & $\begin{array}{c}0,38 \\
0,008 \\
\end{array}$ \\
\hline Aeglidae & $*$ & $\begin{array}{c}0,47 \\
0,000 \\
\end{array}$ & $*$ & $*$ \\
\hline Diptera & * & $\begin{array}{c}0,38 \\
0,009 \\
\end{array}$ & * & $\begin{array}{c}0,37 \\
0,010 \\
\end{array}$ \\
\hline Ceratopogonidae & * & $*$ & $\begin{array}{c}0,39 \\
0,008 \\
\end{array}$ & $*$ \\
\hline Chironomidae & * & $\begin{array}{c}0,38 \\
0,009 \\
\end{array}$ & * & $\begin{array}{c}0,35 \\
0,017 \\
\end{array}$ \\
\hline Empididae & * & \begin{tabular}{|c|}
0,46 \\
0,001 \\
\end{tabular} & \begin{tabular}{c|}
0,36 \\
0,014 \\
\end{tabular} & $\begin{array}{c}0,39 \\
0,008 \\
\end{array}$ \\
\hline Simuliidae & * & $*$ & $\begin{array}{c}0,31 \\
0,033 \\
\end{array}$ & $\begin{array}{c}0,44 \\
0,002 \\
\end{array}$ \\
\hline Elmidae & $*$ & $\begin{array}{c}0,33 \\
0,026 \\
\end{array}$ & $*$ & * \\
\hline Veliidae & $*$ & $\begin{array}{c}0,35 \\
0,015 \\
\end{array}$ & $*$ & * \\
\hline
\end{tabular}

Clorp: clorpirifos, $\lambda$-Cialo: lambda cialotrina, Ciper: cipermetrina, Agrotóx. T: agrotóxicos totales, Riq: riqueza. $*$ : no significativo

\section{Relaciones con las características del hábitat}

En la Tabla 4.10 se muestra la relación entre la abundancia de grandes grupos taxonómicos con las características del hábitat, utilizando los muestreos de Paraguay y Brasil. La concentración de COT, MOPF, MOPG y la fracción de limo en los sedimentos registraron correlación negativa con 11 taxones y positiva con la abundancia de Diptera y Crustacea. La conductividad y el contenido de arena en sedimentos registraron el efecto opuesto, se correlacionaron positivamente con la abundancia de 11 
taxones y negativamente con la abundancia de Diptera y Crustacea. Al correlacionar la abundancia relativa de los taxones con el valor de RBP de ambas regiones, se pudo observar que cuando la puntuación es baja, la abundancia de los Platyhelminthes y Oligochaeta aumenta, mientras que cuando la calidad del hábitat es óptima, aumenta la riqueza de los Plecoptera.

Tabla 4.10. Relaciones entre la abundancia de los macroinvertebrados y las características físicas y químicas del hábitat determinadas para Brasil y Paraguay.

\begin{tabular}{|c|c|c|c|c|c|c|c|c|c|c|}
\hline Grupos Taxonómicos & & Cond & COT & Arena & Limo & Sed fino & L Roc & MOPF & MOPG & RBP \\
\hline \multirow{2}{*}{ Platyhelminthes } & $\mathrm{r}$ & 0,51 & $-0,57$ & 0,40 & $-0,38$ & \multirow[t]{2}{*}{ * } & \multirow[t]{2}{*}{$*$} & $-0,43$ & \multirow[t]{2}{*}{$*$} & $-0,29$ \\
\hline & $\mathrm{p}$ & 0,000 & 0,000 & 0,010 & 0,014 & & & 0,014 & & 0,045 \\
\hline \multirow{2}{*}{ Oligochaeta } & $\mathrm{r}$ & 0,36 & $-0,40$ & 0,55 & $-0,45$ & \multirow[t]{2}{*}{$*$} & \multirow[t]{2}{*}{$*$} & $-0,42$ & \multirow[t]{2}{*}{ * } & $-0,35$ \\
\hline & $\mathrm{p}$ & 0,011 & 0,009 & 0,000 & 0,003 & & & 0,015 & & 0,014 \\
\hline \multirow{2}{*}{ Hirudinea } & $\mathrm{r}$ & $*$ & $*$ & $*$ & $*$ & \multirow[t]{2}{*}{ * } & \multirow[t]{2}{*}{$*$} & \multirow[t]{2}{*}{ F } & $-0,35$ & * \\
\hline & $\mathrm{p}$ & & & & & & & & 0,045 & \\
\hline \multirow{2}{*}{ Nematoda } & $\mathrm{r}$ & 0,51 & $-0,61$ & 0,40 & $-0,63$ & \multirow{2}{*}{ * } & \multirow{2}{*}{$*$} & $-0,62$ & $-0,36$ & \multirow{2}{*}{ * } \\
\hline & $\mathrm{p}$ & 0,000 & 0,000 & 0,009 & 0,000 & & & 0,000 & 0,040 & \\
\hline \multirow{2}{*}{ Gastropoda } & $\mathrm{r}$ & 0,43 & $-0,38$ & 0,34 & $-0,46$ & \multirow{2}{*}{$*$} & \multirow[t]{2}{*}{$*$} & $-0,43$ & \multirow{2}{*}{ * } & \multirow[t]{2}{*}{ * } \\
\hline & $\mathrm{p}$ & 0,002 & 0,015 & 0,028 & 0,002 & & & 0,013 & & \\
\hline \multirow{2}{*}{ Crustacea } & $\mathrm{r}$ & $-0,46$ & 0,34 & $-0,50$ & 0,50 & \multirow[t]{2}{*}{$*$} & $-0,29$ & 0,45 & \multirow{2}{*}{ * } & \multirow{2}{*}{ * } \\
\hline & $\mathrm{p}$ & 0,000 & 0,030 & 0,000 & 0,000 & & 0,043 & 0,009 & & \\
\hline \multirow{2}{*}{ Acari } & $\mathrm{r}$ & 0,56 & $-0,61$ & 0,60 & $-0,53$ & \multirow[t]{2}{*}{$*$} & 0,29 & $-0,64$ & $-0,53$ & * \\
\hline & $\mathrm{p}$ & 0,000 & 0,000 & 0,000 & 0,000 & & 0,046 & 0,000 & 0,002 & \\
\hline Collembola & $\mathrm{r}$ & 0,34 & $-0,41$ & * & $*$ & $*$ & $*$ & $*$ & $-0,35$ & $*$ \\
\hline Conctinoura & $\mathrm{p}$ & 0,017 & 0,007 & & & & & & 0,044 & \\
\hline Enhemerontera & $\mathrm{r}$ & $*$ & * & 0,44 & $-0,35$ & $*$ & $*$ & $*$ & $*$ & * \\
\hline 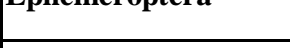 & $\mathrm{p}$ & & & 0,004 & 0,022 & & & & & \\
\hline Trichontera & $\mathrm{r}$ & 0,44 & $-0,49$ & 0,65 & $-0,55$ & $-0,31$ & 0,37 & $-0,58$ & $*$ & $*$ \\
\hline Tincioptera & $\mathrm{p}$ & 0,001 & 0,000 & 0,000 & 0,000 & 0,033 & 0,010 & 0,000 & & \\
\hline Dintera & $\mathrm{r}$ & $-0,37$ & 0,49 & $-0,64$ & 0,54 & 0,30 & $-0,33$ & 0,47 & 0,45 & * \\
\hline Diptera & $\mathrm{p}$ & 0,008 & 0,001 & 0,000 & 0,000 & 0,034 & 0,021 & 0,006 & 0,010 & \\
\hline Coleontera & $\mathrm{r}$ & 0,30 & $-0,47$ & 0,55 & $-0,54$ & * & $*$ & $-0,47$ & $-0,50$ & * \\
\hline Concoptera & $\mathrm{p}$ & 0,036 & 0,002 & 0,000 & 0,000 & & & 0,006 & 0,003 & \\
\hline EPT & $\mathrm{r}$ & 0,36 & $-0,40$ & 0,58 & $-0,46$ & $-0,31$ & $*$ & * & $*$ & * \\
\hline & $\mathrm{p}$ & 0,010 & 0,008 & 0,000 & 0,003 & 0,029 & & & & \\
\hline Ria Fnhemerontera & $\mathrm{r}$ & 0,54 & $-0,57$ & 0,60 & $-0,64$ & $*$ & * & $-0,47$ & $-0,63$ & * \\
\hline 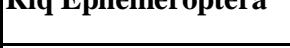 & $\mathrm{p}$ & 0,000 & 0,000 & 0,000 & 0,000 & & & 0,006 & 0,000 & \\
\hline Ria Trichontera & $\mathrm{r}$ & 0,47 & $-0,45$ & 0,51 & $-0,57$ & $*$ & $*$ & $-0,51$ & $*$ & * \\
\hline 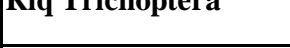 & $\mathrm{p}$ & 0,000 & 0,003 & 0,000 & 0,000 & & & 0,002 & & \\
\hline Riq Plecoptera & $\mathrm{r}$ & * & * & * & * & * & * & * & * & 0,39 \\
\hline & $\mathrm{p}$ & & & & & & & & & 0,005 \\
\hline
\end{tabular}

Cond: conductividad, COT: carbono orgánico total, Sed fino: sedimento fino, L Roc: lecho rocoso, MOPF: materia orgánica particulada fina, MOPG: materia orgánica particulada gruesa, RBP: calidad del hábitat mediante el protocolo rápido de bioevaluación. EPT: porcentaje de Ephemeroptera-Plecoptera-Trichoptera, Riq: riqueza. * no significativo. 
A su vez, los parámetros ambientales que registraron correlación con la abundancia de los grupos taxonómicos presentaron correlación con la concentración de algunos agrotóxicos (Tabla 4.11). Los piretroides, cipermetrina y/o lambda-cialotrina se correlacionaron positivamente con el contenido COT, limo, MOPF y MOPG en los sedimentos y, negativamente con el porcentaje de arena y conductividad del agua. Esta misma relación se observó con la concentración de agrotóxicos totales.

Tabla 4.11. Relaciones entre la concentración de agrotóxicos con las características físicas y químicas del hábitat determinadas para Brasil y Paraguay.

\begin{tabular}{|lc|c|c|c|c|c|c|c|}
\hline Agrotóxicos & \multicolumn{2}{c}{ Cond } & \multicolumn{1}{c}{ COT } & \multicolumn{1}{c}{ Arena } & \multicolumn{1}{c|}{ Limo } & Sed fino & MOPF & MOPG \\
\hline \hline \multirow{2}{*}{ Lambda-Cialotrina } & $\mathrm{r}$ & $-0,39$ & 0,46 & $-0,38$ & 0,46 & $*$ & 0,51 & 0,46 \\
& $\mathrm{p}$ & 0,007 & 0,004 & 0,016 & 0,003 & & 0,004 & 0,012 \\
\hline \multirow{2}{*}{ Cipermetrina } & $\mathrm{r}$ & $-0,34$ & 0,55 & $*$ & 0,39 & $*$ & 0,40 & 0,53 \\
& $\mathrm{p}$ & 0,022 & 0,000 & & 0,015 & & 0,027 & 0,003 \\
\hline \multirow{2}{*}{ Agrotóxicos totales } & $\mathrm{r}$ & $-0,32$ & 0,50 & $*$ & $*$ & 0,32 & 0,49 & 0,59 \\
& $\mathrm{p}$ & 0,030 & 0,001 & & & 0,030 & 0,007 & 0,000 \\
\hline
\end{tabular}

Cond: conductividad, COT: carbono orgánico total, Sed fino: sedimento fino, MOPF: materia orgánica particulada fina, MOPG: materia orgánica particulada gruesa. * no significativo.

\section{DISCUSIÓN}

En los sedimentos de los arroyos estudiados se detectó la presencia de todos los biocidas utilizados con mayor frecuencia en los cultivos regionales. Los agrotóxicos más frecuentemente determinados coinciden con los detectados en trabajos previos en regiones agrícolas de Brasil, los cuales se han centrado principalmente en el estado de Mato Grosso, región del Pantanal (Possavatz et al., 2014, Casara et al., 2012, Miranda et al., 2008, Laabs et al., 2002). Un estudio realizado en nueve sitios sobre la cuenca del río Cuiabá (Brasil) donde se cultiva principalmente soja, maíz y algodón, informó la presencia de clorpirifos, $\lambda$-cialotrina, permetrina, $\alpha$-endosulfán, endosulfán sulfato y malatión en muestras de sedimento de fondo en concentraciones de hasta dos órdenes de magnitud mayor a las detectadas en el presente estudio (Possavatz et al., 2014). Miranda et al. (2008) analizaron 23 agrotóxicos en muestras de sedimentos de 25 sitios en 17 ríos del Pantanal (Mato Grosso, Brasil) y detectaron la presencia de los piretroides $\lambda$-cialotrina (1 a $5 \mathrm{ng} / \mathrm{g}$ ), deltametrina $(20 \mathrm{ng} / \mathrm{g}$ ) y permetrina (1 a $7 \mathrm{ng} / \mathrm{g}$ ). Otro estudio realizado en la cuenca noreste del Pantanal monitoreó 29 agrotóxicos, de los cuales se detectaron 19. La frecuencia de detección fue de $68 \%$ en las muestras de agua 
superficial $(n=139)$, y $62 \%$ en muestras de sedimento $(n=26)$, siendo endosulfán $(\alpha, \beta)$, endosulfán sulfato y el herbicida ametrina los compuestos más frecuentes (Laabs et al., 2002).

Al comparar las concentraciones de los agrotóxicos detectados en la Selva Paranaense con los resultados obtenidos en los arroyos de cuenca agrícola de la región pampeana (Argentina) se pudo observar mayores concentraciones en esta última. La máxima concentración del clorpirifos fue 1,3; 1,5; 3,6 y 7,4 ng/g ps en Paraguay, Brasil, Arrecifes y La Plata respectivamente. La concentración de cipermetrina fue máxima en Arrecifes (8,3 ng/g ps), seguida por Brasil (4,9 ng/g ps), La Plata (1,9 ng/g ps) y Paraguay (1,2 ng/g ps). El organoclorado endosulfán y su producto de degradación, endosulfán sulfato, resultaron ser dos a tres órdenes de magnitud mayor en los arroyos pampeanos (endosulfán: 32; 2,1;0,8;0,5 ng/g ps y endosulfán sulfato: 156; 12;0,6;0,5 ng/g ps en La Plata, Arrecifes, Paraguay y Brasil respectivamente).

El uso del DDT para agricultura está prohibido en Brasil desde 1985, pero su uso como control de vectores se informó hasta 1997 (Dores, 2015). Laabs et al. (2002) realizaron un muestreo en arroyos del noreste del Pantanal y determinaron DDT en el $79 \%$ de las muestras de sedimentos y su producto de degradación, DDE, en el 36\%; con concentraciones máximas de 1,5 y 1,4 ng/g, respectivamente. Estudios más recientes han detectado DDT sólo esporádicamente y DDE ocasionalmente en sedimentos y agua del Pantanal (Dores, 2015). En la presente tesis, en los arroyos de Brasil se detectó DDT y sus productos de degradación, DDD y DDE, con mayor frecuencia y concentraciones más elevadas que las reportadas previamente $(1,1 ; 3,8$ y $5,7 \mathrm{ng} / \mathrm{g}$ ps respectivamente). En Paraguay la frecuencia de detección y las concentraciones fueron menores (DDT 0,49 ng/g ps y DDE 1,9 ng/g) y en los muestreos realizados en Arrecifes, Argentina, sólo se detectó DDT y DDE en baja concentración $(0,29$ y 0,28 ng/g ps respectivamente) y DDD en mayor concentración, pero sólo en tres arroyos $(1,2 ; 4,4$ y $7,3 \mathrm{ng} / \mathrm{g} \mathrm{ps})$.

De los agrotóxicos determinados en el presente estudio, los piretroides presentan la mayor toxicidad para los invertebrados acuáticos, debido a que contribuyen con el mayor porcentaje a la Unidad Toxica (UT) total, principalmente en los arroyos de Brasil. Resulta frecuente la aplicación simultánea de insecticidas piretroides con el producto sinérgico piperonil butóxido (PBO), cuyo efecto es inhibir las enzimas oxidasa 
de función mixta que contribuyen a la detoxificación. PBO tiene baja toxicidad para los organismos acuáticos (Amweg et al., 2006). No obstante, Weston et al. (2006) informaron que concentraciones de PBO de 2-4 $\mu \mathrm{g} / \mathrm{l}$ en agua casi duplicaron la toxicidad de sedimentos para H. azteca. Amweg et al. (2006) determinaron que una concentración de PBO de 12,5 ng/g en sedimento y 2,3 $\mu \mathrm{g} / \mathrm{l}$ en agua casi duplicó la toxicidad de permetrina para H. azteca. Las concentraciones de PBO detectadas en el presente estudio pudieron haber aumentado la toxicidad de los piretroides y, sugieren que el cálculo de la UT probablemente subestime la toxicidad calculada para la sumatoria de los agrotóxicos totales determinada.

Casi todas las muestras de sedimento de los arroyos estudiados contenían múltiples agrotóxicos de al menos dos clases de biocidas diferentes, lo que generó incertidumbre en la estimación de los efectos tóxicos. Aunque los efectos combinados de los biocidas de una misma clase pueden predecirse relativamente bien, los efectos combinados de la mezcla de varias clases son más difíciles de predecir (Lydy et al., 2004). Bjergager et al. (2011) evaluaron el potencial sinérgico de los fungicidas en los piretroides en un microcosmos acuático. En tratamientos con piretroide-fungicida, las comunidades de cladóceros, copépodos y quironómidos mostraron una mayor disminución en su abundancia, en comparación con los tratamientos de piretroide sólo. Los ostrácodos y rotíferos no se vieron afectados significativamente por ninguno de los tratamientos. En el presente trabajo de tesis, con las concentraciones determinadas de endosulfán, endosulfán sulfato o clorpirifos resulta improbable que por sí solos causen toxicidad aguda significativa a la mayoría de los invertebrados acuáticos, pero podrían contribuir a la toxicidad aguda cuando se mezclan con otros agrotóxicos. Si bien generalmente se presume que los biocidas de clases similares y con el mismo modo de acción, actúan por adición de concentración, los agrotóxicos con diferentes modos de acción pueden actuar por acción independiente, antagonista o sinérgicamente (Trimble et al., 2009). Existe, además, un efecto mucho más difícil de evaluar y predecir que son los efectos crónicos o subletales, producidos por las bajas concentraciones de los agrotóxicos o sus mezclas (Cooper 1993).

Para este trabajo se determinó la concentración de los biocidas en sedimentos, porque los más comúnmente usados en la región (endosulfán, clorpirifos, piretroides) son hidrofóbicos y tienden a adsorberse a la fracción particulada. Sin embargo, algunos de los insecticidas sistémicos de utilización creciente, como los neonicotinoides, están 
siendo progresivamente más utilizados en la producción de soja en América del Sur, y tienen una elevada solubilidad en agua (Hunt et al., 2016). Los neonicotinoides se aplican a menudo en combinación con piretroides para el control de las plagas de hemípteros en la soja. Estudios recientes en regiones productoras de soja de América del Sur detectaron imidacloprid en el $43 \%$ de las muestras de agua superficial (De Geronimo et al., 2014) y tiametoxam en el $100 \%$ de las muestras de aguas superficiales (Rocha et al., 2015). Por esta razón, se sugiere que la concentración de los agrotóxicos determinados en sedimento en el presente trabajo subestima la toxicidad para la fauna residente.

Las áreas estudiadas en Brasil y Paraguay están en una región de características edáficas y climáticas homogéneas y pertenecen a la misma provincia biogeográfica, la Selva Paranaense (Morrone, 2014). En principio, cabría esperar que la composición de los ensambles de invertebrados sea similar, sin embargo, se observaron diferencias. La riqueza taxonómica y la abundancia resultaron mayores en Paraguay, como así también los índices de diversidad y equitatividad fueron significativamente diferentes (Margalef, Shannon-Wiener, Simpson y Pielou). La mayor proporción de limo se determinó en Brasil, característica que se asocia con la erosión agrícola, mientras que en Paraguay esta fracción fue menor y mayor la de arena, probablemente asociado con la retención del material fino en las franjas de atenuación más anchas y extensas.

En la presente tesis se determinó las variables ambientales que tienen mayor injerencia en la composición de los ensambles de macroinvertebrados en los arroyos regionales. Las variables que describen cualidades del sustrato, fundamentalmente la materia orgánica y textura de los sedimentos, son la que poseen mayor influencia. Tres variables que caracterizan la materia orgánica: COT, MOPF y MOPG y dos que caracterizan la textura: porcentaje de limo y arena, muestran correlación con la abundancia de numerosos grupos taxonómicos. Se detectó el mayor contenido de COT, MOPF, MOPG en Brasil que, conjuntamente con el limo, afectan negativamente a casi todos los grupos, con la excepción de Diptera, el cual mostró correlación positiva. Este grupo taxonómico resultó ser el más abundante en Brasil, donde representó 57\% de la abundancia total, contra sólo $27 \%$ en Paraguay (Figura 4.1). Asimismo, Diptera y Bivalvia, más abundantes en Brasil, registraron correlación positiva con algunos agrotóxicos; interpretándose que su mayor tolerancia representa una ventaja competitiva, dado que la eliminación de los grupos más sensibles resulta en una mayor 
disponibilidad de recursos para los tolerantes. Por el contrario, los taxones Coleoptera, Ephemeroptera, Trichoptera y \% EPT fueron más abundantes en Paraguay, los cuales, resultaron favorecidos por el porcentaje de arena y desfavorecidos por el porcentaje de limo. La mayoría de los Ephemeroptera y algunos Trichoptera y Coleoptera, mostraron también correlación inversa con la concentración de agrotóxicos. Los resultados obtenidos coinciden con la literatura, Richards et al. (1993) informaron que los factores morfológicos más importantes que afectan a las comunidades de invertebrados en arroyos en una región dominada por la agricultura están relacionados con la composición del sustrato y la distribución de sedimentos finos. En 24 sitios de la cuenca de la bahía Sanginaw, Michigan EE. UU. evaluaron la morfología y atributos del hábitat, utilizando el Índice de Evaluación Cuantitativa del Hábitat (QHEI). Sustratos con proporciones de sedimentos finos o limo orgánico se clasificaron con menor puntaje que los sustratos compuestos principalmente de adoquines y grava. La riqueza de EPT (número de taxones de Ephemeroptera, Plecoptera y Trichoptera) observada mostró una correlación positiva con la puntuación del sustrato QHEI. La depositación de sedimentos finos, además de cambiar el tipo de sustrato disponible para los invertebrados, puede alterar la morfología del arroyo y reducir la diversidad estructural del hábitat utilizado por los organismos bentónicos, rellenando intersticios y cubriendo superficies rocosas (Wood \& Armitage, 1997). Varios estudios han identificado reducciones en densidad y biomasa de macroinvertebrados a partir de la deposición de sedimentos en suspensión. Sin embargo, no siempre la reducción es debido a las respuestas diferenciales de cada taxón al sustrato (Lenat et al., 1981; Erman \& Erman, 1984). De hecho, el hábitat de algunas especies puede mejorar con los sedimentos finos, lo que resultaría en un cambio en la composición del ensamble de macroinvertebrados (Richards et al., 1993). En esta tesis, se observó que el alto contenido de materia orgánica y porcentaje de limo favoreció la abundancia de sólo algunos grupos, mientras que la mayoría se correlacionó negativamente. Resulta de interés señalar también, que ambas características, COT y \% limo, se correlacionaron positivamente con la concentración de agrotóxicos. Es bien conocido que muchos biocidas son hidrofóbicos y se adsorben a los sedimentos (Hunt et al., 2016). Por lo cual, con la información disponible, no es posible dilucidar si el efecto observado es debido sólo al tipo de sustrato o a la acumulación de agrotóxicos en el mismo. La correlación entre la abundancia de numerosos grupos taxonómicos y la concentración de agrotóxicos 
sugiere que no se puede desestimar su efecto $y$, que la toxicidad contribuye a la composición de los ensambles.

El ancho de la franja de atenuación, como se informó anteriormente, se correlacionó negativa y significativamente con las concentraciones de los biocidas en Brasil, donde hubo una variabilidad sustancial en el ancho de la franja. Por el contrario, en Paraguay, donde los arroyos presentaban una franja generalmente boscosa a lo largo de toda su longitud, con mayor ancho y menor variabilidad; no se observó relación con la concentración de biocidas. Los resultados obtenidos en Brasil son consistentes con otros estudios realizados en Europa, América del Norte y Sudamérica donde han observado que el ancho de la zona ribereña es un importante atenuador del ingreso de agrotóxicos a los arroyos (Di Marzio et al., 2010; Bunzel et al., 2014; Reichenberger et al., 2007; Aguiar et al., 2015). Bunzel et al. (2014) analizaron 663 muestras de sitios ubicados en cuatro estados de Alemania y observaron que los tramos forestados aguas arriba y las franjas de atenuación pueden mitigar los efectos y la exposición de los agrotóxicos. Asimismo, un estudio realizado en el área central del cultivo de soja en Argentina evidenció que la mortalidad del anfípodo, Hyalella curvispina, se correlacionó significativamente con la concentración de endosulfán en agua y sedimentos y, a su vez, estos se correlacionaron inversamente con la distancia entre el cultivo y el arroyo (Di Marzio et al., 2010). Varios factores influyen en el ancho necesario para proteger los cuerpos de agua de la exposición a los agrotóxicos, incluyendo gradiente, tipo de vegetación, propiedades del suelo, tipos y cantidad de biocidas aplicados (Reichenberger et al., 2007; Bunzel et al., 2014).

Debido a que casi todos los arroyos de la Selva Paranaense estudiados en la presente tesis tenían una zona buffer forestada relativamente grande, es posible que los efectos sobre los ensambles de macroinvertebrados fuera menos evidente que los observados en otros estudios similares donde los arroyos poseen menor ancho y mayor variabilidad en la franja de atenuación. En cada sitio muestreado se midió, inmediatamente aguas arriba, el ancho mínimo observado de la franja y se confirmó la medición utilizando las imágenes LANDSAT. En las imágenes satelitales se aprecia que, para la mayoría de los arroyos, las franjas de atenuación forestadas se extendían a lo largo de toda la cuenca e incluso alrededor de los pequeños afluentes. Por el contrario, estudios previos que han establecido zonas de amortiguación de ribera eficaces para mitigar los efectos de los agrotóxicos sobre los ensambles de 
macroinvertebrados, han evaluado generalmente arroyos con zonas buffer protegidas mucho más pequeñas que los del presente estudio. Un estudio en Ontario informó que el área forestal dentro de una zona de ribera de $30 \mathrm{~m}$ estaba positivamente correlacionada con el aumento de la riqueza de Ephemeroptera, Plecoptera y Trichoptera (EPT) y la diversidad de taxones (Rios \& Bailey, 2006). Se sugiere que la mayor riqueza de taxones observada en los arroyos de Paraguay se deba, al menos en parte, a que las franjas de atenuación fueran más grandes comparadas con las de Brasil.

Varios autores han demostrado que la presencia de franjas de atenuación forestadas a lo largo de las márgenes de los arroyos puede mitigar parcialmente los efectos de los biocidas y se consideran como posibles fuentes de recolonización, ya que proporcionan reservorios de poblaciones de invertebrados, que mejoran la recuperación de las comunidades aguas abajo después de la perturbación (Liess y von der Ohe, 2005; Schäfer et al., 2007; Orlinskiy et al., 2015; Schriever et al., 2007). En un estudio realizado en una región agrícola de Alemania, se observó que las cabeceras forestales aguas arriba mitigaban los efectos de los agrotóxicos en las poblaciones de invertebrados aguas abajo (Orlinskiy et al., 2015). En los arroyos estudiados de Argentina, con producción intensiva de soja, se detectaron niveles de biocidas similares a los determinados para Brasil y Paraguay, aunque en los arroyos pampeanos el impacto sobre los taxones sensibles estaba más claramente correlacionado. Una posible razón de esta discrepancia puede ser que los arroyos de Argentina no poseen franjas de atenuación o son mucho más pequeñas, por lo que las comunidades de invertebrados no serían tan resilientes. Además, otra diferencia es que los ensambles de macroinvertebrados de los sitios muestreados en la Selva Paranaense poseen taxones (EPT) que tiende a ser sensibles no sólo a los biocidas sino también a muchas variables de hábitat y calidad de agua como lo indica su correlación con el índice RBP, coincidentemente con la literatura (Bunzel et al., 2013).

Aunque la regulación de mitigación de agrotóxicos a menudo se centra en las prácticas de aplicación, las medidas a escala de paisaje, tales como la exigencia de mantener franjas de atenuación en las riberas, podrían llegar a ser más fáciles de implementar y fiscalizar. Bereswill et al. (2014) recopilaron la información disponible en la literatura sobre la eficacia y la viabilidad de las medidas de mitigación para la entrada difusa de agrotóxicos a los ecosistemas acuáticos y clasificaron las franjas de 
atenuación como altamente eficaces para atenuar tanto la deriva de la pulverización como la escorrentía. 


\section{Conclusiones}


En el presente trabajo de tesis se determinó que el uso del suelo en la cuenca influye en la concentración de nutrientes en el agua y de agrotóxicos en los sedimentos de los arroyos. La hipótesis planteada fue confirmada, la utilización intensiva de agroquímicos en la agricultura produce un impacto en los ensambles de macroinvertebrados que habitan en los cuerpos de agua adyacentes a los cultivos.

Los agroquímicos se aplican durante el período de crecimiento de los cultivos e ingresan a los arroyos durante los eventos de escorrentía superficial producidos por las lluvias posteriores a las aplicaciones. Los agrotóxicos detectados en las muestras de sedimentos de todos los arroyos de cuencas agrícolas son los más utilizados en los cultivos de las regiones estudiadas y en su mayoría son hidrofóbicos, por tal motivo son parcialmente retenidos en los sedimentos de los arroyos donde su permanencia es más prolongada que en la fase acuosa. La composición de los ensambles de invertebrados resultó significativamente distinta en los arroyos agrícolas. Los taxones que caracterizan los ensambles de ambientes de bajo impacto, arroyos de cuencas con ganadería extensiva sobre pasturas naturales, y la reserva fueron Hyalellidae, Aeglidae, Paleomonidae y Caenidae. La fauna de invertebrados en los arroyos agrícolas se caracterizó por la dominancia de Hirudinea, Oligochaeta, Gastropoda, Bivalvia y ocasionalmente Chironomidae. Estos resultados son coincidentes con lo observado en el primer capítulo "ensayos de toxicidad" y con los datos bibliográficos donde se elaboran clasificaciones basadas en la sensibilidad de distintos taxones de macroinvertebrados. Crustacea representó el taxón más abundante en la mayoría de los ambientes Pampeanos con bajo impacto y $H$. curvispina la especie dominante en muchos de ellos. Se demostró experimentalmente que la sensibilidad de este anfípodo para los agrotóxicos es similar a la de $H$. azteca y que ambos organismos son más sensibles que la mayoría de los taxones de invertebrados de agua dulce. En el estudio de campo se observó que $H$. curvispina está ausente o presente en baja densidad en arroyos agrícolas, representando un buen indicador de la contaminación por agrotóxicos.

En este trabajo la abundancia de varios grupos taxonómicos se correlacionó inversamente con la concentración de los agrotóxicos en los sedimentos o sus unidades tóxicas, fundamentalmente las familias consideradas sensibles; por el contrario, se determinaron correlaciones positivas entre algunos grupos, generalmente los dominantes en los arroyos agrícolas, y las concentraciones de biocidas. Los grupos tolerantes muestran un incremento de la abundancia con el aumento de la concentración 
de los biocidas debido, posiblemente, a que se ven favorecidos por la desaparición de los más sensibles o por el incremento de la oferta alimentaria dado por el enriquecimiento de nutrientes, los cuales llegan a los arroyos junto con los agrotóxicos.

Las características del ambiente que influyen en la composición del ensamble de macroinvertebrados fueron determinadas, las principales variables fueron el porcentaje de materia orgánica y la textura de los sedimentos. Hay grupos que se correlacionaron positivamente con la textura fina (limo, arcilla) y la materia orgánica y negativamente con la gruesa (arena). Se puede conjeturar que la materia orgánica represente un recurso alimenticio para estos grupos. No obstante, son más los taxones que se correlacionan negativamente con la textura fina y la materia orgánica y positivamente con la gruesa. Ciertamente estas variables tienen una influencia "per se" en el habitat, en las características químicas del agua intersticial. Sin embargo, resulta de interes señalar que se detectó correlación positiva entre la materia orgánica y las texturas finas con la concentracion de varios agrotóxicos y relaciones inversas entre estos últimos y la textura gruesa, de modo tal que la toxicidad contribuye en una magnitud dificil de cuantificar en el efecto de estas variables ambientales.

Se observó reiteradamente correlaciones positivas entre la concentración de PRS y la concentración de agrotóxicos y negativas entre el PRS y la abundancia de algunos grupos taxonómicos. El PRS aplicado sobre el cultivo, se adsorbe al suelo e ingresa a los arroyos con la fracción particulada de la escorrentia superficial en simultaneidad, muchas veces, con los agrotóxicos. Por tal motivo, el PRS representa un buen indicador del impacto agrícola.

En la presente tesis se determinó que la presencia de una franja de terreno sin cultivar, cubierta de vegetación natural, tiene un efecto atenuador del impacto agrícola en los arroyos. El ancho de la franja se correlacionó negativamente con la concentración de agrotóxicos. En Brasil y Paraguay se estudiaron zonas de características ambientales bastante homogéneas, ambas cuentan con el mismo suelo, clima y corresponden a la misma región biogeográfica. No obstante, se registraron diferencias en la composición de los ensambles de macroinvertebrados. Paraguay cuenta con mayor riqueza taxonómica, abundancia y mayor índice de diversidad. La diferencia más evidente entre ambas regiones es el ancho en las franjas de atenuación, siendo mayor en Paraguay. Ambos países tienen legislación que exige a los productores dejar una franja sin cultivar 
entre el cultivo y los arroyos. El efecto atenuador de las franjas fue confirmado en la presente tesis. Por tal motivo, sería importante implementar una normativa semejante en nuestra región para limitar el transporte de agroquímicos desde los cultivos a los arroyos. 


\section{Bibliografía}

Aguiar T.R., Bortolozo F.R., Hansel F.A., Rasera K., Ferreira M.T., 2015. Riparian buffer zones as pesticide filters of no-till crops. Environ. Sci. Pollut. Res. 22: 10618-10626. doi:10.1007/s11356-015-4281-5.

Alba-Tercedor J., 1996. Macroinvertebrados acuáticos y calidad de agua de los ríos. IV Simposio del agua en Andalucía (SIAGA). Almería. 2: 203-213.

Amweg E.L., Weston D.P., Johnson C.S., You J., Lydy M.J., 2006. Effect of piperonyl butoxide on permethrin toxicity in the amphipod Hyalella azteca. Environ. Toxicol. Chem. 25 (7): 1817-1825.

ANVISA (Agência Nacional De Vigilância Sanitária), 2010. Resolución RDC No 28 : Regulamento Técnico para o Ingrediente Ativo Endossulfam em decorrência da Reavaliação Toxicológica.

APHA (American Public Health Association), 1995. Standard Methods for the Examination of Water and Wastewater. Washington. 1193 pp.

APHA (American Public Health Association), 2005. Standard Methods for the Examination of Water and Wastewater (20 ed.). Washington.

Armendáriz L. C., Ocón C., Rodrigues Capítulo A., 2012. Potential responses of oligochaetes (Annelida, Clitellata) to global changes: experimental fertilization in a lowland stream of Argentina (South America). Limnologica 42: 118-126.

Astoviza MJ, Cappelletti N, Bilos C, Migoya MC, Colombo JC (2015) Massive airborne Endosulfan inputs related to intensive agricultura in Argentina's Pampa. Chemosphere 144:1459-1466.

Athor J., 2009. Parque Costero del Sur - Naturaleza, Conservación y Patrimonio Cultural. Fundación de Historia Natural "Félix de Azara", Buenos Aires, 528 pp.

Barbour M.T. \& Gerritsen J., 1996. Subsampling of Benthic Samples: A Defense of the Fixed-Count Method. J. North Am. Benthol. Soc. 15, 386. doi:10.2307/1467285

Barbour M.T., Diamond J.M., Yoder C.O., 1996. Biological assessment strategies: Applications and Limitations; in Whole effluent toxicity testing: An evaluation of methods and prediction of receiving system impacts (Grothe D.R., Dickson K.L. and Reed-Judkins D.K.). SETAC Press, Pensacola, Florida. 245-270

Barbour M.T., Gerritsen J., Snyder B.D., Stribling J.B., 1999. Rapid bioassessment protocols for use in streams and wadeable rivers: Periphyton, Benthic Macroinvertebrates and Fish. 2nd Edition. EPA/841-B-99-002. USEPA, Office of Water, Washington, D.C. 197 pp.

Bejarano F., Souza J., Weber JM., Guadarrama C., Escamilla E., Beristaín B., Acosta M., Cárcamo MI., Ramírez F., 2008. El endosulfán y sus alternativas en América Latina. RAPAL-IPEN-RAPAM-UACH. Santiago de Chile 148 pp.

Bereswill R., Streloke M., Schulz R., 2014. Risk mitigation measures for diffuse pesticide entry into aquatic ecosystems: proposal of a guide to identify appropriate measures on a catchment scale. Integrated Environmental Assessment and Management 10 (2): 286-298. 
Bjergager M.A., Hanson M.L., Lissemore L., Henriquez N., Solomon K.R., Cedergreen N., 2011. Synergy in microcosms with environmentally realistic concentrations of prochloraz and esfenvalerate Aquatic Toxicology, 101: 412-422.

Borin M., Passonia M., Thieneb M., Tempesta T., 2010. Multiple functions of buffer strips in farming areas. Europ. J. Agronomy 32: 103-111.

Bouchard R.W. Jr., 2004. Guide to Aquatic Macroinvertebrates of the Upper Midwest. Water Resources Center, University of Minnesota, St Paul, MN. 208 pp.

Bruno D., Belmar O., Sánchez-Fernández D., Guareschi S., Millán A., Velasco J., 2014. Responses of Mediterranean aquatic and riparian communities to human pressures at different spatial scales. Ecolog. Ind. 45, 456-464.

Bueno A., Batistela M.J., Bueno R.C.O., Franca-Neto J., Nishikawa M.A.N., Filho A.L., 2011. Effects of integrated pest management, biological control and prophylactic use of insecticides on the management and sustainability of soybean. Crop Prot. 30 (7): 937-945.

Bunzel K., Kattwinkel M., Liess M., 2013. Effects of organic pollutants from wastewater treatment plants on aquatic invertebrate communities. Water Res. 47: 597-606. doi: 10.1016/j.watres.2012.10.031.

Bunzel K., Liess M., Kattwinkel M., 2014. Landscape parameters driving aquatic pesticide exposure and effects. Environ. Pollut. 186: 90-97. doi: 10.1016/j.envpol.2013.11.021.

Carter J.L. \& Resh V.H., 2013. Analytical Approaches Used in Stream Benthic Macroinvertebrate Biomonitoring Programs of State Agencies in the United States. United States Geological Survey Open-File Report 2013-1129.

CASAFE (Cámara Argentina de Sanidad Agropecuaria y Fertilizantes), 2012. Mercado Argentino de Productos Fitosanitarios 2012. Disponible en: http://www.casafe.org/publicaciones/estadisticas/ Acceso 2017.

Casara K.P., Vecchiato A.B., Lourencetti C., Pinto A.A., Dores E.F., 2012. Environmental dynamics of pesticides in the drainage area of the São Lourenço River headwaters, Mato Grosso State, Brazil. J. Braz. Chem. Soc. 23: 1719-1731.

Castanheira É.G. \& Freire F., 2013. Greenhouse gas assessment of soybean production: implications of land use change and different cultivation systems. J. Clean. Prod. 54: 49-60. doi: 10.1016/j.jclepro.2013.05.026.

CIAFA (Cámara de la industria argentina de fertilizantes y agroquímicos), 2015. Consumo de fertilizantes en el agro 2015. Disponible en: http://www.ciafa.org.ar/files/WKtNkYAJ72xppWqLgPvbdFywAE8qGAwuDyYa iD8f.pdf Acceso 2017.

Clarke K.R. \& Gorley R.N., 2001. PRIMER v5: User Manual/Tutorial PRIMER-E: Plymouth Routines in Multivariate Ecological Research, 91 pp.

Clarke K.R. \& Warwick, R.M., 2001. Change in Marine Communities, an approach to statistical analysis and interpretacion, 2nd Edition. PRIMER-E: Plymouth Routines in Multivariate Ecological Research.

Clarke R.T., Wright J.F., Furse M.T., 2003. RIVPACS models for predicting the expectedmacroinvertebrate fauna and assessing the ecological quality of rivers. Ecological Modelling 160 (3): 219-233. 
$\begin{array}{lllll}\text { Código Florestal (lei } & \text { federal } & \mathrm{n}^{\mathrm{o}} & 12.651 / 12), & \end{array}$ http://www2.camara.leg.br/legin/fed/lei/2012/lei-12651-25-maio-2012-613076normaatualizada-pl.pdf Acceso 2018.

Cooper CM., 1993. Biological effects of agriculturally derived surface-water pollutants on aquatic systemsFa review. J Environ Qual 22: 402-408.

Corigliano M., Gualdoni C., Oberto A.M., Raffaini G.B., 2005. Distribución altitudinal de macroinvertebrados en paisajes fluviales rurales y urbanos en subcuencas del río Carcarañá, Pcia. Córdoba. Rev. univ. Nac. Río Cuarto. 25: 125-142.

Cortelezzi A., Ocón C., Lopez Van Oosterom V., Cepeda R., Rodrigues Capítulo A., 2015. Nutrient enrichment effect on macroinvertebrates in a lowland stream of Argentina. Porto Alegre. Iheringia, Serie Zoologia 105(2): 228-234. https://dx.doi.org/10.1590/1678-476620151052228234.

Cruz-Miranda S.G., Stanford-Camargo S.G., Ibarra González M.P., Medina-Ortiz G.R., Morales Moreno A., 2015. Hidrofílidos (Coleoptera: Hydrophilidae) de dos localidades de la sierra de Huautla Morelos, México. Entomología Mexicana 2: 608-612.

De Geronimo E., Aparicio V.C., Barbaro S., Portocarrero R., Jaime S., Costa J.L., 2014. Presence of pesticides in surface water from four sub-basins in Argentina. Chemosphere 107: 423-431.

Derpsch R., 2010. Avances y perspectivas para la siembra directa a nivel mundial. El Productor 121: 18-22. Disponible en: http://issuu.com/genow/docs/productor121. Acceso 2017.

DGEEC (Dirección General de Estadística, Encuestas y Censos), 2015. Atlas Censal del Paraguay. Asunción. Secretaría Técnica de Planificación. Disponible en: http://www.dgeec.gov.py/Publicaciones/Biblioteca/anuario2015/Anuario\%20Esta distico\%202015.pdf. Acceso 2018.

Di Marzio W.D., Sáenz M.E., Alberdi J.L., Fortunato N., Cappello V., Montivero C., Ambrini G., 2010. Environmental impact of insecticides applied on biotech soybean crops in relation to the distance from aquatic ecosystems. Environ. Toxicol. Chem. 29(9): 1907-1917. doi:10.1002/etc.246

Domínguez E \& Fernández HR., 1998. Calidad de los ríos de la cuenca del Salí (TucumánArgentina) medida por un índice biótico. Serie conservación de la Naturaleza $n^{\circ} 12$. Fundación Miguel Lillo, Republica Argentina, 39 pp.

Dominguez E. \& Fernandez H. R., 2009. Macroinvertebrados bentónicos. Sistemática y biología. $1^{\mathrm{a}}$ ed. Fundación Miguel Lillo, Tucumán. 656 pp.

Dores E.J.G.C., 2015. Pesticides in the Pantanal. In: Bergier, I., Assine, M.L. (Eds.), Dynamics of the Pantanal Wetland in South America. The Handbook of Environmental Chemistry. Springer International Publishing, Switzerland. http://dx.doi.org/10.1007/698_2015_356.

Duggan I.C., Green J.D., Thompson K., Shiel R.J., 2001. The influence of macrophytes on the spatial distribution of littoral rotifers. Freshwater Biology 46:777-786.

Egler M.A., Buss D.F., Moreira J.C., Baptista D.F., 2012. Influence of agricultural landuse and pesticides on benthic macroinvertebrate assemblages in an agricultural river basin in southeast Brazil. Braz. J. Biol. 72: 437-443. 
Ekboir J., 2001. Sistemas de innovación y política tecnológica: siembra directa en el MERCOSUR. Capítulo: Cambio técnico e impacto ambiental. En: Díaz Rossello, R. (Editor). Siembra Directa en el Cono Sur. INIA La Estanzuela, Colonia, Uruguay. 1-19.

Erman D.C. \& Erman N.A., 1984. The response of invertebrates to substrate size and heterogeneity. Hydrobiologia, 108: 75-78.

FARN (Fundación Ambiente y Recursos Naturales), 2015. Agroquímicos, un debate nacional pendiente por Di Paola María Marta. https://farn.org.ar/wpcontent/plugins/download-attachments/includes/download.php?id=18083. Acceso 2018 .

Ferreiro N., Feijoó C., Giorgi A., Rosso J., 2014. Macroinvertebrates select complex macrophytes independently of their body size and fish predation risk in a Pampean stream. Hydrobiologia. doi:10.1007/s 10750-014-1953-y.

Fierro P., Bertrán C., Mercado M., Peña-Cortés F., Tapia J., Hauenstein E., VargasChacoff L., 2012. Benthic macroinvertebrates assemblages as indicators of water quality applying a modified biotic index in a spatio-seasonal context in a coastal basin of southern Chile. Rev. Biol. Mar. Oceanogr. 47: 23-33.

Fierro P., Bertrán C., Mercado M., Peña-Cortés F., Tapia J., Hauenstein E., Caputo L., Vargas-Chacoff L., 2015. Landscape composition as a determinant of diversity and functional feeding groups of aquatic macroinvertebrates in southern rivers of the Araucanía, Chile. Lat. Am. J. Aquat. Res. 43: 186-200.

Fierro P., Bertrán C., Tapia J., Hauenstein E., Peña-Cortés F., Vergara C., Cerna C., Vargas-Chacoff L., 2017. Effects of local land-use on riparian vegetation, water quality, and the functional organization of macroinvertebrate assemblages. Science of the Total Environment 609: 724-734.

Fierro P., Valdovinos C., Vargas-Chacoff L., Bertrán C., Arismendi I., 2017. Macroinvertebrates and fishes as bioindicators of stream water pollution. In: Tutu, H. (Ed.), Water Quality. Intechopen, Rijeka 23-38.

FOCUS 2007. "Landscape and Mitigation Factors in Aquatic Risk Assessment. Volume 2. 33 Detailed Technical Reviews". Report of the FOCUS Working Group on Landscape 34 and Mitigation Factors in Ecological Risk Assessment, EC Document Reference 35 SANCO/10422/2005 v2.0. 436 pp.

Friberg-Jensen U., Wendt-Rasch L., Woin P., Christoffersen K., 2003. Effects of the pyrethroid insecticide, cypermethrin, on a freshwater community studied under field conditions. I. Direct and indirect effects on abundance measures of organisms at different trophic levels. Aquatic Toxicology 63: 357-371.

Gabellone N., Claps M., Solari L., Neschuk N., 2005. Nutrients, conductivity and plankton in a landscape approach to a Pampean saline lowland river (Salado River, Argentina). Biogeochemistry 75: 455-477.

García-López G.A., Arizpe N., 2010. Participatory processes in the soy conflicts in Paraguay and Argentina. Ecological Economics, 70(2): 196-206.

Gerth W., Li J., Giannico R., 2017. Agricultural land use and macroinvertebrate assemblages in lowland temporary streams of the Willamette Valley, Oregon, USA. Agric. Ecosyst. Environ. 236: 154-165. 
Gibbins C.N., Dilks C.F., Malcolm R., Soulsby C., Juggins S., 2001. Invertebrate communities and hydrological variation in Caringorm mountain streams. Hydrobiologia 462: 205-219.

Giddings J.M., Solomon K.R., Maund S.J., 2001. Probabilistic risk assessment of cotton pyrethroids. II. Aquatic mesocosm and field studies. Environ. Toxicol. Chem. 20 (3): 660-668.

Gómez N., Sierra M.V., Cortelezzi A., Rodrígues-Capítulo A., 2008. Effects of discharges from the textile industry on the biotic integrity of benthic assemblages. Ecotoxicology and Environmental Safety 69: 472-479.

González-Córdoba M., Zúñiga M.C., Manzo V., 2015. Riqueza genérica y distribución de Elmidae (Insecta: Coleoptera, Byrrhoidea) en el departamento del Valle del Cauca, Colombia. Instituto de Investigación de Recursos Biológicos "Alexander von Humboldt" Bogotá, Colombia. Biota Colombiana 16(2): 51-74.

Gücker B., Boëchat I.G., Giani A., 2009. Impacts of agricultural land use on ecosystem structure and whole-stream metabolism of tropical Cerrado streams. Freshw. Biol. 54: 2069-2085. doi:10.1111/j.1365-2427.2008.02069.x

Hering D., Moog O., Sandin L., Verdonschot P., 2004. Overview and application of the AQEM assessment system. Hydrobiología 516: 1-20.

Hunke P., Mueller E.N., Schröder B., Zeillhofer P., 2015. The Brazilian Cerrado: assessment of water and soil degradation in catchments under intensive agricultural use. Ecohydrology 8: 1154-1180.

Hunt L., Bonetto C., Resh V.H., Buss D.F., Fanelli S., Marrochi N., Lydy M.J., 2016. Insecticide concentrations in stream sediments of soy production regions of South America. Sci. Total Environ. 547: 114-124. doi: 10.1016/j.scitotenv.2015.12.140

Jergentz S., Mugni H., Bonetto C., Schulz R., 2004a. Runoff-related endosulfan contamination and aquatic macroinvertebrate response in rural basins near Buenos Aires, Argentina. Archives of Environmental Contamination and Toxicology 46: 345-353.

Jergentz S., Mugni H., Bonetto C., Schulz R., 2005. Assessment of insecticide contamination in runoff and stream water of small agricultural streams in the main soybean area of Argentina. Chemosphere 61: 817-826.

Jergentz S., Pessacq P., Mugni H., Bonetto C., Schulz R., 2004b. Linking in situ bioassays and dynamics of macroinvertebrates to assess agricultural contamination in streams of the Argentine Pampa. Ecotoxicology and Environmental Safety 59: 133-141. doi: 10.1016/j.ecoenv.2004.06.007

Jones K.B., Neale A.C., Nash M.S., Van Remortel R.D., Wickham J.D., Riitters K.H., O’Neill R.V., 2001. Predicting nutrient and sediment loadings to streams from landscape metrics: a multiple watershed study from the United States Mid-Atlantic Region. Landsc. Ecol. 16: 301-312.

Laabs V., Amelung W., Pinto A.A., Wantzen M., da Silva C.J., Zech W., 2002. Pesticides in surface water, sediment, and rainfall of the northeastern Pantanal basin, Brazil. J. Environ. Qual. 31: 1636-1648. 
Lammert M. \& Allan D., 1999. Assessing biotic integrity of streams: effects of scale in measuring the influence of land use/cover and habitat structure on fish and microinvertebrates. Environmental Management 23: 257-270.

Lenat D.R. \& Barbour M.T., 1994. Using benthic macroinvertebrate community structure for rapid, cost-effective, water quality monitoring: rapid bioassessment. In Biological monitoring of aquatic systems (Loeb SL \& A Spacie). Lewis Publishers, Ann Arbor, Michigan, USA 187-215.

Lenat D.R., Penrose D.L., Eagleson K.W., 1981. Variable effects of sediment addition on stream benthos. Hydrobiologia, 79: 187-19.

Leps J. \& Smilauer P., 2003. Multivariate Analysis of Ecological Data Using CANOCO. Cambridge University Press, Cambridge, UK.

Liess M. \& Von Der Ohe P.C., 2005. Analyzing effects of pesticides on invertebrate communities in streams. Environ. Toxicol. Chem. 24: 954-965.

Lydy M., Belden J., Wheelock C., Hammock B., Denton D., 2004. Challenges in regulating pesticide mixtures. Ecology and Society. 9 (6): 1. https://www.ecologyandsociety.org/vol9/iss6/art1/

Magurran A. E., 1988. Ecological diversity and its measurement. Princeton University Press, New Jersey. 180 pp.

MAGyP (Ministerio de Agricultura, Ganadería y Pesca de la Nación); SIIA sistema integrado de información agropecuaria. Disponible en: https://datos.magyp.gob.ar/reportes.php?reporte=Estimaciones. Acceso 2017.

Marino D. \& Ronco A., 2005. Cypermethrin and chlorpyrifos concentration levels in surface water bodies of the Pampa Ondulada, Argentina. Bulletin of Environmental Contamination and Toxicology 75: 820-826. doi:10.1007/s00128005-0824-7

Matthaei C.D., Piggott J.J., Townsend C.R., 2010. Multiple stressors in agricultural streams: interactions among sediment addition, nutrient enrichment and water abstraction. J. Appl. Ecol. 47: 639-649. doi:10.1111/j.1365-2664.2010.01809.x

Merritt R.W., Cummins K.W. \& Berg M.B., 2008. An introduction to the aquatic insects of North America ( $4^{\circ} \mathrm{ed}$ ). Kendall-Hunt Publ. Co. Dubuque, IA. 1158 pp.

Meybeck M., 1998. Man and river interface: multiple impacts on water and particulates chemistry illustrated in the Seine river basin. Hydrobiologia 373/374: 1-20.

Miller C., Denis J., Ator S. \& Brakebill J., 1997. Nutients in streams during baseflow in selected environmental settings of the Potomac River basin. J. Am. Water Res. Assoc. 33: 1155-1171.

Ministerio de Agricultura y Ganadería, 2009. República del Paraguay. Ley No 3742/09: de control de productos fitosanitarios de uso agrícola. Disponible en: http://www.senave.gov.py/docs/leyes/LEY3742-2009.pdf Acceso 2018.

Miranda K., Cunha M.L.F., Dores E.F.G.C., Calheiros D.F., 2008. Pesticide residues in river sediments from the Pantanal Wetland, Brazil. Journal of Environmental Science and Health Part B. 43(8): 717-722. 
Miserendino M.L. \& Masi C.I., 2010. The effects of land use on environmental features and functional organization of macroinvertebrate communities in Patagonian low order streams. Ecological Indicators 10: 311 - 319.

Miserendino M.L. \& Pizzolón L.A., 1999. Rapid assesment of river water quality using macroinvertebrates: A family level biotic index for the Patagonic andean zone. Acta Limnológica Brasillensia 11: 137-148.

Miserendino M.L., Brand C., Di Prinzio C.Y., 2008. Assessing urban impacts on water quality, benthic communities and fish in streams of the Andes mountains, Patagonia (Argentina). Water, Air, and Soil Pollution 194: 91-110.

Miserendino M.L., Casaux R., Archangelsky M., Di Prinzio C.Y., Brand C., Kutschker A.M., 2011. Assessing land-use effects on water quality, in-stream habitat, riparian ecosystems and biodiversity in Patagonian northwest streams. Science of the Total Environment 409: 612-624.

Moltoni L., 2012. Evolución del mercado de herbicidas en Argentina. Economía y Desarrollo Agroindustrial. INTA - Instituto de Ingeniería Rural 1 (2): 1-6.

Morrone J.J., 2014. Biogeographical regionalisation of the Neotropical region. Zootaxa 3782:110 pp.

Mugnai R., Nessimian J.L., Ferdandes Baptista D., 2010. Manual de identificación de Macroinvertebrados acuáticos del Estado de Rio de Janeiro. $1^{\circ}$ Ed. Technical Books, Rio de Janeiro, Brasil. 155 pp.

Mugni H., 2009. Concentración de nutrientes y toxicidad de pesticidas en aguas superficiales de cuencas rurales. Tesis doctoral, Universidad de La Plata. 140 pp.

Mugni H., Demetrio P., Bulus G., Ronco A., Bonetto C., 2011b. Effect of aquatic vegetation on the persistence of cypermethrin toxicity in water. Bulletin of Environmental Contamination and Toxicology 86: 23-27.

Mugni H., Paracampo A., Bonetto C., 2013a. Nutrient concentrations in a pampasic first order stream with different land uses in the surrounding plots (Buenos Aires, Argentina). Bulletin of Environmental Contamination and Toxicology 91: 391395.

Mugni H., Paracampo A., Demetrio P., Scalise A., Solis M., Fanelli S., Bonetto C., 2015. Acute Toxicity of Endosulfan to the Non-target Organisms Hyalella curvispina and Cnesterodon decemmaculatus. Bulletin of Environmental Contamination and Toxicology. doi:10.1007/s00128-015-1608-3

Mugni H., Paracampo A., Marrochi N., Bonetto C., 2012. Cypermethrin, chlorpyrifos and endosulfan toxicity to two non-target freshwater organisms. Fresenius Environmental Bulletin 21 (8): 2085-2089.

Mugni H., Paracampo A., Marrochi N., Bonetto C., 2013b. Acute toxicity of cypermethrin to the non target organism Hyalella curvispina. Environmental toxicology and pharmacology 35: 88-92. doi: 10.1016/j.etap.2012.11.008

Mugni H., Ronco A., Bonetto C., 2011a. Insecticide toxicity to Hyalella curvispina in runoff and stream water within a soybean farm (Buenos Aires, Argentina). Ecotoxicol. Environ. Saf. 74: 350-354. doi: 10.1016/j.ecoenv.2010.07.030

Neumann M. \& Dudgeon D., 2002. The impact of agricultural runoff on stream benthos in Hong Kong, China.Water Research 36 (12): 3103-3109. 
Nieser N. \& Melo A.L. 1997. Os Heterópteros Aquáticos de Minas Gerais. Belo Horizonte, UFMG. 180pp.

Ocon C.S. \& Rodríguez A., 2004. Presence and abundance of Ephemeroptera and other sensitive macroinvertebrates in relation with habitat conditions in pampean streams (Buenos Aires, Argentina). Archiv Fur Hydrobiologie 159: 473-487.

Omernik J.M. 1977. Non-point source - stream nutrient level relationships: a nationwide study. EPA Ecological Research Series EPA-600/3-77-105. USEPA, Office of Research and Development, Environmental Research Laboratory, Corvallis, Oregon, USA, $150 \mathrm{pp}$

OPDS (Organismo Provincial para el Desarrollo Sostenible), 2013. Plaguicidas en el territorio bonaerense: información toxicológica, ecotoxicológica y comportamiento ambiental.

Orlinskiy P., Münze R., Beketov M., Gunold R., Paschke A., Knillmann S., Liess M., 2015. Forested headwaters mitigate pesticide effects on macroinvertebrate communities in streams: Mechanisms and quantification. Sci. Total Environ. 524/525, 115-123. doi:10.1016/j.scitotenv.2015.03.143

Paracampo A., Mugni H., Demetrio P., Pardi M., Bulus G., Asborno M., Bonetto C., 2012. Toxicity persistence in runoff and soil from experimental soybean plots following insecticide applications. J. Environ. Sci. Health, Part B 47: 761-768.

Pengue W., 2000. Cultivos transgénicos ¿Hacia dónde vamos? Lugar Editorial, Buenos Aires.

Pérez G. \& Roldán G., 1978. Niveles de contaminación por detergentes y su influencia en las comunidades bénticas del Río Rionegro (Antioquia). Actualidades Biológicas 7(24): 27-36.

Pizzolon L.A. \& Miserendino M.L., 2001. - The performance of two regional biotic indices for running water quality in Northern Patagonian Andes. Acta Limnol. Bras., 13(1): 11-27.

Plafkin J.L., Barbour M.T., Porter K.D., Gross S.K., Hughes R.M., 1989. Rapid bioassessment protocols for use in streams and rivers: Benthic macroinvertebrates and fish. USEPA, Office of Water Regulations and Standards, Washington, D.C. EPA 440-4-89-001.

Possavatz J., Zeilhofer P., Pinto A.A., Tives A.L., Dores E., 2014. Resíduos de pesticidas em sedimento de fundo de rio na Bacia Hidrográfica do Rio Cuiabá, Mato Grosso, Brasil. Ambiente Água 9: 83-96.

Potter K.M., Cubbage F.W., Schaberg R.H., 2005. Multiple-scale landscape predictors of benthic macroinvertebrate community structure in North Carolina. Landsc Urban Plann 71: 77-90.

Probst M., Berenzen N., Lentzen-Godding A., Schulz R., Liess M., 2005. Linking land use variables and invertebrate taxon richness in small and medium-sized agricultural streams on a landscape level. Ecotoxicol Environ Saf 60: 140-146.

Quirós R. \& Drago E., 1999. The environmental state of Argentinean lakes: an overview. Lakes and Reservoirs: Res. and Manag. 4: 55-64.

Rasmussen J.J., Baattrup-Pedersen A., Wiberg-Larsen P., McKnight U.S., Kronvang B., 2011. Buffer strip width and agricultural pesticide contamination in Danish 
lowland streams: Implications for stream and riparian management. Ecol. Eng. 37: 1990-1997. doi:10.1016/j.ecoleng.2011.08.016

Reichenberger S., Bach M., Skitsschak A., Frede H., 2007. Mitigation strategies to reduce pesticide inputs into ground- and surface water and their effectiveness; a review. Science of the Total Environment 384(1-3):1-35.

Ribbe L., Delgado P., Salgado E., Flügel W.A., 2008. Nitrate pollution of surface water induced by agricultural non-point pollution in the Pocochay watershed, Chile. Desalination 226(1-3): 13-20.

Richards C., Host G.E., Arthur J.W., 1993. Identification of predominant environmental factors structuring stream macroinvertebrate communities within a large agricultural catchment. Freshw. Biol. 29: 285-294.

Rios S.L. \& Bailey R.C., 2006. Relationship between riparian vegetation and stream benthic communities at three spatial scales. Hydrobiologia 553: 153-160. doi:10.1007/s10750-005-0868-z

Rocha M.P., Dourado P.L.R., Rodriques M.S., Raposo J.L., Grisolia A.B., Oliveira K.M.P., 2015. The influence of industrial and agricultural waste on water quality in the Agua Boa Stream (Dourados, Mata Grosso do Sul, Brazil). Environ. Monit. Assess. 187 (7): 442.

Rodrigues-Capítulo, A., Tangorra, M. y Ocón, C., 2001. Use of benthic macroinvertebrates to assess the biological status of Pampean streams in Argentina. Aquatic Ecology 35: 109-119.

Roldán G. \& Ramírez J., 2008. Fundamentos de Limnología Neotropical. 2. ed. Medellín Colombia.: Editorial Universidad de Antioquia. 439 pp.

Roldán Pérez G., 1999. Los macroinvertebrados y su valor como indicadores de la calidad del agua. Revista de la Academia Colombiana de Ciencias Exactas Físicas y Naturales 23 (88): 375-387.

Rosenberg D.M. \& Resh V.H., 1993. Introduction to freshwater biomonitoring and benthic macroinvertebrates. In: D.M. Rosenberg \& V.H. Resh, eds. Freshwater Biomonitoring and Benthic Macroinvertebrates. Chapman and Hall, New York.

Schäfer, R.B., Caquet, T., Siimes, K., Mueller, R., Lagadic, L., Liess, M., 2007. Effects of pesticides on community structure and ecosystem functions in agricultural streams of three biogeographical regions in Europe. Sci. Total Environ. 382, 272285. doi: 10.1016/j.scitotenv.2007.04.040

Schriever C.A., Hansler-Ball M., Holmes C., Maund S., Liess M., 2007. Agricultural intensity and landscape structure: influences on the macroinvertebrate assemblages of small streams in northern Germany. Environ. Toxicol. Chem. 26: 346-357.

Schultz R.C., Isenhart T.M, Colletti J.P., Simpkins W.W., Udawatta R.P., Schultz P.L., 2009. Riparian and upland buffer practices. In Garrett H.E. (ed.) North American Agroforestry an Integrated science and practice, $2^{\circ}$ ed. American Society of Agronomy, Madison, WI 163- 218 pp.

Schulz, R. \& Liess, M., 1999a. A field study of the effects of agriculturally derived insecticide input on stream macroinvertebrate dynamics. Aquatic Toxicology 46: $155-176$. 
Schulz, R. \& Liess, M., 1999b. Validity and ecological relevance of an active in situ bioassay using gammarus pulex and limnephilus lunatus. Environ Toxicol Chem 18: 2243-2250.

SENASA, 2011. Resolución 511/2011 del Servicio Nacional de Sanidad y Calidad Agropecuaria. Disponible en: http://www.senasa.gob.ar/normativas/resolucion511-2011-senasa-servicio-nacional-de-sanidad-y-calidad-agroalimentaria Acceso 2018.

SENAVE (Servicio Nacional de Calidad y Sanidad Vegetal y de Semillas), 2010. Resolucion 635/10: por la cual se suspende la emision de nuevos registros y la importacion al pais de productos técnicos y formulados a base de endosulfán en todas sus concentraciones. Disponoble en: http://www.matusdubarry.com/v2/images/stories/resoluciones/SENAVE/RESOLUCION\%20635_1 0\%20POR\%20LA\%20CUAL\%20SE\%20SUSPENDE\%20LA\%20EMISION\% 20 DE\%20NUEVOS\%20REGISTROS\%20Y\%20LA\%20IMPORTACION\%20AL\% 20PAIS\%20DE\%20..........pdf Acceso 2018.

Smetanová S., Bláha L., Liess M., Schäfer R.B., Beketov M.A., 2014. Do predictions from Species Sensitivity Distributions match with field data? Environmental Pollution 189: 126-133. doi: 10.1016/j.envpol.2014.03.002

Solis M., 2017. Impacto de agroquímicos en arroyos de cuencas rurales. Tesis Doctoral. Universidad Nacional de La Plata (UNLP). Facultad de Ciencias Naturales y Museo. $131 \mathrm{pp}$.

Solis M., Mugni H., Hunt L., Marrochi M.N., Fanelli S., Bonetto C., 2016. Land use effect on invertebrate assemblages in Pampasic streams (Buenos Aires, Argentina). Environmental Monitoring and Assessment 188:539.

Spangler P.J., 1982. Coleoptera. In Hurlbert S.H. \& Villalobos-Figueroa A. (eds.). Aquatic biota of México, Central America, and the West Indies. San Diego State University, San Diego. California. p. 328-397.

Stefanidis K., Panagopoulos Y., Mimikou M., 2016. Impact assessment of agricultural driven stressors on benthic macroinvertebrates using simulated data. Science of the Total Environment 540: 32-42. doi.org/10.1016/j.scitotenv.2015.08.015

Stone M.L., Whiles M.R., Webber J.A., Williard K.W.J., Reeve J.D., 2005. Macroinvertebrate Communities in Agriculturally Impacted Southern Illinois Streams. J. Environ. Qual. 34 (3): 907-917. doi:10.2134/jeq2004.0305

Ter Braak C.J.F. \& Smilauer P., 1998. CANOCO Reference Manual and User's Guide to Canoco for Windows: Software for Canonical Community Ordination. Ithaca, NY: Microcomputer Power.

Trimble, A.J., Weston, D.P., Belden, J.B., Lydy, M.G., 2009. Identification and evaluation of pyrethroid insecticide mixtures in urban sediments. Environ. Toxicol. Chem. 28 (8), 1687-1695.

UNEP (United Nations Environment Program), 2011. Stockholm convention on persistent organic pollutants. UNEP/POPS/COP.5/36. Geneva, Switzerland. http://chm.pops.int/Portals/0/download.aspx?d=UNEP-POPS-COP.536.English.pdf Acceso 2018.

USDA (United States Department of Agriculture), 1996. Soil survey laboratory methods manual. Soil Survey Investigations Report $n^{\circ}$. 42, Version 3.0. 
USEPA (U.S. Environmental Protection Agency), 2000. Methods for Measuring the Toxicity and Bioaccumulation of Sediment-associated Contaminants with Freshwater Invertebrates, second ed. USEPA, Washington, DC. (EPA 600/R99/064).

USEPA (U.S. Environmental Protection Agency), 2000. Methods for Measuring the Toxicity and Bioaccumulation of Sediment-Associated Contaminants with Freshwater Invertebrates, EPA/600/R-99/064, 2 $2^{\circ}$ ed.; Office of Research and Development: Washington DC, USA.

USEPA (U.S. Environmental Protection Agency), 2002. Methods for Measuring the Acute Toxicity of Effluents and Receiving Waters to Freshwater and Marine Organisms, EPA 821-R-02-012, 5th ed; Office of Water: Washington DC, USA.

USEPA (U.S. Environmental Protection Agency), 2007. Method 3550C Ultrasonic extraction. Revision 3. Washington DC, USA.

USEPA (U.S. Environmental Protection Agency), 2015a. Species Sensitivity Distribution Generator. https://www.epa.gov/caddis-vol4/caddis-volume-4-dataanalysis-advanced-analyses-controlling-for-natural-variability\#tab-5 Acceso 2018.

USEPA (U.S. Environmental Protection Agency), 2015b. ECOTOX Data base. https://cfpub.epa.gov/ecotox/quick_query.htm Acceso 2018.

Velásquez S.M. \& Miserendino M.L., 2003. Habitat type and macroinvertebrate assemblages in low order Patagonian streams. Archiv fur Hydrobiologie 158(4): 461-483.

Wan M.T., Kuo J., Buday C., Schroeder G., Van Aggelen G., Pasternak J., 2005. Toxicity of $\alpha-, \beta-,(\alpha+\beta)$-endosulfan and their formulated and degradation products to Daphnia magna, Hyalella azteca, Oncorhynchus mykiss, Oncorhynchus kisutch, and biological implications in streams. Environmental Toxicology and Chemistry 24 (5): 1146-1154.

Weston D.P. \& Jackson C.J., 2009. Use of Engineered Enzymes to Identify Organophosphate and Pyrethroid-Related Toxicity in Toxicity Identification Evaluations. Environmental Science \& Technology 43: 514-5520. doi:10.1021/es900434z

Weston D.P., Amweg E.L., Mekebri A., Ogle R.S., Lydy M.J., 2006. Aquatic effects of aerial spraying for mosquito control over an urban area. Environ. Sci. Technol. 40 (18): 5817-5822.

Weston D.P., Ding Y., Zhang M., Lydy M.J., 2013. Identifying the cause of sediment toxicity in agricultural sediments: The role of pyrethroids and nine seldommeasured hydrophobic pesticides. Chemosphere 90: 958-964. doi: 10.1016/j.chemosphere.2012.06.039

Weston D.P., You J., Harwood A.D., Lydy M.J., 2009. Whole sediment toxicity identification evaluation tools for pyrethroid insecticides: III. Temperature manipulation. Environmental Toxicology and Chemistry 28 (1): 173-180.

Wogram J. \& Liess M., 2001. Rank ordering of macroinvertebrate species sensitivity to toxic compounds, by comparison with that of Daphnia magna. Bulletin of Environmental Contamination and Toxicology, 67: 360-367.

Wood P.J. \& Armitage P.D., 1997. Biological effects of fine sediment in the lotic environment. Environ. Manage. 21: 203-217. 
You J, Weston DP, Lydy MJ., 2004b. A Sonication Extraction Method for the Analysis of Pyrethroid, Organophosphate, and Organochlorine Pesticides from Sediment by Gas Chromatography with Electron-Capture Detection. Archives of Environmental Contamination and Toxicology, 47 (2): 141-147.

You J., Schuler L.J., Lydy M.J., 2004a. Acute Toxicity of Sediment-Sorbed Endrin, Methoxychlor, and Endosulfan to Hyalella azteca and Chironomus tentans. Bull. Environmental Contamination and Toxicology 73: 457-464. doi:10.1007/s00128004-0451-8

Zhang X., Liu X., Zhang M., Dahlgren R.A., 2010. A review of vegetated buffers and meta-analysis of their mitigation efficacy in reducing nonpoint source pollution. Journal of Environmental Quality 39: 76-84. 
Anexo 
APÉNDICE A. Ensayos de toxicidad.

Tabla A1. Resultados de la distribución de sensibilidad de las especies para clorpirifos

\begin{tabular}{|c|c|c|c|c|}
\hline Taxones & $\begin{array}{c}\mathbf{L C}_{50} \\
(\mu \mathrm{g} / \mathrm{L})\end{array}$ & $\begin{array}{c}\text { Desviación } \\
\text { St }\end{array}$ & $\begin{array}{l}\text { Proporción } \\
\text { de Taxones } \\
\text { más sensible }\end{array}$ & $\begin{array}{c}\mathbf{N}^{0} \mathrm{de} \\
\text { Observaciones }\end{array}$ \\
\hline Daphnia ambigua & 0,037 & 0,033 & $0 \%$ & 2 \\
\hline Deleatidium sp. & 0,050 & & $1 \%$ & 1 \\
\hline Hyalella azteca & $\mathbf{0 , 0 7 0}$ & 0,114 & $2 \%$ & 15 \\
\hline Ceriodaphnia dubia & 0,070 & 0,113 & $3 \%$ & 22 \\
\hline Procloeon sp. & 0,081 & & $3 \%$ & 1 \\
\hline Pseudagrion sp. & 0,100 & & $4 \%$ & 1 \\
\hline Amphipoda & 0,110 & & $5 \%$ & 1 \\
\hline Hyalella curvispina & $\mathbf{0 , 1 3 8}$ & & $6 \%$ & 1 \\
\hline Paratya australiensis & 0,148 & 0,256 & $6 \%$ & 10 \\
\hline Palaemonetes pugio & 0,150 & & $7 \%$ & 2 \\
\hline Hyalella curvispina* (Mugni et al 2012 - Solis 2017) & 0,221 & 0,351 & $8 \%$ & 5 \\
\hline Culex sitiens & 0,240 & & $9 \%$ & 1 \\
\hline Aedes taeniorhynchus & 0,299 & 0,463 & $9 \%$ & 3 \\
\hline Daphnia carinata & 0,300 & 0,137 & $10 \%$ & 5 \\
\hline Gammarus lacustris & 0,322 & 0,428 & $11 \%$ & 3 \\
\hline Culex restuans & 0,392 & 0,081 & $12 \%$ & 3 \\
\hline Culex tritaeniorhynchus ssp. summorosus & 0,449 & 0,289 & $12 \%$ & 6 \\
\hline Simulium vittatum & 0,455 & 0,891 & $13 \%$ & 7 \\
\hline Macrobrachium rosenbergii & 0,458 & 0,260 & $14 \%$ & 2 \\
\hline Daphnia pulex & 0,471 & 0,622 & $15 \%$ & 8 \\
\hline Aedes togoi & 0,480 & & $15 \%$ & 1 \\
\hline Daphnia longispina & 0,490 & 0,301 & $16 \%$ & 2 \\
\hline Palaemonetes argentinus & 0,490 & & $17 \%$ & 1 \\
\hline Aedes sticticus & 0,500 & & $18 \%$ & 1 \\
\hline Chironomus dilutus & 0,514 & 0,196 & $18 \%$ & 4 \\
\hline Culex tarsalis & 0,530 & 0,323 & $19 \%$ & 5 \\
\hline Thamnocephalus platyurus & 0,530 & & $20 \%$ & 1 \\
\hline Aedes triseriatus & 0,532 & 0,375 & $21 \%$ & 4 \\
\hline Aedes canadensis & 0,549 & 0,276 & $21 \%$ & 2 \\
\hline Chironomus sp. & 0,600 & & $22 \%$ & 1 \\
\hline Aedes atropalpus & 0,600 & & $22 \%$ & 1 \\
\hline Simocephalus vetulus & 0,632 & 0,144 & $24 \%$ & 2 \\
\hline Cloeon dipterum & 0,658 & 0,209 & $24 \%$ & 4 \\
\hline Aedes vexans & 0,665 & 0,160 & $25 \%$ & 3 \\
\hline Culex pipiens ssp. pipiens & 0,666 & 0,330 & $26 \%$ & 3 \\
\hline Culex pipiens ssp. molestus & 0,736 & 0,365 & $27 \%$ & 5 \\
\hline Gammarus pulex & 0,752 & 0,591 & $27 \%$ & 5 \\
\hline Leptoceridae & 0,818 & 0,037 & $28 \%$ & 2 \\
\hline Chaoborus obscuripes & 0,845 & 0,390 & $29 \%$ & 4 \\
\hline Peltodytes sp. & 0,849 & 0,036 & $30 \%$ & 2 \\
\hline Paramelita nigroculus & 0,900 & & $30 \%$ & 1 \\
\hline
\end{tabular}




\begin{tabular}{|c|c|c|c|c|}
\hline Macrobrachium lar & 0,961 & 0,354 & $31 \%$ & 2 \\
\hline Anopheles quadrimaculatus & 1,000 & & $32 \%$ & 1 \\
\hline Culex peus & 1,036 & 0,084 & $33 \%$ & 4 \\
\hline Culex pipiens ssp. quinquefasciata & 1,036 & 0,249 & $33 \%$ & 13 \\
\hline Culex melanurus & 1,037 & 0,352 & $34 \%$ & 4 \\
\hline Aedes cantans & 1,100 & & $35 \%$ & 1 \\
\hline Anopheles stephensi & 1,123 & 0,402 & $36 \%$ & 8 \\
\hline Anisops sardeus & 1,192 & 0,173 & $36 \%$ & 2 \\
\hline Aedes communis & 1,200 & & $37 \%$ & 1 \\
\hline Heptageniidae & 1,204 & 1,954 & $38 \%$ & 2 \\
\hline Globodera rostochiensis & 1,220 & 0,111 & $39 \%$ & 4 \\
\hline Chaoborus americanus & 1,290 & & $39 \%$ & 1 \\
\hline Chironomus tepperi & 1,300 & & $40 \%$ & 1 \\
\hline Gammarus fasciatus & 1,339 & 0,879 & $41 \%$ & 2 \\
\hline Maxillopoda & 1,415 & 0,251 & $42 \%$ & 2 \\
\hline Pteronarcella badia & 1,422 & 0,529 & $42 \%$ & 3 \\
\hline Anopheles freeborni & 1,579 & 0,220 & $43 \%$ & 12 \\
\hline Neoplea striola & 1,856 & 0,149 & $44 \%$ & 6 \\
\hline Chironomus utahensis & 1,981 & 0,377 & $45 \%$ & 3 \\
\hline Procambarus acutus ssp. acutus & 2,000 & & $45 \%$ & 1 \\
\hline Claassenia sabulosa & 2,034 & 0,581 & $46 \%$ & 3 \\
\hline Laccophilus fasciatus & 2,100 & & $47 \%$ & 2 \\
\hline Romanomermis culicivorax & 2,100 & & $48 \%$ & 1 \\
\hline Sigara arguta & 2,160 & & $48 \%$ & 1 \\
\hline Procladius sp. & 2,609 & 1,243 & $49 \%$ & 3 \\
\hline Chironomus tentans & 2,673 & 1,627 & $50 \%$ & 5 \\
\hline Aedes punctor & 2,700 & & $51 \%$ & 1 \\
\hline Macrobrachium lanchesteri & 2,791 & 0,057 & $52 \%$ & 4 \\
\hline Gammarus fossarum & 2,900 & & $52 \%$ & 1 \\
\hline Culiseta incidens & 2,924 & 0,144 & $53 \%$ & 6 \\
\hline Culicoides variipennis & 3,023 & 0,128 & $54 \%$ & 11 \\
\hline Anopheles gambiae & 3,108 & 0,490 & $55 \%$ & 2 \\
\hline Anax imperator & 3,209 & 0,241 & $55 \%$ & 4 \\
\hline Aedes excrucians & 3,300 & & $56 \%$ & 1 \\
\hline Culiseta annulata & 3,500 & & $57 \%$ & 1 \\
\hline Diaptomus forbesi & 3,600 & & $58 \%$ & 2 \\
\hline Triops longicaudatus & 4,000 & & $58 \%$ & 1 \\
\hline Chironomus riparius & 4,395 & 2,442 & $59 \%$ & 3 \\
\hline Plea minutissima & 4,421 & 0,334 & $60 \%$ & 4 \\
\hline Laccophilus maculosus ssp. maculosus & 4,600 & & $61 \%$ & 1 \\
\hline Culex tritaeniorhynchus & 4,753 & 0,951 & $61 \%$ & 8 \\
\hline Daphnia magna & 4,956 & 1,146 & $62 \%$ & 16 \\
\hline Chaoborus punctipennis & 5,400 & & $63 \%$ & 2 \\
\hline Crocothemis erythraea & 5,800 & & $64 \%$ & 1 \\
\hline Thermonectus basillaris & 6,000 & & $64 \%$ & 1 \\
\hline Procambarus sp. & 7,400 & 0,568 & $65 \%$ & 8 \\
\hline
\end{tabular}




\begin{tabular}{|c|c|c|c|c|}
\hline Anopheles albimanus & 8,000 & & $66 \%$ & 1 \\
\hline Asellus aquaticus & 8,096 & 0,036 & $67 \%$ & 2 \\
\hline Xanthocnemis zealandica & 8,440 & & $67 \%$ & 1 \\
\hline Culex pipiens & 8,725 & 1,103 & $68 \%$ & 51 \\
\hline Ranatra linearis & 8,822 & 0,331 & $69 \%$ & 4 \\
\hline Berosus styliferus & 9,000 & & $70 \%$ & 1 \\
\hline Plecoptera & 10,00 & & $70 \%$ & 1 \\
\hline Odonata & 11,40 & & $71 \%$ & 1 \\
\hline Glyptotendipes paripes & 12,00 & & $72 \%$ & 1 \\
\hline Culex pipiens ssp. pallens & 12,06 & 1,493 & $73 \%$ & 13 \\
\hline Notonecta maculata & 13,02 & 0,242 & $73 \%$ & 3 \\
\hline Culex quinquefasciatus & 14,00 & 1,316 & $74 \%$ & 45 \\
\hline Belostoma sp. & 15,00 & & $75 \%$ & 1 \\
\hline Dicrotendipes californicus & 16,73 & 0,535 & $76 \%$ & 2 \\
\hline Aedes aegypti & 17,33 & 0,870 & $76 \%$ & 41 \\
\hline Tropisternus lateralis & 20,40 & 0,575 & $77 \%$ & 2 \\
\hline Tanytarsus sp. & 20,78 & 2,065 & $78 \%$ & 2 \\
\hline Pteronarcys californica & 20,80 & 0,354 & $79 \%$ & 3 \\
\hline Chironomus decorus & 21,95 & 1,075 & $79 \%$ & 6 \\
\hline Hydrophilus triangularis & 24,49 & 0,124 & $80 \%$ & 2 \\
\hline Hydropsychidae & 30,00 & & $81 \%$ & 1 \\
\hline Parapoynx stratiotata & 34,35 & 0,139 & $82 \%$ & 4 \\
\hline Notonecta undulata & 35,20 & & $82 \%$ & 2 \\
\hline Hygrotus sp. & 40,00 & & $83 \%$ & 1 \\
\hline Procambarus clarkii & 41,00 & & $84 \%$ & 1 \\
\hline Cricotopus sp. & 42,37 & 0,710 & $85 \%$ & 3 \\
\hline Chironomus plumosus & 49,63 & 0,673 & $85 \%$ & 15 \\
\hline Chironomus crassicaudatus & 52,00 & & $86 \%$ & 1 \\
\hline Branchiura sowerbyi & 66,00 & & $87 \%$ & 2 \\
\hline Eriocheir sinensis & 80,23 & 0,430 & $88 \%$ & 8 \\
\hline Hydrophilus sp. & 100,0 & & $88 \%$ & 1 \\
\hline Spiralothelphusa hydrodroma & 156,9 & 0,088 & $89 \%$ & 4 \\
\hline Parathelphusidae & 156,9 & 0,088 & $89 \%$ & 4 \\
\hline Trichodactylus borellianus & 242,3 & & $91 \%$ & 1 \\
\hline Dugesia japonica & 307,5 & 0,232 & $91 \%$ & 4 \\
\hline Goeldichironomus holoprasinus & 380,0 & & $92 \%$ & 1 \\
\hline Zilchiopsis collastinensis & 441,4 & 0,636 & $93 \%$ & 2 \\
\hline Oziotelphusa senex ssp. senex & 552,0 & 0,230 & $94 \%$ & 15 \\
\hline Neocaridina denticulata & 631,2 & 0,177 & $94 \%$ & 4 \\
\hline Aedes albopictus & 666,4 & 0,928 & $95 \%$ & 26 \\
\hline Pomacea canaliculata & 978,0 & & $96 \%$ & 1 \\
\hline Bulinus truncatus & 1320 & & $97 \%$ & 1 \\
\hline Lanistes carinatus & 2710 & & $97 \%$ & 1 \\
\hline Anopheles sinensis & 4700 & & $98 \%$ & 1 \\
\hline Brachionus calyciflorus & 11950 & 0,003 & $99 \%$ & 5 \\
\hline Sialis lutaria & 21700 & & $100 \%$ & 1 \\
\hline
\end{tabular}


Tabla A2. Resultados de la distribución de sensibilidad de las especies para endosulfán

\begin{tabular}{|c|c|c|c|c|}
\hline Taxones & $\begin{array}{l}\mathrm{LC50} \\
(\mu \mathrm{g} / \mathrm{L})\end{array}$ & $\begin{array}{c}\text { Desviación } \\
\text { St }\end{array}$ & $\begin{array}{c}\text { Porcentaje } \\
\text { de Taxones } \\
\text { más sensible }\end{array}$ & $\begin{array}{c}\mathbf{N}^{\circ} \text { de } \\
\text { Observaciones }\end{array}$ \\
\hline Mesocyclops longisetus & 0,018 & 0,069 & $1 \%$ & 2 \\
\hline Eucyclops sp. & 0,100 & & $2 \%$ & 1 \\
\hline Alonella sp. & 0,200 & & $4 \%$ & 1 \\
\hline Paratelphusa jacquemontii & 0,269 & 0,209 & $5 \%$ & 4 \\
\hline Palaemonetes paludosus & 0,337 & 0,123 & $6 \%$ & 4 \\
\hline Daphnia longispina & 0,346 & 0,088 & $8 \%$ & 2 \\
\hline Diaptomus sp. & 0,600 & & $9 \%$ & 1 \\
\hline Atalophlebia australis & 0,685 & 0,096 & $11 \%$ & 5 \\
\hline Cheumatopsyche sp. & 0,832 & 0,327 & $12 \%$ & 3 \\
\hline Cypria sp. & 0,900 & & $14 \%$ & 1 \\
\hline Amphipoda & 1,000 & & $15 \%$ & 1 \\
\hline Caridina laevis & 1,558 & 0,260 & $16 \%$ & 2 \\
\hline Jappa kutera & 1,721 & 0,173 & $18 \%$ & 8 \\
\hline Macrobrachium rosenbergii & 2,543 & 0,765 & $19 \%$ & 14 \\
\hline Hyalella curvispina & 3,264 & & $21 \%$ & 1 \\
\hline Macrobrachium lamarrei & 4,211 & 0,077 & $22 \%$ & 4 \\
\hline Macrobrachium dayanum & 5,043 & 0,075 & $24 \%$ & 4 \\
\hline Palaemonetes argentinus & 6,280 & & $25 \%$ & 1 \\
\hline Gammarus lacustris & 6,671 & 0,095 & $26 \%$ & 4 \\
\hline Pteronarcys californica & 6,761 & 0,514 & $28 \%$ & 3 \\
\hline Gammarus fasciatus & 7,114 & 0,128 & $29 \%$ & 3 \\
\hline Hyalella azteca & 7,286 & 0,172 & $31 \%$ & 3 \\
\hline Asellus aquaticus & 10,00 & & $32 \%$ & 1 \\
\hline Sigara alternata & 12,65 & 0,017 & $34 \%$ & 2 \\
\hline Caridina weberi & 12,74 & 0,353 & $35 \%$ & 16 \\
\hline Atalophlebia sp. & 12,93 & 0,031 & $36 \%$ & 2 \\
\hline Eretes sticticus & 15,81 & 0,281 & $38 \%$ & 2 \\
\hline Moina micrura & 16,20 & & $39 \%$ & 1 \\
\hline Hyalella curvispina* (Mugni et al 2012, 2015) & 16,56 & 0,115 & $41 \%$ & 4 \\
\hline Paramelita nigroculus & 19,20 & & $42 \%$ & 1 \\
\hline Enallagma sp. & 21,88 & 0,107 & $44 \%$ & 3 \\
\hline Spicodiaptomus chelospinus & 44,72 & 0,069 & $45 \%$ & 2 \\
\hline Pseudagrion sp. & 46,00 & & $46 \%$ & 1 \\
\hline Chironomus plumosus & 53,00 & & $48 \%$ & 1 \\
\hline Ceriodaphnia dubia & 53,30 & & $49 \%$ & 1 \\
\hline Radix luteola & 60,00 & & $51 \%$ & 1 \\
\hline Culex pipiens ssp. quinquefasciata & 66,00 & & $52 \%$ & 1 \\
\hline Culex quinquefasciatus & 70,71 & 2,805 & $54 \%$ & 4 \\
\hline Procambarus clarkii & 100,8 & 0,881 & $55 \%$ & 2 \\
\hline Ischnura sp. & 138,1 & 0,206 & $56 \%$ & 8 \\
\hline Lamellidens marginalis & 139,2 & 1,705 & $58 \%$ & 4 \\
\hline Culex fatigans & 142,3 & 0,032 & $59 \%$ & 2 \\
\hline
\end{tabular}




$\begin{array}{lcccc}\text { Lamellidens corrianus } & 179,9 & 1,537 & 61 \% & 4 \\ \text { Ephemera orientalis } & 224,0 & & 62 \% & 1 \\ \text { Daphnia magna } & 265,9 & 0,441 & 64 \% & 28 \\ \text { Daphnia pulex } & 300,0 & & 65 \% & 1 \\ \text { Crocothemis erythraea } & 395,0 & & 66 \% & 1 \\ \text { Anopheles stephensi } & 473,4 & & 68 \% & 1 \\ \text { Daphnia carinata } & 478,0 & & 69 \% & 1 \\ \text { Cambarus sp. } & 500,0 & & 71 \% & 1 \\ \text { Potamonautes sp. } & 616,7 & 0,318 & 72 \% & 4 \\ \text { Hydra viridissima } & 670,0 & & 74 \% & 1 \\ \text { Moina macrocopa } & 731,0 & 0,933 & 75 \% & 2 \\ \text { Hydra vulgaris } & 810,0 & & 76 \% & 1 \\ \text { Aedes aegypti } & 1000 & & 78 \% & 1 \\ \text { Bellamya dissimilis } & 1800 & & 79 \% & 1 \\ \text { Trichodactylus borellianus } & 1906 & & 81 \% & 1 \\ \text { Barytelphusa cunicularis } & 2256 & 0,008 & 82 \% & 3 \\ \text { Lanistes carinatus } & 3400 & & 84 \% & 1 \\ \text { Radix natalensis } & 4794 & 0,057 & 85 \% & 2 \\ \text { Brachionus calyciflorus } & 5150 & & 86 \% & 4 \\ \text { Tubifex tubifex } & 6000 & & 88 \% & 1 \\ \text { Physella acuta } & 6400 & & 89 \% & 2 \\ \text { Semisulcospira libertina } & 7400 & & 91 \% & 1 \\ \text { Oziotelphusa senex ssp. senex } & 7735 & 0,129 & 92 \% & 18 \\ \text { Cipangopaludina malleata } & 8500 & & 94 \% & 1 \\ \text { Zilchiopsis collastinensis } & 13469 & 1,202 & 95 \% & 2 \\ \text { Barytelphusa guerini } & 17780 & & 96 \% & 1 \\ \text { Indoplanorbis exustus } & 21000 & & 98 \% & 1 \\ \text { Melanopsis dufouri } & 39892 & 0,030 & 99 \% & 3\end{array}$

Tabla A3. Resultados de la distribución de sensibilidad de la especie para cipermetrina

\begin{tabular}{lcccc}
\hline Taxones & $\begin{array}{c}\text { LC50 } \\
(\mathbf{\mu g} / \mathbf{L})\end{array}$ & $\begin{array}{c}\text { Desviación } \\
\mathbf{S t}\end{array}$ & $\begin{array}{c}\text { Porcentaje } \\
\text { de Taxones } \\
\text { más sensible }\end{array}$ & $\begin{array}{c}\mathbf{N}^{\mathbf{0}} \mathbf{d e} \\
\text { Observaciones }\end{array}$ \\
\hline Palaemonetes argentinus & 0,002 & & $1 \%$ & 1 \\
Trichodactylus borellianus & 0,011 & 0,044 & $3 \%$ & 4 \\
Tanytarsus sp. & 0,012 & & $4 \%$ & 1 \\
Macrobrachium rosenbergii & 0,031 & & $6 \%$ & 1 \\
Diaptomus forbesi & 0,032 & 0,058 & $8 \%$ & 8 \\
Hyalella curvispina & $\mathbf{0 , 0 3 5}$ & & $\mathbf{9 \%}$ & $\mathbf{1}$ \\
Hyalella curvispina* (Mugni et al 2011b, & $\mathbf{0 , 0 4 6}$ & $\mathbf{0 , 3 7 0}$ & $\mathbf{1 1 \%}$ & $\mathbf{8}$ \\
2012, 2013b) & 0,050 & & $13 \%$ & 1 \\
Piona carnea & 0,060 & & $15 \%$ & 1 \\
Tanypus nubifer & 0,063 & & $16 \%$ & 1 \\
Culex fuscocephala & 0,072 & & $18 \%$ & 1 \\
Aedes vexans & 0,073 & & $20 \%$ & 1 \\
Culex restuans & & & &
\end{tabular}




\begin{tabular}{|c|c|c|c|c|}
\hline Ranatra filiformis & 0,082 & 0,119 & $22 \%$ & 8 \\
\hline Triops longicaudatus & 0,084 & & $23 \%$ & 1 \\
\hline Gammarus pulex & 0,088 & 0,131 & $25 \%$ & 6 \\
\hline Culex pipiens & 0,100 & 0,345 & $27 \%$ & 2 \\
\hline Culex sp. & 0,102 & 0,505 & $28 \%$ & 2 \\
\hline Procambarus clarkii & 0,117 & 0,100 & $30 \%$ & 10 \\
\hline Procladius sp. & 0,130 & & $32 \%$ & 1 \\
\hline Chaoborus sp. & 0,200 & & $34 \%$ & 1 \\
\hline Caecidotea brevicauda & 0,200 & & $34 \%$ & 1 \\
\hline Chironomus utahensis & 0,210 & & $37 \%$ & 1 \\
\hline Aedes stimulans & 0,244 & 0,203 & $39 \%$ & 3 \\
\hline Clibanarius africanus & 0,309 & & $41 \%$ & 1 \\
\hline Cricotopus sp. & 0,388 & 0,118 & $42 \%$ & 2 \\
\hline Goeldichironomus holoprasinus & 0,548 & 0,056 & $44 \%$ & 2 \\
\hline Cloeon dipterum & 0,600 & & $46 \%$ & 1 \\
\hline Glyptotendipes paripes & 0,700 & & $47 \%$ & 2 \\
\hline Acartia tonsa & 0,750 & & $49 \%$ & 1 \\
\hline Culex quinquefasciatus & 0,795 & 1,062 & $51 \%$ & 13 \\
\hline Thamnocephalus platyurus & 0,829 & & $53 \%$ & 1 \\
\hline Ceriodaphnia dubia & 0,889 & & $54 \%$ & 1 \\
\hline Macrobrachium lar & 1,193 & 0,067 & $56 \%$ & 2 \\
\hline Culex tritaeniorhynchus & 1,217 & 0,589 & $58 \%$ & 3 \\
\hline Heptageniidae & 1,300 & & $59 \%$ & 1 \\
\hline Odonata & 1,400 & & $61 \%$ & 1 \\
\hline Hydropsychidae & 1,400 & & $61 \%$ & 1 \\
\hline Chironomus decorus & 1,580 & 0,277 & $65 \%$ & 4 \\
\hline Anopheles stephensi & 1,900 & & $66 \%$ & 1 \\
\hline Culex pipiens ssp. quinquefasciata & 2,027 & 0,579 & $68 \%$ & 2 \\
\hline Chironomus crassicaudatus & 2,245 & 0,385 & $70 \%$ & 2 \\
\hline Aedes aegypti & 2,561 & 0,947 & $72 \%$ & 29 \\
\hline Dicrotendipes californicus & 3,955 & 0,093 & $73 \%$ & 2 \\
\hline Ephemera orientalis & 4,500 & & $75 \%$ & 1 \\
\hline Hydrophilus sp. & 8,300 & & $77 \%$ & 1 \\
\hline Culex pipiens ssp. pallens & 8,392 & 0,869 & $78 \%$ & 17 \\
\hline Simulium vittatum & 9,800 & & $80 \%$ & 1 \\
\hline Daphnia magna & 12,80 & 1,502 & $82 \%$ & 13 \\
\hline Thermocyclops oblongatus & 29,00 & & $84 \%$ & 1 \\
\hline Unio elongatulus ssp. eucirrus & 76,37 & 0,106 & $85 \%$ & 3 \\
\hline Branchiura sowerbyi & 96,68 & 0,282 & $87 \%$ & 8 \\
\hline Brachionus calyciflorus & 140,8 & 1,951 & $89 \%$ & 2 \\
\hline Aedes albopictus & 465,6 & 0,663 & $91 \%$ & 17 \\
\hline Lymnaea acuminata & 514,6 & 0,153 & $92 \%$ & 4 \\
\hline Anopheles sinensis & 1600 & & $94 \%$ & 1 \\
\hline Oziotelphusa senex ssp. senex & 2000 & & $96 \%$ & 1 \\
\hline Melanoides tuberculata & 5847 & 0,266 & $97 \%$ & 4 \\
\hline Lamellidens marginalis & 26485 & 0,084 & $99 \%$ & 4 \\
\hline
\end{tabular}


Tabla A4. Resultados de la distribución de sensibilidad de la especie para lambdacialotrina

\begin{tabular}{|c|c|c|c|c|}
\hline Taxones & $\begin{array}{c}\mathrm{LC}_{50} \\
(\mu \mathrm{g} / \mathrm{L})\end{array}$ & $\begin{array}{c}\text { Desviación } \\
\text { St }\end{array}$ & $\begin{array}{l}\text { Porcentaje de } \\
\text { Taxones más } \\
\text { sensible }\end{array}$ & $\begin{array}{c}\mathrm{N}^{\circ} \text { de } \\
\text { Observaciones }\end{array}$ \\
\hline Hyalella curvispina & 0,004 & & $2 \%$ & 1 \\
\hline Macrobrachium lar & 0,008 & 0,269 & $5 \%$ & 2 \\
\hline Pseudodiaptomus forbesi & 0,017 & & $8 \%$ & 1 \\
\hline Notonecta glauca & 0,019 & 0,098 & $11 \%$ & 2 \\
\hline Eurytemora affinis & 0,019 & & $15 \%$ & 1 \\
\hline Chironomus dilutus & 0,022 & 0,343 & $18 \%$ & 2 \\
\hline Anisops sardeus & 0,025 & 0,012 & $21 \%$ & 2 \\
\hline Gammarus pulex & 0,028 & 0,080 & $24 \%$ & 2 \\
\hline Macrobrachium nipponense & 0,034 & 0,219 & $27 \%$ & 6 \\
\hline Sigara striata & 0,049 & & $31 \%$ & 1 \\
\hline Proasellus coxalis & 0,059 & 0,175 & $34 \%$ & 2 \\
\hline Chaoborus obscuripes & 0,076 & & $37 \%$ & 1 \\
\hline Caenis horaria & 0,094 & 0,616 & $40 \%$ & 2 \\
\hline Asellus aquaticus & 0,103 & 0,191 & $44 \%$ & 2 \\
\hline Cloeon dipterum & 0,113 & 0,046 & $47 \%$ & 2 \\
\hline Culex annulirostris & 0,130 & & $50 \%$ & 1 \\
\hline Procambarus clarkii & 0,160 & & $53 \%$ & 1 \\
\hline Ceriodaphnia dubia & 0,300 & & $56 \%$ & 1 \\
\hline Daphnia galeata & 0,397 & & $60 \%$ & 1 \\
\hline Caridina laevis & 0,536 & 0,298 & $63 \%$ & 2 \\
\hline Culex quinquefasciatus & 0,665 & 1,417 & $66 \%$ & 5 \\
\hline Macropelopia sp. & 0,843 & 0,116 & $69 \%$ & 2 \\
\hline Erythromma viridulum & 0,883 & 0,358 & $73 \%$ & 2 \\
\hline Daphnia magna & 1,040 & & $76 \%$ & 1 \\
\hline Simocephalus vetulus & 1,340 & & $79 \%$ & 1 \\
\hline Culex tritaeniorhynchus & 1,562 & 0,227 & $82 \%$ & 2 \\
\hline Aedes aegypti & 3,100 & 0,904 & $85 \%$ & 22 \\
\hline Culex pipiens & 52,493 & 0,125 & $89 \%$ & 3 \\
\hline Anopheles sinensis & 80,000 & & $92 \%$ & 1 \\
\hline Anopheles stephensi & 258,836 & 0,881 & $95 \%$ & 5 \\
\hline Aedes albopictus & 605,073 & 0,411 & $98 \%$ & 16 \\
\hline
\end{tabular}


APÉNDICE B. Estudios de campo

Tabla B1. Planilla de campo utilizada en Paraguay y Brasil.

Sitio Coordenadas

Fecha Hora Personas

Descripción

Muestreo: aguas Arriba del puente: m ó Abajo del puente: $\mathrm{m}$

Clima: Temp. ambiental: Fecha última lluvia:

Muestras para análisis: Sedimento - textura/metales/COT Pesticidas

Muestra de organismos: sustratos:

Método de muestreo:

Calidad de agua: Temp. $\left({ }^{\circ} \mathrm{C}\right)$ Conduct (uS/com) $\mathrm{pH}$ DO $(\mathrm{mg} / \mathrm{L})$ Turbidez (NTU) Olor

\begin{tabular}{|c|l|l|l|l|}
\hline \multirow{2}{*}{$\begin{array}{c}\text { Amonio } \\
(\mathrm{mg} / \mathrm{L})\end{array}$} & $<0.5$ & $0.5-1$ & $1-5$ & $5-10$ \\
\cline { 2 - 5 } & & & & \\
\hline
\end{tabular}

\begin{tabular}{|c|c|c|c|c|c|c|c|}
\hline \multirow{2}{*}{$\begin{array}{c}\text { Nitrato } \\
(\mathrm{ppm})\end{array}$} & $<1$ & $1-2$ & $2-4$ & $4-6$ & $6-8$ & $8-10$ & $10-15$ \\
\cline { 2 - 8 } & & & & & & & \\
\hline
\end{tabular}

\begin{tabular}{|l|l|l|l|}
\hline \multicolumn{4}{|c|}{ Fósforo (ppm) } \\
\hline$<0.1$ & & $1-2$ & \\
\hline $0.1-0.2$ & & $2-3$ & \\
\hline $0.2-0.3$ & & $3-4$ & \\
\hline $0.3-0.4$ & & $4-5$ & \\
\hline $0.4-0.6$ & & $5-6$ & \\
\hline $0.6-0.8$ & & $6-7$ & \\
\hline $0.8-1$ & & $7-8$ & \\
\hline & & $8-10$ & \\
\hline
\end{tabular}

Hidrología: Veloc. prom. $(\mathrm{m} / \mathrm{s})$ máx.

Ancho para caudal (m) Ancho máx. (m) Ancho típico (m)

Profundidad máx. (m) para caudal (m) Prof. típica (m)

Canalizado $\%$ sombra

Tipo de hábitat: Rápido \% Corredera \% Pozón \% $(100 \%$ total $)$

MO: MOPF \% MOPG \%

Vegetación: Emergente Sumergida

Flotante Árboles

Mapa/dibujo: mostrar: Cosechas y franja (m) - aguas arriba y abajo del puente (2 lados del arroyo), pastura, otro uso de tierra. (Ver reverso). 
Sitio

Fecha

Conteo del sustrato (mm): (entrar una marca para cada uno, total de 100)

\begin{tabular}{|l|l|l|}
\hline \multicolumn{1}{|c|}{ Tamaño } & \multicolumn{1}{c|}{ Incrustado } & Suelto \\
\hline$<4$ & & \\
\hline $4-5,7$ & & \\
\hline $5,7-8$ & & \\
\hline $8-11,3$ & & \\
\hline $11,3-16$ & & \\
\hline $16-22,6$ & & \\
\hline $22,6-32$ & & \\
\hline $32-45$ & & \\
\hline $45-64$ & & \\
\hline $64-90$ & & \\
\hline $90-128$ & & \\
\hline $128-181$ & & \\
\hline $181-256$ & & \\
\hline $256-362$ & & \\
\hline $362-512$ & & \\
\hline$>512$ & & \\
\hline
\end{tabular}

RBP (evaluación de la calidad del hábitat)

\begin{tabular}{|c|c|c|c|c|c|c|c|c|c|c|c|c|c|c|c|c|c|c|c|c|}
\hline \multirow{2}{*}{ Parámetros } & \multicolumn{5}{|c|}{ Óptimo } & \multicolumn{5}{|c|}{ Subóptimo } & \multicolumn{5}{|c|}{ Marginal } & \multicolumn{5}{|c|}{ Deficiente } \\
\hline & 20 & 19 & 18 & 17 & 16 & 15 & 14 & 13 & 12 & 11 & 10 & 9 & 8 & 7 & 6 & 5 & 4 & 3 & 2 & 1 \\
\hline Sustrato /cobertura & & & & & & & & & & & & & & & & & & & & \\
\hline Variabilidad del leche & & & & & & & & & & & & & & & & & & & & \\
\hline Velocidad/profundida & & & & & & & & & & & & & & & & & & & & \\
\hline Depósitos de sedimen & & & & & & & & & & & & & & & & & & & & \\
\hline Caudal & & & & & & & & & & & & & & & & & & & & \\
\hline Alteración de canal & & & & & & & & & & & & & & & & & & & & \\
\hline Frecuencia de rápido & & & & & & & & & & & & & & & & & & & & \\
\hline Estabilidad de las oril & & & & & & & & & & & & & & & & & & & & \\
\hline $\begin{array}{l}\text { Protección de vegetac } \\
\text { izquierda }\end{array}$ & & & & & & & & & & & & & & & & & & & & \\
\hline $\begin{array}{l}\text { Protección de vegetac } \\
\text { derecha }\end{array}$ & & & & & & & & & & & & & & & & & & & & \\
\hline $\begin{array}{l}\text { Ancho de vegetación } \\
\text { izquierda }\end{array}$ & & & & & & & & & & & & & & & & & & & & \\
\hline $\begin{array}{l}\text { Ancho de vegetación } \\
\text { derecha }\end{array}$ & & & & & & & & & & & & & & & & & & & & \\
\hline
\end{tabular}


Tabla B2. Resultado de la evaluación de la calidad del hábitat (RBP) de los sitios de Paraguay y Brasil, siguiendo la metodología de Barbour et al., 1999.

\begin{tabular}{|c|c|c|c|c|c|c|c|c|c|c|c|c|c|c|}
\hline \multicolumn{15}{|c|}{ Evaluación de la calidad del hábitat (RBP) } \\
\hline & itio & $\begin{array}{l}\text { Sust / } \\
\text { cober }\end{array}$ & Lecho & $\begin{array}{c}\text { Veloc I } \\
\text { prof }\end{array}$ & \begin{tabular}{|l|} 
depos \\
sedim
\end{tabular} & caudal & Canal & Rápidos & Orillas & $\begin{array}{c}\text { Prot } \\
\text { veg izq }\end{array}$ & $\begin{array}{c}\text { Prot } \\
\text { veg der }\end{array}$ & $\begin{array}{l}\text { Ancho } \\
\text { veg izq }\end{array}$ & $\begin{array}{l}\text { Ancho } \\
\text { veg der }\end{array}$ & Total \\
\hline \multirow{16}{*}{ 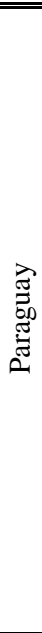 } & P1 & 14 & 14 & 14 & 10 & 18 & 20 & 16 & 16 & 10 & 10 & 10 & 10 & 162 \\
\hline & P2 & 16 & 16 & 15 & 17 & 18 & 20 & 16 & 16 & 10 & 10 & 10 & 10 & 174 \\
\hline & P3 & 14 & 12 & 14 & 12 & 18 & 20 & 12 & 15 & 10 & 10 & 10 & 10 & 157 \\
\hline & P4 & 15 & 18 & 15 & 18 & 18 & 20 & 16 & 16 & 2,5 & 2,5 & 2,5 & 2,5 & 146 \\
\hline & P5 & 13 & 16 & 15 & 16 & 18 & 20 & 18 & 16 & 10 & 10 & 10 & 10 & 172 \\
\hline & P6 & 10 & 6 & 13 & 5 & 18 & 20 & 10 & 11 & 10 & 10 & 10 & 10 & 133 \\
\hline & P7 & 18 & 18 & 16 & 18 & 18 & 20 & 16 & 18 & 10 & 10 & 10 & 10 & 182 \\
\hline & P8 & 10 & 16 & 13 & 15 & 18 & 20 & 13 & 15 & 5 & 5 & 5 & 5 & 140 \\
\hline & P9 & 15 & 16 & 14 & 16 & 18 & 20 & 18 & 16 & 9 & 9 & 9 & 9 & 169 \\
\hline & P10 & 17 & 16 & 15 & 16 & 18 & 20 & 13 & 15 & 6,5 & 10 & 6,5 & 10 & 163 \\
\hline & $\mathrm{P} 11$ & 15 & 17 & 15 & 18 & 18 & 20 & 16 & 15 & 8 & 8 & 7 & 8 & 165 \\
\hline & P13 & 15 & 16 & 14 & 16 & 18 & 20 & 17 & 15 & 7,5 & 7,5 & 7,5 & 7,5 & 161 \\
\hline & $\mathrm{P} 14$ & 10 & 16 & 11 & 18 & 18 & 20 & 15 & 16 & 6,5 & 10 & 6,5 & 10 & 157 \\
\hline & P15 & 10 & 5 & 6 & 5 & 18 & 20 & 1 & 10 & 1 & 1 & 1 & 1 & 79 \\
\hline & P16 & 15 & 14 & 16 & 11 & 18 & 20 & 13 & 15 & 10 & 3 & 10 & 3 & 148 \\
\hline & P17 & 16 & 16 & 15 & 16 & 18 & 20 & 16 & 16 & 5,5 & 5,5 & 4,5 & 4,5 & 153 \\
\hline \multirow{18}{*}{$\overline{\widetilde{T}}$} & B2 & 18 & 14 & 14 & 16 & 18 & 20 & 14 & 13 & 10 & 10 & 10 & 10 & 167 \\
\hline & B3 & 16 & 17 & 11 & 11 & 18 & 20 & 9 & 11 & 10 & 10 & 10 & 10 & 153 \\
\hline & B7 & 15 & 14 & 16 & 17 & 18 & 20 & 16 & 15 & 10 & 10 & 8 & 8 & 167 \\
\hline & B10 & 16 & 14 & 15 & 14 & 18 & 20 & 15 & 10 & 5 & 5 & 1 & 1 & 134 \\
\hline & B11 & 19 & 17 & 11 & 15 & 18 & 20 & 19 & 16 & 10 & 10 & 6,5 & 6,5 & 168 \\
\hline & B12 & 15 & 16 & 11 & 11 & 18 & 20 & 7 & 11 & 10 & 10 & 10 & 10 & 149 \\
\hline & B13 & 15 & 16 & 14 & 18 & 18 & 20 & 16 & 19 & 10 & 10 & 10 & 10 & 176 \\
\hline & B14 & 20 & 14 & 14 & 18 & 18 & 20 & 18 & 18 & 10 & 10 & 10 & 10 & 180 \\
\hline & B15 & 11 & 13 & 10 & 15 & 18 & 20 & 8 & 8 & 10 & 10 & 10 & 10 & 143 \\
\hline & B16 & 11 & 12 & 13 & 11 & 20 & 20 & 13 & 17 & 10 & 10 & 10 & 10 & 157 \\
\hline & B17 & 15 & 14 & 15 & 14 & 18 & 20 & 15 & 18 & 10 & 10 & 10 & 10 & 169 \\
\hline & B18 & 11 & 13 & 13 & 15 & 18 & 20 & 18 & 16 & 10 & 10 & 10 & 10 & 164 \\
\hline & B19 & 16 & 14 & 13 & 16 & 18 & 20 & 16 & 15 & 10 & 10 & 10 & 10 & 168 \\
\hline & B20 & 15 & 15 & 14 & 16 & 18 & 20 & 12 & 11 & 10 & 10 & 10 & 10 & 161 \\
\hline & B21 & 13 & 15 & 14 & 13 & 18 & 20 & 13 & 13 & 10 & 10 & 10 & 10 & 159 \\
\hline & B22 & 18 & 15 & 11 & 18 & 18 & 20 & 20 & 11 & 10 & 10 & 10 & 10 & 171 \\
\hline & B23 & 18 & 15 & 14 & 15 & 18 & 20 & 19 & 12 & 10 & 10 & 10 & 10 & 171 \\
\hline & B24 & 16 & 14 & 11 & 15 & 18 & 20 & 18 & 11 & 10 & 10 & 10 & 10 & 163 \\
\hline
\end{tabular}

Sust / cober: Sustrato / Cobertura, Lecho: variabilidad del lecho, Veloc / prof : velocidad / profundidad, Depos sedim: depósitos de sedimento, Canal: alteración del canal, Rápidos: frecuencia de rápidos, Orillas: estabilidad de las orillas, Prot veg izq: protección de la vegetación izquierda, Prot veg der: protección de la vegetación derecha, Ancho veg izq: ancho de la vegetación izquierda, Ancho veg der: ancho de la vegetación derecha. 